INTERNATIONAL JOURNAL OF SYSTEMATIC BACTERIOLOGY

Vol. 18, No. 2 April 1968

Copyright 1968 by the Iowa State University Press

pp. $69-189$

\title{
COOPERATIVE DESCRIPTION OF TYPE CULTURES OF STREPTOMYCES. II. SPECIES DESCRIPTIONS FROM FIRST STUDY
}

Elwood B. Shirling and David Gottlieb

Department of Botany and Bacteriology,

Ohio Wesleyan University, Delaware, Ohio, and Department of Plant Pathology, University of Illinois, Urbana, Illinois !

ABSTRACT. Confusionexists in taxonomy and nomenclature of the genus Streptomyces (Actinomycetales) and related genera because of inadequatedescriptions for the species or lack of uniformity in criteria and methods for their characterization. More than 40 collaborating laboratories representing 18 nations are joined in an international effort to assemble and redescribe authentic type strains or neotype strains for the named species in the genera Streptomyces and Streptoverticillium. Uniform descriptive criteria and standardized methods and media, developed under the supervision of the Subcommittee on Taxonomy of Actioomycetes, American Society for Microbiology and the Subcommittee on Taxonomy of Actinomycetes of the International Committee on Bacteriological Nomenclature, have been officially adopted for this purpose. The type strain for each species (identified only by code number) is studied under these standard procedures in cooperating laboratories in 3 different nations. Data returned by these collaborators, including photo micrographs and electron micrographs, were used to prepare the illustrated standardized emendations to descriptions for loo Streptomyces (Actinomyces) or Streptoverticillium species included in this report. Emendationstodescriptions for additional species will be included in reports to follow. Type specimens (strains) of the 100 species for which emended characterizations have been completed, are now deposited in the American Type Culture Collection and the Centraalbureau voor Schimmelcultures for distribution to other culture collections of the world as reference cultures.

Reprints of this article may be purchased from the International Microbiological Fund, 221 Science Hall, Iowa State University, Ames, Iowa 50010 U.S.A. Price for single copies: \$2.00. 


\section{Collaborators and authors of descriptions, first study:}

\section{Group A-1}

Anderson, Lucia E. and Sara Wold. Parke, Davis and Co., Detroit, Michigan, U.S.A.

Baldacci, E., G. Farina and R. Locci. Ist. Patol. Vegetale, Univ. Milano, Via Celoria N. 2, Milano, Italy

Gauze, G.F., T.P. Preobrazhenskaya, E.S. Kudrina, T.S. Maximova and M.A. Sveshnikova. Acad. Med. Sciences of USSR, Inst. New Antibiotics, Bolshaia Pirogovskaia 11, Moscow, USSR.

\section{Graup A-2}

Cross, T. and A. Maciver. Postgraduate School of Studies in Biological Sciences, Univ. of Bradford, Bradford, 7 , Yorkshire, England.

Johanides, Vera and Tea Blazekovic. Laboratorij za industrijsku mikrobiologiju. Tehnoloski fakultet, Pierottijeva 6, Zagreb, Jugorlavija.

Trejo, W. and R. Bennett. E.R. Squibb and Sons, New Brunswick, New Jersey, U.S.A.

\section{Group A-3}

Crook, Kenneth E., Jr. and Carol S. Cassidy. Bristol Labs., Inc., Syracuse, New York, U.S.A.

deVries, G.A. Centraalbureau voor Schimmelcultures, Baarn, Netherlands.

Krasil'nikov, N.A. Inst. Microbiol., Acad. Sciences, Moscow B-133, USSR.

\section{Group A-4}

Dietz, Alma, Upjohn Co., Kalamazoo, Michigan, U.S.A.

Mach, F. Inst. fur Mikrobiologie, Greifswald, Ludwig-Jahn-Str. 15, German Democratic Republic.

Kuznetsov, V.D. USSR Res. Inst. for Antiobiotics, Moscow, USSR.

\section{Group A-5}

Higgens, Calvin E, and R. E. Kastner. Eli Lilly and Co., Indianapolis, Indiana, U.S.A.

Prauser, H. Inst. Mikrobiol. Exptl. Therapie, Beuthenbergstr. 1 , Jena, German Democratic Republic.

Szab6, 1. Magyar Tudományos Akedémia, Talajtana És Agrokémiai Kutató Intézete, Budapest, Hungary.

$$
\text { Group A-6 }
$$

Hirsch, P. Dept. Microbiology and Public Health, Michigan State Univ., East Lansing, Michigan, U.S.A. 
Shewan, J.M. and T.G. Mitchell, Torry Research Station, Aberdeen, Scotland.

Tsyganov, V.A. Res. Inst. of Antibiotics, Leningrad, L-20, USSR.

Group A-7

McClung, Norvel M.* and Gene Michaels. Dept. Microbiol., Univ. Georgia, Athens, Ga., U.S.A. *(Present address: Dept. Bot . and Bact., Univ. South Florida, Tampa, Florida.)

Margalith, P. Lab. of Microbiol., Israel Inst. of Tech. Haifa, Israel.

Wallhausser, Karl H. Mikrobiolog. Unters ab., Farbwerke Hoechst $A G$, Frankfurt a $/ M-$ Hochst, Germany.

\section{Group A-8}

Oliver, T.J. Abbott Laboratories, N. Chicago, Illinois, U.S.A. Spyvee, J. and J.Elliott. Boots Pure Drug Co., Ltd., Antibiot. and Ferm. Div., Nottingham, England.

Naka zawa, K., M. Shibata, K. Yamamoto, E. Higashide, T. Iwa sa and T. Hasegawa. Takeda Chem. Ind., Ltd. Juso-Higashiyodogawaku, Osaka, Japan.

\section{Group-9}

Nishimura, H., M. Mayama and K. Tawara. Shionogi Res. Lab., Shionogi and Co., Ltd., Fukushima-ku, Osaka, Japan.

Pridham, T.G. Northern Utilization Res. and Dev. Div. Peoria, Illinois, 61604, U.S.A.

W6znicka, Wanda. Pánstwowy Zaklad Higieny, Ul. Chocimska 24, Warszawa 12, Poland.

\section{Group A-10}

Brinkmann, Rolf. Organic Chem. Inst., Univ of Gottingen, Gottingen, Germany.

Ohara, Y. and H. Nonomura. Faculty of Engineering, Yamanashi Univ., Kofu, Japan.

Routien, J.B. and Corinne Clevenger. Charles Pfizer and Co., Inc., Groton, Connecticut, U.S.A.

\section{Group A-11}

Hutter, Ralf. Mikrobiol. Institut, Eidg. Tech. Hochschule, 8006 Zurich, Switzerland.

Falcão de Morais, J.O. Inst. de Química da Univ. Fed. de Pernambuco, Recife, Pernambuco, Brazil.

Okami, Y. Nat'l Inst. of Health of Japan, Shinagawa, Tokyo, Japan.

\section{Group A-12}

Margalith, P. Labor. of Microbiol., Dept. of Food and Biotechnology, Technion, Haifa, Israel. 
Vernon, T.R. Dept. Scientific and Ind. Res., Private Bag, Auckiand $\mathrm{Cl}$, New Zealand.

Williams, S.T. Hartley Botan. Labor., Univ. of Liverpool, Liverpool, England.

\section{Group $\mathbf{A}-13$}

Řeháčk, Z, and Alena Riłicova, Czech. Acad. of Science, Inst. of Microbiol., Prague 4, Budejovicka No. 1083, Czechoslovakia. Sanchez-Marroquin, A. Miami 40, Mexico 18 / D.F., Mexico. Williams, S.T. Hartley Botan. Labor., Univ. of Liverpool, Liverpool, England.

$$
\text { -................ }
$$

Since 1962 the collaborators listed above and numerous other cooperators have been participating in an international effort to assemble and redescribe type strains or suggested neotype strains for the named species in the genus Streptomyces. This comprehensive effort was first identified as the International Cooperative Project for Description and Deposition of Type Culture of Streptomyces; later shortened to International Streptomyces Project (ISP). The rationale, scope, extensive background preparation, and general plan for the project were explained in the first paper of this series.

This report includes descriptions for 100 type strains or suggested neotype strains of Streptomyces species included in the first international cooperative study. These strains have been deposited with the Centraalbureau voor Schimmelcultures and the American Type Culture Collection for distribution to the leading culture collections of the world, and are recommended as authentic reference cultures for the species. Additional cooperative studies characterizing another three hundred or more species have been completed or are in progress. These type strains will also be distributed to culture collections as cooperative descriptions are published in subsequent reports.

\section{METHODS}

Minimum descriptive criteria to be used in characterization of streptomycetes were first outlined and officially adopted by the Subcommittee on Taxonomy of Actinomycetes of the International Committee on Bacteriological Nomenclature (Gottlieb, 1963). These criteria, together with detailed instructions for standardization of methods and media for the ISP, were published under the title, Methods for Characteriation of Streptomyces Species (Shirling and Gottlieb, 1966). The procedures in this publication have been' formally adopted hy the Subcommittee on Actinomycetes of the Committee on Taxonomy, ASM, as minimal criteria for characterization of species of Streptomyces, Streptoverticillium and related genera. Further uniformity in the ISP study has been achieved through the use of preformulated dehydrated culture media prepared and distributed by Difco Laboratories ${ }^{1}$. The formulations by Difco are the same as those given in the official methods

'Difco Laboratories, Detroit, Michigan, U.S.A. 4820 L. 
cited above.

The ISP description for each species is based upon data submitted by three independent collaborators according to the plan described in our first paper. These collaborators followed the methods approved by the Subcommittee. The descriptive data were then submitted to $\mathrm{Dr}$. E. Shirling for collation. In rare instances where significant disagreement occurred in reports from the three laboratories, the culture was either submitted to a fourth collaborator or withdrawn for re-study.

Since the present study is primarily concerned with species previously described by other methods, each standardized description becomes an emendation to previous descriptions. It neither replaces the original description nor precludes future use of additional criteria of taxonomic significance. The collaborators who studied the species are to be regarded as the authors for the emendation. They are listed as cooperating groups at the beginning of this paper and identified by group number in each description. Earlier descriptions for each culture, including the description ascribed to the original author, are cited whenever possible. These references are given to complete the record and do not imply recognition of valid publication. For citations to validly published descriptions the Index Bergeyana should be consulted.

\section{CULTURES}

All specific epithets for the genera Streptomyces for Actinomyces sensu. Krasil'nikov 1941) and Streptoverticillium, for which type strains or suitable neotype strains can be obtained, are subjects for redescription according to the plan of the ISP. In order to develop a comprehensive reference collection of redescribed type specimens, each available type strain is included without consideration of validity of publication or the legitimacy and correctness of a name. Except for species recently placed in the genus Streptoverticillium (Farina and Locci, 1966; Baldacci et al.. 1966) the generic name used by the author or the contributor of the type strain has been followed. Que stions of nomenclature must therefore be referred to the Index Bergeyana (Buchanan et al., 1966)

Aut hority for identification of the type strain as well as the source of the type strain is included with each description.

Cultures were distributed to collaborating teams more or less in the order received by the coordinator for the project. The 100 type strains described in this report are selected from the first group of 130 strains submitted for redescription. Publication of descriptions based upon reports from two groups ( $A-i 2$ and $A-13$ ) has been delayed because one of the original cooperators was unable to report. These strains were submitted to a fourth laboratory and will be included in the next publication.

\section{ANALYSIS OF A TYPICAL ENTRY}

The first entry, Streptomyces achromogenes Okami and Umezawa is used as the basis for analysis of a typical entry.

1. The species name Streptomyces achromogenes was used by Okami and Umezawa in the first description for the species and was the name used to identify the type strain submitted to us. Although the name is given as validly published and legi timate in Index Bergeyana, our 
use of the name does not constitue an opinion on nomenclatural status. Names not validly published or not legitimate are also included in the study if type specimens are available. Type strains appear alphabetically by specific epithet.

2. Description (followed by citation). The citation following the species name is a reference to a copy of the original description for the type strain of the species. This first description remains an essential part of the complete description; the description prepared by ISP collaborators is an emendation to the description cited after the specific name. For validly published epithets, this citation will usually agree with the citation in Index Bergeyana (as is the case, for example, with $\underline{\mathrm{S}}$. achromogenes). However, in some instances the citation for a specific epithet in Index Bergeyana leads to a publication containing the name, only, without an accompanying description delimiting the species (usually in conjunction with a paper on antibiotic production). In other instances the first description by an author may have been accompanied only by a Streptomyces strain number (see S. flaveolus); the specific epithet was assigned in a separate publication. The first citation in our work is therefore not chosen as the first use of an epithet, but is a reference to the original description assigned to the specific epithet and type strain of the species under study. The reference cited may or may not constitute valid publication of the epithet. Patent applications and patents are used as the source for original descriptions not published elsewhere. If a description first published in a patent or other invalid source was later validly published without significant change, the valid publication is cited. Where appropriate, additional citations are given to indicate other references containing descriptions, additional characterizations, strain numbers, or specific epithets for the species and strain under study.

3. Type strain (followed by strain designation). For most validly published species, and for most species named and described in patents, the type strain is designated by an identifying code (numbers and/or letters chosen by the original investigator or laboratory). The authors' identifying code for the type strain of $\underline{S}$. achromogenes, for example, is $\mathrm{Z}-4-1$. The expression ibid indicates that this designation was included in the article containing the original description (as cited in the previous line). When this is not the case, the authority for the type strain designation is enclosed in parantheses after the type strain number (see $\underline{\mathbf{S}}$. autotrophicus and $\underline{\mathbf{S} \text {. californicus). }}$. When the original characterization of a species is based on a collection of cultures or strains, rather than a single type specimen, the reference containing the collection of strains is cited and the one strain selected by the author (or a representative of the author) in response to our request, is used to designate the type strain. ${ }^{2}$ (See A. acrimycini.)

Synonyms referring to the same type specimen and resulting from transfer of an organism to or from another genus (together with appropriate citation) may be given immediately after the entry designating the authnrity for the type strain (see $\underline{A}$. acrimycini). Opinions

\footnotetext{
2 The terms holotype, syntype and lectotype are not used in the International Code of Nomenclature of Bacteria and therefore have been avoided in this work.
} 
regarding the correct name are beyond the scope of this work. Synonyms or homonyms arising from other causes are not included.

4. ISP number and culture source. ISP 5028 is the accession number for S. achromogenes in the International Streptomyces Project collection at Ohio Wesleyan University: it is the 28th culture received. The accession number is followed by the immediate source from which the ISP received the specimen and the strain number used by the contributor to identify the specimen. If the contributor indicated an additional strain number as equivalent for the exact specimen,

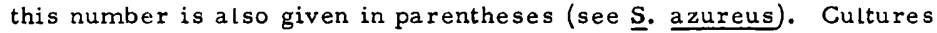
received by ISP from repositories usually show the repository strain number followed by the source from which the repository received the strain and the original depositor's strain number (see S. caelestis). These notations are intended to establish clearly the identity between the ISP strain number and the type strain designated in item 3, above.

5. Authors of ISP description. Each ISP description is based upon data submitted by one of the 13 collaborating groups listed at the beginning of this paper (A-1 through A-13; the letter A designates groups for the first cooperative study). Authorship for each description is ascribed to the appropriate group and is indicated by group number rather than by names of collaborators to conserve publication space. For S. achromogenes, for example, authors of the ISP emendation identified as Group A-l are: Anderson, L.E., S. Wold, E. Baldacci, G. Farina, R. Locci, G.F. Gauze, T.P. Preobrazhenskaya, E.S. Kudrina, T.S. Maximova and M.A. Sveshinikova (see page 70).

6. Spore chain morphology. The RF spore chains of $\underline{\mathrm{S}}$. achromogenes are shown in Figure 1. Illustrations of other morphologies are indicated in table 1. Spore chain morphology is generally defined by assigning the type strain to the appropriate morphological section of the genus Streptomyces as originally delimited by Pridham et a (1958). Except for verticillate sections, Pridham's section names have been changed only slightly to conform to Rule $5 \mathrm{~d}-1$ of the International Code of Nomenclature of Bacteria. Orthographic changes proposed for the sections of Pridham et al. are given in table 1. A Section name is not applied to those species placed in the genus Streptoverticillium by Baldacci et al. (1966) or Farina and Locci (1966); other truly verticillate species are tentatively placed in a section Verticillati of the genus Streptomyces, with additional descriptive terms in conformance to the original verticillate sections suggested by Pridham et al. as follows: monoverticillate (MV), monoverticillate-spira $(\overline{M V}-S)$, biverticillate (or monoverticillateumbellate, Baldacci, 1966) (BIV), and biverticillate-spiral (BIV-S).

When more than one type of spore chain morphology appears to be characteristic for a species, it is arbitrarily placed into one section with appropriate reference to common variations; or in some cases it is assigned alternatively to two sections (see $\underline{\mathbf{S}}$. caelestis).

Difficulty is occasionally experienced in the interpretation of the sections Retinaculiaperti and Spirales. Some "spiral cultures (either as characteristic growth or, more often, through degeneracy, change in medium, or suboptimal conditions of culture) produce short spore chains. Such short chains may form only one turn of a spiral, hooks and loops of small diameter, or irregular and poorly 


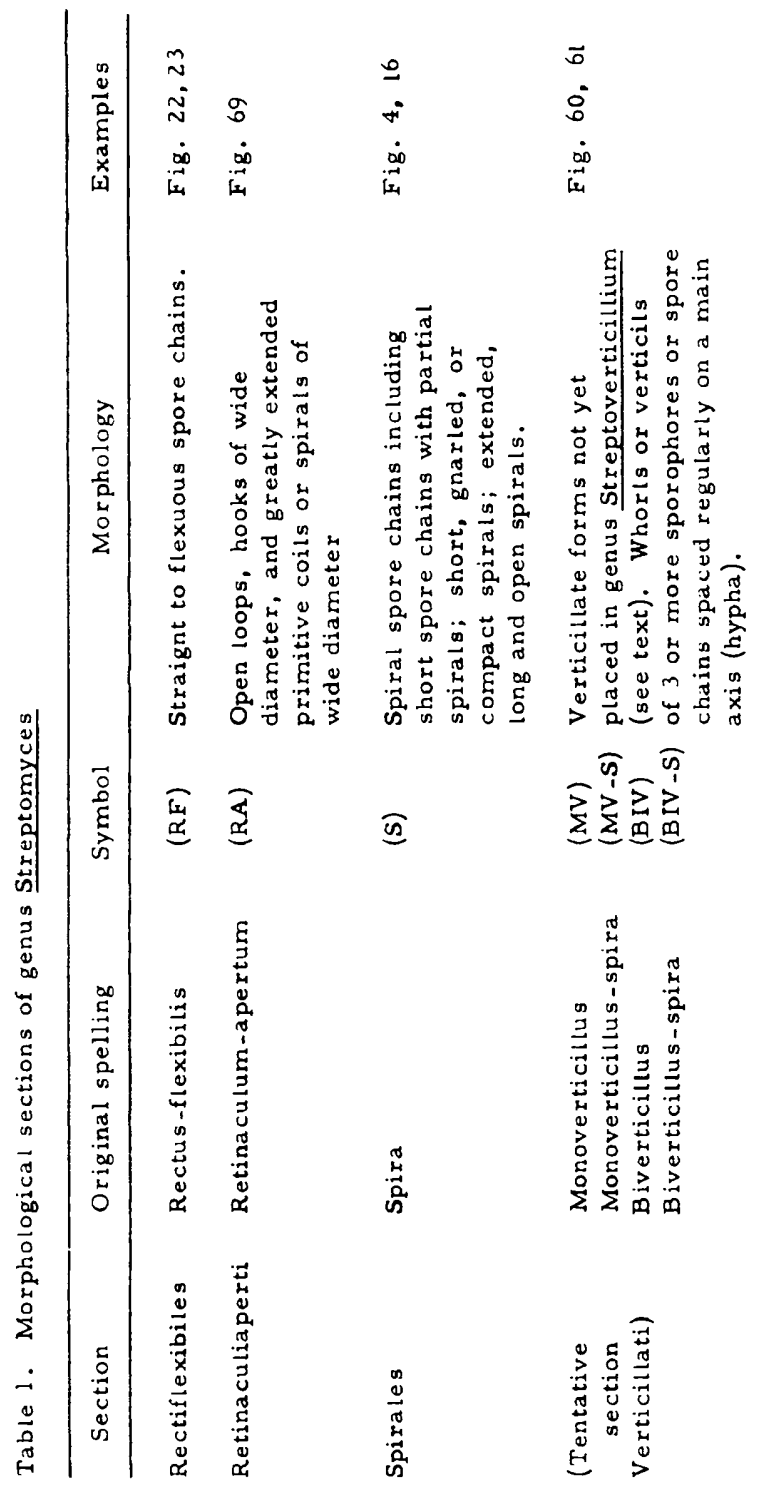


defined spirals. These are not properly placed with the RA cultures which typically show hooks, loops, or primitive coils of large diameter. For these cultures, and others where assignment to a morphological section was in question, either photographs and draw ings from collaborators or actual cultures were examined by a special subcommittee: Dr. T.G. Pridham, Dr. E.J. Backus and Dr. H.D. Tresner. On the basis of their recommendations several atypical cultures have been placed in section Spirales in preference to section Retinaculiaperti as first reported by the collaborating team. In such cases, the text of the description directs attention to the atypical morphology (see, for example, $\underline{\text {. cacaoi, }}$. caelestis). It should be noted that correct assignment to a spore chain morphology section is difficult when short spore chains (less than 10 spores per chain) are reported on all media.

7. Spore surface. Smooth, warty, spiny, or hairy spore surface silhouettes can be distinguished at a magnification of about $8000 \mathrm{x}$ or greater. The smooth spore surface of $\underline{\mathbf{S}}$. achromogenes is shown in figure 1. Other examples of spore surface are seen in figures 7 (smooth), 79 (warty), 15 (spiny) and 3 (hairy). For the ISP description, this characteristic was determined in at least two electron microscope laboratories. H.D. Tresner and M.C. Davies of Lederle Laboratories and A. Dietz and J. Mathews of Upjohn Company provided electron microscope data for cooperators without electron micros cope facilities.

8. Color of colony. The mass color of sporulating aerial mycelium on four media is defined in terms of a system of seven color wheels developed by Tresner and Backus (1963). Each wheel, made from color tabs selected from the Color Harmony Manual ${ }^{3}$ is identified by a single color-series name. The sporulating surface of $S$. achromogenes, for example falls within the range of color tabs in the Gray color-series (wheel) on all four ISP test media. Other colorseries in the Tresner-Backus system are White, Red, Yellow, Green, Blue and Violet. Color of the sporulating aerial mycelium may sometimes vary with the medium; reports from different collaborators may differ on appropriate color-series; or, more rarely, the aerial mass color may appear to be intermediate between two color-series. Minor variations usually fall within the range of color chips in a single color-series wheel and are therefore not reported. Significant variations are included in the text of the description (see $\mathbf{A}$. acrimycini, S. cinereoruber).

9. Reverse side of colony. Pigmentation of the substrate mycelium is determined by observing the reverse side of the growth after removal of most of the agar medium with a razor blade. S. achromogenes is described as having no distinctive pigment in the substrate mycelium. Strains are characterized as lacking distinctive substrate pigment if

3Printed patterns for assembling the color wheels, together with reprints of the Tresner-Backus paper can be obtained without cost from Prof. E.B. Shirling, ISP, Ohio Wesleyan University, Delaware, Ohio 43015, U.S.A. Color Harmony Manual chips used in the guide may be purchased from Color Standards Department, Container Corporation of America, 38 South Dearborn St., Chicago, Illinois 60603, U.S.A. 
the reverse side of the colony is colorless, greenish yellow, light or pale yellow, yellowish gray, olive, light olive brown, orange yellow, yellowish brown or olive brown. (These colors are found in hues $\mathrm{C}, \mathrm{CO}$ and $\mathrm{COO}$ of the Prauser color guide or in hues $1,11 / 2,2$ and 3 of the complete Color Harmony Manual ${ }^{3}$ ). Within this range, differences in value and chroma as well as hue are neither clearly identified nor reliably constant with species. They are probably not useful for species differentiation. On the other hand, the presence or absence of a red, blue or violet, or distinct green pigment in the substrate mycelium on one or more media is a differential property of taxonomic value (Szabo and Marton, 1964). A substrate pigment may be a $\mathrm{pH}$ indicator (see below) in which case color may vary with changes in $\mathrm{pH}$ of the medium during culture growth or the ultimate $\mathrm{pH}$ of the medium. Indicator pigments are detected by observing the effect of 0.05 $\mathrm{N} \mathrm{NaOH}$ and $0.05 \mathrm{~N} \mathrm{HCl}$ on the color of the reverse side of the colony after removal of most of the agar. (For examples of distinctive substrate colors, some of which are $\mathrm{pH}$ indicators, see descriptions for S. althioticus, S. aureoverticillatus, S. califor-

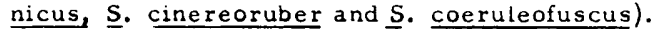

10. Color in medium. S. achromogenes is an example of a chromogenic species; the type strain produces dark (melanoid) pigment in media containing a source of tyrosine (peptone-yeast-iron agar, tyrosine agar). Peptone-yeast-iron agar is used as a sensitive indicator for the melanin (= tyrosinase or polyphenol oxidase) reaction. In this medium melanin production is rapid and a positive reaction is evident in 2-4 days. It should be noted, however, that darkening of this medium may sometimes result from $\mathrm{H}_{2} \mathrm{~S}$ production or from production of pigments other than melanins in the medium. Darkening of tyrosine agar is more definite evidence of true melanin production, but this defined medium often yields poor growth and is not sufficiently sensitive for some cultures. Darkening of tryptone-yeast extract broth within 2 days also confirms positive melanin reactions observed on peptone-yeast-iron agar. For a few type strains, collaborators recorded darkening of the medium only in peptone-yeast-iron agar or indicated slow or weak darkening of tyrosine or peptone media. Such strains are usually described in the ISP report as producers of melanoid (dark) pigments but with additional qualifying statements as appropriate. (See, for example, S. flavopersicus, S. canus.) The term melanoid, as used here, connotes a dark pigment, which may or may not be melanin from a polyphenol oxidase reaction.

Pigments other than melanoids may be found in the medium. Unlike melanoids, these may be found in ISP media that do not contain tyrosine as well as in highly organic media. Traces of yellow, gray, or faint brown pigment are probably not distinctive, especially in yeast-malt agar and oatmeal agar. Distinct yellow, red, blue or violet pigments in the medium are of taxonomic significance. The red-blue-violet pigments are often $\mathrm{pH}$ sensitive. As

\footnotetext{
${ }^{4}$ Prepared for ISP collaborators by H. Prauser (1964) from color tabs
} of Baumann's Farbtonkarte Atlas I. 
in the case of reverse color, $\mathrm{pH}$ sensitivity of pigments in the medium is a significant taxonomic criterion as well as an important factor in establishing the actual color observed. (See description for A. bicolor, yellow, not $\mathrm{pH}$ sensitive; $\underline{\text { S. althioticus, }}$ blue-violet or red, $\mathrm{pH}$ sensitive.)

11. Carbon utilization. The ability of a type strain to utilize each of nine carbon compounds as the sole source of carbon is determined by incorporating each carbon source, separately, into Pridham and Gottlieb's basal salts medium and inoculating with washed inoculum. Precautions regarding sterilization procedures for the carbon sources and preparation of washed inoculum are given in the ISP methods (Shirling and Gottlieb, 1966). Unfor tunately many streptomycetes produce visible traces of growth on the basal medium without added carbon source. Positive utilization must therefore be judged on the basis of significantly more growth on the medium enriched with a given carbon source than on the basal medium alone. In the case of $\underline{\mathrm{S}}$. achromogenes, for example, growth on $\underline{D}$-glucose, L- arabinose, D-mannitol and $\underline{D}$-fructose is reported as clearly better than traces of growth (if any) on the carbon-free basal medium. Trace growth (if any) on sucrose, D-xylose and raffinose is similar to the carbon-free control and therefore these carbon sources are not utilized. Reports of variable growth (as with rhamnose and $\underline{I}$-inositol for $\underline{\mathbf{S}}$. achromogenes) may represent indecision on the part of all three collaborating laboratories as to whether growth on these media is or is not significantly different from the no-carbon control or, more often, indicates variable reports ranging from positive growth to traces of growth (or no growth) or even variable data from duplicate cultures. Cellulose was included in the original list of carbon-sources for the utilization test. It was withdrawn because negative or doubtful utilization was reported for all of the 130 cultures in the first study. 


\section{ISP CHARACTERIZATIONS OF TYPE STRAINS}

Streptomyces achromogenes Okami and Umezawa. Description: Okami and Umezawa in Umezawa et al. 1953b,261-268. Type strain: Z-4-1 (ibid.) ISP $502 \overline{8}$ from Y. Okami as Z-4-1. ISP description by Group A-1.

Spore chain morphology: Section Rectiflexibiles. Mature spore chains generally 10 to 50 spores per chain (Fig. 2). This morphology is seen on yeast-malt agar, oatmeal agar, salts-starch agar and glycerolasparagine agar. One observer recorded some loops or hooks on saltsstarch agar. Spore surface: Smooth (Fig. l).

Color of colony: Aerial mass color in the Gray color-series on yeastmalt agar, oatmeal agar, and glycerol-asparagine agar.

Reverse side of colony: No distinctive pigments on yeast-malt agar, oatmeal agar, salts-starch agar or glycerol-asparagine agar; substrate pigment is not a $\mathrm{pH}$ indicator.

Color in medium: Melanoidpigments formed in peptone-yeast-iron agar, tyrosine agar and other organic media. Pigments other than melanoids not formed in yeast-malt agar, oatmeal agar, salts-starch agar or glycerol-asparagine agar.

Carbon utilization: D-Glucose, L-arabinose, D-mannitol and Dfructose are utilized for growtin. No growth or only trace of growth on sucrose, D-xylose and raffinose. Variable reports of slight growth with rhamnose and $\underline{I}$-inositol.

Actinomyces acrimycini Preobrazhenskaya, Blinov and Ryabova. Description: Preobrazhenskaya et al. in Gauze et al. 1957, 140,141. Type strain: 7699 (ibid.; type strain selected by Preobrazhenskaya, personal communication). Streptomyces acrimycini (Preobrazhenskaya, Blinov and Ryabova) Pridham et al. 1958, $\overline{65}$. IST 51 35 from T.P. Preobrazhenskaya as 7699 . ISP description by Group A-1.

Spore chain morphology: Section Spirales, with many loose spirals, but spore chains representative of Section $\mathrm{RA}$ and some flexuous chains were also observed (Fig. 4). Mature spore chains generally 10 to 50 spores per chain; longer chains are sometimes observed. This morphology is seen on yeast-malt agar, oatmeal agar, salts-starch agar and glycerol-asparagine agar. Spore surface: Hairy (Fig. 3).

Color of colony: Aerial mass color in the Green color-series on yeast-malt agar and salts-starch agar; Green or Gray series on oatmeal agar and glycerol-asparagine agar.

Reverse side of colony: No distinctive pigments on yeast-malt agar, oatmeal agar, salts-starch agar or glycerol-asparagine agar; substrate pigment is not a $\mathrm{pH}$ indicator. (One observer reports slight change from green to light green with addition of $0.05 \mathrm{~N} \mathrm{NaOH.)}$

Color in medium: Melanoid pigments not formed in peptone-yeast-iron agar and tyrosine agar. No pigment found in medium in yeast-malt agar, oatmeal agar, salts-starch agar or glycerol-asparagine agar.

Carbon utilization: D-Glucose, L-arabinose, D-xylose, I-inositol, D-mannitol, D-fructose- and rhamnose are utilized for growth. No growth or only trace of growth on sucrose and raffinose.

Streptomyces albirecticuli Nakazawa. Description: Nakazawa 1955. 647-649. Type strain: 3724 (ibid.). ISP 5051 from K. Nakazawa as 3724. ISP description by Group A-1. 


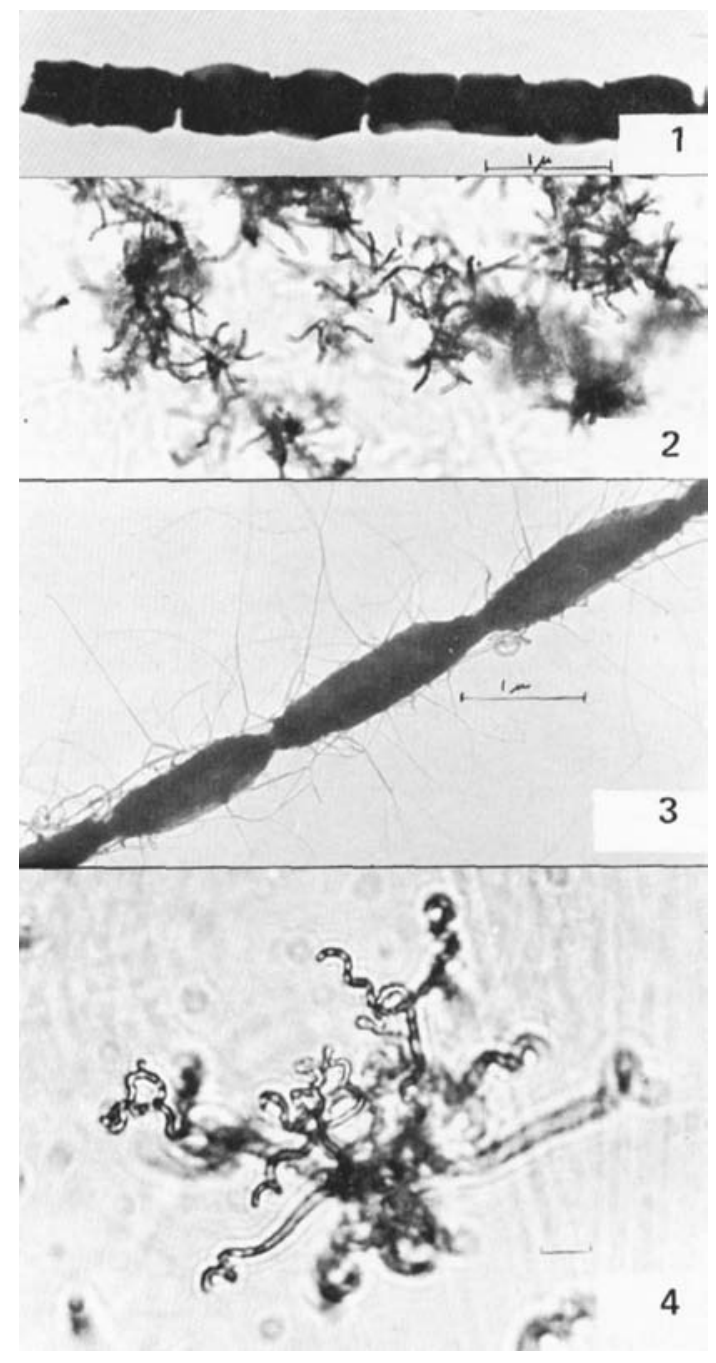

Figure 1. S. achromogenes. Smooth spores; electron micrograph from 14 day culture on salts-starch agar. ${ }^{1,}$ *

Figure 2. S. achromogenes. RF spore chains $(378 x)$ on Waksman's starch agar $B, 32$ days. ${ }^{2}$

Figure 3. A. acrimycini. Hairy spores; electron micrograph from 14 day culture on yeast-malt agar. ${ }^{1}$

Figure 4. A. acrimycini. Spiral spore chains $(720 \mathrm{x})$ on yeast-malt agar, $1 \overline{4}$ days. ${ }^{3}$

* Sources of illustrations are indicated by superscript number following legend for each figure, and are listed by number after the bibliography. 
Spore chain morphology: Section Verticillati. Both monoverticillate and umbellate moverticillate (biverticillate) sporophores are found ( $F$ ig. 6). Mature spore chains generally 10 to 50 spores per chain on suitable media. This morphology is seen on yeast-malt agar, oatmeal agar and salts-starch agar after 2-3 weeks; poor growth of aerial mycelium on glycerol-asparagine agar and variable aerial growth on oatmeal agar and salts-starch agar. Spore surface: Smooth (Fig. 5).

Color of colony: Aerial mass color in the Yellow or White colorseries on yeast-malt agar, oatmeal agar and salts-starch agar.

Reverse side of colony: No distinctive pigments on yeast-malt agar, oatmeal agar, salts-starch agar or glycerol-asparagine agar; substrate pigment is not a $\mathrm{pH}$ indicator.

Color in medium: Melanoid pigments are formed in peptone-yeastiron agar and tyrosine agar. Pigments other than melanoids not formed in yeast-malt agar, oatmeal agar, salts-starch agar or glycerol-asparagine agar.

Carbon utilization: D-Glucose and I-inositol are utilized for growth. No growth or only trace of growth on L-arabinose, sucrose, D-xylose, D-mannitol, rhamnose and raffinose. Variable reports on growth with D-fructose.

Streptomyces alboniger Porter, Hewitt, Hesseltine, Krupka, Lowery, Wallace, Bohonos and Williams. Description: Porter et al. 1952, 409410; see also Hesseltine et al. 1954, 16-22. Type strain: P-638 (H. Tresner, personal communication). ISP 5043 from H. Tresner, Lederle Laboratories as P-638. ISP description by Group A-3.

Spore chain morphology: Section Rectiflexibiles. Mature spore chains generally 10 to 50 or more spores per chain. This morphology is scen on catmeal agar, salts-starch agar and glycerol-asparagine agar. Spore surface: Smooth (Fig. 7).

Color of colony: Aerial mass color in the White color-series on oatmeal agar, salts-starch agar and glycerol-asparagine agar; aerial mycelium poorly developed or absent on yeast-malt agar.

Reverse side of colony: No distinctive pigments on yeast-malt agar, oatmeal agar, salts-starch agar or glycerol-asparagine agar, except that transient dark reverse colors ranging from very dark brown to nearly black are sometimes reported on salts-starch agar and glycerolasparagine agar. Reverse pigment is not a $\mathrm{pH}$ indicator.

Color in medium: Melanoid pigments not formed (or only a faint brown) in peptone-yeast-iron agar in 2 to 4 days, but transient dark pigments are reported on various media for older cultures. All 3 observers reported dark pigment in salts-starch agar in 7 days. This pigment is not $\mathrm{pH}$ sensitive.

Carbon utilization: D-Glucose, L-arabinose, I-inositol and $\underline{D}$-mannitol are utilized for growth. No growth or only trace of growth on sucrose and rhamnose. Variable reports on growth with $\underline{D}$-fructose, D-xylose and raffinose.

Actinomyces albovinaccus Kudrina. Description: Kudrina in Gauze et al. 1957b, 113 and 118. Type strain: 273/53 (Preobrazhenskaya, personal communication). Streptomyces albovinaceus (Kudrina) Pridham et al. 1958, 57. ISP 5136 from T.P. Preobrazhenskaya as $273 / 53$. ISP description by Group A-1.

Spore chain morphology: Section Rectiflexibiles. Short spore chains 


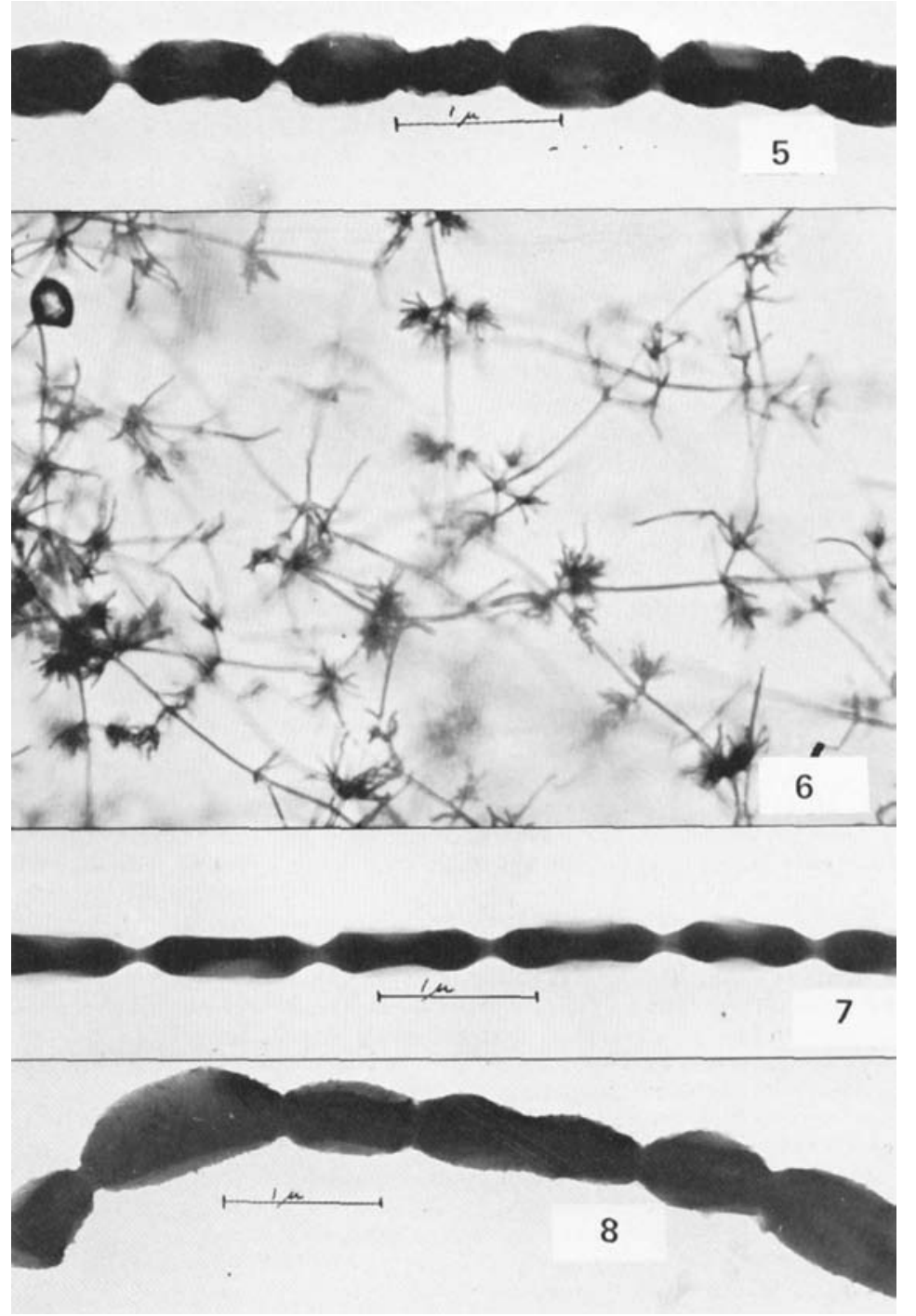

Figure 5. S. albireticuli. Smooth spores; electron micrograph from 14 day culture on oatmeal agar. ${ }^{1}$

Figure 6. S. albireticuli. BIV (umbellate monoverticillate) spore chains on salts-starch agar, 14 days. ${ }^{4}$

Figure 7. S. alboniger. Smooth spores; electron micrograph from 14 day cüture on oatmeal agar. ${ }^{1}$

Figure 8 . S. althioticus. Spiny spores, very short spines; electron micrograph from 14 day culture on yeast-malt agar. ${ }^{1}$ 
of more than 3 spores per chain. This morphology with sporulating aerial mycelium is found on yeast-malt agar, oatmeal agar, saltsstarch agar and glycerol-asparagine agar. Spore surface: Smooth.

Color of colony: Aerial mass color in the White color-series on yeast-malt agar, oatmeal agar, salts-starch agar and glycerol-asparagine aga $r$.

Reverse side of colony: No distinctive pigments on yeast-malt agar, oatmeal agar, salts-starch agar or glycerol-asparagine agar; substrate pigment is not a $\mathrm{pH}$ indicator.

Color in medium: Melanoid pigments not formed in peptone-yeastiron agar and tyrosine agar. No pigment found in medium in yeastmalt agar, oatmeal agar, salts-starch agar or gycerol-asparagine agar.

Carbon utilization: D-Glucose, L-arabinose, D-xylose, D-mannitol, D-fructose and rhamnose are utilized for growth. No growth or only trace of growth on sucrose, I-inositol and raffinose.

Streptomyces althioticus Yamaguchi, Nakayama, Takeda, Tawara, Maeda, Takeuchi and Umezawa. Description: Yamaguchi et al. 1957, 195-200. Type strain: 245-Z2 (ibid). ISP 5092 from $\mathrm{H}$. Yamaguchi as 245-Z2. ISP description by Group A-7.

Spore chain morphology: Section Spirales, but flexuous sporophores are also common, especially on yeast-malt agar. Mature spore chains generally 10 to 50 spores per chain. This morpbology is observed on yeast-malt agar, oatmeal agar, salts-starch agar and glycerol-asparagine agar. Spore surface: Spiny, with only minor surface irregularities suggestive of spines or warts (Fig. 8).

Color of colony: Aerial mass color in the Gray color-series on yeastmalt agar, oatmeal agar, salts-starch agar and glycerol-asparagine agar.

Reverse side of colony: Grayed yellow modified to blue-violet or red on yeast-malt agar, oatmeal agar, salts-starch agar and glycerolasparagine agar. Reverse pigment is $\mathrm{pH}$ indicator; it is changed from red or reddish brown to blue or blue-violet by addition of $0.05 \mathrm{~N} \mathrm{NaOH}$.

Color in medium: Melanoid pigments not formed or occurring only in trace amounts in peptone-yeast-iron agar and tyrosine agar; blueviolet or red pigment (depending upon $\mathrm{pH}$ ) occurs in medium in yeastmalt agar, oatmeal agar, salts-starch agar and glycerol-asparagine agar. This pigment is $\mathrm{pH}$ sensitive becoming blue or blue-violet when tested with $0.05 \mathrm{~N} \mathrm{NaOH}$ and red when tested with $0.05 \mathrm{~N} \mathrm{HCl}$.

Carbon utilization: D-Glucose, L-arabinose, D-xylose, I-inositol, D-mannitol, D-fructose and rhamnose are utilized for growth. No growth or only trace of growth on raffinose. Variable reports on growth with sucrose.

Actinomyces atroolivaceus Preobrazhenskaya, Blinov and Ryabova. Description: Preobrazahenskaya et al. in Gauze et al. 1957,140 and 143. Type strain: 4776 (ibid; type strain selected by Preobrazhenskaya, personal communication). Streptomyces atroolivaceus (Preobrazhenskaya, Blinov and Ryabova) Pridham et al. 1958,68. ISP 5137 from T.P. Preobrazhenskaya as 4776 . ISP description by Group A-1.

Spore chain morphology: Section Rectiflexibiles ( ig. 10). Mature spore chains generally 10 to 50 spores per chain. This morphology is seen on yeast-malt agar, oatmeal agar, salts-starch agar and glycerol- 


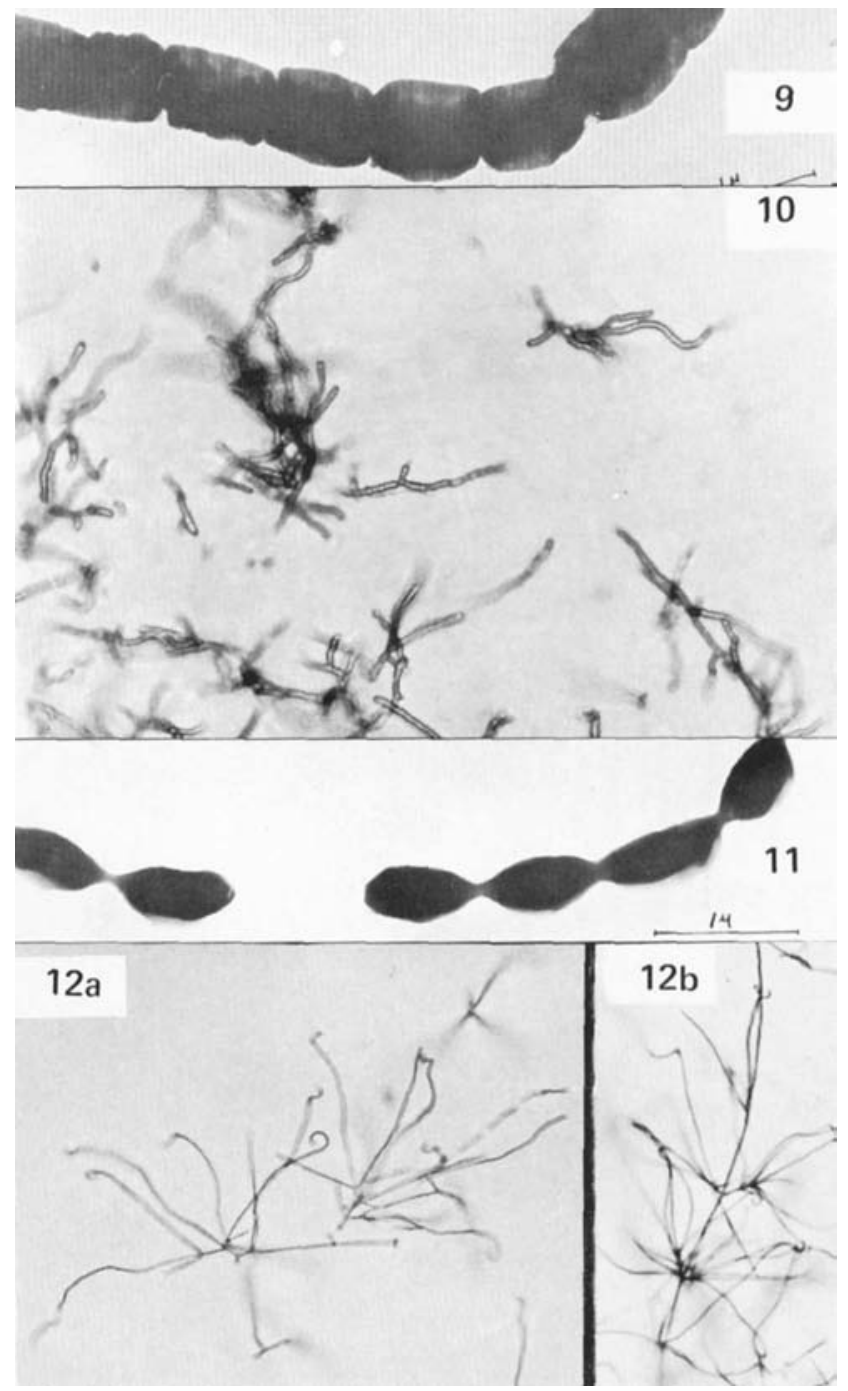

Figure 9. A. atroolivaceus. Smooth spores (but with minor surface irregularities suggestive of warty spores); electron micrograph from 14 day culture on yeast-malt agar. ${ }^{1}$

Figure 10. A. atroolivaceus, RF spore chains $(720 x)$ on yeast-malt agar, 7 days. $^{3}$

Figure 11. A. aureoverticillatus. Smooth spores; electron micrograph from 14 day culture on oatmeal agar. ${ }^{1}$

Figure 12. A. aureoverticillatus. (a) RA spore chains (625x) on saltsstarch agār, 13 days. ${ }^{5}$ (b) Pseudo-verticillate arrangement of spore chains $(300 x)$ on salts-starch agar, 14 days. ${ }^{4}$ 
asparagine agar. Spore surface: Smooth (Fig. 9).

Color of colony: Aerial mass color in the Gray color-series on yeastmalt agar, oatmeal agar, salts-starch agar and glycerol-asparagine agar.

Reverse side of colony: No distinctive pigments on yeast-malt agar, oatmeal agar, salts-starch agar or glycerol-asparagine agar; substrate pigment is not a $\mathrm{pH}$ indicator.

Color in medium: Melanoid pigments not formed in peptone-yeastiron agar and tyrosine agar. No pigment found in medium in yeastmalt agar, oatmeal agar, salts-starch agar or glycerol-asparagine agar.

Carbon utilization: D-Glucose, L-arabinose, D-xylose, D-fructose and rhamnose are utilized for growth. Variable reports on growth with sucrose, I-inositol, $\underline{D}-$ mannitol and raffinose. (Two collaborators reported difficulty in observing results because of poor growth on all carbon sources with Pridham and Gottlieb basal medium.)

Actinomyces aureoverticillatus Krasil'nikov and Yün Chi-sheng. Description: Krasil'nikov and Yün Chi-sheng 1960, 482-489. Type strain: 1077 (ibid.). ISP 5080 from V. D. Kuznetsov as INMI-1077. ISP description by Group A-11.

Spore chain morphology: Section Retinaculiaperti but spore chains representative of Section Rectiflexibiles are common. Pseudoverticillate sporophores (suggesting Section Verticillati) are found, especially on salts-starch agar. Verticils are not evenly spaced on an enlarged axial hypha as in true verticillate forms ( $F$ ig. 12). Mature spore chains generally 10 to 50 spores per chain. This morphology is seen on yeastmalt agar, oatmeal agar, salts-starch agar and glycerol-asparagine agar, but aerial mycelium is not abundant on yeast-malt agar or oatmeal agar. Spore surface: Smooth (Fig. 11).

Color of colony: Aerial mass color in the Red color-series on saltsstarch agar and glycerol-asparagine agar (White is also found on these media and on poorly sporulated surface on yeast-malt agar).

Reverse side of colony: Grayed yellow modified to red on yeast-malt agar, oatmeal agar, salts-starch agar and glycerol-asparagine agar. Substrate pigment is a $\mathrm{pH}$ indicator; it is changed from orange to yellow by addition of $0.05 \mathrm{~N} \mathrm{NaOH}$, and from orange to red with $\mathrm{HCl}$.

Color in medium: Melanoid pigments not formed in peptone-yeastiron agar and tyrosine agar. No pigment found in medium in yeast-malt agar, oatmeal agar, salts-starch agar or glycerol-asparagine agar.

Carbon utilization: D-Glucose, L-arabinose, D-xylose, I-inositol, D-mannitol, D-fructose and raffinose are utilized for growth. No growth or only trace of growth on rhamnose. Variable reports on growth with sucrose.

Streptomyces autotrophicus Takamiya and Tubaki. Description: Takamiya and Tubaki 1956, 58-64. Type strain: aa-1-1 (A. Takamiya, personal communication). Nocardia autotrophica (Takamiya and Tubaki) Hirsch 1960, 391-414. ISP 5011 rom A. Takamiya as aa-1-1. ISP description by Group A-2.

Spore chain morphology: Section Rectiflexibiles Observers report wide variation in spore chain length ( 3 to more than 50 spores per chain). Reports also differ in reference to media supporting characteristic spore chain development; oatmeal agar is not useful for morpho- 
logical observations for this culture. Spore surface: Smooth.

Special morphological characteristics: Aerial spores are characteristically cylindrical, rather than oval or spherical, suggesting segmentation spores.

Color of colony: Aerial mass color in the Yellow color-series on yeast-malt agar and glycerol-asparagine agar; White or Yellow colorseries on oatmeal agar and salts-starch agar.

Reverse side of colony: No distinctive pigments on yeast-malt agar, oatmeal agar, salts-starch agar or glycerol-asparagine agar; substrate pigment is not a $\mathrm{pH}$ indicator.

Color in medium: Melanoid pigments not formed in peptone-yeastiron agar and tyrosine agar. No pigment found in medium in yeast-malt agar, oatmeal agar, salts-starch agar or glycerol-asparagine agar.

Carbon utilization: D-Glucose, L-arabinose, sucrose, D-xylose, I-inositol, D-mannitol, D-fructose and rhamnose are utilized for growth. Variable reports on growth with raffinose. All observers report growth on basal medium without added carbon source.

Streptomyces azureus Donovick, Pagano, Vandeputte. Description: Donovick et al. U.S. Patent 2, 982,689; also Streptomyces sp. Pagano, Weinstein, Stout, Donovick 1955-56, 554-559. Type strain: IMRU 3705 (U.S. Patent 2, 982, 689). ISP 5106 from W. Trejo, Squibb Inst. Med. Res. as IMRU 3705 (SC-2364). ISP description by Group A-10.

Spore chain morphology: Section Spirales. Some sporophores supporting spiral spore chains appear to arise singly, in pairs or in simple or branched whorls along an axial hypha (suggesting verticillate morphology) especially on salts-starch agar and glycerol-asparagine agar. Mature spore chains generally 10 to 50 spores per chain. This morphology is seen on yeast-malt agar, oatmeal agar, salts-starch agar and glycerol-asparagine agar. Spore surface:S mooth

Color of colony: Aerial mass color in the Blue color-series on yeastmalt agar, oatmeal agar, salts-starch agar and glycerol-asparagine agar.

Reverse side of colony: No distinctive pigments on yeast-malt agar, oatmeal agar, salts-starch agar or glycerol-asparagine agar; substrate pigment is not a pH indicator.

Color in medium: Melanoid pigments formed in peptone-yeast-iron agar, tyrosine agar and tryptone-yeast extract broth. Pigments (other than melanoids) not formed in yeast-malt agar, oatmeal agar, saltsstarch agar or glycerol-asparagine agar.

Carbon utilization: D-Glucose, L-arabinose, sucrose, D-xylose, I-inositol, D-mannitol, D-fructose, rhamnose and raffinose are utilized for growth.

Actinomyces badius Kudrina. Description: Kudrina in Gauze et al. $1957 \mathrm{a}, 78$ and 87 . Type strain 1203/53 (ibid.; type strain selected by Preobrazhenskaya, personal communication). Streptomyces badius (Kudrina) Pridham et al. 1958, 58. ISP 5139 from T. P. Preobrazhenskaya as $1203 / 53$. ISP description by Group A-1.

Spore chain morphology: Section Rectiflexibles. Mature spore chains generally 10 to 50 spores per chain (Fig. 14). This morphology is found on yeast-malt agar, oatmeal agar, salts-starch agar and glycerolas paragine agar. Spore surface: Smooth (Fig. 13).

Color of colony: Aerial mass color in the Yellow color-series on 

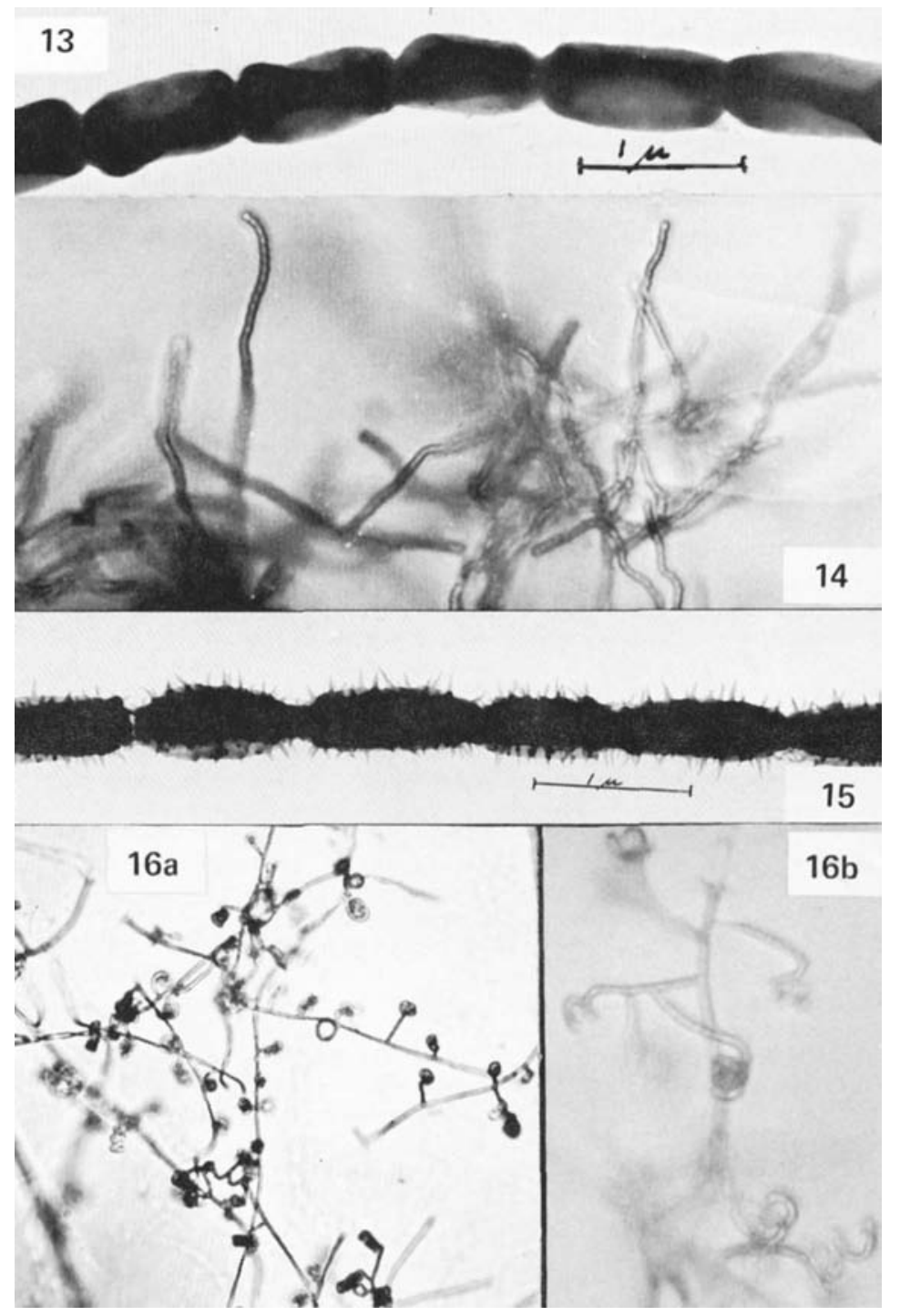

Figure 13. A. badius. Smooth spores; electron micrograph from 14 day culture on salts-starch agar. ${ }^{3}$

Figure 14. A. badius. RF spore chains $(720 \mathrm{x})$ on salts-starch agar, 14 day $8 .{ }^{3}$

Figure 15. A. bicolor. Spiny spores; electron micrograph from 14 day culture on oatmeal agar. ${ }^{1}$

Figure 16. A. bicolor. Spiral spore chains. (a) $300 x$ on yeast-malt agar, 7 days. ${ }^{6}$ (b) $875 x$ on yeast-malt agar, 14 days. 7 
yeast-malt agar, oatmeal agar, salts-starch agar and glycerol-asparagine agar (or intermediate between Gray series and Yellow series - one observer).

Reverse side of colony: No distinctive pigments on yeast-malt agar, oatmeal agar, salts-starch agar or glycerol-asparagine agar; substrate pigment is not a $\mathrm{pH}$ indicator.

Color in medium: Melanoid pigments not formed in peptone-yeastiron agar, but some variable darkening was observed in tyrosine agar and tryptone-yeast broth; other pigments not formed.

Carbon utilization: D-Glucose, L-a rabinose, D-xylose, D-mannitol and D-fructose are utilized for growth. No growth or only trace of growth on sucrose, I-inositol, rhamnose and raffinose.

Actinomyces bicolor Preobrazhenskaya. Description: Preobrahenskava in Gauze et al. 1957, 123 and 127. Type strain: 5104 (Preobrazhenskaya, personal communication). Streptomyces bicolor (Preobrazhenskaya) Pridham et al. 1958, 66. Not Actinomyces bicolor Trolldenier 1903, 108; not Nocardia bicolor (Trolldenier) de Mello and St. Antonio Fernandes 1919, 106. ISP 5140 from T.P. Prebrazhenskaya as 5104. ISP description by Group A-3.

Spore chain morphology: Section Spirales Mature spore chains generally 10 to 50 spores per chain (Fig. 16). This morphology is seen on yeast-malt agar, oatmeal agar, salts-starch agar and glycerolasparagine agar. Spore surface: Spiny (Fig. 15).

Color of colony: Aerial mass color in the Blue color-series on yeast-malt agar, oatmeal agar, salts-starch agar and glycerol-asparagine agar.

Reverse side of colony: No distinctive pigments on yeast-malt agar, oatmeal agar, salts-starch agar or glycerol-asparagine agar; substrate pigment is not a $\mathrm{pH}$ indicator.

Color in medium: Melanoid pigments are formed in peptone-yeastiron agar, tyrosine agar and tryptone-yeast broth; yellow pigment found in medium in yeast-malt agar, oatmeal agar, salts-starch agar and glycerol-asparagine agar. This pigment is not $\mathrm{pH}$ sensitive when tested with $0.05 \mathrm{~N} \mathrm{NaOH}$ or $\mathrm{HCl}$.

Carbon utilization: D-Glucose, L-arabinose, sucrose, D-xylose, I-inositol, D-mannitol, D-fructose, rhamnose and raffinose are utilized for growth.

Streptomyces blastmyceticus Watanabe, Tanaka, Fukuhara, Miyairi, Yonehara and Umezawa. Description: Watanabe et al. 1957, 39-45. Type strain: $455 \mathrm{Dl}$ (ibid.). ISP 5029 from H. Yonehara as $455 \mathrm{Dl}$. ISP description by Group $\mathrm{A}-2$.

Spore chain morphology: Section Verticillati. Both monoverticillate and umbellate monoverticillate (biverticillate) spore chains are found. Spore chains short; usually only 3 to 10 spores per chain (Fig. 18). This morphology is seen on oatmeal agar; mature spore chains may not develop on other ISP media. Spore surface: Smooth (Fig. 17).

Color of colony: Aerial mass color in the Gray or Green color-series on oatmeal agar. Better sporulation and color is produced on tomato paste-oatmeal agar or on Hickey and Tresner's agar. On these media an olive-gray color (Gray color-series) is produced. (Immature and poorly sporulated aerial growth on other media may appear to place this 
species in the Yellow or Red color-series.)

Reverse side of colony: Characteristic grayed yellow on yeast-malt agar and grayed greenish yellow to olive-brown on oatmeal agar, saltsstarch agar and glycerol-asparagine agar; substrate pigment is not a $\mathrm{pH}$ indicator.

Color in medium: Melanoid pigments formed in peptone-yeast-iron agar and tryptone-yeast broth. Pigments, other than melanoids, not formed in yeast-malt agar, oatmeal agar, salts-starch agar or glycerolas paragine agar.

Carbon utilization: D-Glucose, L-arabinose, I-inositol and D-fructose are utilized for growth. No growth or only trace of growth on Dxylose, rhamnose and raffinose. Utilization of sucrose and D-mannitol doubtful.

Streptomyces cacaoi (Waksman) Waksman and Henrici. Description: Actinomyces cacaoi Waksman in Bunting 1932, 515-517; Streptomyces cacaoi (Waksman) Waksman and Henrici 1948, 951. Iype strain: IMRU 3082 (Waksman 1961, 183). ISP 5057 from S. A. Waksman as IMRU 3082. ISP description by Group A-11.

Spore chain morphology: Section Spirales Spore chains are poorly developed on all ISP media. Spirals, when formed, are open. Incomplete spirals, loops, hooks or even flexuous chains may be common when spore chains are short. These are not typical of the large hooks and loops of RA cultures. Mature spore chains may contain 10 to 50 spores per chain on yeast-malt agar, salts-starch agar and glycol-asparagine agar, but long chains are not common. Oatmeal agar is not suitable for observation of morphology or aerial mass color. Spore surface: Smooth (Fig. 19).

Color of colony: Aerial mass color in the White color-series on yeast-malt agar, salts-starch agar and glycerol-asparagine agar.

Reverse side of colony: No distinctive pigments on yeast-malt agar, oatmeal agar, salts-starch agar or glycerol-asparagine agar; substrate pigment is not a $\mathrm{pH}$ indicator.

Color in medium: Melanoid pigments not formed in peptone-ycastiron agar, tyrosine agar and tryptone-yeast extract broth. No pigment found in medium in yeast-malt agar, oatmeal agar, salts-starch agar or glycerol-asparagine agar.

Carbon utilization: D-Glucose, L-arabinose, D-xylose, D-mannitol and $\underline{D}$-fructose are utilized for growth. No growth or only trace of growth on I- inositol and rhamnose. Utilization of sucrose and raffinose doubtful.

Streptomyces caelestis de Boer, Dietz, Wilkins, Lewis and Savage. Description: de Boer et al. 1955, 831-836. Type strain: NRRL $2418=$ UC 2011 (Dietz, personal communication). ISP 5084 from C. W. Hesseltine as NRRL 2418 from A. Dietz, Upjohn Co. as UC 2011. ISP description by Group $A-9$.

Spore chain morphology: Section Spirales or Retinaculiaperti.

Spirals are usually poorly developed and show only a few turns; loops and hooks are of small diameter and therefore are not representative of typical RA cultures (Fig. 21). Short spore chains; usually only 3 to 10 spores per chain on yeast-malt agar, oatmeal agar and salts-starch agar. Spore surface: Smooth (Fig. 20). 


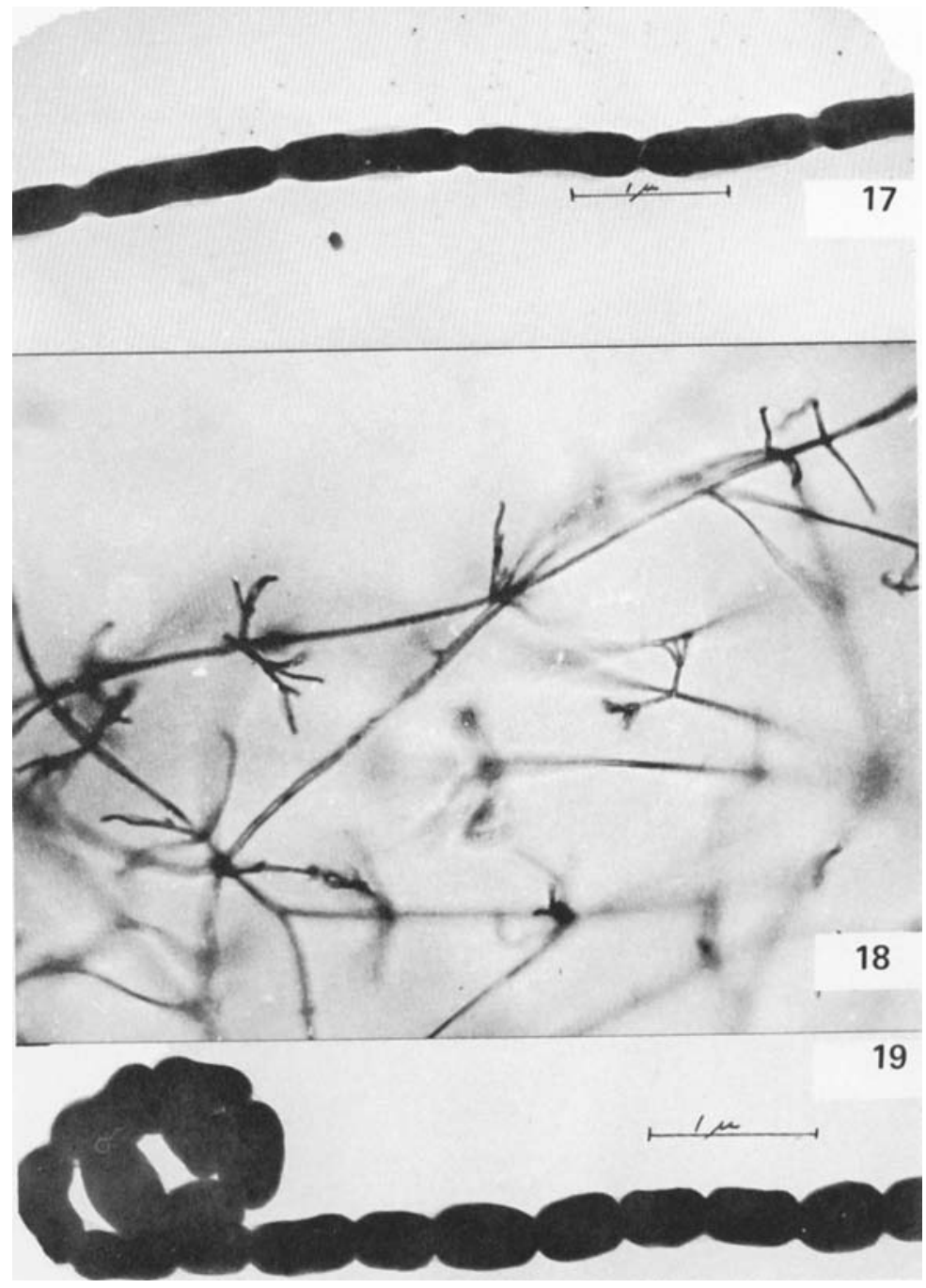

Figure 17. S. blastmyceticus. Smooth spores; electron micrograph from 14 day culture on oatmeal agar. ${ }^{1}$

Figure 18. S. blastmyceticus. BIV (umbellate monoverticillate) spore chains $(500 x)$ on oatmeal agar, 7 days. 8

Figure 19. S. cacaoi. Smooth spores; electron micrograph from 14 day culture on yeast-malt agar. ${ }^{1}$ 


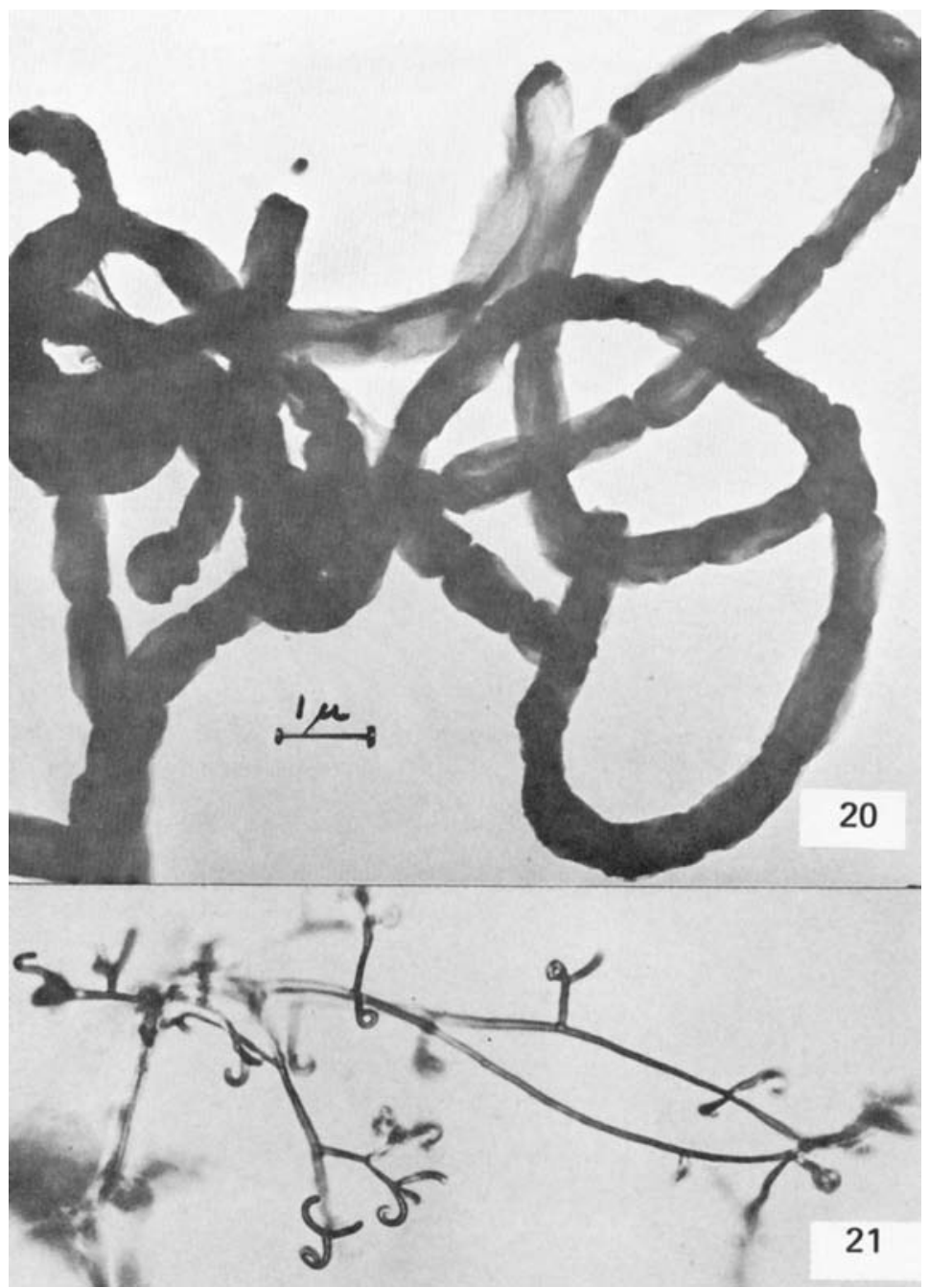

Figure 20. S. caelestis. Smooth spores; electron micrograph from 21 day culture on oatmeal agar. 9

Figure 21. S. caelestis. Spiral or RA spore chains (400x) on oatmeal agar, 14 days. Short spore chains form incomplete spirals, or hooks and loops of small diameter.10 
Color of colony: Aerial mass color in the Blue color-series on yeastmalt agar, oatmeal agar, salts-starch agar and glycerol-asparagine agar.

Reverse side of colony: No distinctive pigments on yeast-malt agar, oatmeal agar, salts-starch agar or glycerol-asparagine agar; substrate pigment is not a $\mathrm{pH}$ indicator.

Color in medium: Melanoid pigments formed in peptone-yeast-iron agar and tyrosine agar. Pigments, other than melanoids, not formed in yeast-malt agar, oatmeal agar, salts-starch agar or glycerol-asparagine agar.

Carbon utilization: D-Glucose, L-arabinose, sucrose, D-xylose, I-inositol, D-fructose, rhamnose and raffinose are utilized for growth. No growth or only trace of growth on D-mannitol.

Streptomyces californicus (Waksman and Curtis) Waksman and Henrici. Descriptions: Actinomyces californicus Waksman and Curtis 1916, 122; Waksman 1919, 104; Streptomyces californicus (Waksman and Curtis) Waksman and Henrici 1948, 936. Type strain: IMRU 3312 (Waksman 1961, 186). ISP 5058 from S. A. Waksman as IMRU 3312. ISP description by Group A-3.

Spore chain morphology: Section Rectiflexibiles. Mature spore chains generally 10 to 50 or more spores per chain (Fig. 23). This morphology is seen on yeast-malt agar, oatmeal agar, salts-starch agar and glycerol-asparagine agar. Spore surface: Smooth (Fig. 22).

Color of colony: Aerial mass color in the Red color-series on yeastmalt agar, oatmeal agar, salts-starch agar and glycerol-asparagine agar. (One observer recorded both Gray series and Violet series for aerial color on oatmeal agar, salts-starch agar and glycerol-asparagine agar. This difference may be due to $\mathrm{pH}$ - see below.)

Reverse side of colony: Modified by Violet or Red on yeast-malt agar, oatmeal agar, salts-starch agar and glycerol-asparagine agar; substrate pigment is a $\mathrm{pH}$ indicator and is changed from blue-violet to red by addition of $0.05 \mathrm{HCl}$, or from red to blue-violet by addition of $\mathrm{NaOH}$.

Color in medium: Melanoid pigments not formed in peptone-yeastiron aga $r$ and tyrosine agar; pigment is found in medium in oatmeal agar and glyce rol-asparagine agar. It is $\mathrm{pH}$ sensitive when tested with 0.05 $\mathrm{N} \mathrm{NaOH}$ or $\mathrm{HCl}$, showing same change as noted for reverse color.

Carbon utilization: D-Glucose, D-xylose, D-mannitol and $\underline{D}-$ fructose are utilized for growth. No growth or only trace of growth on L-a rabinose, sucrose, I-inositol, rhamnose and raffinose.

Streptomyces canescens Hickey, Corum, Hidy, Cohen, Nager and Kropp. Description: Streptomyces canescus (sic) Hickey et al. 1952, 472-475. Type strain: NRRL 2419 (U.A. Phillips, Commercial Solvents Corp., personal communication). ISP 5001 from U. A. Phillips, Commercial Solvents Corp. as NRRL 2419. ISP description by Group A-1.

Spore chain morphology: Section Rectiflexibles. Mature spore chains generally 10 to 50 spores per chain.(Fig. 25). This morphology is observed on yeast-malt agar, oatmeal agar, salts-starch agar and glycerol-asparagine agar. Spore surface: Smooth (Fig. 24).

Color of colony: Aerial mass color in the Yellow color-series on 


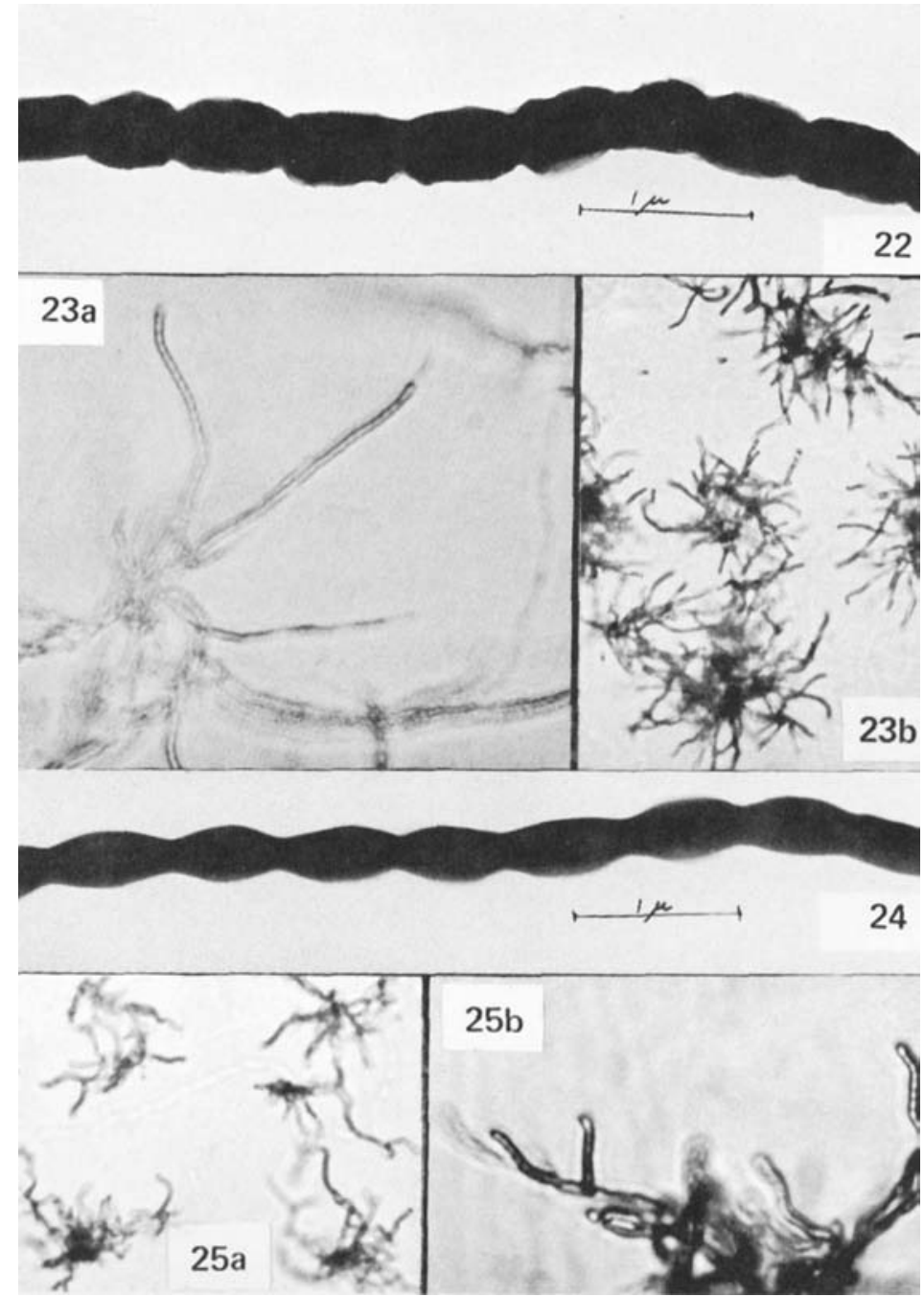

Figure 22. S. californicus. Smooth spores; electron micrograph from 14 day culture on yeast-malt agar. 1

Figure 23. S. californicus. RF spore chains on glycerol-asparagine agar; (a) $875 x^{7}$, (b) $300 x$.

Figure 24. S. canescens. Smooth spores; electron micrograph from 14 day culture on yeast-malt agar. 1

Figure 25. S. canescens. RF spore chains on: (a) Waksman's starch agar $B(3 \overline{8} 9 x) .2$ (b) Yeast-malt agar $(720 x) .{ }^{3}$ 
yeast-malt agar, oatmeal agar, salts-starch agar and glycerol-asparagine agar.

Reverse side of colony: No distinctive pigments on yeast-malt agar, oatmeal agar or glycerol-asparagine agar; grayed greenish yellow on salts-starch agar; substrate is not a $\mathrm{pH}$ indicator.

Color in medium: Melanoid pigments not formed in peptone-yeastiron aga $r$ and tyrosine agar. No pigment found in medium in yeastmalt agar, oatmeal agar, salts-starch agar or glycerol-asparagine agar.

Carbon utilization: D-Glucose, D-xylose and D-mannitol are utilized for growth. No growth or only trace of growth on sucrose, Iinositol, rhamnose and raffinose. Variable reports on growth with $\bar{D}_{-}$ fructose and $\underline{L}$-arabinose.

Streptomyces canus Heinemann, Kaplan, Muir and Hooper. Description: Heinemann et al 1953, 1239-1242. Type strain: 456786 (K. Crook, Bristol Laboratories, personal communication). ISP 5017 from K. E. Crook, Bristol Laboratories as 456786. ISP description by Group A-2.

Spore chain morphology: Section Spirales, but some spore chains representative of Section $\underline{R F}$ and $\underline{R A}$ are also found. Mature spore chains long, generally 10 to 50 or tuore spores per chain (Fig. 27). This morphology is seen on yeast-malt agar, oatmeal agar, saltsstarch agar and glycerol-asparagine agar. Spore surface: Spiny (Fig. 26).

Color of colony: Aerial mass color in the Gray color-series on yeast-malt agar, oatmeal agar, salts-starch agar and glycerol-asparagine agar.

Reverse side of colony: No distinctive pigments on yeast-malt agar, oatmeal agar, salts-starch agar or glycerol-asparagine agar, except for dark brown on glycerol-asparagine agar in 14 to 21 days. Substrate is not a $\mathrm{pH}$ indicator.

Color in medium: True melanoid pigments probably not formed in peptone-yeast-iron agar and tyrosine agar. Reports differed on production of melanoid pigments. (Each of 2 observers reported dark pigment, but on different test media; a third collaborator saw no melanoid pigment in peptone-yeast-iron agar or tyrosine agar, but dark brown pigment in the substrate mycelium on glycerol-asparagine agar. An additional test showed no characteristic melanoid pigment.) Pigments other than dark pigments noted above not formed in yeast-malt agar, oatmeal agar or salts-starch agar.

Carbon utilization: D-Glucose, L-arabinose, sucrose, D-xylose, I-inositol, D-mannitol, D-fructose and rhamnose are utilized for growth. Variable reports on growth with raffinose.

Streptomyces chartreusis Calhoun and Johnson. Description: Calhoun and Johnson 1956, 294-298; see also Leach et al. 1953, 4011-4012. Type strain: NRRL 2287 = UC 2012 (Calhoun and Johnson, ibid. ; . Dietz, Upjohn Co., personal communication). ISP 5085 from C. W. Hesseltine, Northern Utilization Research and Development Division, U.S. Dept. of Agriculture as NRRL 2287 from Upjohn Company as U.C. 2012. ISP description by Group A-7.

Spore chain morphology: Section Spirales. (Clusters of spiral spore chains sometimes resemble whorls or verticils. Pseudoverticils are 

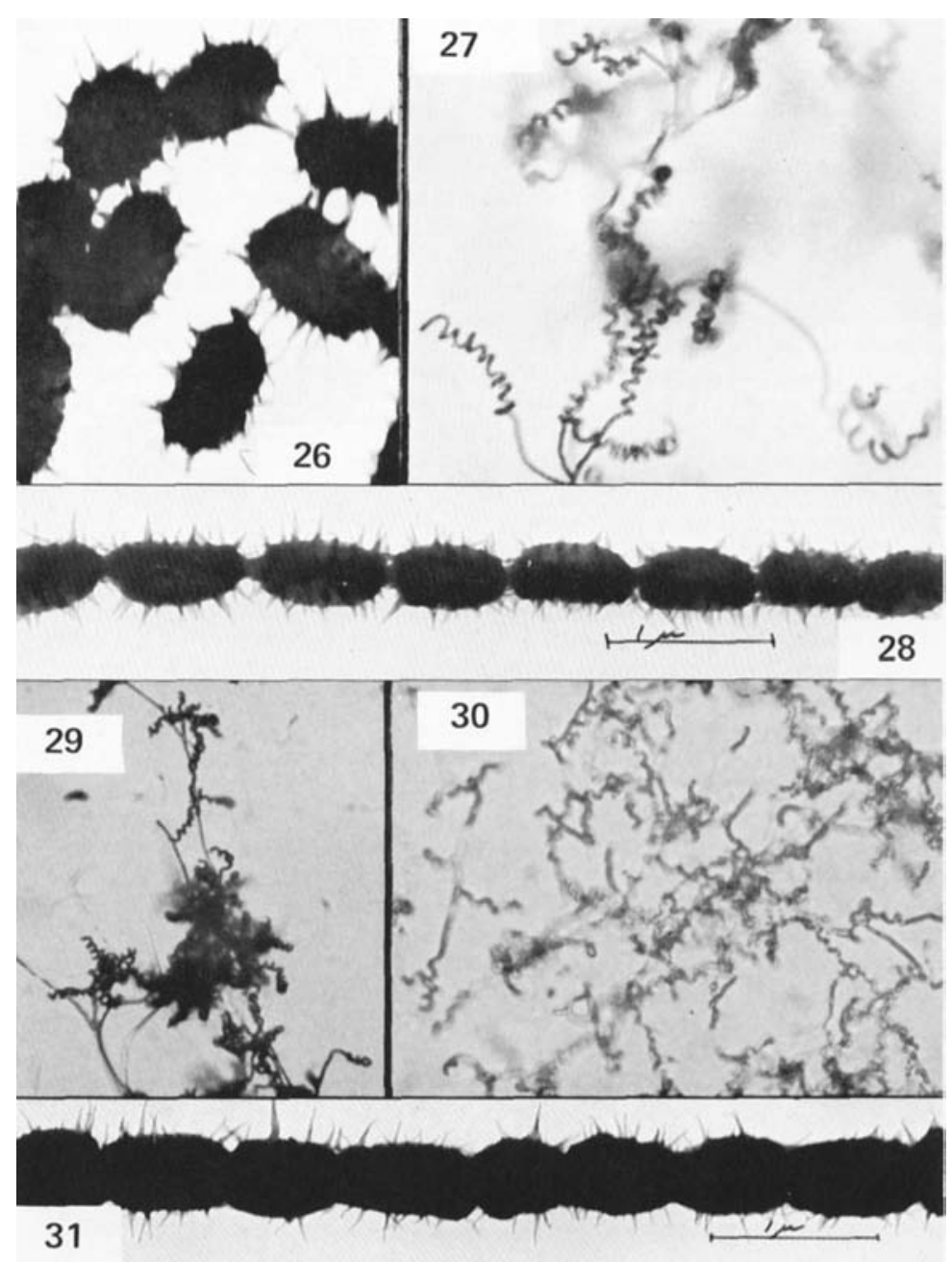

Figure 26. S. canus. Spiny spores; electron micrograph from 21 day culture on oatmeal agar."

Figure 27 . S. canus. Spiral spore chains $(500 x)$ on salts-starch agar, 7 days. $8^{-}$

Figure 28. S. chartreusis. Spiny spores; electron micrograph from 14 day culture on yeast-malt agar. ${ }^{12}$

Figure 29. S. chartreusis. Spiral spore chains (300x) on glycerola sparagine agar. ${ }^{12}$

Figure 30 . S. chattanoogensis. Open spirals (320x) on salts-starch agar, 21 days. 13

Figure 31. S. chattanoogensis. Spiny spores; electron micrograph from 14 day cuiture on oatmeal agar. 1 
not uniformly distributed and do not arise from an axial hypha characteristic of true verticillate forms.) Mature spore chains generally 10 to 50 spores per chain (Fig. 29). This morphology is seen on yeastmalt agar, oatmeal agar, and salts-starch agar and glycerol-asparagine agar. Spore surface: Spiny (Fig. 28).

Color of colony: Aerial mass color in the Blue color-series on yeastmalt agar, oatmeal agar, salts-starch agar and glycerol-asparagine agar. (Gray series also reported on oatmeal agar.)

Reverse side of colony: No distinctive pigments on yeast-malt agar, oatmeal agar, salts-starch agar or glycerol-asparagine agar; substrate is not $\mathrm{pH}$ indicator.

Color in medium: Melanoid pigments formed in peptone-yeast-iron agar and tryptone-yeast broth, but not in tyrosine agar. Pigments other than melanoids not formed in yeast-malt agar, oatmeal agar, salts-starch agar or glycerol-asparagine agar.

Carbon utilization: D-Glucose, L-arabinose, sucrose, D-xylose, I-inositol, D-mannitol, D-fructose, rhamnose and raffinose are utilized for growth.

Streptomyces chattanoogensis Burns and Holtman. Description: Burns and Holtman 1959, 398-404. Type strain: J-23=ATCC 13358 (Burns, personal communication). ISP 5002 from J. Burns as J-23. ISP description by Group A-2.

Spore chain morphology: Section Spirales, but spore chains representative of Section Rectiflexibiles and Section Retinaculiapertiare also found (Fig. 30). Mature spore chains generally 10 to 50 spores per chain on suitable media. This morphology is seen on yeast-malt agar, oatmeal agar, salts-starch agar and glycerol-asparagine agar. Spore surface: Spiny (Fig. 31).

Color of colony: Aerial mass color in the Yellow or White colorseries on yeast-malt agar, oatmeal agar, salts-starch agar and glycerol-asparagine agar. Yellow, when present, is a very pale yellow.

Reverse side of colony: No distinctive pigments on yeast-malt agar, oatmeal agar, salts-starch agar or glycerol-asparagine agar; substrate is not a $\mathrm{pH}$ indicator.

Color in medium: Melanoid pigments not formed in peptone-yeastiron agar and tyrosine agar. Yellow pigment found in medium in yeastmalt agar, oatmeal agar, salts-starch agar and glycerol-asparagine agar; this pigment is not $\mathrm{pH}$ sensitive when tested with $0.05 \mathrm{~N}$. NaOH or $\mathrm{HCl}$.

Carbon utilization: D-Glucose, I-inositol, D-mannitol, D-fructose, raffinose and sucrose are utilized for growth. No growth or only trace of growth on D-xylose, rhamnose and L-arabinose.

Streptomyces chrysomallus Lindenbein. Description: Lindenbein 1952,369-371. Type strain: Schönb. 192 (ibid.; type strain selected by Wilde, personal communication). ISP 5128 from P. Wilde as Schön. 192. ISP description by Group A-12.

Spore chain morphology: Section Rectiflexibiles. Mature spore chains generally 10 to 50 or more spores per chain. Typical mor phology on yeast-malt agar, oatmeal agar, salts-starch agar and glycerolasparagine agar. Spore surface: Smooth (some surface irregularities are present, but are less distinct than on characteristic warty spores). 
Color of colony: Aerial mass color in the Yellow color-series on yeast-malt agar, oatmeal agar, salts-starch agar and glycerolasparagine agar.

Keverse side of colony: No distinctive pigments (yellow to grayed yellow) on yeast-malt agar, oatmeal agar, salts-starch agar or glycerol-asparagine agar; substrate pigment is not a $\mathrm{pH}$ indicator.

Color in medium: Melanoid pigments not formed in peptone-yeastiron agar and tyrosine agar. Yellow pigment found in medium in yeastmalt agar and oatmeal agar; traces of yellow pigment may be formed in salts-starch agar and glycerol-asparagine agar. This pigment is not a $\mathrm{pH}$ indicator.

Carbon utilization: D-Glucose, L-arabinose, D-xylose, D-mannitol, D-fructose and rhamnose are utilized for growth. No growth or only trace of growth on sucrose, I-inositol and raffinose.

Streptomyces cinereoruber Corbaz, Ettlinger, Keller-Schierlein and $Z$ ähner. Description: Corbaz et al. 1957a, 329-332. Type strain: ETH 7451 (ibid.). ISP 5012 from R. Hütter as ETH 7451. ISP description by Group A-2.

Spore chain morphology: Section Rectiflexibiles. Mature spore chains long, often more than 50 spores per chain (Fig. 33). This morphology is found on yeast-malt agar, oatmeal agar, salts-starch agar and glycerol-asparagine agar. Spore surface: Smooth (Fig. 32).

Color of colony: Aerial mass color in the Gray color-series on oatmeal agar; Red series or Gray series on yeast-malt agar, salts-starch agar and glycerol-asparagine agar. Nearly all color tabs selected by collaborators are near-gray containing some pink or red.

Reverse side of colony: The characteristic grayed yellow is modified by red on yeast-malt agar or red to violet on oatmeal agar, salts-starch agar and glycerol-asparagine agar. A change from red to blue reverse color by addition of $0.05 \mathrm{~N} \mathrm{NaOH}$ is reported by one observer only.

Color in medium: Melanoid pigments formed in peptone-yeast-iron agar and tryptone-yeast broth. Pigments other than melanoids probably not formed in yeast-malt agar, oatmeal agar, salts-starch agar or glycerol-asparagine agar.

Carbon utilization: D-Glucose, L-arabinose and D-xylose are utilized for growth. No growth or only trace of growth on sucrose, I-inositol, D-mannitol, rhamnose and raffinose. Growth on D-fructose is doubtful.

Actinomyces coeruleofuscus Preobrazhenskaya. Description: Preobrazhenskaya in Gauze et al. 1957, 123 and 128. Type strain: $2922 / 57$ (neotype, Preobrazhenskaya, personal communication). Streptomyces coeruleofuscus (Preobrazhenskaya) Pridham et al. 1958, 67. ISP 5144 from T.P. Preobrazhenskaya as 2922/57. ISP description by Group A-3.

Spore chain morphology: Section Spirales. Mature spore chains long, often more than 50 spores per chain (Fig. 35). This morphology is found on yeast-malt agar, oatmeal agar, salts-starch agar and glycerol-asparagine agar. Spore surface: Spiny (Fig. 34).

Color of colony: Aerial mass color in the Blue color-series on yeastmalt agar, oatmeal agar, salts-starch agar and glycerol-asparagine agar. 


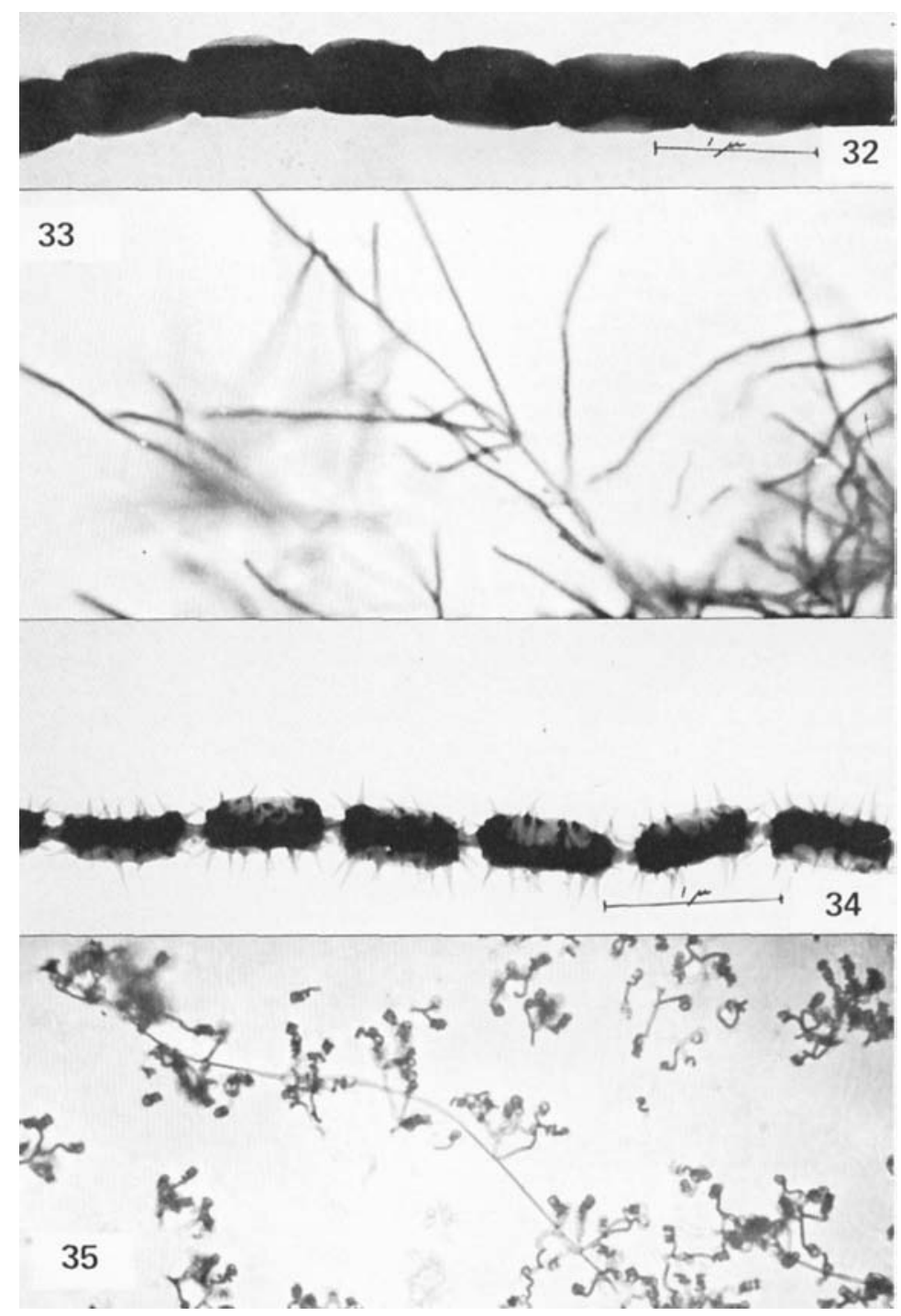

Figure 32. S. cinereoruber. Smooth spores; electron micrograph from 21 day culture on glycerol-asparagine agar. ${ }^{11}$

Figure 33. S. cinereoruber. RF spore chains $(500 x)$ on yeast-malt agar. 8

Figure 34. A. coeruleofuscus. Spiny spores; electron micrograph from 14 day culture on oatmeal agar. 1

Figure 35. A. coeruleofuscus. Spiral spore chains on oatmeal agar, 14 days. ${ }^{6}$ 
Reverse side of colony: Variable in color; it is yellow-brown modified by red on yeast-malt agar and characteristic grayed yellow or grayed greenish yellow (center of growth) modified by green, red and brown (borders) on oatmeal agar, salts-starch agar and glycerolasparagine agar. Substrate is not a pH indicator, except that one observer reports that on glycerol-asparagine agar the reverse color is changed from olive green to bluish green by addition of $0.05 \mathrm{~N} \mathrm{NaOH}$, and from olive green to very pale red with $\mathrm{HCl}$.

Color in medium: Melanoid pigments formed in peptone-yeast-iron agar, tryptone-yeast broth, and some other media. Pigments other than melanoids not formed in yeast-malt agar, oatmeal agar, saltsstarch agar and glycerol-asparagine agar.

Carbon utilization: D-Glucose, L-arabinose, sucrose, D-xylose, I-inositol, D-mannitol, $\underline{D}$-fructose, rhamnose and raffinose are utilized for growth.

Actinomyces coerulescens Preobrazhenskaya. Description: Preobrazhenskaya in Gauze et al. 1957, 113 and 120. Type strain: 4562 (ibid.; type strain selected by Preobrazhenskaya, personal communication). Streptomyces coerulescens (Preobrazhenskaya) Pridham et al. 1958, 67. ISP 5146 from T.P. Preobrazhenskaya as 4562. ISP description by Group A-3.

Spore chain morphology: Section Spirales. Mature spore chains generally 10 to 50 spores per chain (Fig. 37). Typical morphology on yeast-malt agar, oatmeal agar, salts-starch agar and glycerol-asparagine agar. Spore surface: Spiny (Fig. 36).

Color of colony: Aerial mass color in the Blue color-series on yeastmalt agar, oatmeal agar, salts-starch agar and glycerol-asparagine agar.

Reverse side of colony: No distinctive pigments on yeast-malt agar, oatmeal agar, salts-starch agar and glycerol-asparagine agar; substrate is not a $\mathrm{pH}$ indicator.

Color in medium: Melanoid pigments formed in peptone-yeast-iron agar and tryptone-yeast broth. Pigments other than melanoids not formed in yeast-malt agar, oatmeal agar, salts-starch agar and glycerol-asparagine agar.

Carbon utilization: D-Glucose, L-arabinose, sucrose, D-xylose, I-inositol, D-mannitol, D-fructose, rhamnose and raffinose are utilized for growth.

Streptomyces collinus Lindenbein. Description: Lindenbein 1952, 380-382. Type strain: Ist 301 (ibid.). ISP 5129 from P. Wilde as Ist 301. ISP description by $\mathrm{G}$ roup $\mathrm{A}-1$.

Spore chain morphology: Section Spirales or Retinaculiaperti, Spore chains are short resulting in poorly developed spirals of only a few turns; loops and hooks are of small diameter and the refore are not representative of true RA cultures (Fig. 39). Distinct spore chains relatively short, often with only 3 to 10 spores per chain; longer chains occur, but often coalesce as masses of spores. This morphology is seen on yeast-malt agar, oatmeal agar, salts-starch agar and glycerolas paragine agar. Spore surface: Smooth (Fig. 38).

Special morphological characteristics: After 14 days, subglobose bodies, composed primarily of masses of spores, can be seen. They 


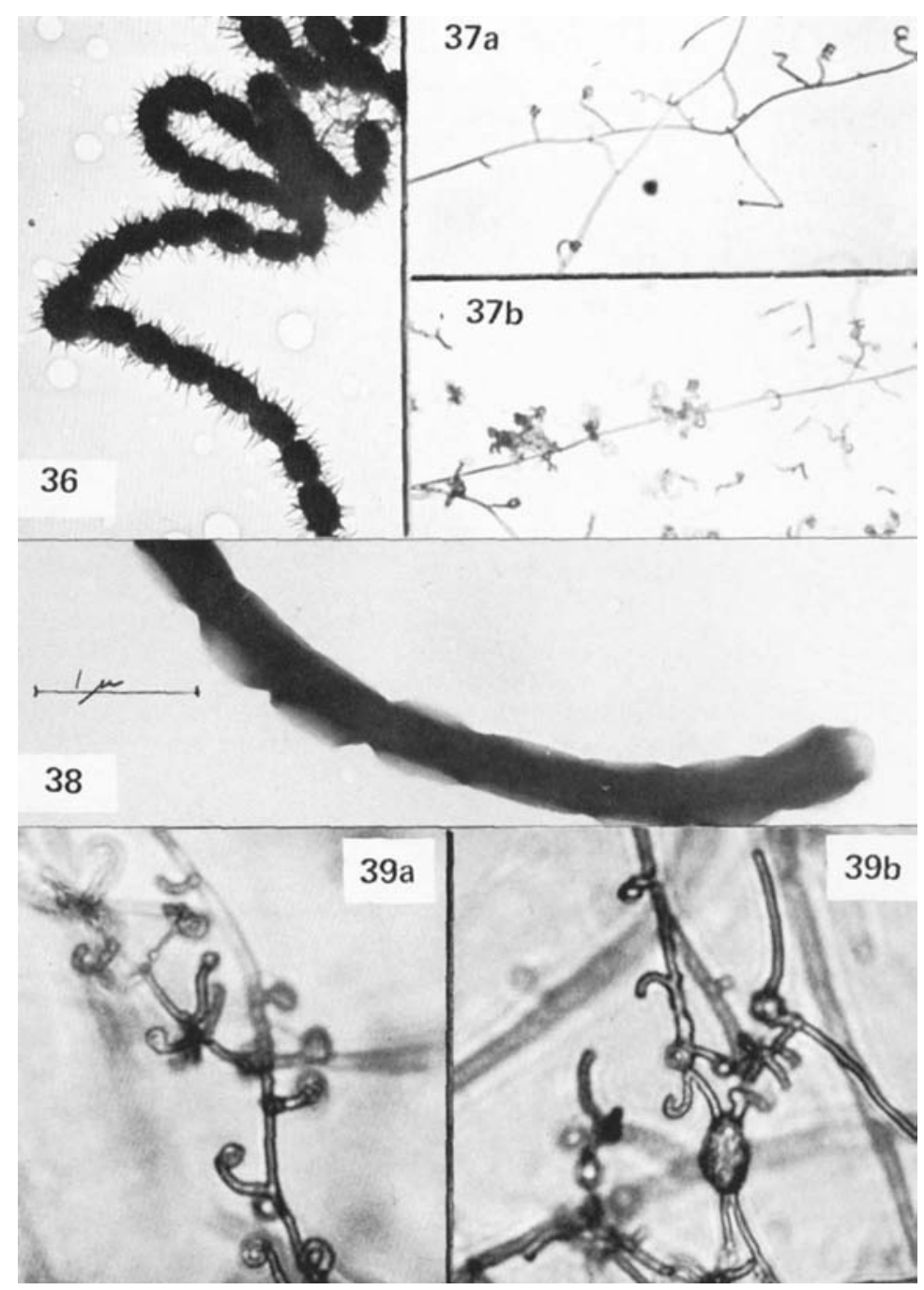

Figure 36. A. coerulescens. Spiny spores; electron micrograph from 14 day culture on oatmeal agar. 6

Figure 37. A. coerulescens. Spiral spore chains (300x); (a) oatmeal agar, (b) glycērol-asparagine agar. 7

Figure 38. S. collinus. Smooth spores; electron micrograph from 14 day culture on salts-starch agar.

Figure 39 . S. collinus. $(720 x) \cdot{ }^{3}$ (a) Spirals and partial spirals on saltsstarch agar; (b) partial spirals and coalesced spore mass on oatmeal agar. 
appear to originate at the hooked or spiral ends of $\underline{R A}$ spore chains and to be held together by fluid.

Color of colony: Aerial mass color in the Gray color-series on yeast-malt agar, oatmeal agar, salts-starch agar and glycerol-asparagine agar; or (by one observer) in the Red series on salts-starch agar.

Reverse side of colony: No distinctive pigments on yeast-malt agar, oatmeal agar, salts-starch agar or glycerol-asparagine agar.

Color in medium: Melancid pigments formed in peptone-yeast-iron agar and sometimes in tryptone-yeast broth, but not on tyrosine agar. Pigments other than melanoids not formed in yeast-malt agar, oatmeal agar, salts-starch or glycerol-asparagine agar.

Carbon utilization: D-Glucose, L-arabinose, sucrose, I-inositol, D-mannitol, D-fructose, rhamnose and raffinose are utilized for growth. Two of 3 observers also found good growth with D-xylose.

Actinomyces cremeus Kudrina. Description: Kudrina in Gauze et al. $1957 \mathrm{a}, 92$ and 93 . Type strain: $815 / 54$ (815/34 (sic), ibid. ; type $815 / 54$ selected by Preobrazhenskaya, personal communication). Streptomyces cremeus (Kudrina) Pridham et al. 1958, 66. ISP 5147 from T.P. Preobrazhenskaya as $815 / 54$. ISP description by Group A-4.

Spore chain morphology: Section Retinaculiaperti, but with many straight to flexuous spore chains. Open coils and primitive spirals are common (Fig. 41). In the original description (Kudrina, ibid.), this is characterized as a spiral culture. Mature spore chains long, often more than 50 spores per chain. This morphology is observed on yeast-malt agar, oatmeal agar, salts-starch agar and glycerol-asparagine agar. Spore surface: Smooth (Fig. 40).

Color of colony: Aerial mass color in the Red color-series on yeastmalt agar and salts-starch agar; Yellow series on glycerol-asparagine agar; Yellow or Red series on oatmeal agar.

Reverse side of colony: No distinctive pigments on yeast-malt agar, o atmeal agar, salts-starch agar or glycerol-asparagine agar; substrate is not a $\mathrm{pH}$ indicator (one observer reports slight change from pale yellow to pale pink with $0.05 \mathrm{~N} \mathrm{NaOH}$ ).

Color in medium: Melanoid pigments not formed in peptone-yeastiron agar and tyrosine agar. No pigments or only traces of yellow pigments in yeast-malt agar, oatmeal agar, salts-starch agar and glycerol-asparagine agar.

Carbon utilization: $\underline{D}-G l u c o s e, \underline{L}-a$ rabinose, $\underline{D}$-xylose and $\underline{D}$-fructose are utilized for growth. No growth or only trace of growth on sucrose, I-inositol, D-mannitol, rhamnose and raffinose.

Streptomyces curacoi Cataldi. Description: Cataldi in Trejo and Bennett 1963, 683-684; see also Cataldi, et al. 1962, U.S. Patent 3,015,607. Type strain: A TCC 13,385 (ibid.). ISP 5107 from W. Trejo, Squibb Inst. for Med. Res, as SC $3064=$ ATCC 13, 385. ISP description by Group A-7.

Spore chain morphology: Section Spirales. Mature spore chains generally more than 10 and less than 50 spores per chain; long chains not common. This morphology is seen on yeast-malt agar, oatmeal agar, salt-starch agar and glycerol-asparagine agar, but formation of sporulating aerial mycelium was not uniformly good in different laboratories with this strain. Spore surface: Spiny (Fig. 42 ). 


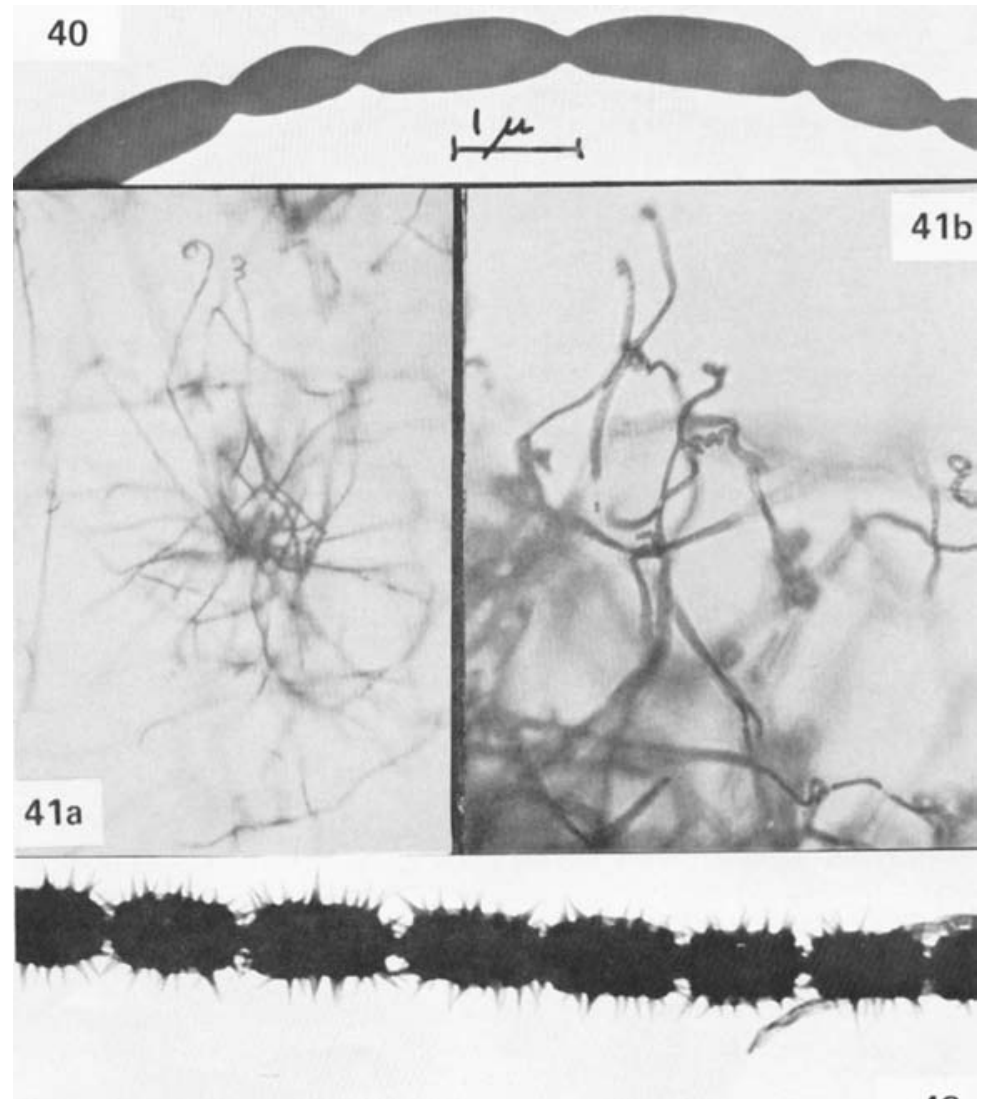

Figure 40. A. cremeus. Smooth spores; electron micrograph from 14 day cultur $\bar{r}$ on glycerol-asparagine agar. ${ }^{14}$

Figure 41. A cremeus: (a) RA spore chains (250x) on oatmeal agar, 21 days. (b) RA spore chains showing occasional spirals $(400 \mathrm{x})$ on saltsstarch agar, 14 days. ${ }^{14}$

Figure 42. S. curacoi. Spiny spores; electron micrograph from 14 day culture on oatmeal agar. 1 
Color of colony: Aerial mass color in the Blue color-series on salts-starch agar and on other media (yeast-malt agar, oatmeal agar, glycerol-asparagine agar) when mature spores occur; immature spore chains or non-sporulating aerial mycelium appears white.

Reverse side of colony: No distinctive pigments on yeast-malt agar, oatmeal agar, salts-starch agar or glycerol-asparagine agar; substrate is not $\mathrm{pH}$ indicator.

Color in medium: Melanoid pigments formed in peptone-yeast-iron agar, tyrosine agar and tryptone-yeast broth. Pigments other than melanoids not formed in yeast-malt agar, oatmeal agar, salts-starch agar or glycerol-asparagine agar.

Carbon utilization: D-Glucose, L-arabinose, sucrose, D-xylose, $\underline{I}$-inositol, D-mannitol and $\underline{D}$-fructose are utilized for growth. Trace of growth on rhamnose or raffinose.

Actinomyces cyaneofuscatus Kudrina. Description: Kudrina in Gauze et al. 1957, 78 and 85 . Type strain: 99/54 (ibid.; type strain selected by Preobrazhenskaya, personal communication). Streptomyces cyaneofuscatus (Kudrina) Pridham et al. 1958, 58. ISP 5148 from T. P. Preobrazhenskaya as 99/54. ISP description by Group A-4.

Spore chain morphology: Section Rectiflexibiles. Mature spore chains generally 10 to 50 spores per chain (Fig. 44). Typical morphology on yeast-malt agar, oatmeal agar, salts-starch agar and glycerol-asparagine agar. Spore surface: Smooth (Fig. 43).

Special morphological characteristics: Coremia may be formed on oatmeal agar, salts-starch agar and tyrosine agar.

Color of colony: Aerial mass color in the Yellow color-series on yeast-malt agar, oatmeal agar, salts-starch agar and glycerol-asparagine agar.

Reverse side of colony: No distinctive pigments on yeast-malt agar, oatmeal agar, salts-starch agar or glycerol-asparagine agar. Reverse color is changed from pale yellowish green to pink by addition of 0.05 $\mathrm{N} \mathrm{HCl}$ or from pale yellow to yellowish green with $\mathrm{NaOH}$.

Color in medium: Melanoid pigments formed in peptone-yeast-iron agar. Pigments other than a weak yellow pigment, a re not formed in yeast-malt agar, oatmeal agar, salts-starch agar or glycerol-asparagine agar; but on a glucose-mineral salts medium (CPI Kuznetsov: Glucose $2 \% ; \quad \mathrm{KNO}_{3} 0.1 \% ; \quad \mathrm{MgSO}_{4} 0.05 \% ; \mathrm{NaCl} 0.05 \% ; \mathrm{K}_{2} \mathrm{HPO}_{4}$ $0.05 \% ; \quad \mathrm{CaCO}_{3} 0.3 \%$; Agar $2.0 \%$ ) blue pigment is formed in the medium. Blue pigment is $\mathrm{pH}$ sensitive, changing from blue to pink with $0.05 \mathrm{~N} \mathrm{HCl}$.

Carbon utilization: D-Glucose, D-xylose, D-mannitol, D-fructose and rhamnose are utilized for growth. No growth or only trace of growth on L-arabinose, sucrose, $\underline{1}$-inositol and raffinose.

Actinomyces daghestanicus Sveshnikova. Description: Sveshnikova in Gauze et al. 1957, 59. Type strain: 2656/55 (ibid.; type strain selected by Preobrazhenskaya, personal communication). Streptomyces daghestanicus (Sveshnikova) Pridham et al. 1958. ISP 5149 from T.P. Preobrazhenskaya as $2656 / 55$. ISP description by Group A-4.

Spore chain morphology: Section Retinaculiaperti but with some well defined $s$ piral spore chains. Mature chains generally 10 to 50 spores per chain. Typical morphology on yeast-malt agar, oatmeal 


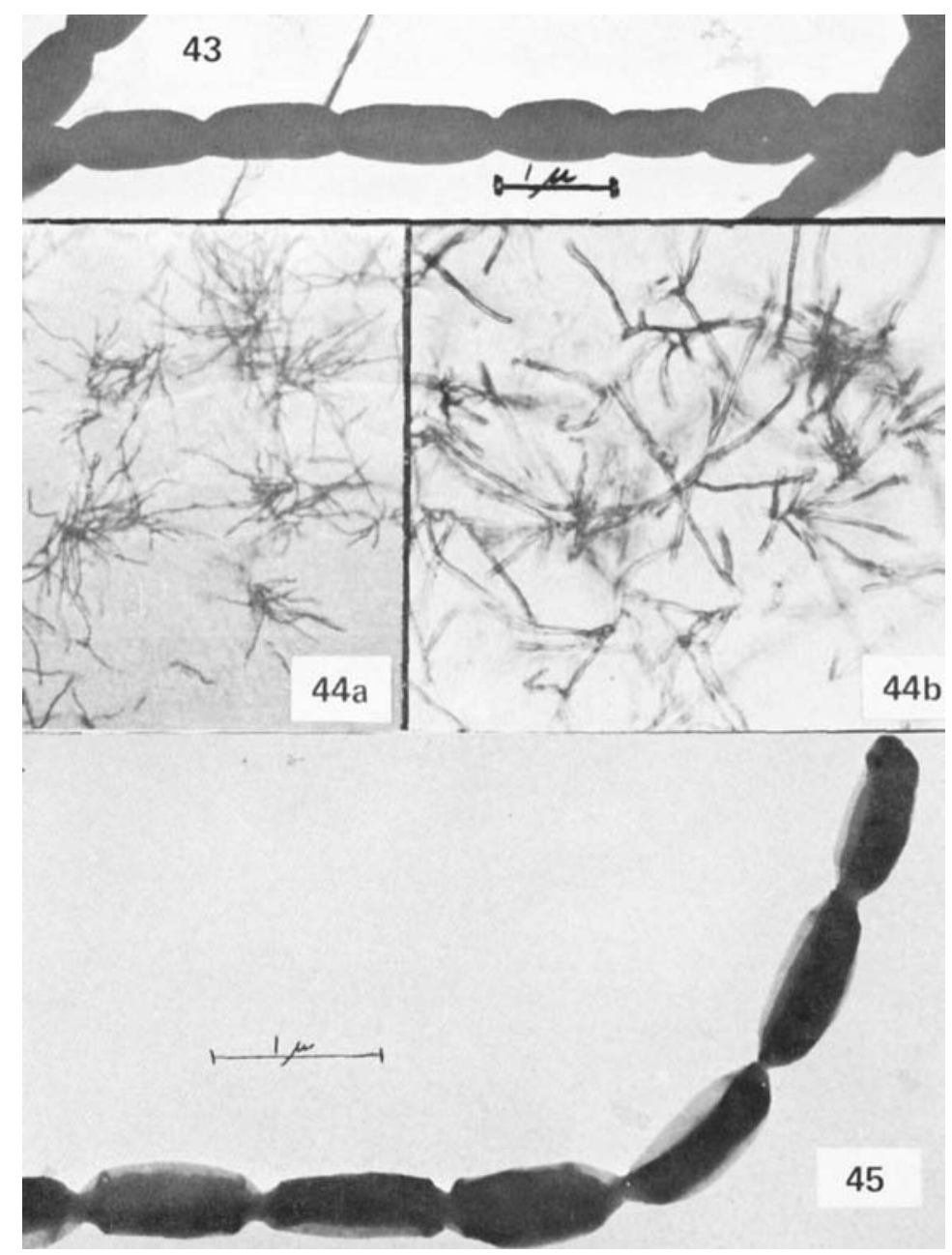

Figure 43. A. cyaneofuscatus. Smooth spores; electron micrograph from 21 day culture on yeast-malt agar. ${ }^{14}$

Figure 44. A. cyaneofuscatus. RF spore chains; (a) oatmeal agar, 14 days, approximately $250 \times{ }^{15}$ (b) glycerol-asparagine agar, 14 days, approximately $450 \times{ }^{14}$

Figure 45. A. daghestanicus. Smooth spores; electron micrograph from 14 day culture on oatmeal agar. ${ }^{1}$ 
agar, salts-starch agar and glycerol-asparagine agar. Spore surface: Smooth with some minor irregularities suggesting wartiness (Fig. 45).

Color of colony: Aerial mass color in the Red color-series on yeastmalt agar, oatmeal agar, salts-starch agar and glycerol-asparagine agar.

Reverse side of colony: Grayed yellow to yellow-brown on yeastmalt agar, oatmeal agar, salts-starch agar and glycerol-asparagine agar; the color is changed only slightly or not at all by addition of 0.05 $\mathrm{N} \mathrm{NaOH}$ or $\mathrm{HCl}$.

Color in medium: Melanoid pigments not formed in peptone-yeastiron agar and tyrosine agar. No pigment found in medium in yeastmalt agar, oatmeal agar, salts-starch agar or glycerol-asparagine agar.

Carbon utilization: D+Clucose, L-arabinose, D-xylose, D-mannitol, $\underline{D}$-fructose and rhamnose are utilized for growth. No growth or only trace of growth on sucrose, $\underline{I}$-inositol and raffinose.

Streptomyces echinatus Corbaz, Ettlinger, Gäumann, KellerSchierlein, Kradolfer, Neipp, Prelog, Reusser and Zähner. Description: Corbaz et al. 1957, 199. Type strain: ETH 8331 (ibid.). ISP 5013 from R. Hütter as ETH 8331. ISP description by Group A-2.

Spore chain morphology: Section Retinaculiaperti or Spirales. Tight spirals sometimes occur at tips of sporophores. Observers recorded both RA and Spirales morphology (Fig. 47). Mature spore chains generally 10 to 50 spores per chain. This morphology is observed on yeast-malt agar, oatmeal agar, salts-starch agar and glycerolasparagine agar. Spore surface: Spiny (Fig. 46).

Color of colony: Aerial mass color in the Gray color-series on yeastmalt agar, oatmeal agar, salts-starch agar and glycerol-asparagine agar.

Reverse side of colony: Grayed yellow modified by green on oatmeal agar, salts-starch agar and glycerol-asparagine agar. Substrate pigment is not a pH indicator.

Color in medium: Melanoid pigments formed in peptone-yeast-iron agar, tyrosine agar and tryptone-yeast broth. Pigments other than melanoids not formed in yeast-malt agar, oatmeal agar, salts-starch agar or glycerol-asparagine agar.

Carbon utilization: D-Glucose, L-arabinose, D-xylose, I-inositol, D-mannitol, D-fructose, rhamnose and raffinose are utilized for growth (growth on L-arabinose and D-xylose is less than on other sugars). No growth or only trace of growth on sucrose.

Streptomyces eurythermus Corbaz, Ettlinger, Gäumann, KellerSchierlein, Neipp. Prelog, Reusser and Zähner. Description: Corbaz et al. 1955, 1202-1209. Type strain: ETH 6677 (ibid.; see also Hütter et al. 1961, 172). ISP 5014 from R. Hütter as ETH 6677. ISP description by Group A-1.

Spore chain morphology: Section Retinaculiaperti (including many straight and flexuous spore chains and occasional spirals). Mature spore chains generally 10 to 50 spores per chain (Fig. 49). This morphology is observed on yeast-malt agar, oatmeal agar, salts-starch agar and glycerol-asparagine agar. Spore surface: Smooth (Fig. 48).

Color of colony: Aerial mass color in the Gray color-series on yeast- 


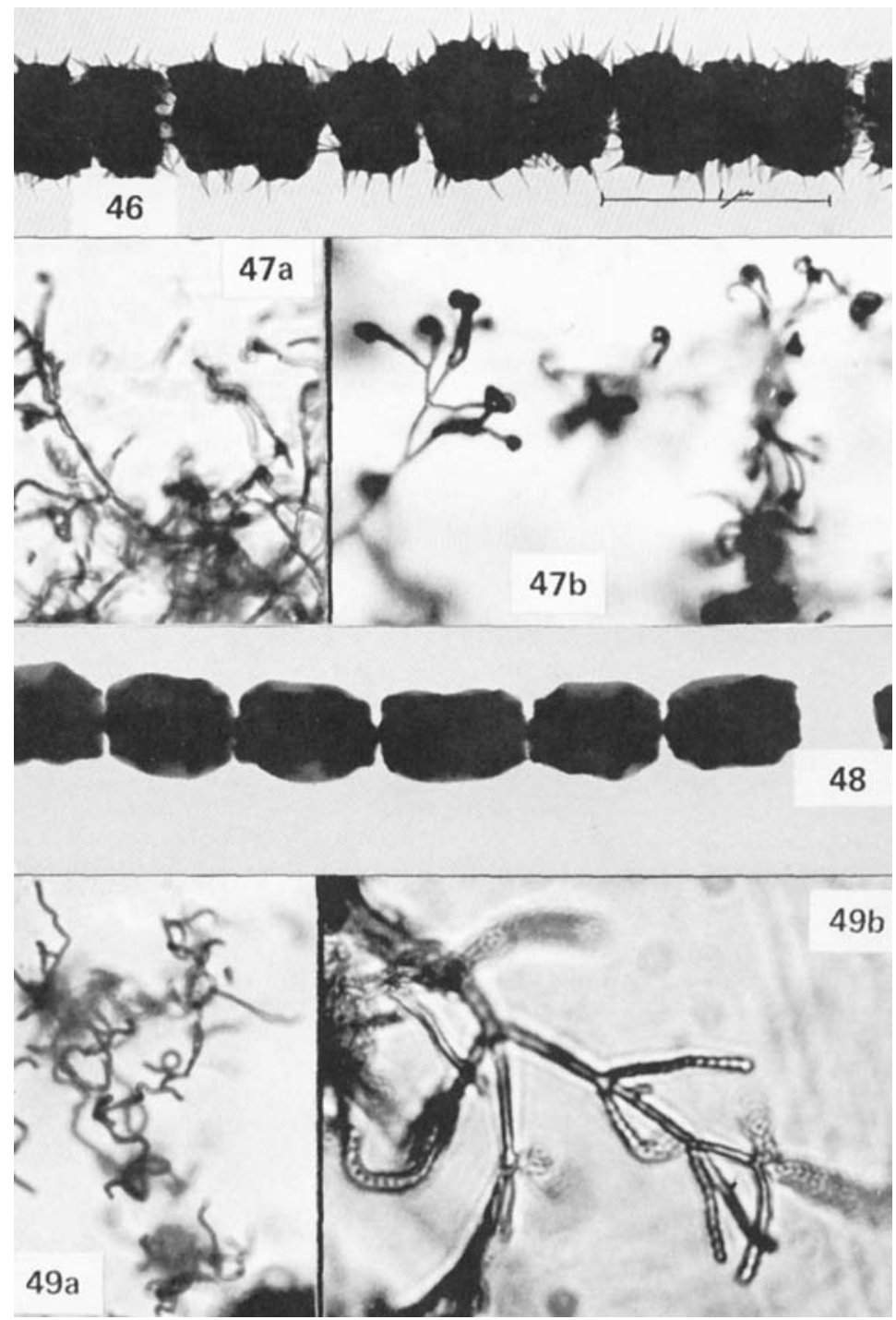

Figure 46. S. echinatus. Spiny spores; electron micrograph from 14 day culture on oatmeal agar. ${ }^{1}$

Figure 47. S. echinatus. RA to Spiral spore chains on glycerolasparagine agar, 7 to 1 days. (a) Hooks and spirals $(320 \mathrm{x}){ }^{13}$ (b) Tight spirals at tips of spore chains. $(500 x) .8$

Figure 48. S. eurythermus. Smooth spores; electron micrograph from 14 day culture on yeast-malt agar. 1

Figure 49. S. eurythermus. (a) RA spore chains $(389 x)$ on salts-starch agar, 34 days. ${ }^{2}$ (b) Straight and hooked spore chains (720x) on glycerol-asparagine agar, 14 days. ${ }^{3}$ 
malt agar, oatmeal agar, salts-starch agar and glycerol-asparagine agar.

Reverse side of colony: No distinctive pigments on yeast-malt agar, oatmeal agar, salts-starch agar or glycerol-asparagine agar; substrate pigment is not a $\mathrm{pH}$ indicator. (One observer reports slight change from yellowish brown to reddish brown with addition of $0.05 \mathrm{~N} \mathrm{NaOH}$ ).

Color in medium: Melanoid pigments formed in peptone-yeast-iron agar, tyrosine agar and tryptone-yeast broth. Pigments other than melanoids not formed in yeast-malt agar, oatmeal agar, salts-starch agar or glycerol-asparagine agar.

Carbon utilization: D-Glucose, L-arabinose, sucrose, D-xylose, D-mannitol and D-fructose are utilized for growth. Variable reports on growth with $\underline{1}$-inositol, rhamnose and raffinose.

Streptomyces exfoliatus (Waksman and Curtis) Waksman and Henrici. Descriptions: Actinomyces exfoliatus Waksman and Curtis 1916, 116 and 127; Waksman 1919, 114-115; Streptomyces exfoliatus (Waksman and Curtis) Waksman and Henrici 1948, 951. Type strain: IMRU 3316 (Waksman 1961, 205-206). ISP 5060 from S. A. Waksman as IMRU 3316. ISP description by Group A-4.

Spore chain morphology: Section Rectiflexibiles. Mature spore chains generally 10 to 50 spores per chain (Fig. 51). Typical morphology on oatmeal agar. (Some sporulating aerial mycelium with typical morphology on yeast-malt agar, salts-starch agar and glycerol-asparagine agar.) Spore surface: Smooth (Fig. 50).

Special morphological characteristics: One observer reported fragmentation and spore formation in substrate-mycelium on yeastmalt agar, oatmeal agar, salts-starch agar and glycerol-asparagine agar in 14 days; anothe $r$ observer reported coremia formation on glycerol-asparagine agar in 14 days.

Color of colony: Aerial mass color in the Red color-series on oatmeal agar; sporulating aerial mycelium is also in the Red series on yeast-malt agar and salts-starch agar, when formed on these media.

Reverse side of colony: No distinctive pigments on yeast-mait agar, oatmeal agar, salts-starch agar or glycerol-asparagine agar; substrate pigment is not a $\mathrm{pH}$ indicator.

Color in medium: Melanoid pigments not formed in peptone-yeastiron agar and tyrosine agar. No pigment found in medium in yeast-malt agar, oatmeal agar, salts-starch agar or glycerol-asparagine agar.

Carbon utilization: D-Glucose, L-arabinose, sucrose, D-xylose, D-fructose, rhamnose and raffinose are utilized for growth. No growth on I-inositol or D-mannitol.

Streptomyces fasiculatus (sic) Pittenger and Nelms. Description: Not published (name only, without characterization, Pittenger and Nelms in McCormick and Hoehn 1953,718-720; unpublished description received by ISP from Pittenger as personal communication). Type strain:

M5-11698 (Pittenger, personal communication). ISP 5054 from D. H. Lively for R. C. Pittenger, Lilly Res. Labs, as M5-11698. ISP description by Group A-11.

Spore chain morphology: Section Spirales. Mature spore chains generally 10 to 50 spores per chain. This morphology is seen on yeastmalt agar, oatmeal agar, salts-starch agar and glycerol-asparagine agar. 


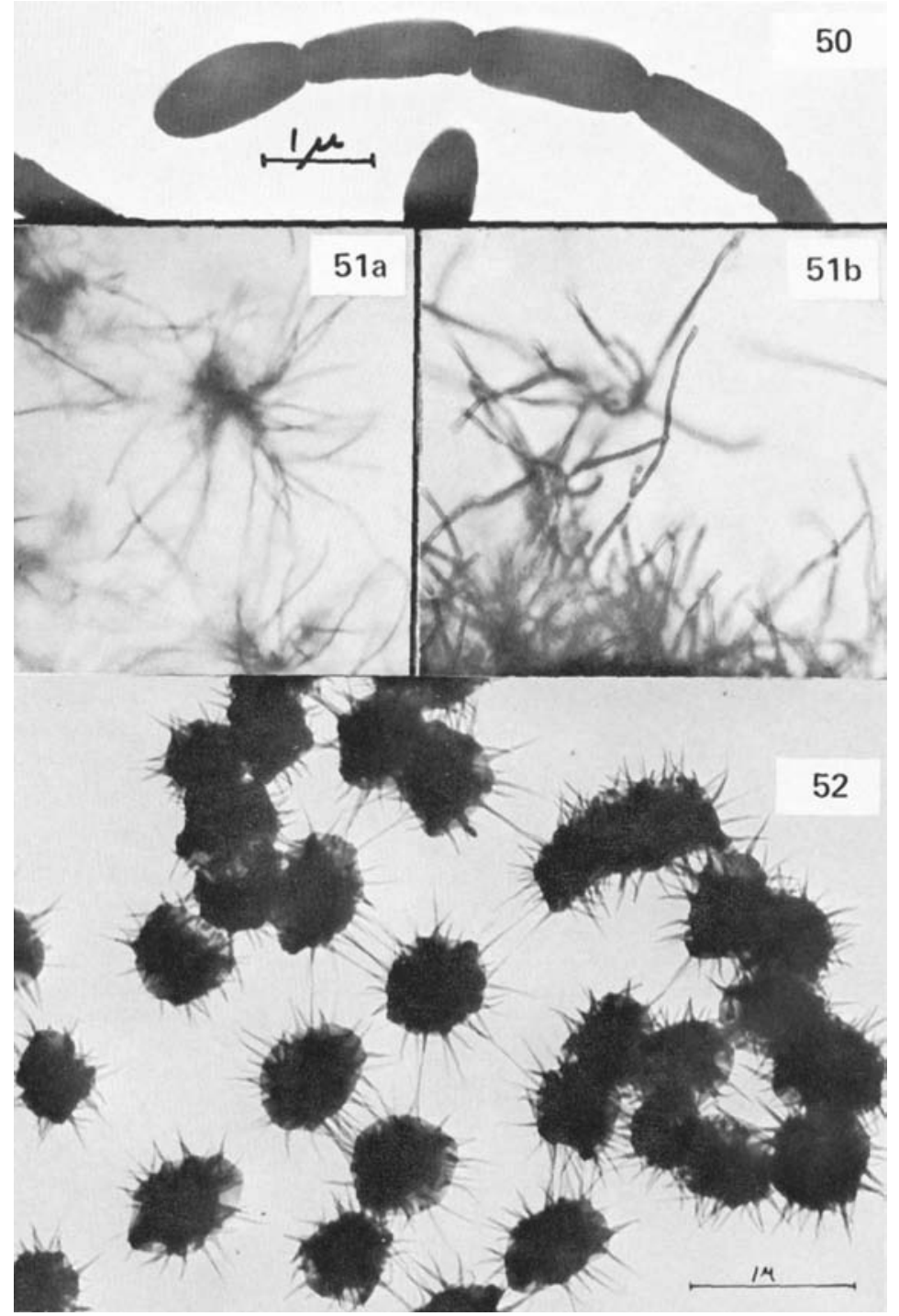

Figure 50. S. exfoliatus. Smooth spores; electron micrograph from 14 day culture on salts-starch agar. ${ }^{14}$

Figure 51. S. exfoliatus. RF spore chains on: (a) oatmeal agar, 21 days. (b) salts-starch agar, 14 days. ${ }^{14}$

Figure 52. S. fasiculatus (sic). Spiny spores; electron micrograph from 14 day culture on oatmeal agar. ${ }^{1}$ 
Spore surface: Spiny (Fig. 52).

Color of colony: Aerial mass color in the Gray color-series on yeast-malt agar and salts-starch agar; Gray and Red series on oatmeal agar; Gray and White series on glycerol-asparagine agar. Predominantly a Gray color-series culture.

Reverse side of colony: No distinctive pigments on yeast-malt agar, oatmeal agar, salts-starch agar or glycerol-asparagine agar; substrate pigment is not a $\mathrm{pH}$ indicator.

Color in medium: Melanoid pigments not formed in peptone-yeastiron agar and tyrosine agar. No pigment found in medium in yeastmalt agar, oatmeai agar, salts-starch agar or glycerol-asparagine. agar.

Carbon utilization: D-Glucose, sucrose, I-inositol, D-mannitol, D-fructose and raffinose are utilized for growth. No growth or only trace of growth on L-arabinose and rhamnose. Utilization of D-xylose doubtful.

Streptomyces felleus Lindenbein. Description: Lindenbein 1952, 374-376; see also Brockmann and Bohne 1954, U. S. Patent 2, 693,433. Type strain: Söt 26 (Wilde, personal communication). ISP 5130 from P. Wilde as Söt 26. ISP description by Group A-3.

Spore chain morphology: Section Rectiflexibiles. Mature spore chains generally 10 to 50 or more spores per chain (Fig. 54). This morphology is observed on yeast-malt agar, oatmeal agar, salts-starch agar and glycerol-asparagine agar. Spore surface: Smooth (Fig. 53).

Color of colony: Acrial mass color in the Yellow color-series on yeast-malt agar, oatmeal agar, salts-starch agar and glycerol-asparagine agar.

Reverse side of colony: No distinctive pigments on yeast-malt agar, catmeal agar, salts-starch agar or glycerol-asparagine agar; substrate pigment is not a $\mathrm{pH}$ indicator.

Color in medium: Melanoid pigments not formed in peptone-yeast-iron agar and tyrosine agar. No pigment in medium or faint yellow to yellou'ish green color in yeast-malt agar, oatmeal agar, salts-starch agar and glycerol-asparagine agar.

Carbon utilization: D-Glucose, L-arabinose, D-xylose, D-mannitol and $\underline{D}$-fructose are utilized for growth. No growth or only trace of growth on sucrose, I-inositol, rhamnose and raffinose.

Streptomyces filamentosus Okami and Umezawa. Description: Okami and Umezawa in Okami, Okuda, Takeuchi, Nitta and Umezawa 1953a, 153-156. Type strain: 1-C-9 (ibid.). ISP 5022 from Y. Okami as 1-C-9. ISP description by Group A-9.

Spore chain morphology: Section Rectiflexibiles. Mature spore chains generally 10 to 50 spores per chain (Fig. 56). This morphology is found on yeast-malt agar, uatmeal agar, salts-starch agar and glycerol-asparagine agar. Spore surface: Smooth (Fig. 55).

Color of colony: Aerial mass color in the Red color-series on yeastmalt agar, oatmeal agar, salts-starch agar and glycerol-asparagine agar.

Reverse side of colony: No distinctive pigments on yeast-malt agar, oatmeal agar, salts-starch agar or glycerol-asparagine agar; substrate pigment is not a pH indicator. 


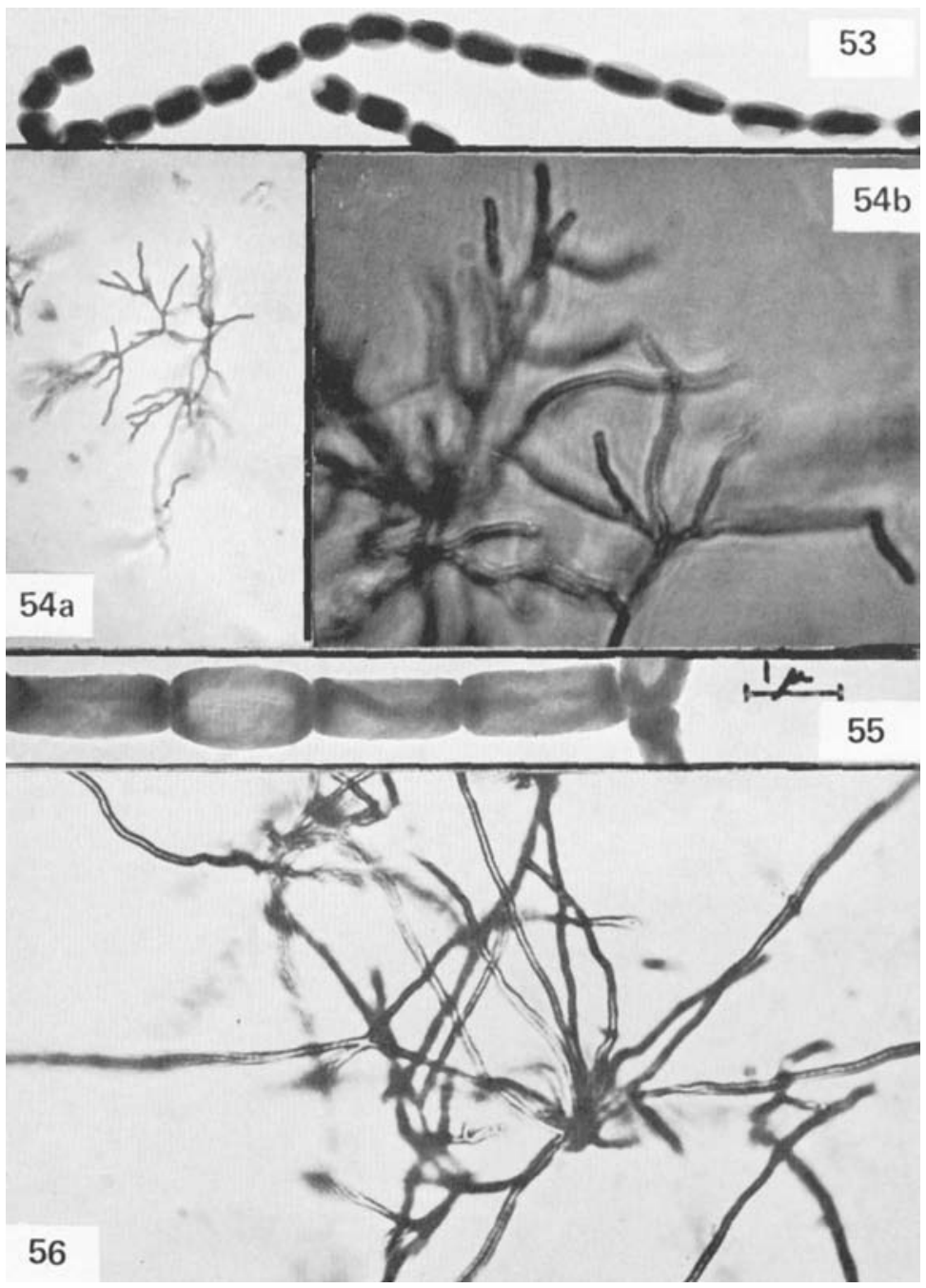

Figure 53. S. felleus. Smooth spores; electron micrograph from 14 day culture on oatmeal agar. ${ }^{16}$

Figure 54. S. felleus. RF spore chains on salts-starch agar, 14 days. (a) $300 x^{6}$, (b) $875 x^{7}$ ?

Figure 55. S. filamentosus. Smooth spores, electron micrograph from 21 day culture on oatmeal agar. 9

Figure 56. S. filamentosus. $\underline{R F}$ spore chains $(400 x)$ on oatmeal agar, 14 days. $\overline{10}$ 
Color in medium: Melanoid pigments not formed in peptone-yeastiron agar and tyrosine agar. No pigment found in medium in yeastmalt agar, oatmeal agar, salts-starch agar or glycerol-asparagine agar.

Carbon utilization: D-Glucose, L-arabinose, sucrose, D-xylose and rhamnose are utilized for growth. No growth or only trace of growth on $\underline{I}$-inositol, D-mannitol and raffinose. Variable reports on utilization of D-fructose.

Streptomyces flaveolus (Waksman) Waksman and Henrici. Descriptions: Actinomyces 168 Waksman 1919, 134-136; Streptomyces

flaveolus (Waksman) Waksman and Henrici 1948, 936. Type strain: IMRU 3319 (Waksman 1961, 208-209). ISP 5061 from S. A. Waksman as IMRU 3319. ISP description by Group A-4.

Spore chain morphology: Section Spirales, but short spore chains representative of Section RA are also common. Mature spore chains generally 10 to 50 spores per chain; shorter chains ( 3 to 10 spores) may be found (Fig. 59). This morphology is seen on yeast-malt agar, oatmeal agar, salts-starch agar and glycerol-asparagine agar (although sporulating aerial mycelium may be poorly developed on oatmeal agar or salts-starch agar). Spore surface: Hairy with some tendency toward spines; carbon-replica method suggests spiny spore surface (Figs. 57, 58).

Special morphological characteristics: Coremia may form on saltsstarch agar.

Color of colony: Aerial mass color in the Gray color-series on yeastmalt agar, oatmeal agar, salts-starch agar and glycerol-asparagine agar. (White series also reported by one observer on salts-starch agar and on glycerol-asparagine agar.)

Reverse side of colony: No distinctive pigments on yeast-malt agar, oatmeal agar, salts-starch agar or glycerol-asparagine agar; substrate pigment is not a pH indicator.

Color in medium: Melanoid pigments not formed in peptone-yeastiron agar and $t$ yrosine agar. Yellow pigment found in medium in yeastmalt agar, glycerol-asparagine agar and sometimes in other media. This pigment is not $\mathrm{pH}$ sensitive when tested with $0.05 \mathrm{~N} \mathrm{NaOH}$ or $\mathrm{HCl}$.

Carbon utilization: D-Glucose, L-arabinoss, sucrose, D-xylose, I-inositol, D-mannitol, D-fructose and rhamnose are utilized for growth. No growth or only trace of growth on raffinose.

Streptomyces flavopersicus Oliver, Goldstein, Bower, Holper and Otto. Description: Oliver et al. 1962, 495-502. Type strain: M-141 (ibid.). ISP 5093 from T. J. Oliver, Abbott Labs. as M-14l. ISP description by Group A-10.

Spore chain morphology: Section Verticillati. Umbellate monoverticillate (biverticillate): individual spore chains may form hooks, loops or primitive spirals (Figs. 60,61). Mature spore chains generally 10 to 50 spores per chain; but shorter chains of 3 to 10 spores are also found. This morphology is seen on yeast-malt agar, oatmeal agar and salts-starch agar. Spore surface: Smooth.

Color of colony: Aerial mass color in the Red color-series on yeastmalt agar, oatmeal agar and salts-starch agar.

Reverse side of colony: No distinctive pigments on yeast-malt agar, oatmeal agar, salts-starch agar or glycerol-asparagine agar; substrate 


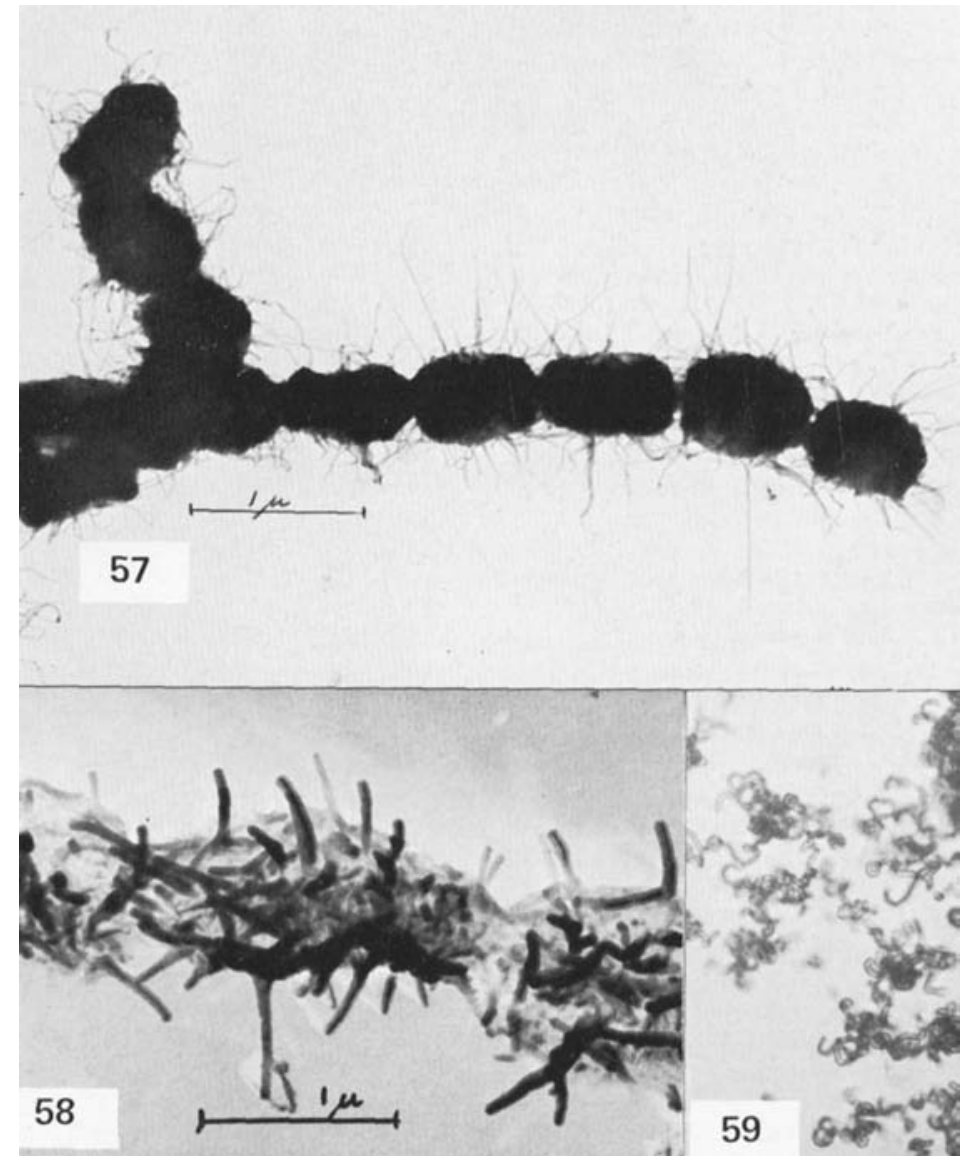

Figure 57. S. flaveolus. Hairy spores; electron micrograph from 14 day culture on yeast-malt agar. 1

Figure 58. S. flaveolus. Carbon replica of hairy spores; electron micrograph from 10 day culture on yeast-malt agar. 17

Figure 59. S. flaveolus. Spiral spore chains with some short or incomplete spiralsand hooks on yeast-malt agar, 21 days. 14 
pigment is not a pH indicator.

Color in medium: Melanoid pigments formed weakly after prolonged cultivation in peptone-yeast-iron agar. No pigment found in medium, or very faint color in yeast-malt agar, oatmeal agar, salts-starch agar and glycerol-asparagine agar.

Carbon utilization: D-Glucose and I-inositol are utilized for growth. No growth or only trace of growth on L-arabinose, sucrose, D-xylose, D-mannitol, rhamnose and raffinose. Utilization of $\underline{D}$-fructose is doubtful.

Actinomyces flavotricini Preobrazhenskaya and Sveshnikova. Description: Preobrazhenskaya and Sveshnikova in Gauze et al. 1957, 44 and 49. Type strain: $11669 / 58$ (neotype, Precbrazhenskaya, personal communication). Streptomyces flavotricini (Preobrazhenskaya and Sveshnikova) Pridham et al. 1958, 60. ISP 5152 from T. P. Preobrazenskaya as $11669 / 58$. ISP description by Group A-5.

Spore chain morphology: Section Rectiflexibiles. Mature spore chains generally long, often with more than 50 spores per chain (Fig. 63). This morphology is seen on yeast-malt agar, oatmeal agar and salts-starch agar, but not on glycerol-asparagine agar. Spore surface: Smooth (Fig. 62).

Color of colony: Aerial mass color in the Red color-series on yeastmalt agar, oatmeal agar and salts-starch agar.

Reverse side of colony: No distinctive pigments on yeast-malt agar, catmeal agar, salts-starch agar and glycerol-asparagine agar; substrate pigment is not a $\mathrm{pH}$ indicator.

Color in medium: Melanoid pigments formed in peptone-yeast-iron agar and tryptone-yeast broth. Pigments other than melanoids not formed in yeast-malt agar, oatmeal agar, salts-starch agar or glycerol-as paragine agar.

Carbon utilization: D-Glucose is utilized for growth; doubtful utilization of $\underline{D}$-fructose. No growth or only trace of growth on $\underline{L}-$ a rabinose, sucrose, D-xylose, I-inositol, D-mannitol, rhamnose and raffinose.

Streptomyces flavovi rens (Waksman) Waksman and Henrici. Descriptions: Actinomyces 128 Waksman 1919, 117-119; Actinomyces flavovirens Waksman 1923, 352; Streptomyces flavovirens (Waksman) Waksman and Henrici 1948, 940. Type strain: IMRU 3320 (Waksman 1961, 210). ISP 5062 from S. A. Waksman as IMRU 3320. ISP description by Group A -4 .

Spore chain morphology: Section Rectiflexibiles. Mature spore chains generally long, often with more than 50 spores per chain (Fig. 65). This morphology is seen on yeast-malt agar, oatmeal agar, salts-starch agar and glycerol-asparagine agar. Spore surface: Smooth (Fig. 64).

Color of colony: Aerial mass color in the Gray color-series on yeast-malt agar, oatmeal agar and salts-starch agar.

Reverse side of colony: Colorless or characteristic grayed yellow modified by green on yeast-malt agar, oatmeal agar, salts-starch agar and glycerol-asparagine agar; substrate pigment is not a $\mathrm{pH}$ indicator.

Color in medium: Melanoid pigments not formed in peptone-yeastiron agar and tyrosine agar. Pigments other than melanoids not formed, 

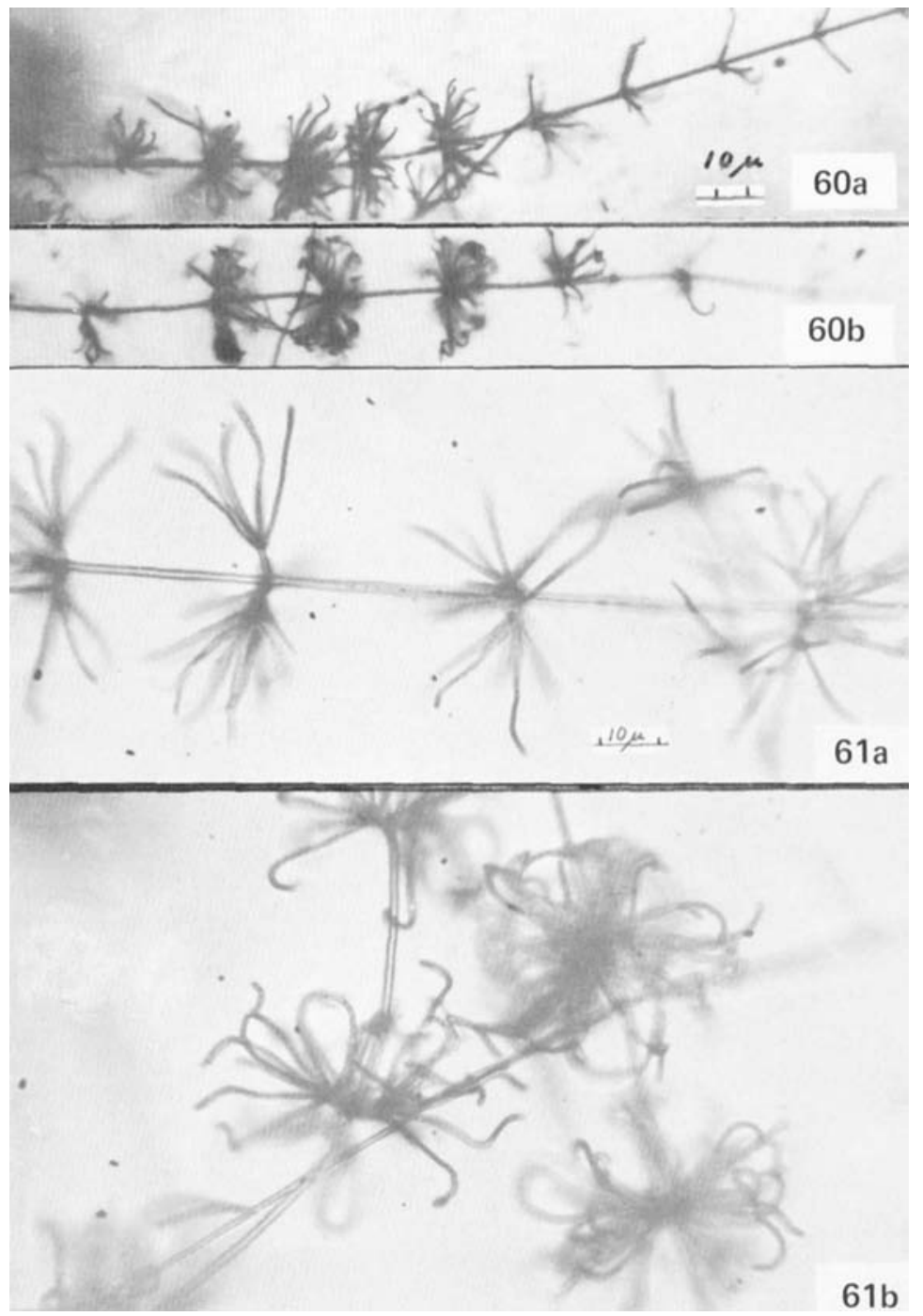

Figure 60. S. flavopersicus. BIV (umbellate monoverticillate) morphology, (350x). (a) Flexuous terminal spore chains on oatmeal agar, 14 days. (b) Spiral terminal spore chains on salts-starch agar, 14 days. 18

Figure 61. S. flavopersicus. BIV (umbellate monoverticillate) morphology, (1000x). (a) Flexuous terminal spore chains on oatmeal agar, 14 days. (b) Spiral and hooked terminal spore chains on saltsstarch agar, 14 days. 18 


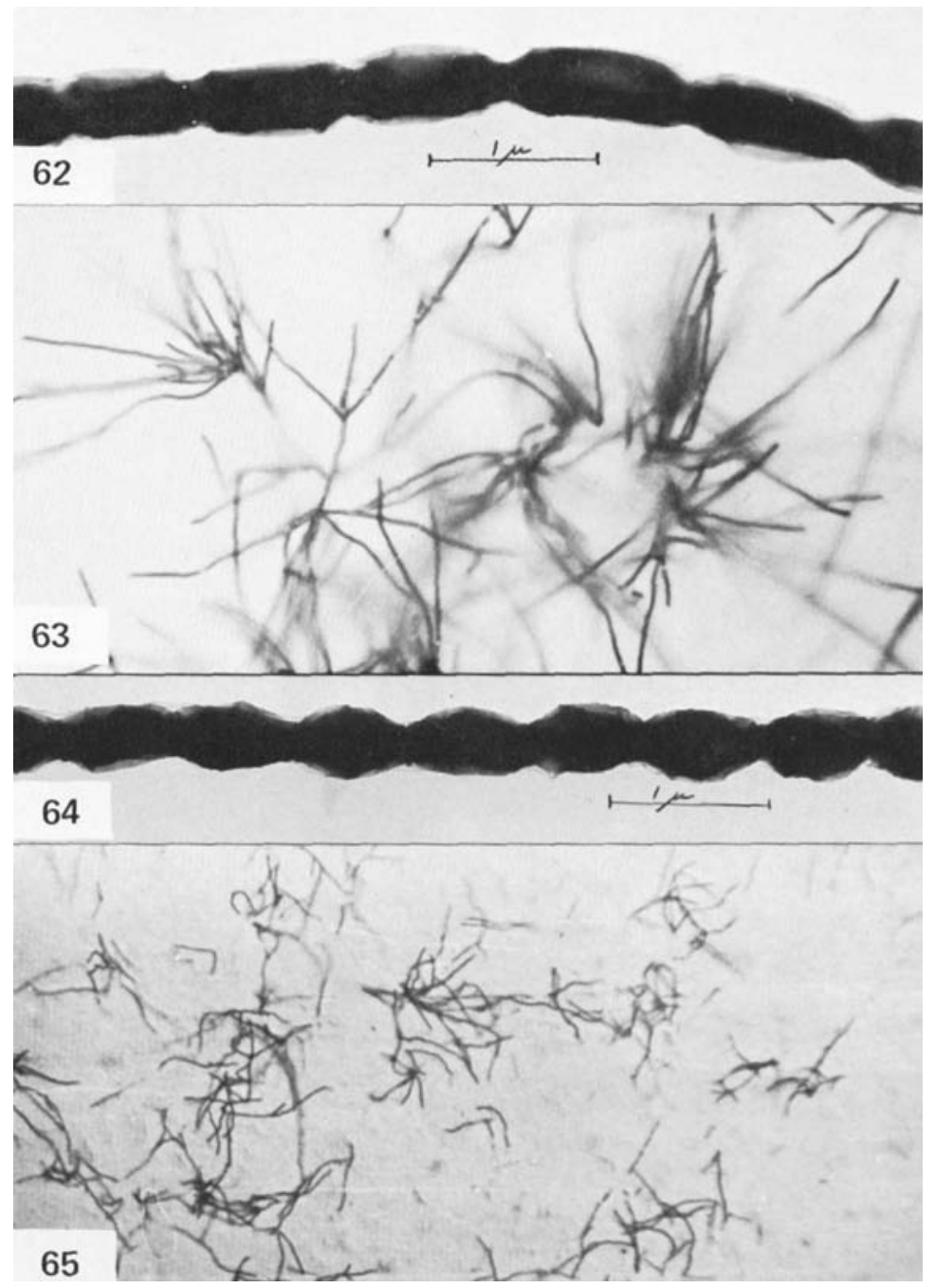

Figure 62. A. flavotricini. Smooth spores; electron micrograph from 14 day culture on yeast-malt agar. ${ }^{1}$

Figure 63. A. flavotricini. RF spore chains $(400 x)$ on oatmeal agar, 11 days. 1

Figure 64. S. flavovirens. Smooth spores; electron micrograph from 14 day culture on oatmeal agar. ${ }^{1}$

Figure 65. S. flavovirens. RF spore chains (300x) on oatmeal agar, 14 day 8.15 


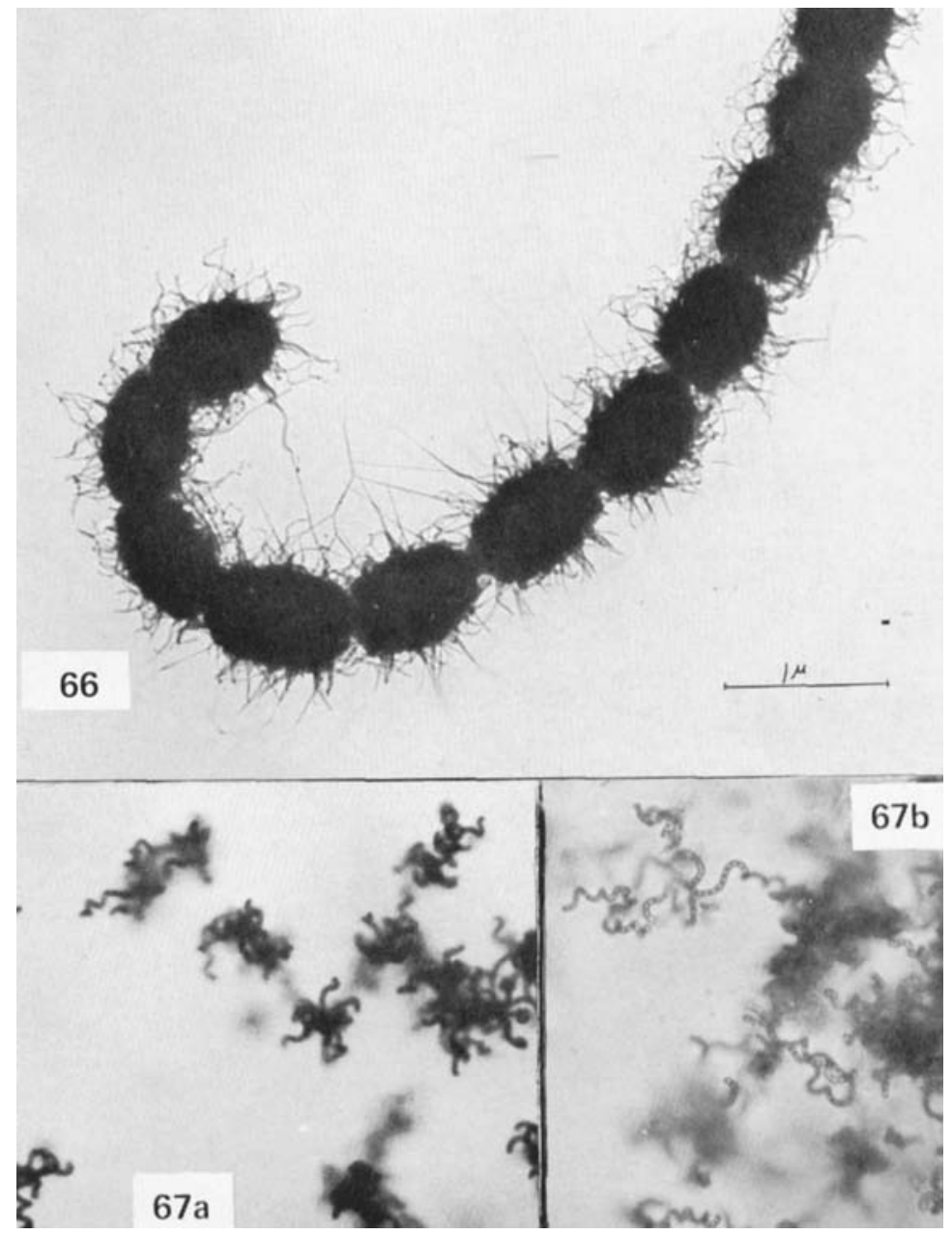

Figure 66. A. flavoviridis. Hairy spores; electron micrograph from 14 day culture on oatmeal agar. ${ }^{1}$

Figure 67. A. flavoviridis. Spiral spore chains (400x). Open spirals and some incomplete spirals on (a) oatmeal agar, 9 days. 19

(b) yeast-malt agar, 14 day 8,20 
or some yellow pigment may be produced in oatmeal agar and glycerolasparagine agar. This pigment is not $\mathrm{pH}$ sensitive when tested with $0.05 \mathrm{~N} \mathrm{NaOH}$ or $\mathrm{HCl}$.

Carbon utilization: D-Glucose, L-arabinose, D-xylose, D-mannitol and rhamnose are utilized for growth. No growth on sucrose, I-inositol and rafinose; trace of growth on D- fructose.

Actinomyces flavoviridis Krasil'nikov. Description: Krasil'nikov 1941, 30; see also Krasil'nikov 1949, 100. Type strain: 2314/53 (neotype, Preobrazhenskaya, personal communication). Streptomyces flavoviridis (Krasil'nikov) Pridham et al. 1958, 69. ISP 5153 from T.P Preobrazhenskaya as $2314 / 53$. ISP description by Group A-5.

Spore chain morphology: Section Spirales (young spore chains may resemble $\underline{\text { RA ) }) . ~ M a t u r e ~ s p o r e ~ c h a i n s ~ g e n e r a l l y ~} 10$ to 50 spores per chain; longer chains are sometimes observed (Fig. 67). This morphology is found on yeast-malt agar, oatmeal agar, salts-starch agar and glycerol-asparagine agar. Spore surface: Hairy (Fig. 66).

Color of colony: Aerial mass color in the Gray or Green series on yeast-malt agar, oatmeal agar, salts-starch agar and glycerol-asparagine agar; color tabs selected by observers are all light olive gray or light olive brown.

Reverse side of colony: No distinctive pigments (grayed yellow to yellow-brown) on yeast-malt agar, oatmeal agar, salts-starch agar or glycerol-asparagine agar; substrate pigment is not a $\mathrm{pH}$ indicator.

Color in medium: Melanoid pigments formed in peptone-yeast-iron agar and tryptone-yeast broth. No other pigment in medium in yeastmalt agar, oatmeal agar, salts-starch agar or glycerol-asparagine agar.

Carbon utilization: D-Glucose, L-arabinose, D-xylose, I-inositol, D-mannitol, D-fructose and rhamnose are utilized for growth. No growth or only trace of growth on sucrose or raffinose.

Streptomyces fradiae (Waksman and Curtis) Waksman and Henrici. Descriptions: Actinomyces fradii (sic) Waksman and Curtis 1916, 125126; Waksman 1919, 119-121; Streptomyces fradiae (Waksman and Curtis) Waksman and Henrici 1948, 954. Type strain: IMRU 3535 (Waksman 1961, 211-212). ISP 5063 from S. A. Waksman as IMRU 3535. ISP description by Group A-5.

Spore chain morphology: Section Retinaculiaperti with characteristic range from straight to spiral spore chains. Straight or flexuous spore chains are most common on yeast-malt agar; RA morphology, including open spirals, best developed on oatmeal agar and salts-starch agar. Mature spore chains generally 10 to 50 spores per chain; longer chains are sometimes observed (Fig. 69). This morphology is seen on yeast-malt agar, oatmeal agar, salts-starch agar and glycerol-asparagine agar. Spore surface: Smooth (Fig. 68).

Color of colony: Aerial mass color in the Red color-series on yeastmalt agar, oatmeal agar, salts-starch agar and glycerol-asparagine agar.

Reverse side of colony: No distinctive pigments on yeast-malt agar, oatmeal agar, salts-starch agar or glycerol-as paragine agar; substrate pigment is not a $\mathrm{pH}$ indicator.

Color in medium: Melanoid pigments not formed in peptone-yeastiron agar and tyrosine agar. No pigment found in medium in yeast-malt 


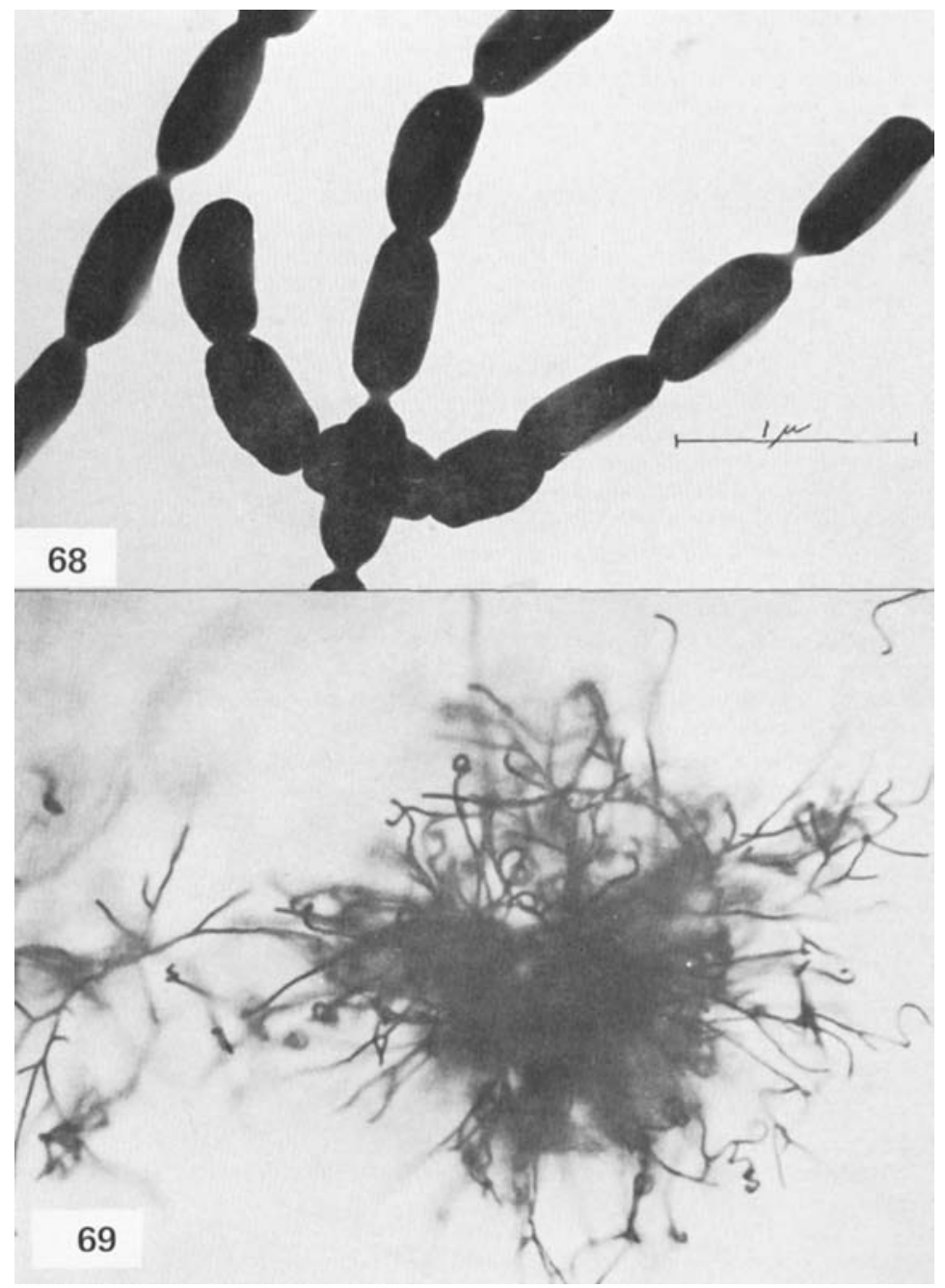

Figure 68. S. fradiae. Smooth spores; electron micrograph from 14 day culture on oatmeal agar. ${ }^{1}$

Figure 69 . S. fradiae. RA spore chains $(400 \mathrm{x})$ on oatmeal agar, II days. ${ }^{19}$ Note straight spore chains, hooks and loops of wide diameter, primitive spirals and some true spirals. 
agar, oatmeal agar, salts-starch agar or glycerol-asparagine agar.

Carbon utilization: D-Gluccse, L-arabinose and $\underline{D}$-fructose are utilized for growth. No growth or only trace of growth on sucrose, Iinositol, D-mannitol, rhamnose and raffinose. Variable reports on growth with D-xylose.

Actinomyces glaucescens Preobrazhenskaya. Deocription: Preobrazhenskaya in Gauze et al. 1957, 122-124. Type strain: 8731 (ibid.; type strain selected by Preobrazhenskaya, personal communication). Streptomyces glaucescens (Preobrazhenskaya) Pridham et al. 1958, 67. ISP 5155 from T.P. Preobrazhenskaya as 8731 . ISP description by Group A-6.

Spore chain morphology: Section Spirales. Mature spore chains short with 3 to 10 spores per chain. Typical morphology on yeast-malt agar, oatmeal agar and salts-starch agar, but not typical on glycerolasparagine agar. Spore surface: Hairy. Hairs are coarse showing some tendency toward spines (Fig. 70).

Color of colony: Aerial mass color in the Blue or Green color-series on yeast-malt agar, oatmeal agar and salts-starch agar. (Color tabs selected by observers fall in both series, but all tabs selected are grayish green.)

Reverse side of colony: Grayed yellow modified by red on yeast-malt agar and glycerol-asparagine agar; modified by green on oatmeal agar and salts-starch agar. Substrate pigment is not a $\mathrm{pH}$ indicator.

Color in medium: Melanoid pigments formed in peptone-yeast-iron agar, tyrosine agar and tryptone-yeast broth. Pigments other than melanoids not formed in yeast-malt agar, oatmeal agar, salts-starch agar or glycerol-asparagine agar.

Carbon utilization: D-Glucose, L-arabinose, D-xylose, $\underline{I}$-inositol, D-mannitol, D-fructose and rhamnose are utilized for growth. No growth or only trace of growth on sucrose and raffinose.

Streptomyces griseobrunneus (Waksman) Waksman, Descriptions: Actinomyces 218 Waksman 1919, 125-127; Streptomyces griseobrunneus (Waksman) Waksman 1961, 220. Type strain: IMRU 3068 (Waksman, 1961). ISP 5066 from S. A. Waksman as IMRU 3068. ISP description by Group A-5.

Spore chain morphology: Section Rectiflexibiles. Mature spore chains generally long, often with more than 50 spores per chain (Fig. 72). This morphology is seen on yeast-malt agar, oatmeal agar, saltsstarch agar and glycerol-asparagine agar. Spore surface: Smooth (Fig. 71).

Special morphological characteristics: Substrate conidia noted by 2 observers.

Color of colony: Aerial mass color in the Yellow color-series on yeast-malt agar, oatmeal agar, salts-starch agar and glycerol-asparagine agar.

Reverse side of colony: No distinctive pigments on yeast-malt agar, oatmeal agar, salts-starch agar or glycerol-asparagine agar; substrate pigment is not a pH indicator.

Color in medium: Melanoid pigments formed in peptone-yeast-iron 


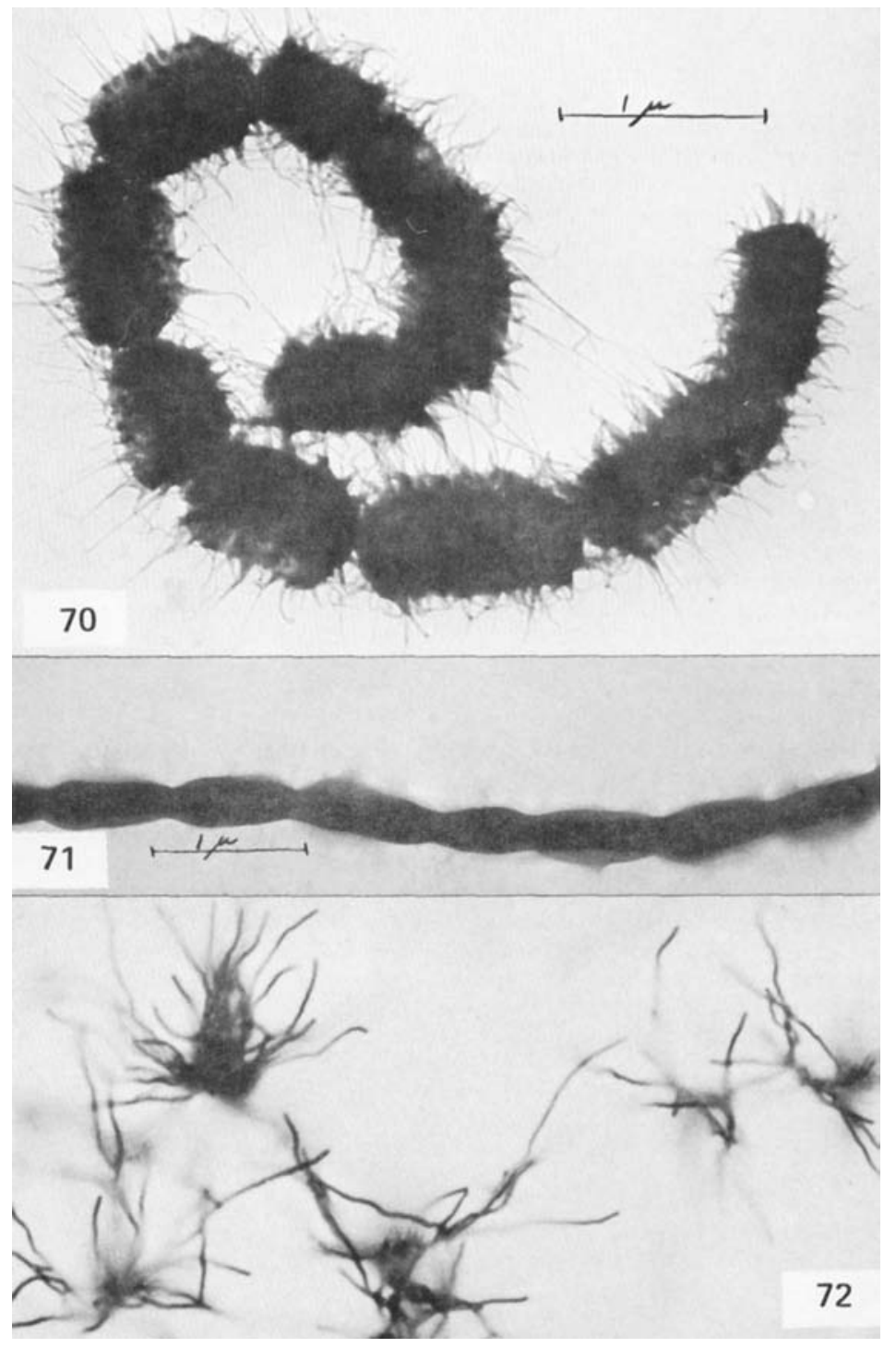

Figure 70. A. glaucescens. Hairy spores; electron micrograph from 14 day culture on oatmeal agar. ${ }^{1}$

Figure 7l. S. griseobrunneus. Smooth spores; electron micrograph from 14 day culture on oatmeal agar. ${ }^{1}$

Figure 72 . S. griseobrunneus. $\underline{\text { RF }}$ spore chains $(400 \mathrm{x})$ on oatmeal agar, 14 days. 19 
agar. Pigments other than melanoids not formed in yeast-malt agar, oatmeal agar, salts-starch agar or glycerol-as paragine agar.

Carbon utilization: D-Glucose, D-xylose, D-mannitol and D-fructose are utilized for growth. No growth or only trace of growth on L-arabinose, sucrose, $\underline{I}$-inositol, rhamnose and raffinose.

Streptoverticillium griseocarneum (Benedict, Lindenfelser, Stodola and Traufler) Baldacci, Farina and Locci. Descriptions: Benedict et al. 1951, 487-497; see also Benedict et al. 1950, 77-78; Baldacci et al 1966, 158-159. Type strain: NRRL B-1068 (Benedict et al. 1951). Streptomyces griseocarneus Benedict, Lindenfelser, Stodola and Traufler 1951, 487. Streptoverticillium griseocarneus (sic) (Benedict et al. ) Baldacci 1958, 25. ISP 5004 from T. Pridham as NRRL B1068. ISP description by $G$ roup $A-1$.

Spore chain morphology: Umbellate monoverticillate (= Streptomyces Section Verticillati, biverticillate). Mature spore chains short, generally 3 to 10 spores per chain (Fig. 74). This morphology is seen on yeast-malt agar, salts-starch agar and glycerol-asparagine agar. Mature spores often not produced until 14-21 days. Spore surface: Smooth (Fig. 73).

Color of colony: Aerial mass color in the Red color-series on yeastmalt agar, salts-starch agar and glycerol-asparagine agar; good spore mass not produced on oatmeal agar.

Reverse side of colony: No distinctive pigments (grayed yellow to yellow-brown) on yeast-malt agar, salts-starch agar or glycerol-asparagine agar; substrate pigment is not a $\mathrm{pH}$ indicator.

Color in medium: Melanoid pigments formed in peptone-yeast-iron agar. Pigments other than melanoids not formed in yeast-malt agar, oatmeal agar, salts-starch agar or glycerol-asparagine agar.

Carbon utilization: D-Glucose is utilized for growth. No growth or only trace of growth on sucrose, rhamnose and raffinose. Variable reports on growth with L-arabinose, D-xylose, I-inositol, D-mannitol and D-fructose (but if growth occurs with these carbon sources it is less than with D-Glucose).

Streptomyces griseolus (Waksman) Waksman and Henrici. Descriptions: Actinomyces 96 Waksman 1919, 121-123; Actinomyces griseolus Waksman 1923, 369; Streptomyces griseolus (Waksman) Waksman and Henrici 1948, 938. Type strain: IMRU 3325 (Waksman, 1961). ISP 5067 from S. A. Waksman as IMRU 3325. ISP description by Group A-5.

Spore chain morphology: Section Rectiflexibiles . Mature spore chains moderately short with 3 to 10 , or sometimes more than 10 , spores per chain (one observer reports 10 to 50 spores per chain)(Fig. 76). This morphology is seen on yeast-malt agar; sporulation on oatmeal agar, salts-starch agar or glycerol-asparagine agar may be poor. Spore surface: Smooth (Fig. 75).

Color of colony: Aerial mass color in the Gray color-series on yeast-malt agar; sporulation usually inadequate for color determination on oatmeal agar, salts-starch agar and glycerol-asparagine agar.

Reverse side of colony: Yellow-brown to brown on yeast-malt aga $r$ and colorless or characteristic grayed yellow to grayed yellow-brown on oatmeal agar, salts-starch agar and glycerol-asparagine agar. Substrate pigment is not a $\mathrm{pH}$ indicator. 


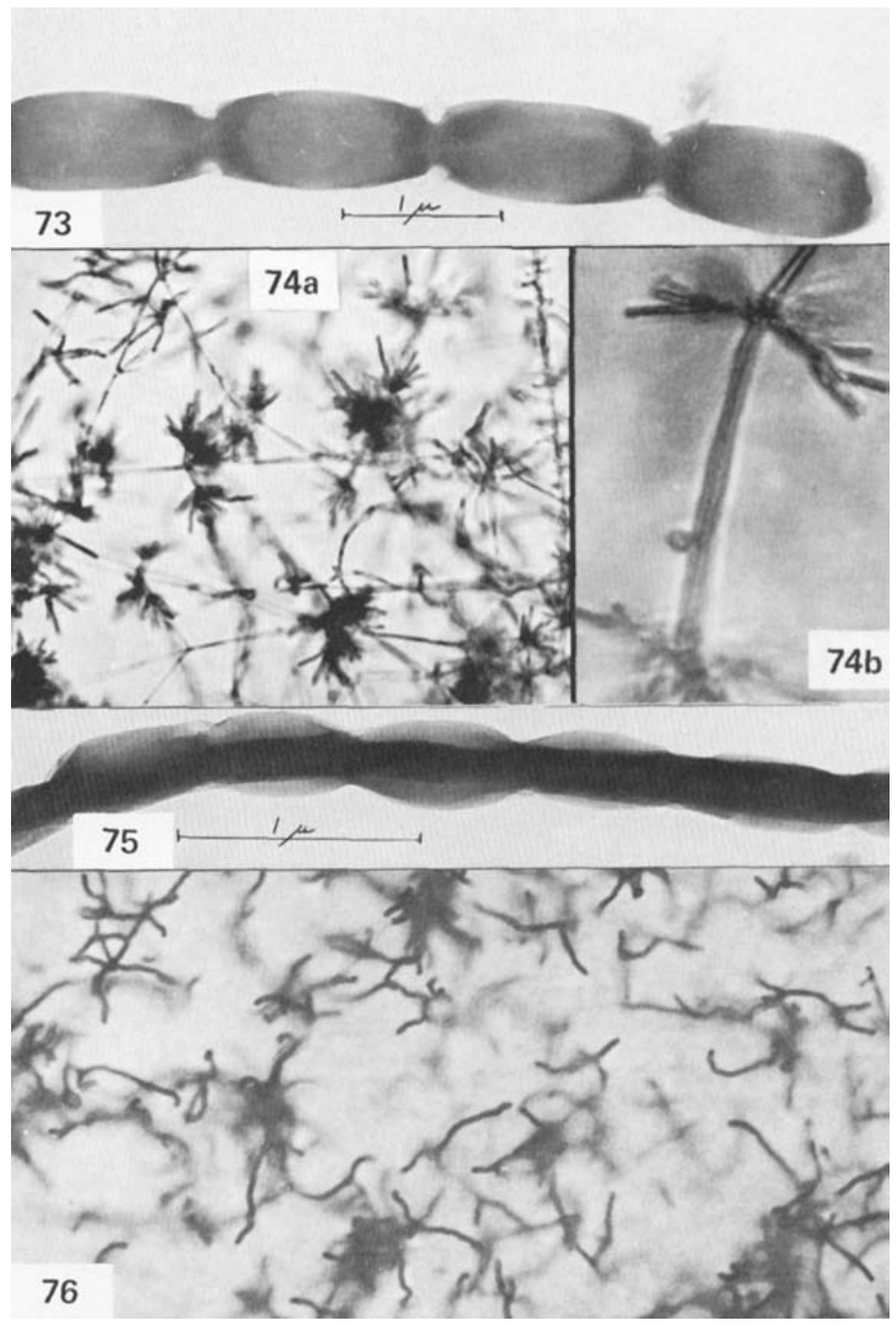

Figure 73. Streptoverticillium griseocarneum. Smooth spores; electron micrograph from 14 day culture on yeast-malt agar. ${ }^{1}$

Figure 74. Streptoverticillium griseocarneum. BIV (monoverticillate umbellate) morphology. (a) On Waksman's starch agar B, 27 days $(389 x) .^{2}$ (b) On glycerol-asparagine agar, 7 days $(720 x) .^{3}$

Figure 75. S. griseolus. Smooth spores; electron micrograph from 14 day culture on yeast-malt agar. ${ }^{1}$

Figure 76. S. griseolus. RF spore ehains $(400 \mathrm{x})$ on salts-starch agar, 9 days. 19 
Color in medium: Melanoid pigments not formed in peptone-yeastiron agar and tyrosine agar. No pigment found in medium in yeastmalt agar, oatmeal agar, salts-starch agar or glycerol-asparagine agar.

Carbon utilization: $\underline{D}-G l u c o s e, \underline{L}-a$ rabinose, $\underline{D}-x y l o s e$ and $\underline{D}-f$ ructose are utilized for growth. No growth or only trace of growth on I-inositol and raffinose. Variable reports on growth with sucrose, D-mannitol and rhamnose. (Interpretation is difficult because of significant growth on the carbon-free basal medium.)

Actinomyces griseomycini Preobrazhenskaya, Blinov and Ryabova. Description: Preobrazhenskaya et al. in Gauze et al . 1957, 133 and 136. Type strain: 13984 (Preobrazhenskaya, personal communication). Streptomyces griseomycini (Preobrazhenskaya et al.) Pridham et al. 1958, 68. ISP 5159 from T.P. Preobrazhenskaya as 13984. ISP description by Group A-6.

Spore chain morphology: Section Spirales or Retinaculiaperti . Sporophores are short and poorly developed but are frequentiy coiled at the tips; true spirals are rare. Hooks and loops are of small diameter and therefore are not representative of typical RA cultures. Mature spore chains short, generally 3 to 10 spores per chain (Fig. 78 ). This morphology is found on yeast-malt agar, oatmeal agar, saltsstarch agar and glycerol-asparagine agar, but sporulation may be poor on oatmeal agar and glycerol-asparagine agar. Spore surface: Hairy. Some smooth spores may be observed (Fig. 77).

Color of colony: Aerial mass color in the Green color-series on yeast-malt agar and salts-starch agar. (One observer placed the culture in the Gray series on these two media).

Reverse side of colony: Grayed yellow modified by green on yeastmalt agar and salts-starch agar; it is colorless, grayed yellow or grayed greenish yellow on oatmeal agar and glycerol-asparagine agar. Substrate pigment is not a $\mathrm{pH}$ indicator.

Color in medium: Melanoid pigments formed in peptone-yeast-iron agar. Pigments other than malanoids not formed in yeast-malt agar, oatmeal agar, salts-starch agar or glycerol-asparagine agar.

Carbon utilization: D-Glucose, L-arabinose, D-xylose, I-inositol, D-mannitol, D-fructose and rhamnose are utilized for growth. No growth or only trace of growth on sucrose and raffinose.

Streptomyces griseoplanus Backus, Tresner and Campbell. Description: Backus et al. 1957, 536-541. Type strain: AA-223 (ibid.). ISP 5009 from H. Tresner as AA-223. ISP description by Group A-2.

Spore chain morphology: Section Spirales. Spore chains range from flexuous to spiral. Spirals are generally open. Mature spore chains generally 10 to 50 spores per chain (Fig. 80). This morphology is seen on yeast-malt agar and oatmeal agar; poor growth on salts-starch agar and glycerol-asparagine agar. Spore surface: Warty (Fig. 79).

Color of colony: Aerial mass color in the Gray color-series on yeast-malt agar and oatmeal agar.

Reverse side of colony: No distinctive pigments (grayed yellow to yellow-brown on yeast-malt agar and colorless or grayed yellow on oatmeal agar, salts-starch agar and glycerol-asparagine agar). Substrate pigment is not a $\mathrm{pH}$ indicator. 

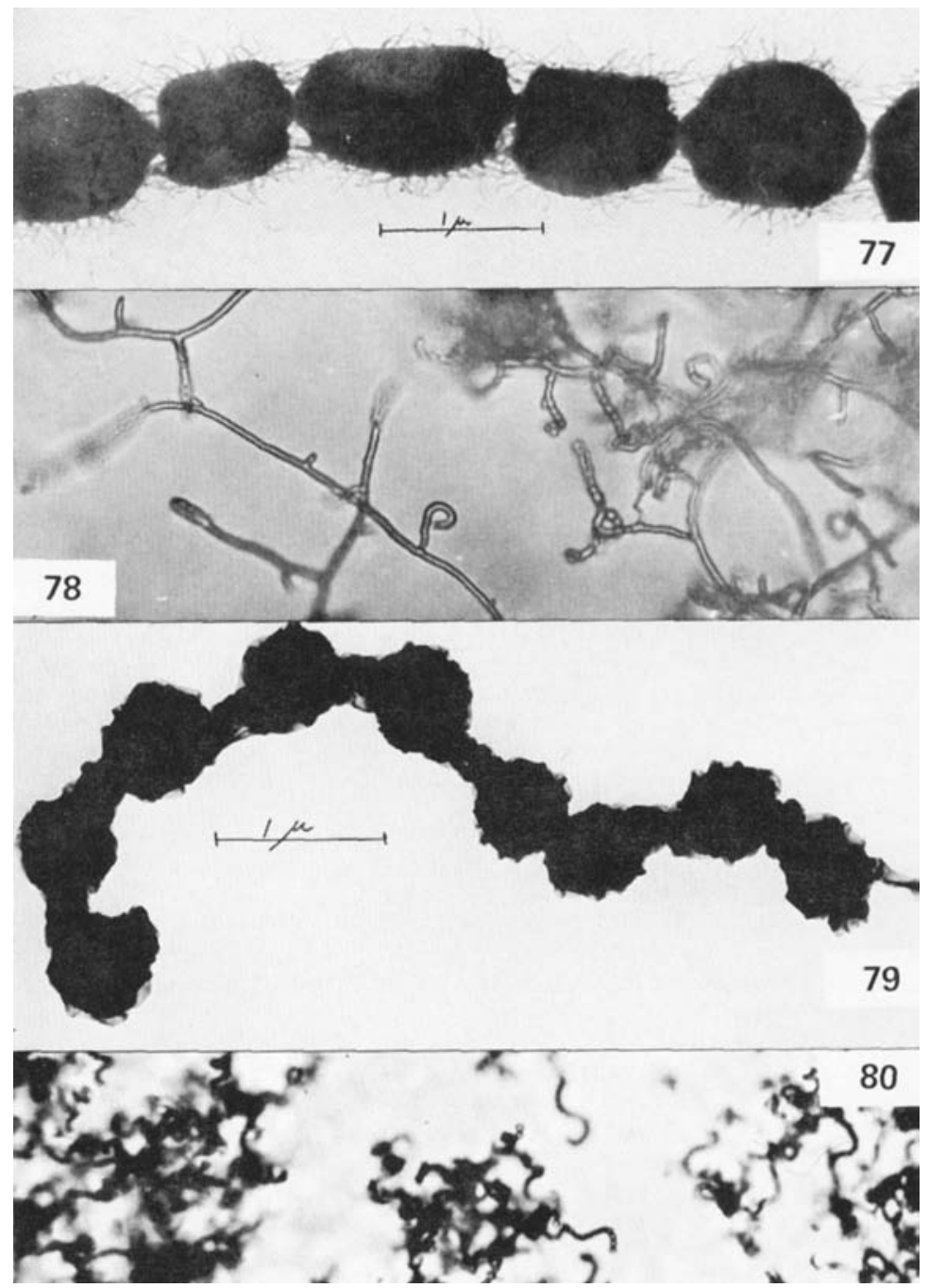

Figure 77. A. griseomycini. Hairy spores; electron micrograph from 14 day culture on oatmeal agar.

Figure 78. A. griseomycini $(1200 x)$. Example of short spore chains in poorly developed spirals or hooks and loops of small diamete, From salts - starch agar, 14 days.

Figure 79. S. griseoplanus. Warty spores; electron micrograph from 14 day culture on yeast-malt agar.

Figure 80. S. griseoplanus. Spiral spore chains, including open spirals and flexuous chains, $(500 x)$ on yeast-malt agar, 7 days. 8 
Color in medium: Melanoid pigments not formed in peptone-yeastiron agar, tyrosine agar or tryptone-yeast broth. No pigment found in medium in yeast-malt agar, oatmeal agar, salts-starch agar or glyce rol-asparagine agar.

Carbon utilization: D-Glucose, L-arabinose, D-xylose, raffinose and $D$-fructose are utilized for growth. No growth or only trace of growth on sucrose, I-inositol, D-mannitol and rhamnose.

Actinomyces griseorubens Preobrazhenskaya, Blinov and Ryabova. Description: Preobrazhenskaya et al. in Gause et al. 1957,140 and 144. Type strain: 6124/১4 (Preobrazhenskaya, personal communication). Streptomyces griseorubens (Preobrazhenskaya et al. ) Pridham et al. 1958,65 . ISP 5160 from T. P. Preobrazhenskaya as $6124 / 54$ description by Group A-6.

Spore chain morphology: Section Spirales or Rectiflexibiles. Flexuous sporophores are the dominant forms; Hooks, loops and some open spirals a re present. On ISP media this culture does not produce the long spore chains with wide diameter hooks and loops charactejistic of typical RA cultures. Mature spore chains moderately short with 3 to 10 or sometimes more than 10, spores per chain (Fig. 82). This morphology is observed on yeast-malt agar. Sporulation is poor on oatmeal agar, salts-starch agar and glycerol-asparagine agar. Spore surface: Spiny with very short spines or sometimes with smooth spores (Fig. 81).

Color of colony: Aerial mass color in the Gray color-series on yeastmalt agar and salts-starch agar.

Reverse side of colony: No distinctive pigment on yeast-malt agar, oatmeal agar, salts-starch agar or glycerol-asparagine agar; substrate pigment is not a $\mathrm{pH}$ indicator.

Color in medium: Melanoid pigments not formed in peptone-yeastiron agar, tyrosine agar or tryptone-yeast broth. No pigment found in medium in yeast-malt agar, oatmeal agar, salts-starch agar or glycerolasparagine agar.

Carbon utilization: D-Glucose, D-xylose, D-mannitol, D-fructose and rhamnose are utilized for growth. No growth or only trace of growth on sucrose and raffinose. Utilization of $\underline{L}$-arabinose and $\underline{I}$-inositol is doubtful.

Actinomyces griseostramineus Preobrazhenskaya, Kudrina, Ryabova and Blinov. Description: Preobrazhenskaya et al. in Gauze et al. 1957, 151 and 155. Type strain: 10381 (Preobrazhenskaya, personal communication). Streptomyces griseostramineus (Preobrazhenskaya et al.) Pridham et al. 1958, 6 5 . ISP 5161 from T. P. Preobrazhenskaya as 10381. IS $\bar{P}$ description by Group A-8.

Spore chain morphology: Section Spirales. Short spore chains may form tight spirals of only a few turns on yeast-malt agar and saltsstarch agár. Hooks and loops suggestive of Section RA may also be found on these media and on oatmeal agar. Mature spore chains short, generally 3 to 10 spores per chain (Fig. 84). This morphology is seen on yeast-malt agar and salts-starch agar, sporulation may be poor on oatmeal agar and glycerol-asparagine agar. Spore surface: Hairy to Spiny: appendages are shorter than characteristic hairs, but longer and more flexuous than typical spines (Fig. 83). 


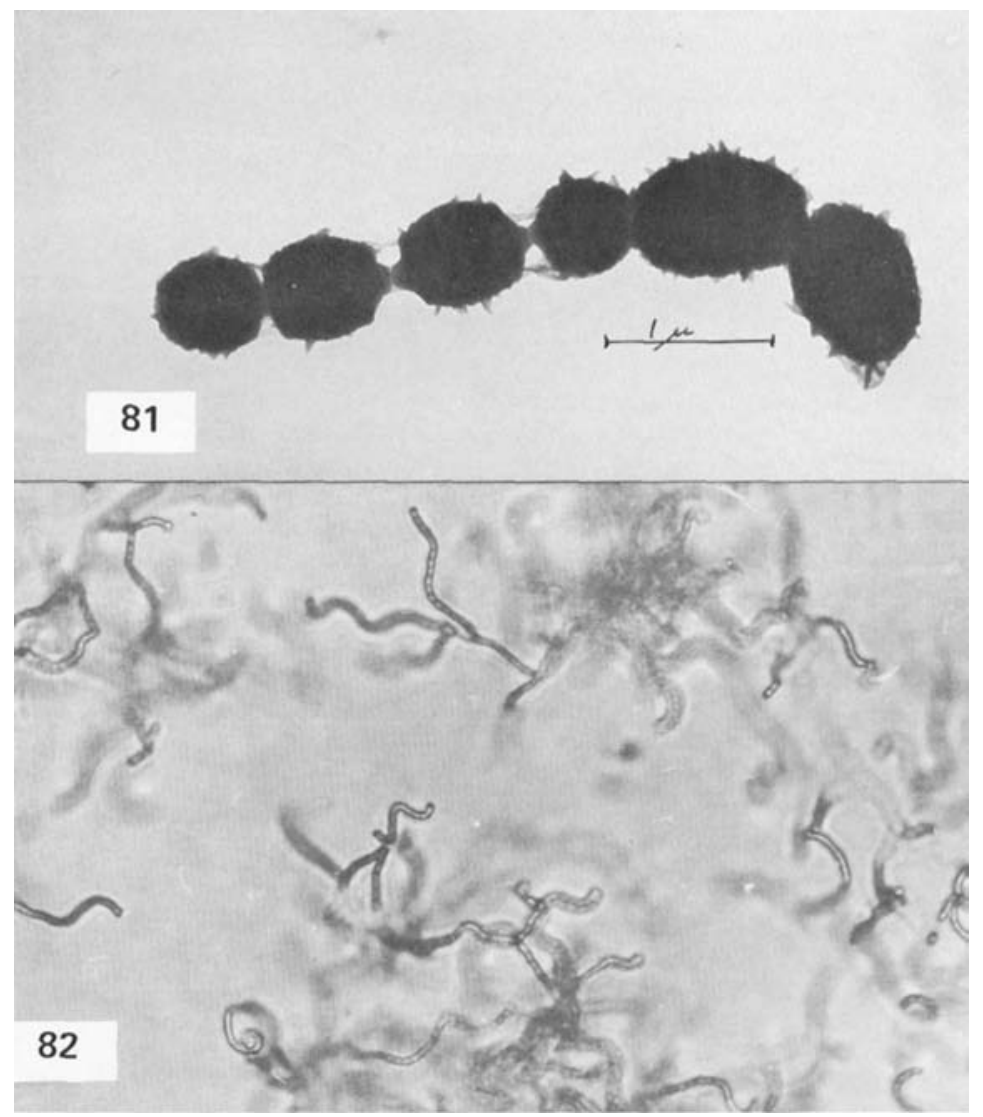

Figure 81. A. griseorubens. Spiny spores; electron micrograph from 14 day culture on oatmeal agar. ${ }^{1}$

Figure 82. A. griseorubens. Spiral to RF spore chains $(1200 \mathrm{x})$ on yeast-malt agar, 14 days. 21 
Color of colony: Aerial mass color in the Green color-series on yeast-malt agar and salts-starch agar.

Reverse side of colony: No distinctive pigment (grayed yellow or grayed yellow modified by green) on yeast-malt agar, oatmeal agar, salts-starch agar or glycerol asparagine agar; substrate pigment is not a $\mathrm{pH}$ indicator.

Color in medium: Melanoid pigments formed in peptone-yeast-iron agar. Pigments other than melanoids not formed in yeast-malt agar, oatmeal agar, salts-starch agar or glycerol-asparagine agar.

Carbon utilization: D-Glucose, L-arabinose, D-xylose, I-inositol, D-mannitol, D-fructose and rhamnose are utilized for growth. No growth or only trace of growth on sucrose. Variable reports on growth with raffinose.

Streptomyces hachijoensis Yamaguchi. Description: Yamaguchi 1954, 10-14. (Antibiotic activity described by Hosoya et al. 1952, 564; Hosoya et al. 1952, 505.) Type strain: H-2609 (Yamaguchi, ibid.). ISP 5114 from $T$. Yamaguchi as H-2609. ISP description by Group A-10.

Spore chain morphology: Section Verticillati. Both monoverticillate and umbellate monoverticillate (biverticillate) spore chains a re found. Mature spore chains short, generally 3 to 10 spores per chain (Fig. 86). This morphology is seen on yeast-malt agar, oatmeal agar, salts-starch agar and glycerol-asparagine agar. Spore surface: Smooth (Fig. 85).

Color of colony: Aerial mass color in the Red color-series on yeastmalt agar, oatmeal agar, salts-starch agar and glycerol-asparagine agar.

Reverse side of colony: No distinctive pigment (grayed yellow to yellow-brown) on yeast-malt agar, oatmeal agar, salts-starch agar or glycerol-asparagine agar; substrate pigment is not a $\mathrm{pH}$ indicator.

Color in medium: Melanoid pigments not formed in peptone-yeastiron agar and tyrosine agar. No pigment in medium, or only trace of yellow, in yeast-malt agar, oatmeal agar, salts-starch agar and glycerol-asparagine agar.

Carbon utilization: D-Glucose and I-inositol a re atilized for growth. No growth or only trace of growth on L-arabinose, sucrose, D-xylose, D-mannitol, D-fructose, rhamnose and raffinose.

Streptomyces halstedii (Waksman and Curtis) Waksman and Henrici. Descriptions: Actinomyces halstedii Waksman and Curtis 1916, 124; Waksman 1919,127; Streptomyces halstedii (Waksman and Curtis) Waksman and Henrici 1948, 953. Type strain: IMRU 3328 (Waksman, 1961). (Sec Hütter et al 1961, page 177, for critical comment on IMRU 3328 as type culture.) ISP 5068 from S. A. Waksman as IMRU 3328. ISP description by Group $A-6$.

Spore chain morphology: Section Rectiflexibiles. Spore chains are predominantly flexuous, but many hooks and some irregular coils similar to RA morphology are found on yeast-malt aga $r$ and glycerol-asparagine agar. Spore chains are short, 3 to 10 spores per chain, on yeastmalt agar, salts-starch agar and glycerol-asparagine agar. Sporulation may be poor, especially on oatmeal agar. Since the original characterization by Waksman (1916) describes closed spirals 7-10u in diameter, the short flexuous or hooked chains may be atypical. Spore surface: 


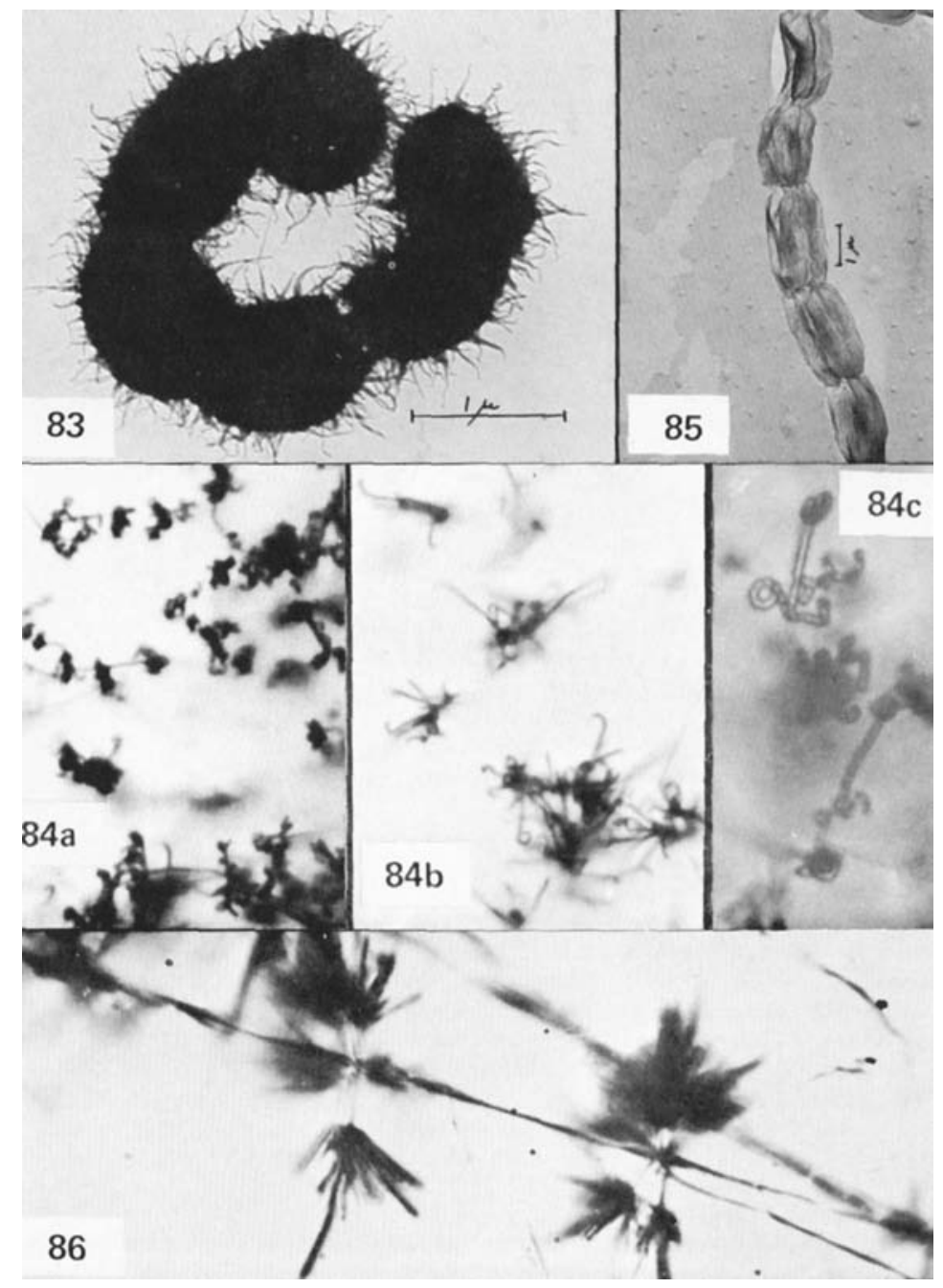

Figure 83. A. griseostramineus. Hairy to spiny spores; electron micrograph from 14 day culture on oatmeal agar. ${ }^{1}$

Figure 84. A. griseostramineus. (a, c) Tight spirals of few turns $(300 x, 900 x)$ on yeast-malt agar, 21 days. ${ }^{3}$ (b) RA morphology $(300 x)$ on yeast-malt agar, 14 days. 22

Figure 85. S. hachijoensis. Carbon replica of smooth sppres; electron micrograph from 10 day culture on yeast-malt agar.

Figure 86. S. hachijoensis. BIV (umbellate monoverticillate) morphology on glycerol-asparagine agar, 21 days. ${ }^{18}$ 
Smout. (Fig. 87).

Special morphological characteristics: Fragmentation of substrate mycelium is noted by one observer.

Color of colony: Aerial mass color in the Gray color-series on yeastmalt agar, salts-starch agar and glycerol-asparagine agar.

Reverse side of colony: No distinctive pigment (grayed yellow to yellow-brown) on yeast-malt agar, oatmeal agar, salts-starch agar or glycerol-asparagine agar; substrate pigment is not a $\mathrm{pH}$ indicator.

Color in medium: Melanoid pigments not formed in peptone-yeastiron agar, tyrosine agar and tryptone-yeast broth. No pigment found in medium in yeast-malt agar, oatmeal agar, salts-starch agar or glyce rol-asparagine agar.

Carbon utilization: D-Glucose, L-arabinose, D-xylose and D-fructose are utilized for growth. No growth or only trace of growth on sucrose, I-inositol, D-mannitol, rhamnose and raffinose.

Streptomyces hawaiiensis Cron, Whitehead, Hooper, Heinemann and Lein. Description: Cron et al. 1956, 63-67. Type strain: ATCC 12236 (K. Crook, Bristol Laboratories, personal communication). ISP 5042 from K. E. Crook as ATCC 12236. ISP description by Group A-1.

Spore chain morphology: Section Spirales, but on some media short or poorly developed spore chains are flexuous or have hooks, loops or open spirals resembling RA morphology. Mature spore chains moderately short with 3 to 10 , or sometimes more than 10 spores per chain (Fig. 89). This morphology is seen on yeast-malt agar, oatmeal agar, salts-starch agar and glycerol-asparagine agar. Spore surface: Spiny (Fig. 88).

Color of colony: Aerial mass color in the White color-series on salts-starch agar and glycerol-asparagine agar; Yellow or White series on yeast-malt agar and oatmeal agar.

Reverse side of colony: No distinctive pigment (grayed yellow to ycllow-brown) on yeast-malt agar, oatmeal agar, salts-starch agar or glycerol-asparagine agar; substrate pigment is not a pH indicator.

Color in medium: Melanoid pigments formed in peptone-yeast-iron aga $r$ and tryptone-yeast broth; pigments other than melanoids not formed in yeast-malt agar, oatmeal agar, salts-starch agar or glycerol-asparagine agar.

Carbon utilization: D-Glucose, L-arabinose, sucrose, I-inositol, D-mannitol, D-fructose, rhamnose and raffinose are utilized for growth; utilization of $\underline{D}$-xylose is doubtful.

Streptove rticillium hiroshimense (Shinobu) Farina and Locci. Descriptions: Shinobu 1955, 43-46; Farina and Locci 1966, 38 and 49;

Baldacci et al. 1966, 159-160. Type strain: 201 = Streptomyces hiroshimensis Shinobu 1955, 43. ISP 5037 from R. Shinobu as 201.

ISP description by Group A-6.

Spore chain morphology: Umbellate monoverticillate (= Streptomyces Section Verticillati, biverticillate). Mature spore chains short, generally 3 to 10 spores per chain(Fig. 91). This morphology is seen on yeast-malt agar, oatmeal agar, salts-starch agar and glycerol-asperagine agar in 14 to 21 days. Spore surface: Smooth (Fig. 90).

Color of colony: Aerial mass color in the Red color-series on yeastmalt agar, oatmeal agar and salts-starch agar. 

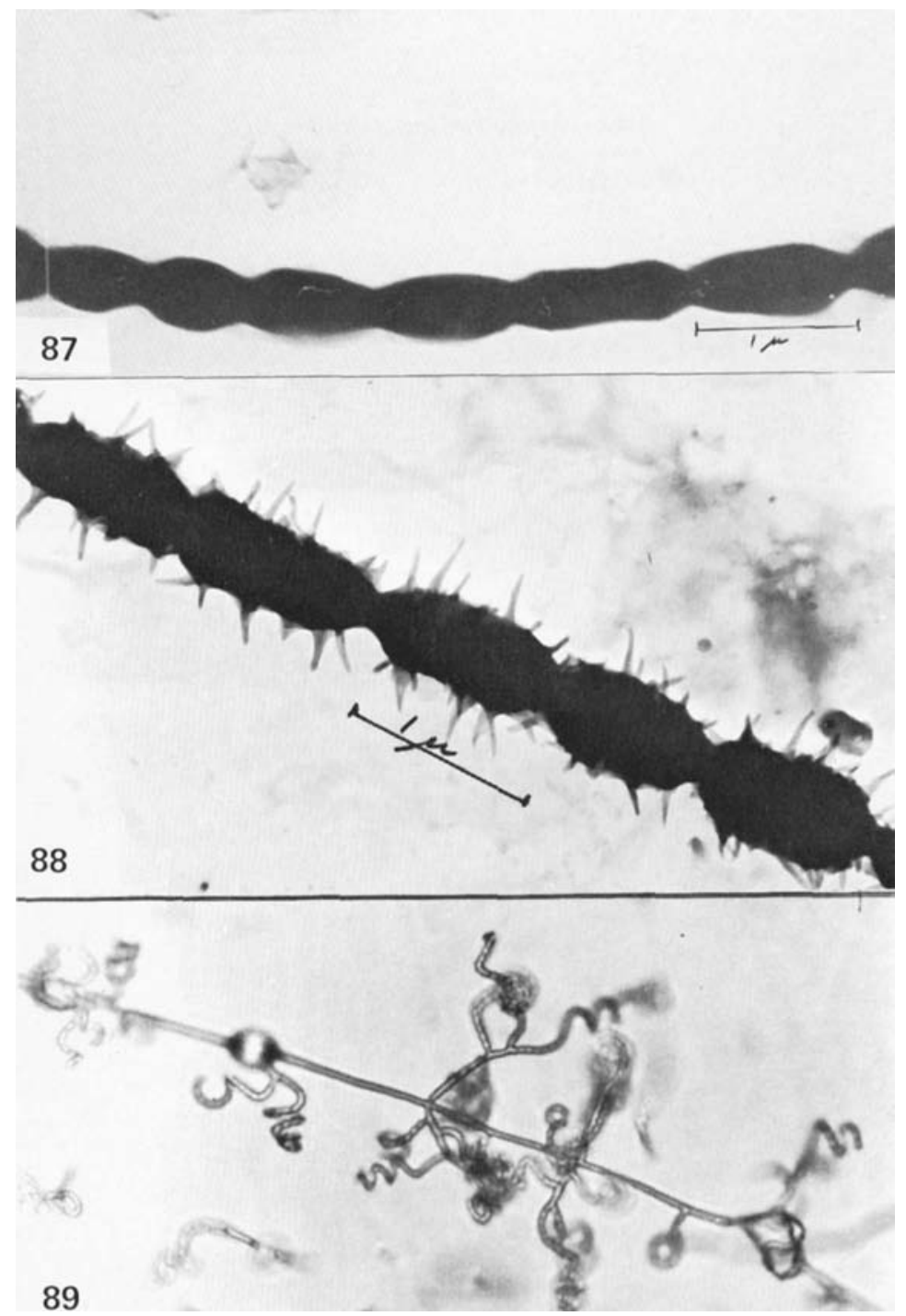

Figure 87. S. halstedii. Smooth spores; electron micrograph from 14 day culture on yeast-malt agar. 1

Figure 88. S. hawaiiensis. Spiny spore chains; electron micrograph from 14 day culture on yeast-malt agar. ${ }^{3}$

Figure 89. S. hawaiiensis. Spiral spore chains $(720 x)$ on oatmeal agar, 7 days. 3 


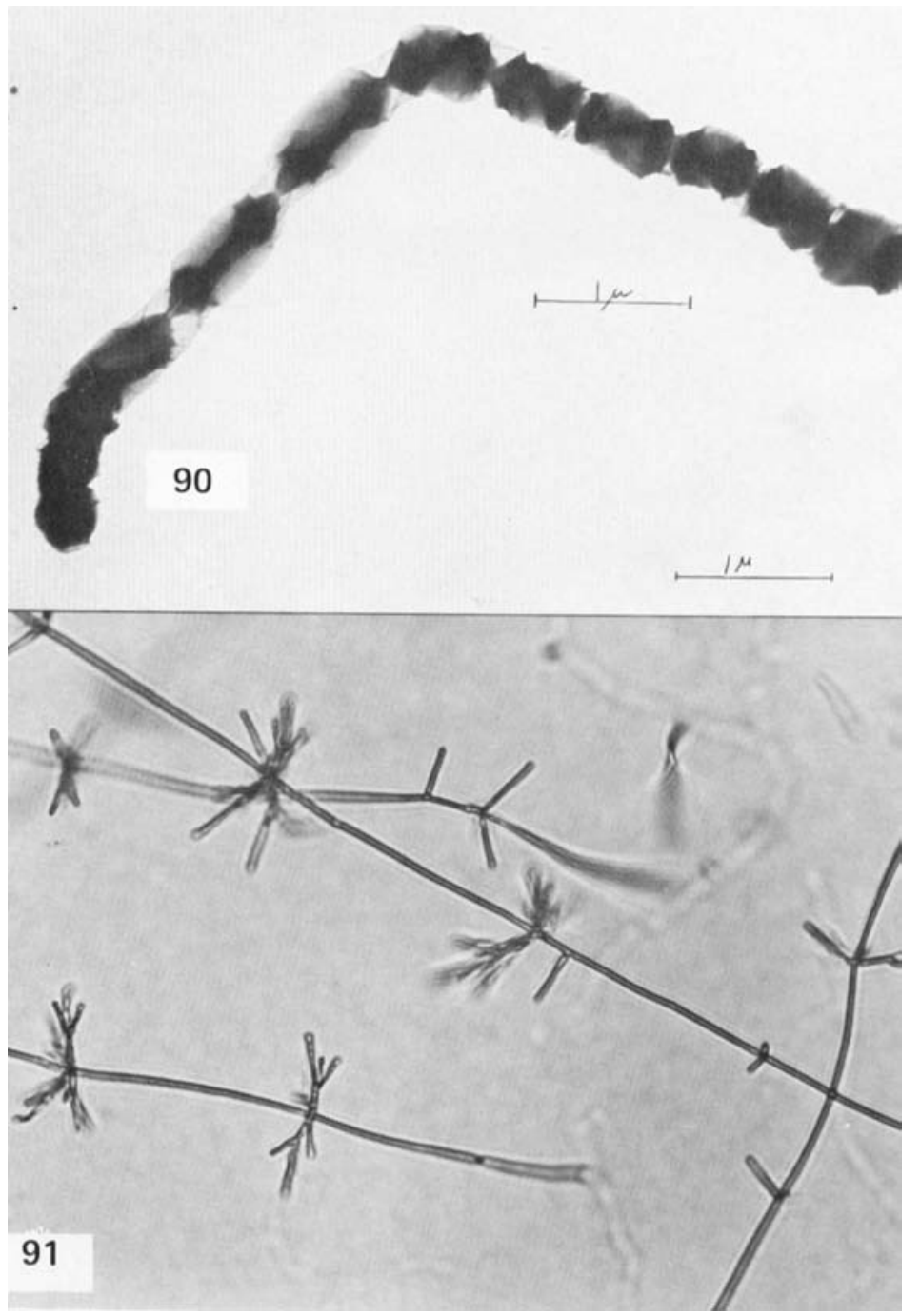

Figure 90. Streptoverticillium hiroshimense. Smooth spores; electron micrograph from 14 day culture on oatmeal agar. ${ }^{1}$

Figure 91. Streptoverticillium hiroshimense. BIV (monoverticillate umbellate) morphology (1200x) on oatmeal agar, 14 days. ${ }^{21}$ 


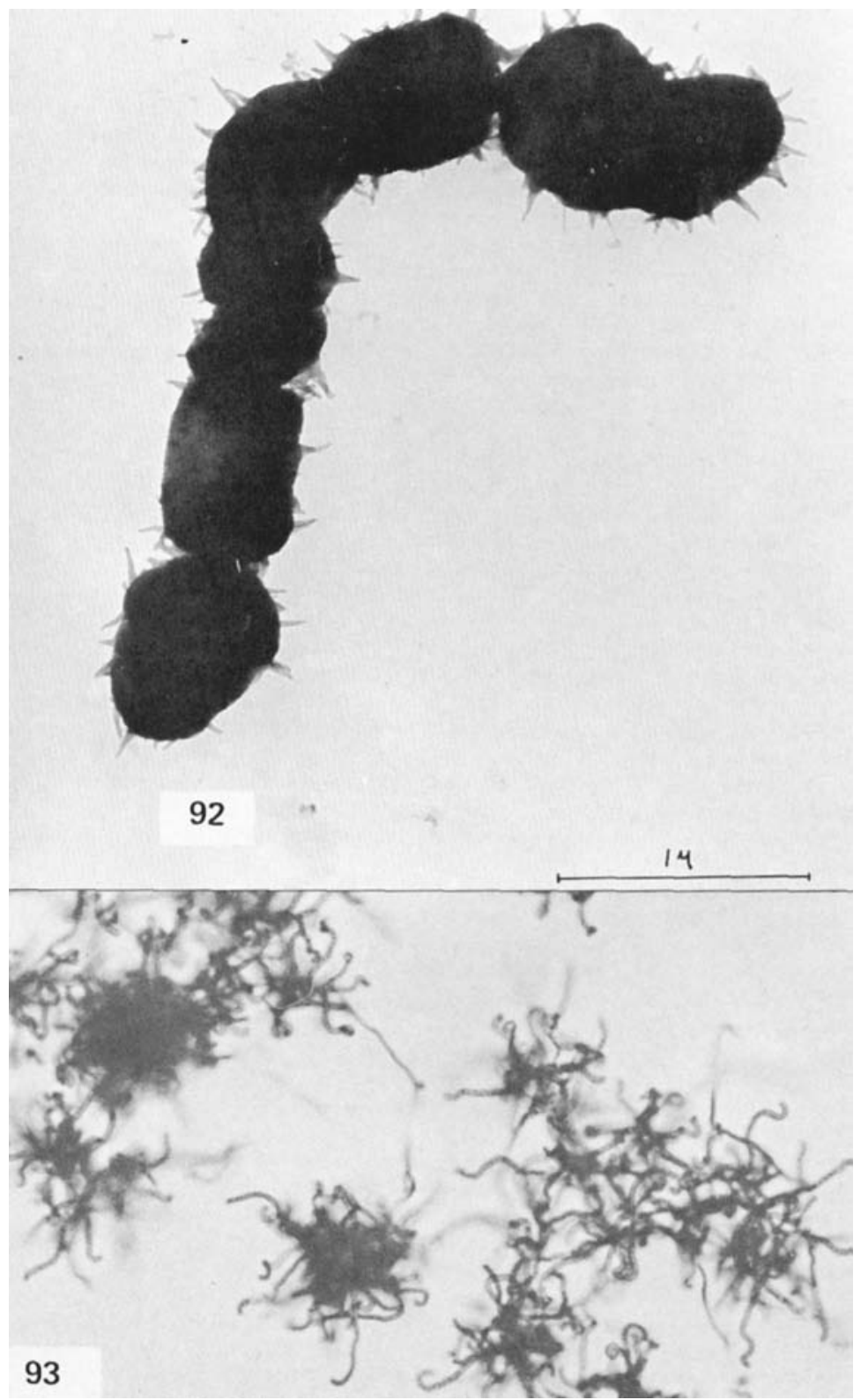

Figure 92. S. hirsutus. Spiny spores; electron micrograph from 14 day culture on yeast-malt agar. ${ }^{1}$

Figure 93. S. hirsutus RA to Spiral spore chains $(400 \mathrm{x})$ on yeastmalt agar, 10 days. 19 
Reverse side of colony: Grayed yellow is modified by red on oatmeal agar, salts-starch agar and glycerol-asparagine agar; or yellow-brown is modified by red on yeast-malt agar. Substrate pigment is not a strong $\mathrm{pH}$ indicator. (One observer reports slight change from pink to brown with $\mathrm{NaOH}$ on oatmeal agar.)

Color in medium: Melanoid pigments formed in peptone-yeast-iron agar and tryptone-yeast broth; pigments other than melanoids not formed in yeast-malt agar, oatmeal agar, salts-starch agar or glycerolasparagine agar.

Carbon utilization: D-Glucose, I-inositol and D-fructose are utilized for growth. No growth or only trace of growth on L-arabinose, sucrose, D-xylose, D-mannitol, rhamnose and raffinose.

Streptomyces hirsutus Ettlinger, Corbaz and Hütter. Description: Ettlinger et al. 1958, 344-345. Type strain: ETH 16660 (ibid.). ISP 5095 from R. Hütter as ETH 16660. ISP description by Group A - 5 .

Spore chain morphology: Section Retinaculiaperti or Spirales. Flexuous spore chains and chains terminating in hooks and loops are common; well developed spirals of more than 1 or 2 turns are rare. Mature spore chains generally 10 to 30 spores per chain (Fig. 93). This morphology is seen on yeast-malt agar, oatmeal agar, salts-starch agar and glycerol-asparagine agar. Spore surface: Spiny (Fig. 92).

Color of colony: Aerial mass color in the Green color-series on yeast-malt agar, oatmeal agar, salts-starch agar and glycerol-asparagine agar.

Reverse side of colony: No distinctive pigment (grayed yellow to grayed greenish yellow) on yeast-malt agar, oatmeal agar, saltsstarch agar or glycerol-asparagine agar; substrate pigment is not a $\mathrm{pH}$ indicator.

Color in medium: Melanoid pigments not formed in peptone-yeastiron agar and tyrosine agar. No pigment found in medium in yeastmalt agar, oatmeal agar, salts-starch agar or glycerol-asparagine agar.

Carbon utilization: D-Glucose, L-arabinose, sucrose, D-xylose, I-inositol, D-mannitol, D-fructose, rhamnose and raffinose are utilized for growth.

Actinomyces kurssanovii Preobrazhenskaya, Kudrina, Ryabova and Blinov, Description: Preobrazhenskaya et al. in Gauze ef al. 1957, 151 and 156. Type strain: 10294 (Preobrazhenskaya, personal communication). Streptomyces kurssanovii (Preobrazhenskaya et al.) Pridham et al. 1958, 69. ISP 5162 from T.P. Preobrazhenskaya as 10294. ISP description by Group A-8.

Spore chain morphology: Section Retinaculiaperti. Spirals are not observed on ISP media. Hooks and loops in the short spore chains are of small diameter and the refore a re not truly representative of $\mathrm{RA}$ morphology (Fig. 95). The original description (Preobrazhenskaya et al., ibid.) characterizes this culture as spiral. Mature spore chains moderately short with 3 to 10 , or sometimes more than 10 , spores per chain. This morphology is seen on yeast-malt agar, oatmeal agar, salts-starch agar; sporulation may be unsatisfactory on glycerol-asparagine agar. Spore surface: Smooth (Fig. 94).

Color of colony: Aerial mass color in the Gray color-series on yeast-malt agar and salts-starch agar. 


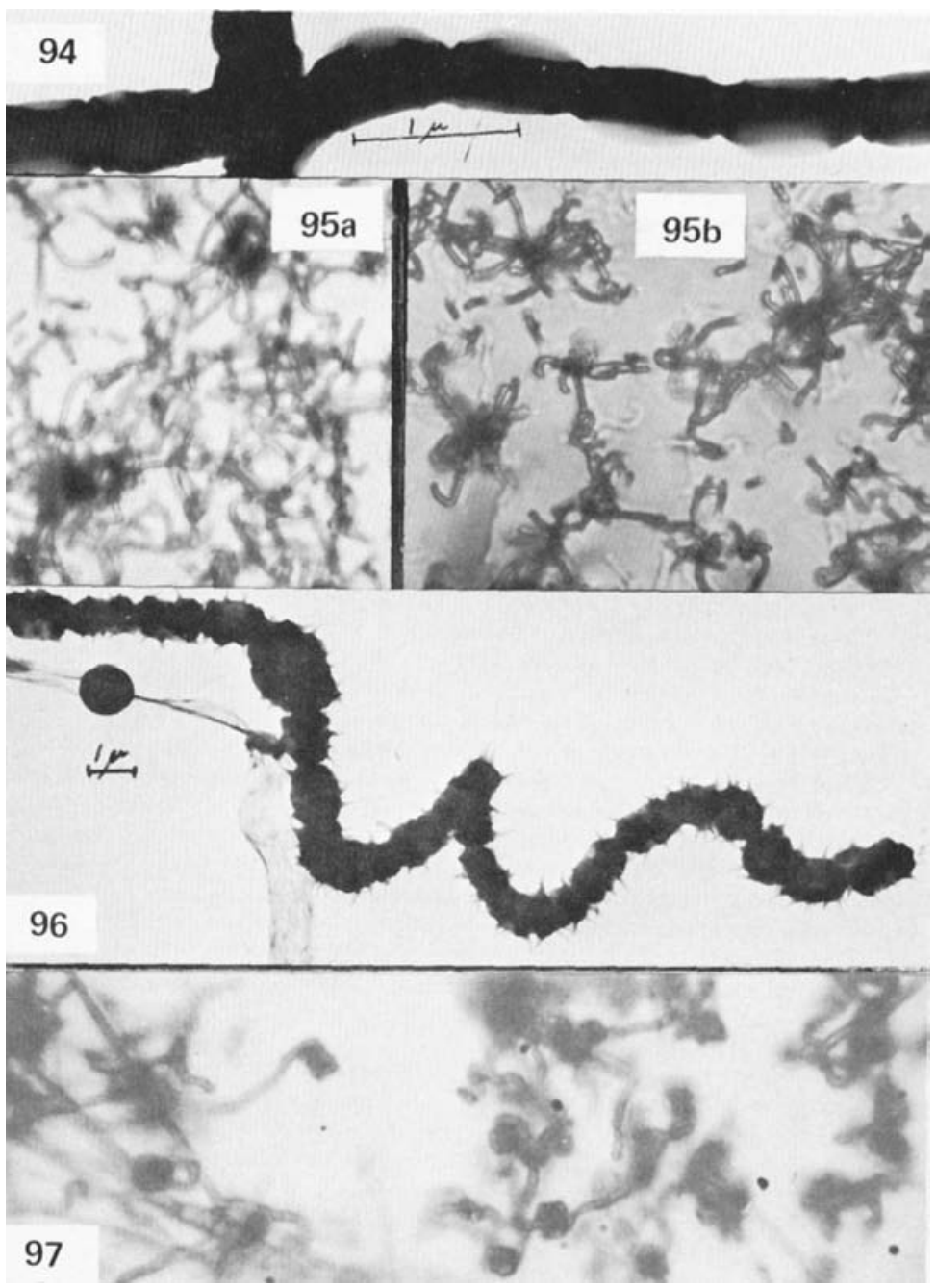

Figure 94. A. kurssanovii. Smooth spores; electron micrograph from 14 day culture on yeast-malt agar. ${ }^{\text {i }}$

Figure 95. A. kurssanovii. Atypical RA or Spiral morphology. The hooks on short spore chains seen here are not characteristic of RA cultures (see Figure 69). They may represent incomplete spirals. (a) Yeast-malt agar, 21 days $(1200 x) \cdot{ }^{23}$ (b) Salts-starch agar, 21 days $(1000 x)^{24}$

Figure 96 . S. Lanatus. Spiny spores; electron micrograph from 10 day culture on yeast-malt agar. 17

Figure 97. S. lanatus. Spiral spore chains (1000x) on oatmeal agar, 21 days. 18 
Reverse side of colony: No distinctive pigment (grayed yellow to yellow-brown) on oatmeal agar, salts-starch agar or glycerol-asparagine agar, but yellow-brown is modified by red on yeast-malt agar. Substrate pigment is not a $\mathrm{pH}$ indicator.

Color in medium: Melanoid pigments formed in peptone-yeast-iron agar; pigments other than melanoids not formed in yeast-malt agar, oatmeal agar, salts-starch agar or glycerol-asparagine agar.

Carbon utilization: D-Glucose, L-arabinose, sucrose, D-xylose, Dfructose and raffinose are utilized for growth. No growth or only trace of growth on I-inositol, D-mannitol and rhamnose.

Streptomyces lanatus Frommer. Description: Frommer 1959, 203205. Type strain: SV 1944 (ibid.). ISP 5090 from C. W. He sseltine as NRRL B-2291 from W. Frommer as SV 1944. ISP description by Group A-10.

Spore chain morphology: Section Spirales Mature spore chains generally 10 to 50 spores per chain (Fig. 97). This morphology is found on yeast-malt agar, oatmeal agar, salts-starch agar and glycerolasparagine agar. Spore surface: Spiny (Fig. 96).

Color of colony: Aerial mass color in the Blue color-series on yeastmalt agar, oatmeal agar and salts-starch agar.

Reverse side of colony: No distinctive pigment on yeast-malt agar, oatmeal agar, salts-starch agar or glycerol-asparagine agar; substrate pigment is not a pH indicator.

Color in medium: Melanoid pigments formed in peptone-yeast-iron agar, tyrosine agar and tryptone-yeast broth. Pigments other than yellow or brown not formed in yeast-malt agar, oatmeal agar, saltsstarch agar or glycerol-asparagine agar.

Carbon utilization: $\underline{D}$-Glucose, L-arabinose, sucrose, D-xylose, $\underline{I}$-inositol, D-mannitol, $\underline{D}$-fructose, rhamnose and raffinose are utilized for growth.

Actinomyces lateritius Sveshnikova. Description: Sveshnikova in Gauze et al. 1957, 68 and 70. Type strain: 6993 (Preobrazhenskaya, personal communication). Streptomyces lateritius (Sveshnikova) Pridham et al. 1958, 67. ISP 5163 from T.P. Preobrazhenskaya as 6993. ISP description by Group A-8.

Spore chain morphology: Section Retinaculiaperti, but spore chains representative of Section $\underline{\mathrm{RF}}$ a re also common. Mature spore chains generally 10 to 50 spores per chain; longer chains are sometimes observed(Fig. 99). This morphology is seen on salts-starch agar. Aerial mycelium is not produced on glycerol-asparagine agar and may be poorly developed on yeast-malt agar and oatmeal agar. Spore surface: Warty (Fig. 98).

Color of colony: Aerial mass color in the Red color-series on saltsstarch agar. When sporulating aerial mycelium is formed on yeastmalt agar or oatmeal agar, it is in the Red color-series.

Reverse side of colony: Grayed yellow is modified by violet or blue (see soluble pigment) on oatmeal agar, salts-starch agar and glycerolasparagine agar. Reverse color is changed from violet to blue by addition of $0.05 \mathrm{~N} \mathrm{NaOH}$, and from violet or blue to red with $0.05 \mathrm{~N} \mathrm{HCl}$.

Color in medium: Melanoid pigments formed in peptone-yeast-iron agar. Blue or violet pigments found in medium in oatmeal agar, saltsstarch agar and glycerol-asparagine agar. This pigment is pH sensitive 


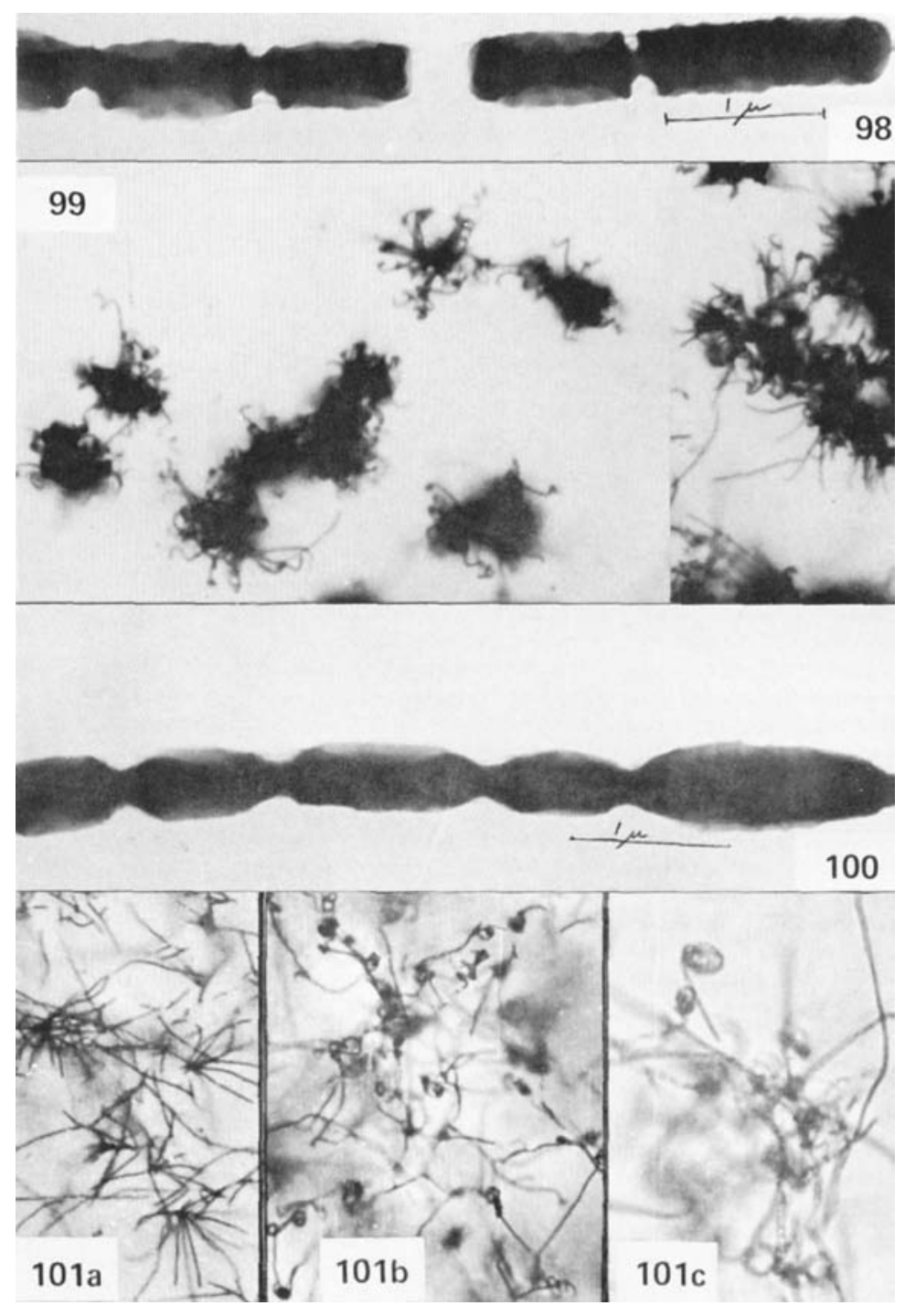

Figure 98. A. Lateritius. Warty spores: electron micrograph from 14 day culture on oatmeal agar. ${ }^{1}$

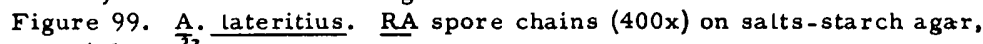
14 days. ${ }^{22}$

Figure 100. S. Lavendulae Smooth spores; electron micrograph from 14 day culture on oatmeal agar. ${ }^{1}$

Figure 10l. S. lavendulae. RA morphology. (a) Straight spore chains $(190 x)$ on oatmeal agar, 14 days. (b, c) Loops and spirals $(190 x, 320 x)$ on salts-starch agar, 20 days. ${ }^{25}$ 
when tested with $0.05 \mathrm{~N} \mathrm{NaOH}$ or $\mathrm{HCl}$. Violet pigment is changed to blue by $0.05 \mathrm{~N} \mathrm{NaOH}$ and to red by $0.05 \mathrm{~N} \mathrm{HCl}$.

Carbon utilization: D-Glucose, L-arabinose, D-xylose, D-fructose and rhamnose are utilized for growth. No growth or only trace of growth on sucrose, D-mannitol and raffinose. Utilization of $\underline{I}$-inositol is doubtful.

Streptomyces lavendulae (Waksman and Curtis) Waksman and Henrici. Descriptions: Actinomyces lavendulae Waksman and Curtis 1916, 126; Waksman 1919, 130-132; Streptomyces lavendulae (Waksman and Curtis) Waksman and Henrici 1948, 944. See also Pridham, Lyons and Seckinger 1965, 225-226. Type strain: IMRU 3440 (Waksman 1961, 234235; neotype, Pridham et al. 1965, 225). ISP 5069 from S. A. Waksman as IMRU 3440-8. ISP description by Group A-6.

Spore chain morphology: Section Retinaculiaperti with many $\underline{R} F$ spore chains as well as coils of wide diameter and some spirals. Mature spore chains 10 to 50 spores per chain; longer chains are often observed (Fig. 101). This morphology is seen on yeast-malt agar, oatmeal agar, salts-starch agar and glycerol-asparagine agar. Spore surface: Smooth (Fig. 100).

Color of colony: Aerial mass color in the Red (or Gray) color-series on yeast-malt agar, oatmeal agar, salts-starch agar and glycerolasparagine agar. Characteristic color is between 3 ge (light grayish yellowish brown) and $4 \mathrm{ec}$ or 5 ec (grayish yellowish pink) color tabs of Tresner-Backus Color Wheels.

Reverse side of colony: No distinctive pigment on yeast-malt agar, oatmeal agar, salts-starch agar or glycerol-asparagine agar; substrate pigment is not a $\mathrm{pH}$ indicator. (One observer reports slight change from yellowish brown to greenish brown by addition of $0.05 \mathrm{~N} \mathrm{NaOH}$.)

Color in medium: Melanoid pigments formed in peptone-yeast-iron agar and usually in tyrosine agar and tryptone-yeast broth. Pigments other than melanoids not formed in yeast-malt agar, oatmeal agar, salts-starch agar or glycerol-asparagine agar.

Carbon utilization: D-Glucose is utilized for growth. No growth or only trace of growth on L-arabinose, sucrose, Dxylose, I-inositol, D-mannitol, rhamnose and raffinose. Limited growth with $\underline{D}$-fructose.

Streptomyces limosus Lindenbein. Description: Lindenbein 1952, 379-380. Type Strain: Bö. Br. 136 (ibid.). ISP 5131 from P. Wilde as Bö. Br. 136 (ETH 23898). ISP description by Group A-4.

Spore chain morphology: Section Rectiflexibiles. Mature spore chains on suitable media generally 10 to 50 spores per chain; longer chains a re sometimes observed. This morphology is seen on yeast-malt agar, salts-starch agar and glycerol-asparagine agar. Spore surface: Smooth (Fig. 102).

Color of colony: Aerial mass color in the Yellow color-series on yeast-malt agar, oatmeal agar, salts-starch agar and glycerol-asparagine aga $r$.

Reverse side of colony: No distinctive pigment on yeast-malt agar, oatmeal agar, salts-starch agar or glycerol-asparagine agar; substrate pigment is not a pH indicator.

Color in medium: Melanoid pigments not formed in peptone-yeastiron agar and tyrosine agar; no pigment found in medium in yeast-malt 


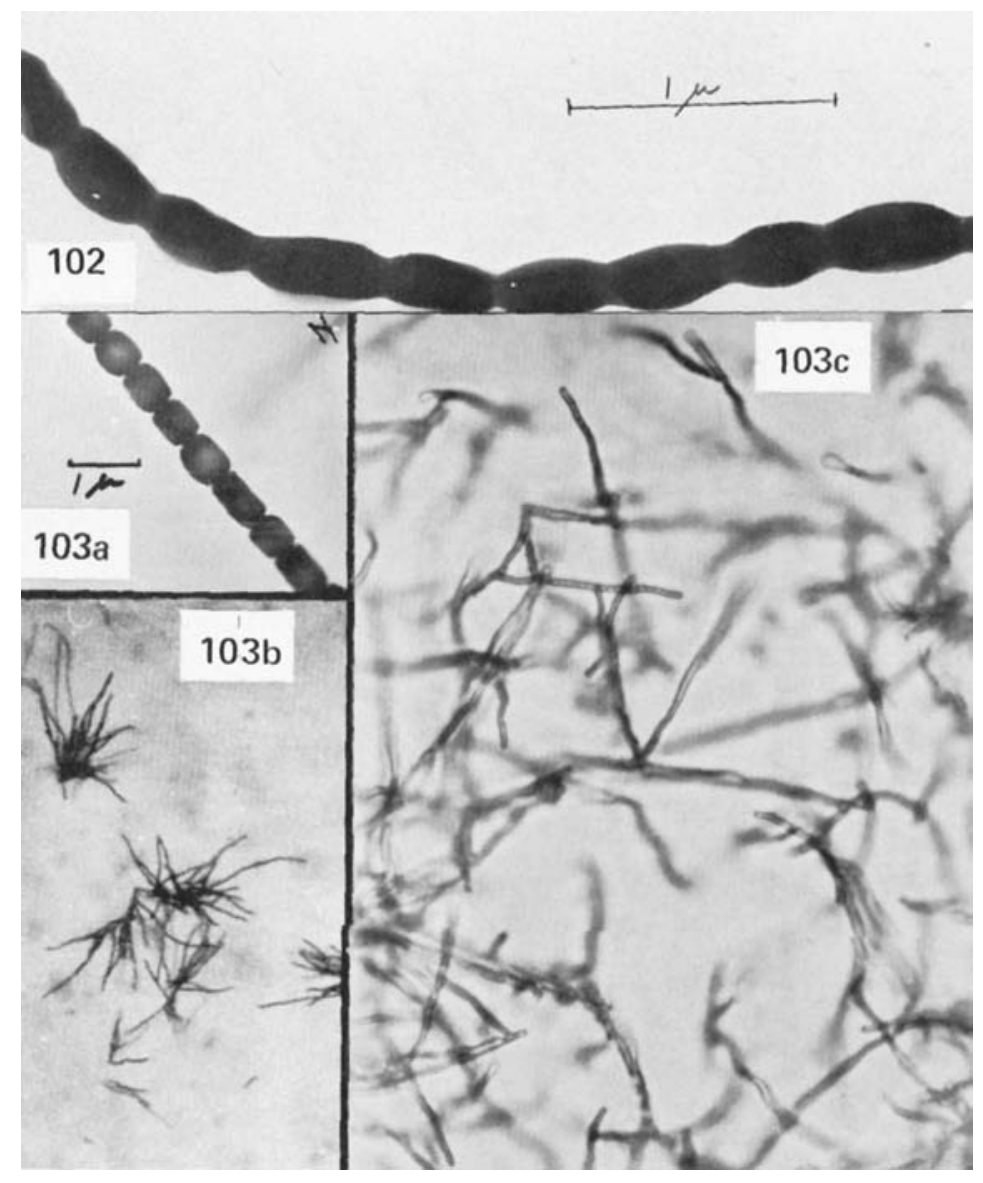

Figure 102. S. limosus. Smooth spores; electron micrograph from 14 day culture on yeast-malt agar. ${ }^{2}$

Figure 103. S. Lipmanii. (a) Smooth spores; electon micrograph from 20 day culture on oatmeal agar. ${ }^{25}$ (b) RF spore chains (190x) on salts-starch agar, 14 days. ${ }^{25}$ (c) RF spore chains $(1200 \mathrm{x})$ on yeast-malt agar. 21 . 
agar, oatmeal agar, salts-starch aga $r$ or glycerol-asparagine agar.

Carbon utilization: D-Glucose, L-arabinose, D-xylose, D-mannitol and D-fructose are utilized for growth. No growth or only trace of growth on sucrose, I-inositol, rhamnose and raffinose.

Streptomyces lipmanii (Waksman and Curtis) Waksman and Henrici. Descriptions: Actinomyces lipmanii Waksman and Curtis 1916, 120 and 123; Waksman 1919, 132-134; Streptomyces lipmanii (Waksman and Curtis) Waksman and Henrici 1948, 952. Type strain: IMRU 3331 (Waksman, 1961). ISP 5070 from S. A. Waksman as IMRU 3331. ISP description by Group $A-6$.

Spore chain morphology: Section Rectiflexibiles. Mature spore chains generally 10 to 50 spores per chain; longer chains are sometimes observed on suitable media (Fig. 103). This morphology is seen on yeast-malt agar and glycerol-asparagine agar. Sporulation may be poor on oatmeal agar and salts-starch agar. Spore surface: Smooth (Fig. 103).

Color of colony: Aerial mass color in the Yellow color-series on yeast-malt agar, salts-starch agar and glycerol-asparagine agar.

Reverse side of colony: No distinctive pigment on oatmeal agar, salts-starch agar or glycerol-asparagine agar; yellow to yellow-brown on yeast-malt agar. Substrate pigment is not a pH indicator.

Color in medium: Melanoid pigments not formed in peptone-yeastiron agar and tyrosine agar. No pigment found in medium in yeast-malt agar, oatmeal agar, salts-starch agar or glycerol-asparagine agar.

Carbon utilization: D-Glucose, D-xylose, D-mannitol, D-fructose and rhamnose are utilized for growth. No growth or only trace of growth on L-arabinose, I-inositol and raffinose. Utilization of sucrose is doubtful.

Actinomyces litmocidini Ryabova and Preobrazhenskaya. Description: Ryabova and Preobrazhenskaya in Gauze et al. 1957, 186 and 187. Type strain: 1823/55 (Preobrazhenskaya, personal communication). Streptomyces litmocidini (Ryabova and Preobrazhenskaya) Pridham et al. 1958, 65. ISP 5164 from T.P. Preobrazhenskaya as 1823/55. ISP description by Group A-8.

Spore chain morphology: Section Rectiflexibiles with some straight spore chains and occasional hooks or primitive spirals suggestive of Section RA. Mature spore chains generally 10 to 50 spores per chain; longer chains are often observed (Fig. 105). This morphology is seen on yeast-malt agar, oatmeal agar, salts-starch agar and glycerol-asparagine agar. Spore surface: Smooth (Fig. 104).

Color of colony: Aerial mass color in the Gray color-series on yeast-malt agar, oatmeal agar, salts-starch agar and glycerol-asparagine agar.

Reverse side of colony: Colorless or characteristic grayed yellow on oatmeal agar, but the grayed yellow is modified by violet or red (depending on $\mathrm{pH}$ ) on salts-starch agar, glycerol-asparagine agar and sometimes on yeast-malt agar. Reverse color is changed from violet to blue by addition of $0.05 \mathrm{~N} \mathrm{NaOH}$, and from violet to red with 0.05 $\mathrm{N} \mathrm{HCl}$.

Color in medium: Melanoid pigments formed in peptone-yeast-iron agar. Violet, blue or red pigments found in medium in yeast-malt agar, 


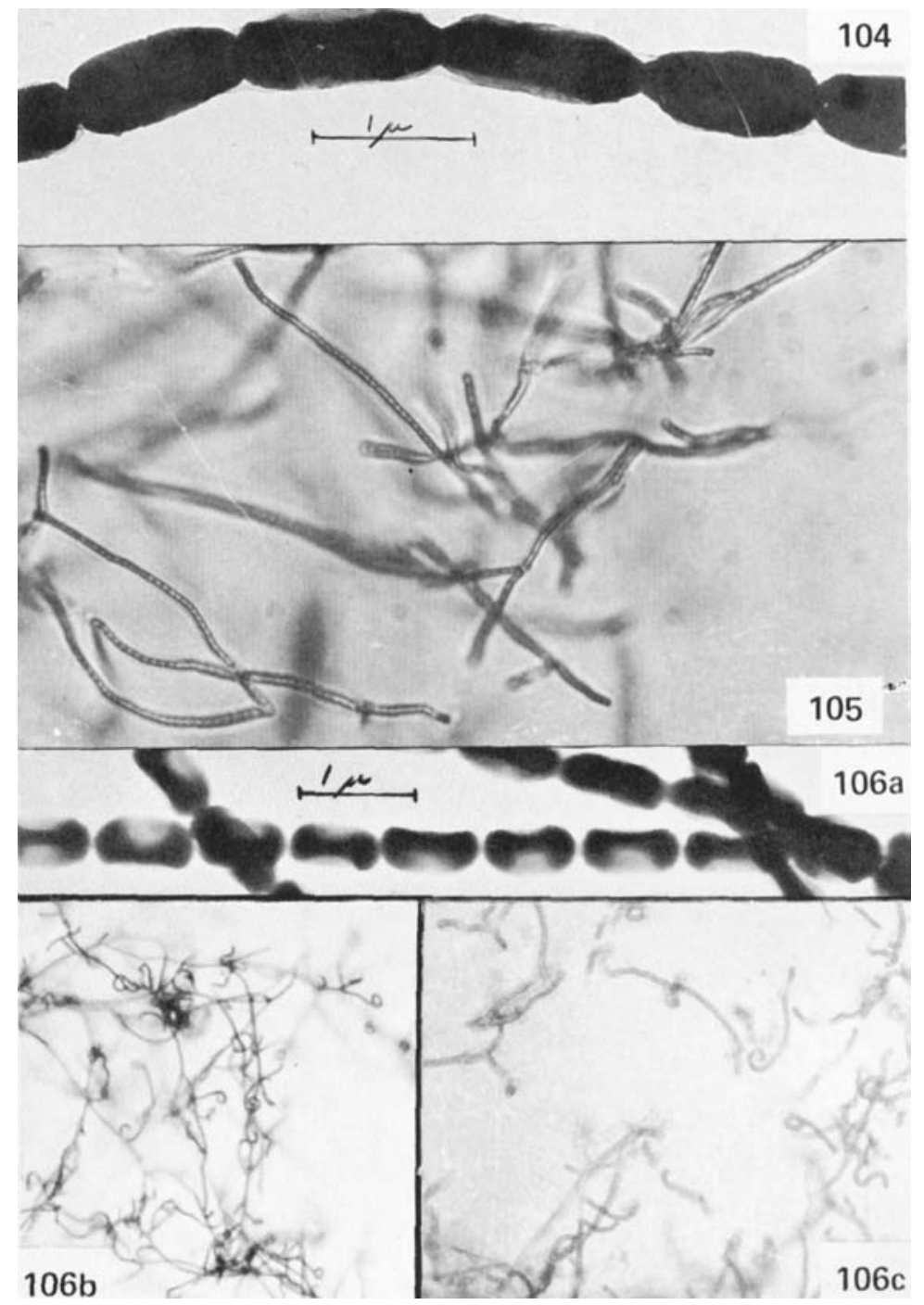

Figure 104. A. Litmocidini. Smooth spores; electron micrograph on 14 day culture on oatmeal agar. ${ }^{1}$

Figure 105. A. Litmocidini. $\frac{R F}{24}$ spore chains $(1200 x)$ on glycerola sparagine agar, 21 days. 24

Figure 106. A. Luridus. (a) Smooth spores; electron micrograph from 14 day culture on salts - starch agar. ${ }^{26}$ (b) $\underline{R A}$ spore chains $(300 x)$ on salts-starch agar. ${ }^{4}$ (c) RA spore chains $(625 x)$ on oatme al agar. 5 
salt-starch agar and glycerol-asparagine agar; violet pigment is changed to blue by $0.05 \mathrm{~N} \mathrm{NaOH}$ and to red by addition of $0.05 \mathrm{~N} \mathrm{HCl}$.

Carbon utilization: D-Glucose and L-arabinose are utilized for growth. No growth or only trace of growth on sucrose, I-inositol, Dmannitol, rhamnose and raffinose. Variable reports on growth with D-xylose and D-fructose.

Actinomyces luridus Krasil'nikov, Koreniako, Meksina, Valedinskai and Vesselov. Description: Krasil'nikov et al. 1957, 558-564. Type strain: INMI 111 (ibid, ). Streptomyces luridus (Krasil'nikov et al.) Waksman 1961, 237. ISP 5081 from V. D. Kuznetsov for N. A.

Krasil'nikov as INMI 111 . ISP description by Group A-11.

Spore chain morphology: Section Retinaculiaperti with characteristic range of flexuous spore chains, hooks, loops and occasional spirals (spirals rare) (Fig. 106). Mature spore chains generally 10 to 50 spores per chain; longer chains are often observed. This morphology is seen on yeast-malt agar, oatmeal agar, salts-starch agar and glycerol-asparagine agar. Spore surface: Smooth (Fig. 106).

Color of colony: Aerial mass color in the Red color-series on yeastmalt agar in 14 days. Sporulating aerial mycelium in the Red colorseries usually develops on oatmeal agar, salts-starch agar and glycerolasparagine aga $r$ in 21 days.

Reverse side of colony: No distinctive pigment on yeast-malt agar, oatmeal agar, salts-starch agar or glycerol-asparagine agar; substrate pigment is not a $\mathrm{pH}$ indicator.

Color in medium: Melanoid pigments formed in peptone-yeast-iron agar, tyrosine agar and tryptone yeast broth. Pigments other than melanoids not formed in yeast-malt agar, oatmeal agar, salts-starch agar or glycerol-asparagine agar.

Carbon utilization: D-Glucose, L-arabinose, D-x ylose and I-inositol are utilized for growth. No growth or only trace of growth on sucrose, D-mannitol, rhamnose and raffinose. Utilization of $\underline{D}$-fructose is doubtful.

Streptomyces macrosporeus Ettlinger, Corbaz and Hütter. Description: Ettlinger et al. 1958, 346-347. Type strain: ETH 7534 (ibid.). ISP strain 5096 from R. Hütter as ETH 7534. ISP description by Group A-7.

Spore chain morphology: Spore chain morphology varies with length of spore chain. Short straight chains or short chains with a single curve or hook (Section Rectiflexililes) are predominant on yeast-malt agar, oatmeal agar and glycerol-asparagine agar. Longer chains on salts-starch agar may show loops and irregular spirals. Mature spore chains short, generally 3 to 10 spores per chain (Fig. 108). Spore surface: Spiny (Fig. 107).

Color of colony: Aerial mass color in the Gray color-series on yeastmalt agar, oatmeal agar and salts-starch agar.

Reverse side of colony: No distinctive pigment (grayed yellow or grayed greenish yellow) on yeast-malt agar, oatmeal agar, salts-starch agar and glycerol-asparagine agar. Reverse color is not a pH indicator.

Color in medium: Melanoid pigments not formed in peptone-yeastiron agar, tyrosine agar or tryptone-yeast broth. No pigment found in 


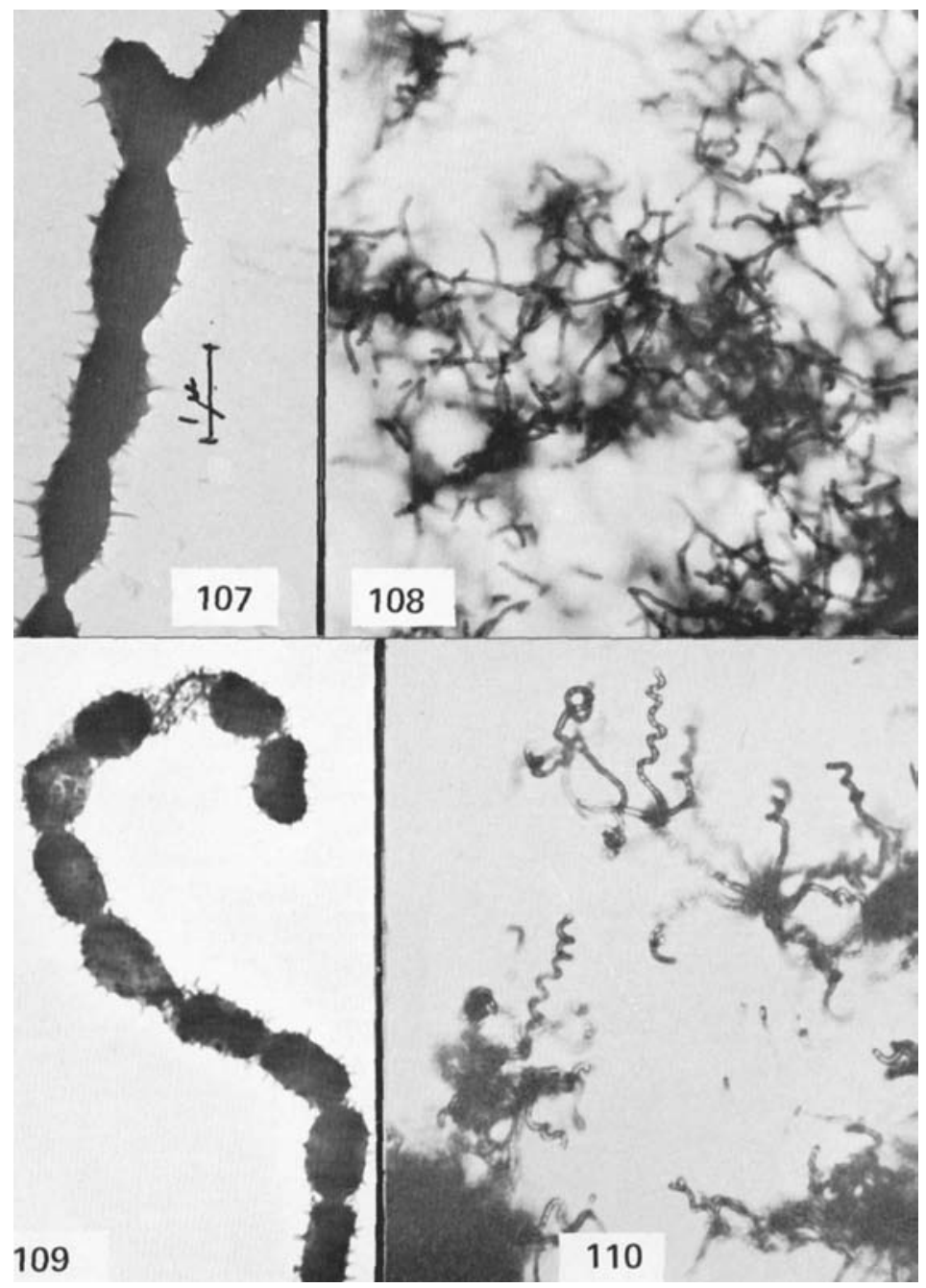

Figure 107. S. macrosporeus. Spiny spores from 14 day culture on yeast-malt agar.

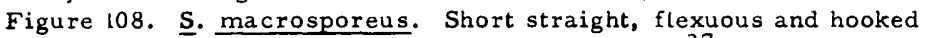
spore chains $(360 \mathrm{x})$ on oatmeal agar, 14 days. 27

Figure 109. A malachticus. Spiny spores; electron micrograph from $2 \mathrm{l}$ day culture on salts - starch agar.

Figure 110. A. malachiticus. Spiral spore chains $(400 \mathrm{x})$ on salts starch agar, 14 days. ${ }^{10}$ 
medium in yeast-malt agar, oatmeal agar, salts-starch agar or glycerol-asparagine agar.

Carbon utilization: D-Glucose, L-arabinose, D-xylose, I-inositol, D-mannitol, D-fructose and rhamnose are utilized for growth. No growth or only trace of growth on sucrose and raffinose.

Actinomyces malachiticus Preobrazhenskaya and Ryabova. Description: Preobrazhenskaya and Ryabova in Gauze et al. 1957, 162 and 164. Type strain: 399/54 (Preobrazhenskaya, personal communication). Streptomyces malachitus (sic) (Preobrazhenskaya and Ryabova) Pridham et al. 1958, 68. ISP 5167 from T.P. Preobrazhenskaya as 399/54. ISP description by Group A-9.

Spore chain morphology: Section Spirales. Mature spore chains generally 10 to 50 spores per chain; longer chains are sometimes observed (Fig. 110). This morphology is seen on yeast-malt agar, oatmeal agar, salts-starch agar and glycerol-asparagine agar; but sporulating aerial mycelium may be poorly developed on glycerol-asparagine agar. Spore surface: Spiny (Fig. 109).

Color of colony: Aerial mass color in the Gray color-series on yeastmalt agar, oatmeal agar and salts-starch agar; white aerial mycelium is typically present on the same media. One observer, only, placed this culture in the Red series (color tab $5 \mathrm{cb}$, grayish yellowish pink) at 21 days on yeast-malt agar, oatmeal agar and salts-starch agar.

Reverse side of colony: No distinctive pigment (grayed yellow to grayed greenish yellow) on yeast-malt agar, oatmeal agar, salts-starch agar or glycerol-asparagine agar; substrate pigment is not a $\mathrm{pH}$ indicator.

Color in medium: Melanoid pigments not formed in peptone-yeastiron aga $r$ and ty rosine agar. No pigment found in medium in yeastmalt agar, oatmeal agar, salts-starch agar or glycerol-asparagine agar.

Carbon utilization: D-Glucose, L-arabinose, sucrose, D-xylose, $\underline{I}$-inositol, D-mannitol, $\underline{D}-$ fructose, rhamnose and raffinose are utilized for growth.

Streptomyces massasporeus Shinobu and Kawato. Description: Shinobu and Kawato 1959, 283-288. Type strain: 602 (ibid.). ISP 5035 from R. Shinobu as 602. ISP description by Group A-4.

Spore chain morphology: Section Spirales, but spore chains representative of Section RA are also present. Mature spore chains generally 10 to 50 spores per chain (Fig. 112). This morphology is seen on yeastmalt agar, oatmeal agar, salts-starch agar and glycerol-asparagine agar. Spore surface: Smooth (Fig. 111).

Special morphological characteristics: Spores frequently coalesce to form moist masses of spores. Small masses may form from single spiral spore chains or large masses may form by the coalescence of many spirals (Fig. 113).

Color of colony: Aerial mass color in the Red color-series on yeastmalt agar, salts-starch agar and glycerol-asparagine agar; Red or Violet series on oatmeal agar.

Reverse side of colony: Grayed yellow modified by red or violet (see $\mathrm{pH}$ ) on yeast-malt agar, oatmeal agar, salts-starch agar and glycerolasparagine agar. Reverse color is changed from violet to red by addition of $0.05 \mathrm{~N} \mathrm{HCl}$ and from red or reddish violet to blue violet by addi- 


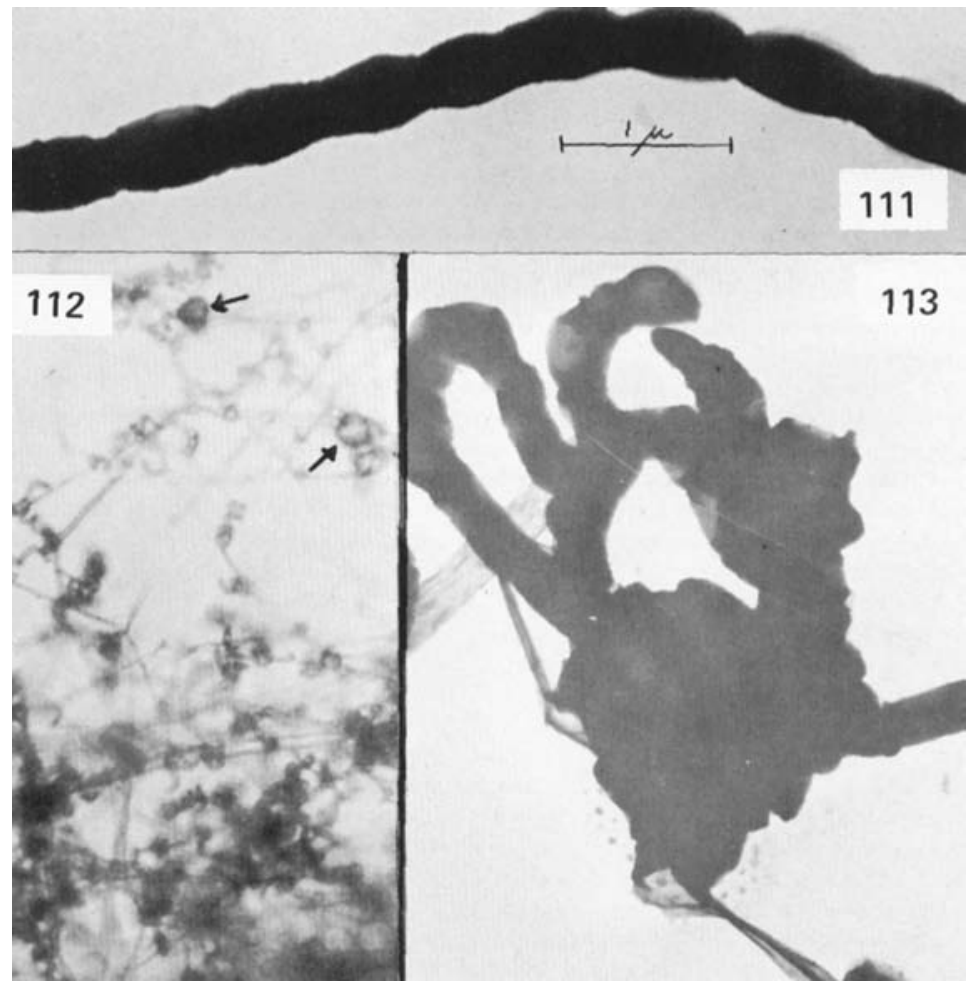

Figure 111. S. massasporeus. Smooth spores; electron micrograph from 14 day culture on oatmeal agar. ${ }^{1}$

Figure 112. S. massasporeus. Spiral spore chains on oatmeal agar, 14 days. Arrows indicate large coalesced masses of spores. 14

Figure 113. S. massasporeus. Flectron micrograph of coalesced spore mass. ${ }^{11}$ 
tion of $0.05 \mathrm{~N} \mathrm{NaOH}$.

Color in medium: Melanoid pigments formed in peptone-yeast-iron agar. Red pigments found in medium in oatmeal agar and glycerolasparagine agar. One observer detected red pigment in yeast-malt agar, oatmeal agar, salts-starch agar and glycerol-asparagine agar in 14 days and violet pigment in these media at 21 days. He also noted a change in color from violet to blue by addition of $0.05 \mathrm{~N} \mathrm{NaOH}$ and from violet to red by addition of $0.05 \mathrm{~N} \mathrm{HCl}$.

Carbon utilization: D-Glucose, L-arabinose, sucrose, $\underline{D}-x y l o s e$, $\underline{I}$-inositol, D-mannitol, D-fructose, rhamnose and raffinose are utilized for growth.

Streptomyces michiganensis Corbaz, Ettlinger, Keller-Schierlein and Zahner. Description: Corbaz et al. 1957b, 205-206. Tvpe strain: ETH 9001 (ibid.). ISP 5015 from R. Hütter as ETH 9001. ISP description by Group A -3 .

Spore chain morphology: Section Rectiflexibiles. Mature spore chains generally long, often with more than 50 spores per chain ( $F i g$. 115). This morphology is seen on yeast-malt agar, oatmeal agar, saltsstarch agar and glycerol-asparagine agar. Spore surface: Smooth (Fig. 114).

Color of colon:: Aerial mass color in the Yellow color-series on yeast-malt agar, oatmeal agar, salts-starch agar and glycerol-asparagine agar.

Reverse side of colony: No distinctive pigment (colorless or characteristic grayed yellow on oatmeal agar, salts-starch aga $r$ and glycerolas paragine aga $r$, to grayed yellow-brown on yeast-malt agar).

Color in medium: Melanoid pigments formed in peptone-yeast-iron agar and tryptone-yeast broth. Yellow pigment found in medium in yeast-malt agar and oatmeal agar. This pigment is not $\mathrm{pH}$ sensitive when tested with $0.05 \mathrm{~N} \mathrm{NaOH}$ or $\mathrm{HCl}$.

Carbon utilization: D-Glucose, D-xylose, I-inositol, D-mannitol and $\underline{D}$-fructose a re utilized for growth. No growth or only trace of growth on L-arabinose, sucrose and rhamnose. Variable reports on growth with raffinose.

Streptomyces minoensis Nishimura. Descriptions: Streptomyces I-523 Nishimura, Sasaki, Mayama, Shimaoka, Tawara, Okamoto and Nakajima 1960, 327-330; Streptomyces minoensis Nishimura 1961, Japanese Patent 19,750. Type strain: I-523 (ibid.). ISP $5031 \mathrm{from}$ H. Nishimura as I-523. ISP description by Group A-11.

Spore chain morphology: Section Retinaculiaperti or Spirales. Flexuous and hooked spore chains suggesting RA morphology are most abundant on yeast-malt aga $r$ and oatmeal agar; open spirals are common on salts-starch agar and glycerol-asparagine agar. Mature spore chains generally long, often with more than 50 spores per chain. Spore surface: Smooth (Fig. 116).

Color of colony: Aerial mass color in the Gray color-series on yeastmalt agar, oatmeal agar, salts-starch agar and glycerol-asparagine agar.

Reverse side of colony: Grayed yellow-brown is sometimes modified slightly by red (see $\mathrm{pH}$ ) on yeast-malt agar, oatmeal agar, salts starch agar and glycerol-asparagine agar. Reverse color is changed 

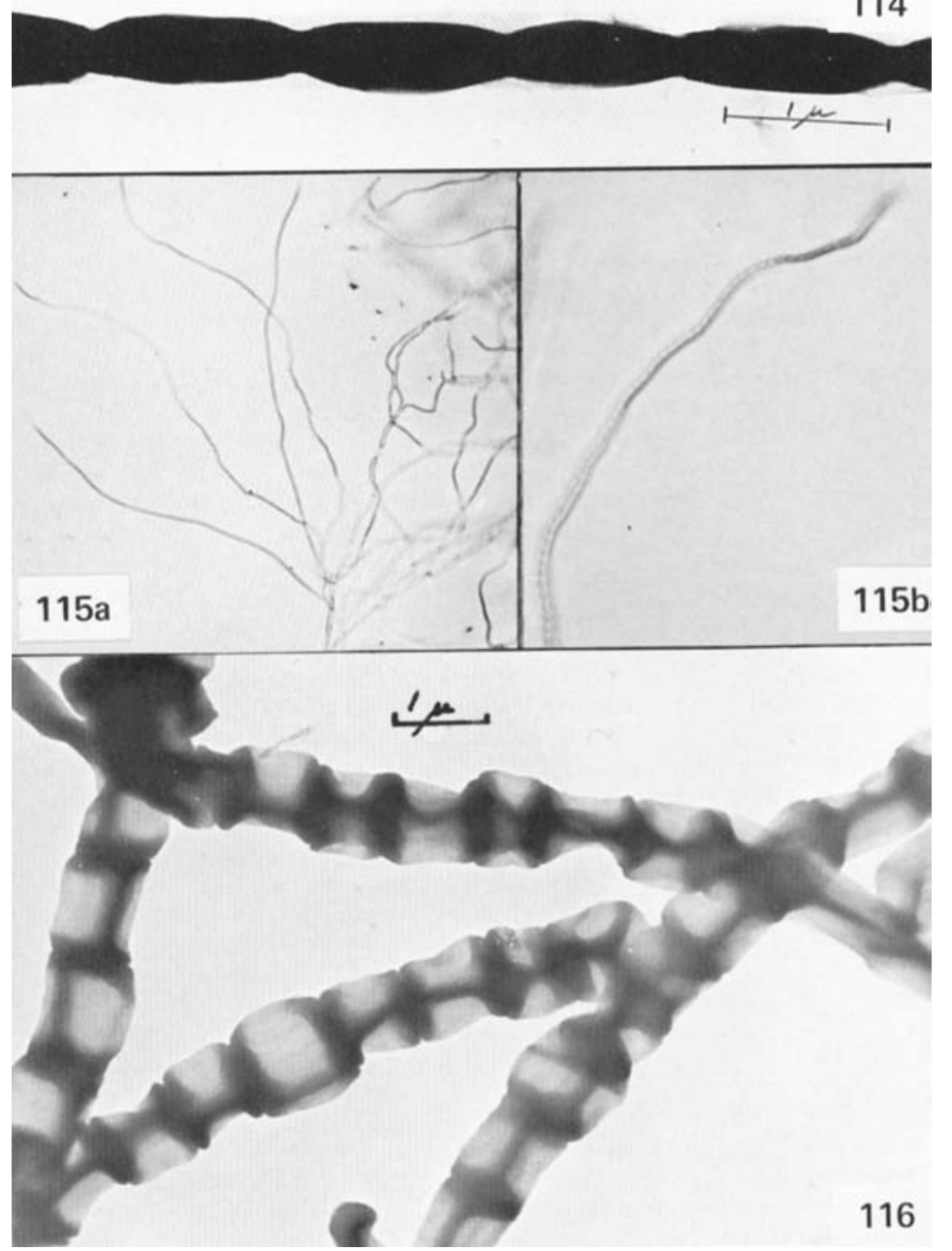

Figure 114 . S. michiganensis. Smooth spores; electron micrograph from 14 day culture on oatmeal agar.

Figure 115. ‥ michiganensis. RF spore chains on: (a) glycerolasparagine agar, 7 days $(300 x) .6$ (b) yeast-malt agar, 21 days $(875 x) .7$

Figure 116. S. minoensis. Smooth spores; electron micrograph from 14 day culture on salts - starch agar. 26 
from yellow brown to red by addition of $0.05 \mathrm{~N} \mathrm{NaOH}$, and from yellowbrown to yellow by $0.05 \mathrm{~N} \mathrm{HCl}$.

Color in medium: Melanoid pigments not formed in peptone-yeastiron agar and tyrosine agar. Pigments found in medium only in trace amounts or not at all in yeast-malt agar, oatmeal agar, salts-starch agar and glycerol-asparagine agar.

Carbon utilization: D-Glucose, L-arabinose, sucrose, D-xylose, I-inositol, D-mannitol, D-fructose and rhamnose are utilized for growth. Utilization of raffinose is doubtful.

Streptomyces murinus Frommer. Description: Frommer 1959, 197199. Type strain: Ital. 1131 (ibid.). ISP 5091 from C.W. Hesseltine as NRRL B-2286 from W. Frommer as Ital. 1131. ISP description by Group A-10.

Spore chain morphology: Section Spirales Mature spore chains generally 10 to 50 spores per chain. This morphology is seen on yeastmalt agar, oatmeal agar, salts-starch agar and glycerol-asparagine agar. Spore surface: Smooth. Air-dried preparations for electron microscopy may show internal contractions that suggest a warty appear ance (Fig. 117).

Color of colony: Aerial mass color in the Red color-series on glycerolasparagine agar; Gray series on salts-starch agar; Gray or Red color-series on oatmeal agar and glycerol-asparagine agar.

Reverse side of colony: Grayed yellow on oatmeal agar and glycerolasparagine agar; grayed yellow or yellow modified by red on yeast-malt agar and salts-starch agar. Substrate pigment is not a pH indicator.

Color in medium: Melanoid pigments not formed in peptone-yeastiron agar and tyrosine agar. Yellow pigment found in medium in yeastmalt agar, oatmeal agar, salts-starch agar and glycerol-asparagine agar; it is not a pH indicator.

Carbon utilization: D-Glucose, D-xylose, D-mannitol and D-fructose are utilized for growth. No growth or only trace of growth on L-arabinose, sucrose, rhamnose and raffinose. Variable reports on growth with I-inositol.

Actinomyces mutabilis Preobrazhenskaya and Ryabova. Description: Preobrazhenskaya and Ryabova in Gauze et al. 1957, 164 and 166. Type strain: B-472 (ibid.; type strain selected by Preobrazhenskaya, personal communication). Streptomyces mutabilis (Preobrazhenskaya and Ryabova) Pridham et al. 1958, 69. ISP 5169 from T.P. Preobrazhenskaya as B-472, ISP descriotion by Group A-9.

Spore chain morphology: Section Spirales or Retinaculiaperti. Spore chains are poorly developed so that hooks, loops or partial spirals are shorter and of smaller diameter than on typical RA cultures. Spirals, when found, are aberrant (Fig. 119). Mature spore chains generally contain only 3 to 10 spores per chain on yeast-malt agar, oatmeal agar, salts-starch agar and glycerol-asparagine agar. Spore surface: Smooth (Fig. 118).

Color of colony: Aerial mass color in the Gray or White color-series on yeast-malt agar and oatmeal agar; White series on salts-starch agar and glycerol-as paragine agar.

Reverse side of colony: No distinctive pigment on yeast-malt agar, oatmeal agar, salts-starch agar or glycerol-asparagine agar; substrate pigment is not $\mathrm{pH}$ indicator. 


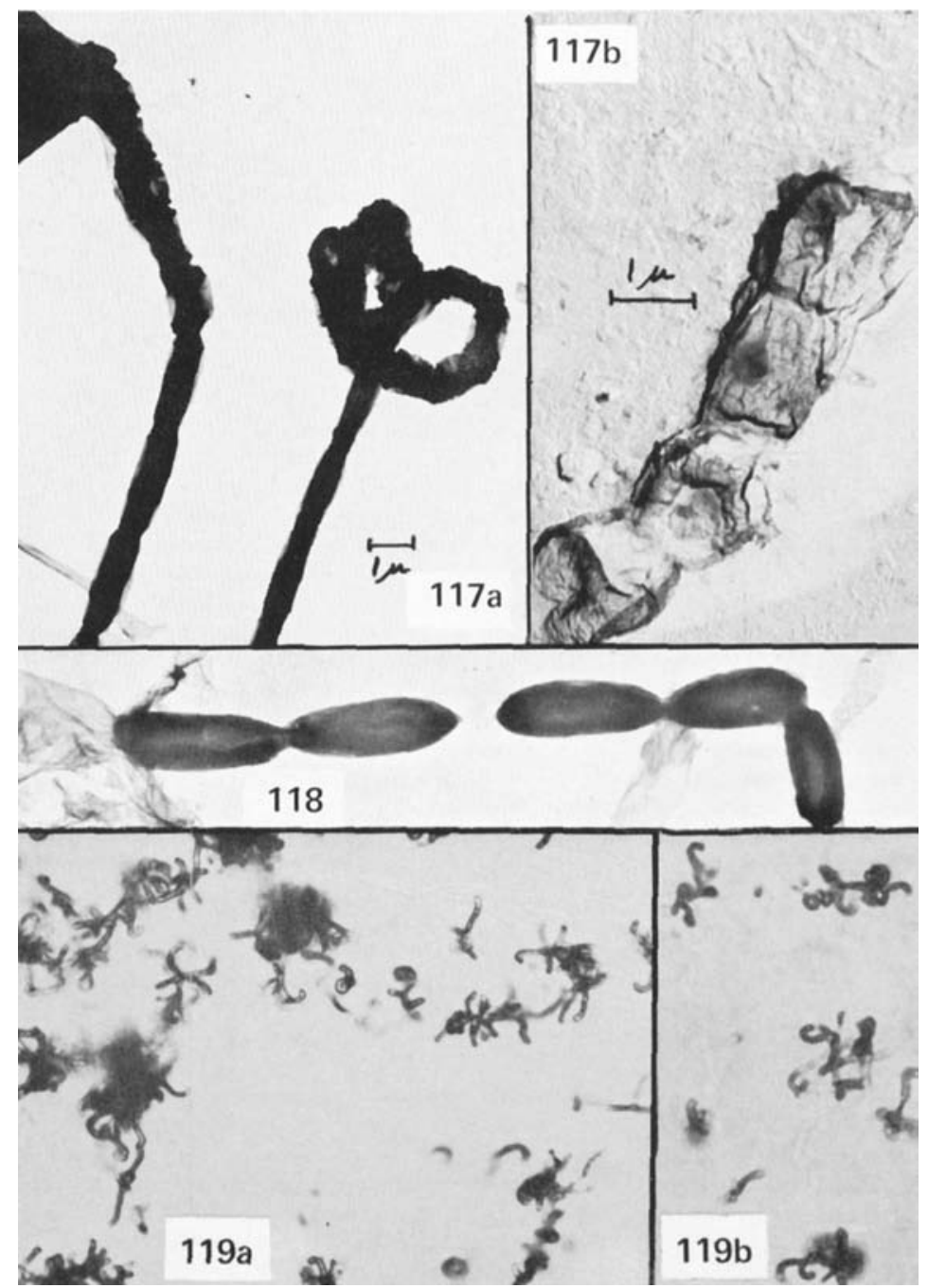

Figure 117. S. murinus. (a) Direct mount, electron micrograph. (b) Carbon replica. ${ }^{17}$ Smooth spores. Suggestion of warty appearance probably due to internal shrinkage in air dried preparations.

Figure 118. A. mutabilis. Smooth spores; electron micrograph from $2 \mathrm{l}$ day culture on glycerol-asparagine agar. 9

Figure 119. A. mutabilis, $(400 x)^{10}$ (a) On oatmeal agar, 14 days. (b) On salts-starch agar, 14 days. Although spiral spore chains of $\underline{A}$. mutabilis are short and poorly developed on all ISP media, these incomplete spirals, hooks and flexuous chains are also not typical of long chain RA cultures (see Figure 69). 
Color medium: Melanoid pigments not formed in peptone-yeast-iron agar, tyrosine agar or tryptone-yeast broth. No pigments found in medium, except for traces of yellow or greenish yellow pigments in yeast-malt agar. This pigment is not $\mathrm{pH}$ sensitive when tested with $0.05 \mathrm{~N} \mathrm{NaOH}$ or $\mathrm{HCl}$.

Carbon utilization: D-Glucose, L-arabinose, D-xylose, I-inositol, D-mannitol, D-fructose and rhamnose a re utilized for growth. Some growth occurs with sucrose as the carbon source; raffinose is not utilized.

Streptomyces narbonensis Corbaz, Ettlinger, Gaümann, Keller, Kradolfer, Kyburz, Neipp, Prelog, Reusser and Zahner. Description: Corbaz et al. 1955,935-942. Type strain: ETH 7346 (ibid.). ISP 5016 from R. Hutter as ETH 7346. ISP description by Group A-4.

Spore chain morphology: Section Rectiflexibiles. Mature spore chains generally 10 to 50 spores per chain; longer chains are sometimes observed (Fig. 121). This morphology is seen on yeast-malt agar, oatmeal agar, salts-starch agar and glycerol-asparagine agar. Spore surface: Smooth (Fig. 120).

Special morphological characteristics: Fragmentation of the substrate mycelium was noted by one observer only; unusual fragmentation of the aerial mycelium was recorded by another observer.

Color of colony: Aerial mass color in the Gray color-series on yeastmalt agar, oatmeal agar, salts-starch agar and glycerol-asparagine agar.

Reverse side of colony: No distinctive pigment (grayed yellow to grayed greenish yellow) on yeast-malt agar, oatmeal agar, salts-starch agar and glycerol-asparagine agar; substrate pigment is not a $\mathrm{pH}$ indicator.

Cobr in mediura: Melanoid pigments formed in peptone-yeast-iron agar. Pigments other than melanoids not formed in yeast-malt agar, oatmeal agar, salts-starch agar or glycerol-asparagine agar.

Carbon utilization: D-Glucose, L-arabinose, sucrose, D-xylose, D-fructose, rhamnose and raffinose are utilized for growth. No growth or only trace of growth on I-inositol and D-mannitol.

Streptomyces nigrifaciens Waksman. Descriptions: Actinomyces 145 Waksman 1919, 167-168; Streptomyces nigrifaciens waksman 1961, 247-248. Type strain: IMRU 3067 (Waksman, 1961 ibid.). ISP 5071 from S. A. Waksman as IMRU 3067. ISP description by Group A-8.

Spore chain morphology: Section Rectiflexibiles. Mature spore chains generally 10 to 50 spores per chain; longer chains are sometimes observed (Fig. 123). This morphology is seen on yeast-malt agar, oatmeal agar and salts-starch agar. Spore surface: .Smooth (Fig. 122).

Color of colony: Aerial mass color in the Gray color-series on yeastmalt agar, oatmeal agar and salts-sta rch agar.

Reverse side of colony: No distinctive pigment (grayed yellow to yellow-brown on yeast-malt agar, salts-starch agar, glycerol-asparagine agar, and grayed greenish yellow on oatmeal agar). Substrate pigment is not a $\mathrm{pH}$ indicator.

Color in medium: Melanoid pigments not formed in peptone-yeastiron agar and tyrosine agar. Some orange to yellow pigment found in medium in yeast-malt agar. In oatmeal agar, salts-starch agar and 


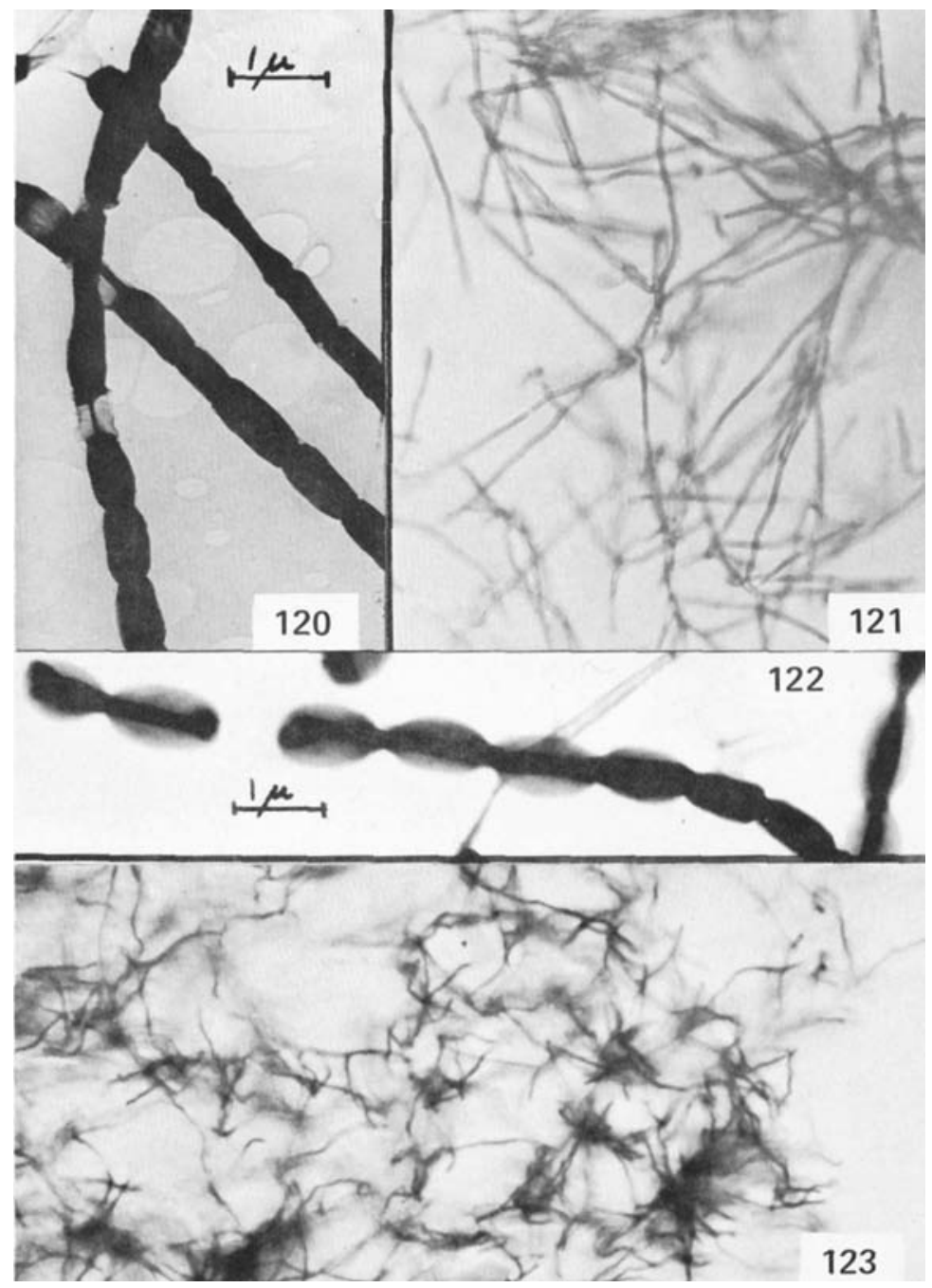

Figure 120. S. narbonensis. Smooth spores; electron micrograph from 14 day culture on oatmeal agar. 15

Figure 121. . narbonensis. RF spore chains on glycerol-a sparagine agar, 21 days. 14

Figure 122. S. nigrifaciens. Smooth spores; electron micrograph from 14 day culture on yeast-malt agar. 23

Figure 123; S. nigrifaciens. $\underline{R}$ spore chains $(400 x)$ on yeast-malt agar. 22 
glycerol-asparagine agar, yellow pigment is very faint or absent; it is not $\mathrm{pH}$ sensitive.

Carbon utilization: D-Glucose, L-arabinose, D-xylose, D-mannitol and rhamnose a re utilized for growth. No growth or only trace of growth on sucrose, I-inositol and raffinose. Variable reports on growth with D-fructose.

Streptomyces nitrosporeus Okami. Description: Ok.ami 1952, 477478. Type strain: 0-20 (ibid.). ISP 5023 from Y. Okami as $0-20$ (NIHJ 21). ISP description by Group A-10.

Spore chain morphology: Section Rectiflexibiles. Mature spore chains generally 10 to 50 spores per chain (Fig. 125). This morphology is seen on yeast-malt agar, oatmeal agar and salts-starch agar. Spore surface: Smooth (Fig. 124).

Color of colony: Aerial mass color in the Gray color-series on yeastmalt agar, oatmeal agar and salts-starch agar.

Reverse side of colony: No distinctive pigment (grayed yellow to yellow-brown) on yeast-malt agar, oatmeal agar, salts-starch agar or glycerol-asparagine agar; substrate pigment is not a $\mathrm{pH}$ indicator.

Color in medium: Melanoid pigments not formed in peptone -yeastiron aga $r$ and tyrosine agar. Indistinct yellow, gray or brownish gray pigment found in medium in yeast-malt agar, oatmeal agar, salts-starch agar and glycerol-asparagine agar; it is not $\mathrm{pH}$ sensitive.

Carbon utilization: D-Glucose, L-arabinose, D-xylose and rhamnose are utilized for growth. No growth or only trace of growth on sucrose, I-inositol, D-mannitol and raffinose. Variable reports on growth with D-fructose.

Streptomyces niveus Smith, Dietz, Sokolski and Savage. Description: Smith et al. 1956, 135-141. Type strain: NRRL 2466 (ibid.). ISP 5088 from C. $\bar{W}$. Hesseltine as NRRL 2466. ISP description by Group A-9.

Spore chain morphology: Section Spirales, with as many as 10 or more well-formed volutions of narrow diameter at the ends of long sporophores (Fig. 126). Mature spore chains generally 10 to 50 spores per chain; longer chains are sometimes observed. This morphology is seen on yeast-malt agar, oatmeal agar, salts-starch agar and glycerolasparagine agar. Spore surface: Smooth (Fig. 126).

Color of colony: Aerial mass color in the Yellow color-series on yeast-malt agar, oatmeal agar, salts-starch agar and glycerol-asparagine agar.

Reverse side of colony: No distinctive pigment on yeast-malt agar, oatmeal agar, salts-starch agar or glycerol-asparagine agar; substrate pigment is not a $\mathrm{pH}$ indicator.

Color in medium: Melanoid pigments not formed in peptone-yeastiron agar and tyrosine agar. Pigment, other than traces of yellow, not formed in yeast-malt agar, oatmeal agar, salts-starch aga or glycerolasparagine agar.

Carbon utilization: D-Glucose, D-xylose and D-fructose are utilized for growth. No growth or only trace of growth on sucrose, I-inositol and raffinose. Variable reports on growth with L-a rabinose, D-mannitol and rhamnose. (Note: Reports from 4 cooperating laboratories indicate unusual disagreement regarding carbon utilization by this strain. The original description includes sucrose, rhamnose and raffinose 


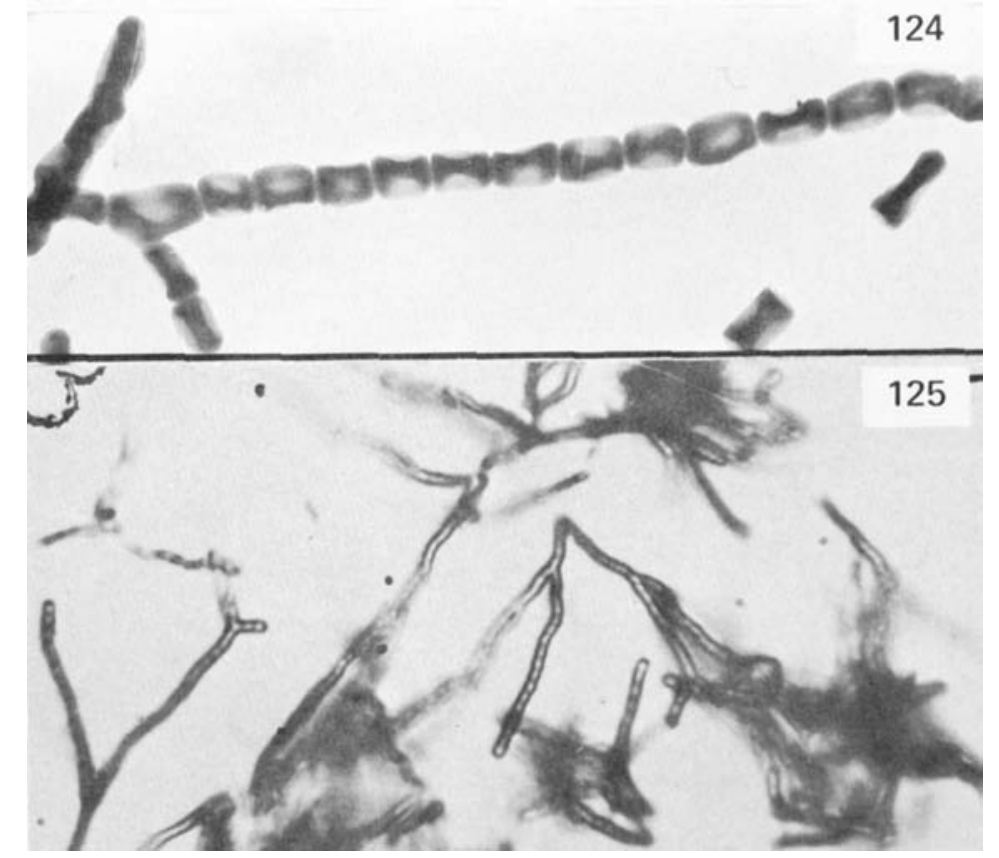

Figure 124. S. nitrosporeus. Smooth spores; electron micrograph from 8 day culture on yeast-malt agar. 28

Figure 125. ‥ nitrosporeus. RF spore chains $(1000 \mathrm{x})$ on oatmeal agar. ${ }^{18}$ 
among carbon sources utilized for growth.)

Streptomyces olivaceus (Waksman) Waksman and Henrici. Descriptions: Actinomyces $206 \mathrm{~W}$ aksman 1919, 168-169; Actinomyces olivaceus Waksman 1923, 354; Streptomyces olivaceus (Waksman) Waksman and Henrici 1948, 950. Type strain: IMRU 3335 (Waksman 1961, 252). ISP 5072 from S. A Waksman as IMRU 3335. ISP description by Group A-8.

Spore chain morphology: Section Spirales, with open spirals intergrading through flexuous spore chains suggestive of Section Rectiflexibiles (Fig. 128). Mature sporc chains generally long, often with more than 50 spores per chain. This morphology is seen on yeast-malt agar, oatmeal agar, salts-starch agar and glycerol-asparagine agar. Spore surface: Smooth (Fig. 127).

Color of colony: Aerial mass color in the Gray color-series on yeastmalt agar, oatmeal agar, salts-starch agar and glycerol-asparagine agar.

Reverse side of colony: Usually grayed yellow on yeast-malt agar, oatmeal agar, salts-starch agar and glycerol-asparagine agar. Production of dark reverse color is variable on these media; substrate pigment is not a pH indicator.

Color in medium: Melanoid pigments not formed in peptone-yeastiron agar and tyrosine agar. No pigment found in medium in yeast-malt agar, oatmeal agar, salts-starch agar or glycerol-asparagine agar.

Carbon utilization: D-Glucose, L-arabinose, D-xylose, I-inositol, D-mannitol, D-fructose and rhamnose are utilized for growth. No growth or only trace of growth on sucrose and raffinose.

Streptomyces orientalis Pittenger and Brigham. Description: Pittenge $r$ and Brigham 1956, 642-647. See also: McCormick, Stark, Pittenger, Pittenger and McGuire 1956, 606-61l; Ziegler, Wolfe and McGuire 1956, 612-618; Griffith and Peck 1956, 619-622. Type strain: M43-05865 (Pittenger and Brigham 1956, 642). ISP 5040 from R. C. Pittenger as M43-05865. ISP description by Group A-11.

Spore chain morphology: Section Rectiflexibiles. Long aerial hyphae give rise to interwoven spore chains of more than 50 spores per strand. Fragmentation of the substrate mycelium also occurs (Fig. 129). This morphology is seen on yeast-malt agar, salts-starch agar and glycerolasparagine agar; thin aerial mycelium on oatmeal agar. Spore surface: Smooth (Fig. 129).

Color of colony: Aerial mass color in the White color-series on yeast-malt agar and glycerol-asparagine agar; White or Gray series on salts-starch agar. Some sectors or colonies with aerial mycelium in the Blue color-series on salts-starch agar were noted by one observer only. The same phenomenon is recorded in the original description (Pittenger and Brigham, op cit p. 643) on Emerson's agar.

Reverse side of colony: No distinctive pigment on yeast-malt agar, oatmeal agar, salts-starch agar or glycerol-asparagine agar; substrate pigment is not a $\mathrm{pH}$ indicator.

Color in medium: Melanoid pigments not formed in peptone-yeastiron agar and tyrosine agar. No pigment found in medium in yeastmalt agar, oatmeal agar, salts-starch agar or glycerol-asparagine agar.

Carbon utilization: D-Glucose, L-arabinose, D-xylose, I-inositol, 


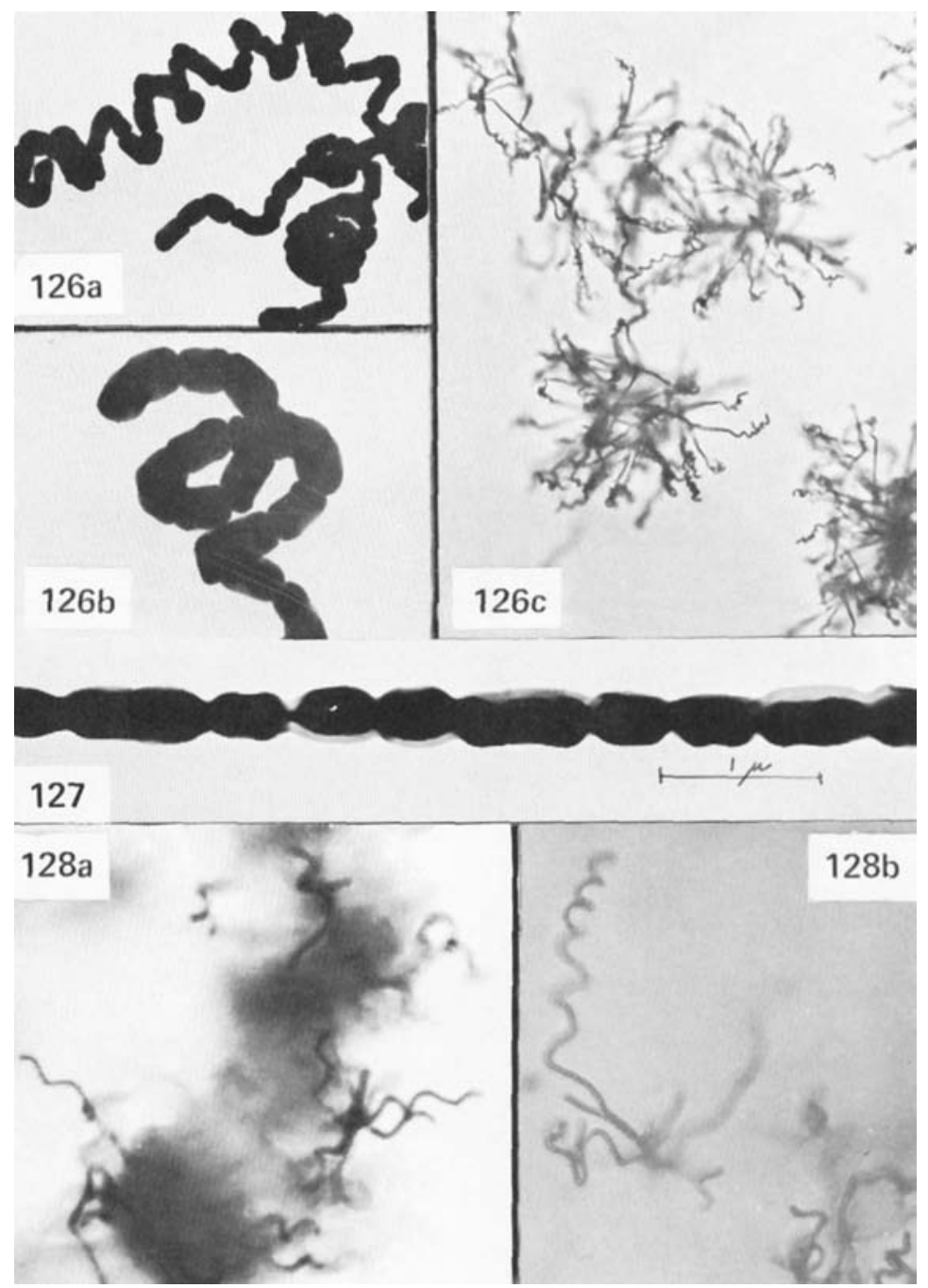

Figure 126. S. niveus $(a, b)$. Smooth spores; electron micrograph from 14 day culture on salts-starch agar. 29 (c) Spiral spore chains (200x) on glycerol-asparagine agar, 21 days. 30

Figure 127. S. olivaceus. Smooth spores; electron micrograph from 14 day culture on yeast-malt agar. ${ }^{l}$

Figure I28. S. olivaceus. Spiral spore chains (open spirals) on: (a) yeast-malt agar, 14 days, $800 x .22$ (b) salts-starch agar, 21 days, $1200 \times .24$ 


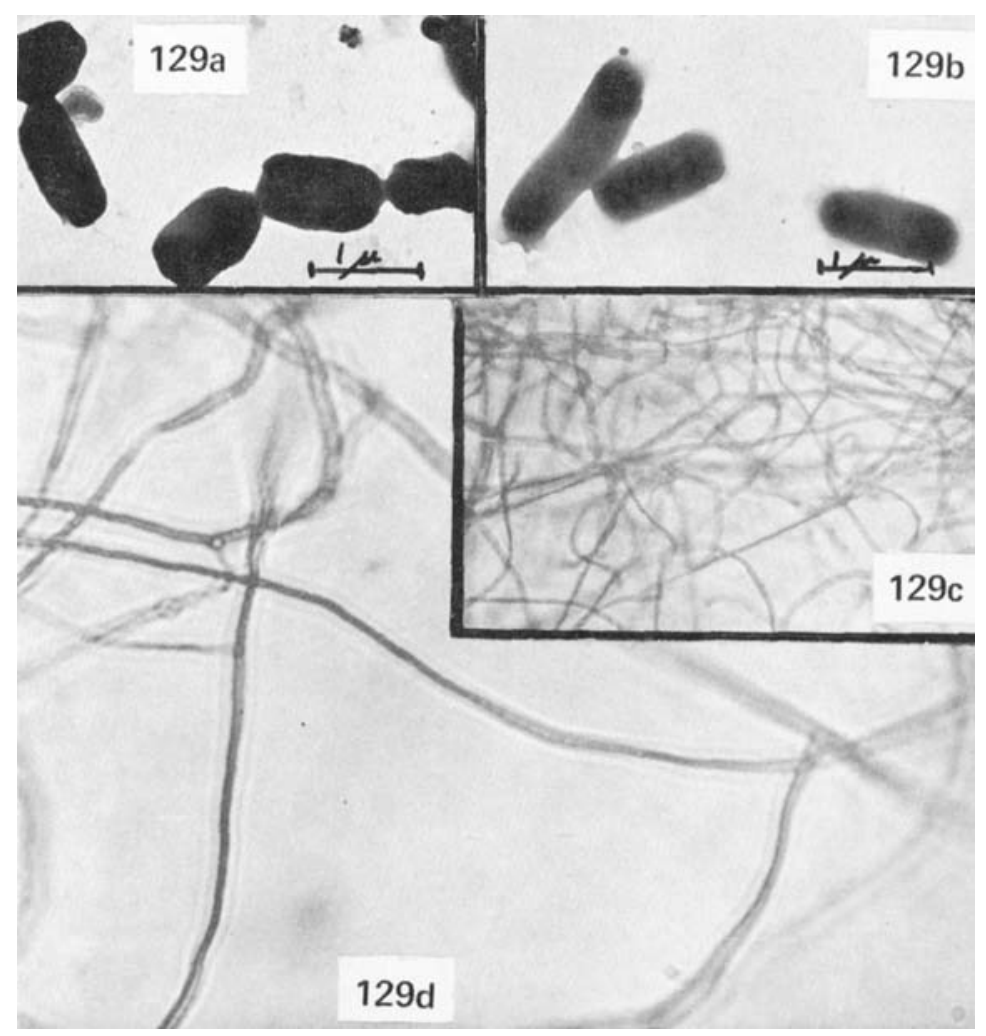

Figure 129. S. orientalis. (a,b) Smooth spores of two types: electron micrograph from 28 day culture on yeast-malt agar. ${ }^{4}$ (c,d) Network of long interwoven RF spore chains on yeast-malt agar, 14 days. 5 
D-mannitol, D-fructose and rhamnose are utilized for growth. Utilization of sucrose and raffinose is doubtful.

Streptomyces parvullus Waksman and Gregory, Description: Waksman and Gregory 1954, 1050-1056. Type strain: IMRU 3677 (ibid.). ISP 5048 from R. Gordon for S. A. Waksman as IMRU 3677. ISP description by Group A-11.

Spore chain morphology: Section Spirales Mature spore chains generally long, often with more than 50 spores per chain (Fig. 131). This morphology is seen on yeast-malt agar, oatmeal agar, saltsstarch agar and glycerol-asparagine agar. Spore surface: Smooth (Fig. 130).

Color of colony: Aerial mass color in the Gray color-series on yeastmalt agar, oatmeal agar, salts-starch agar and glycerol-asparagine agar.

Reverse side of colony: No distinctive pigment (grayed yellow to grayed greenish yellow) on yeast-malt agar, oatmeal agar, salts-starch agar or glycerol-asparagine agar; substrate pigment is not a $\mathrm{pH}$ indicator.

Color in medium: Melanoid pigments not formed in peptone-yeastiron agar and tyrosine agar. No pigment found in medium in yeast-malt agar, oatmeal agar, salts-starch agar or glycerol-asparagine agar.

Carbon utilization: D-Glucose, L-arabinose, sucrose, D-xylose, I-inosito1, D-mannitol, D-fructose and rhamnose are utilized for growth. Variable reports on growth with raffinose.

Streptomyces pilosus Ettlinger, Corbaz and Hütter. Description: Ettlinger et al. 1958, 347-348. Type strain: 11686 (ibid.). ISP 5097 from R. Hütter as ETH 11686. ISP description by Group A-7.

Spore chain morphology: Section Rectiflexibiles to Spirales. Short spore chains include strajght or flexuous chains, hooks, loops and poorly developed spirals. Hooks and loops of small diameter on short sporophores are not typical of the broad hooks and loops of RA cultures. In the original description, (Ettlinger et al., op. cit. p. 348) spore chains are described as open, regular spirals. Mature spore chains moderately short with 3-10 or sometimes more than 10 spores per chain. This morphology is seen on yeast-malt agar, oatmeal agar and salts-starch agar; sporulation may be poor on glycerol-asparagine agar. Spore surface: hairy, with tendency toward spines on some spores (Fig. 132).

Color of colony: Aerial mass color in the Gray color-series on yeastmalt agar, oatmeal agar and salts-starch agar.

Reverse side of colony: Grayed yellow to yellow-brown on glycerolasparagine agar and dark grayed yellow-brown to near black on yeastmalt agar, oatmeal agar and salts-starch agar; substrate pigment is not a pH indicator.

Color in medium: Melanoid pigments formed in peptone-yeast-iron agar and tryptone-yeast extract broth. Pigments other than melanoids not formed in yeast-malt agar, oatmeal agar, salts-starch agar or glycerol-asparagine agar.

Carbon utilization: D-Glucose, L-arabinose, D-xylose, I-inositol, D-mannitol, D-fructose and rhamnose are utilized for growth. No growth or only trace of growth on sucrose and raffinose. 


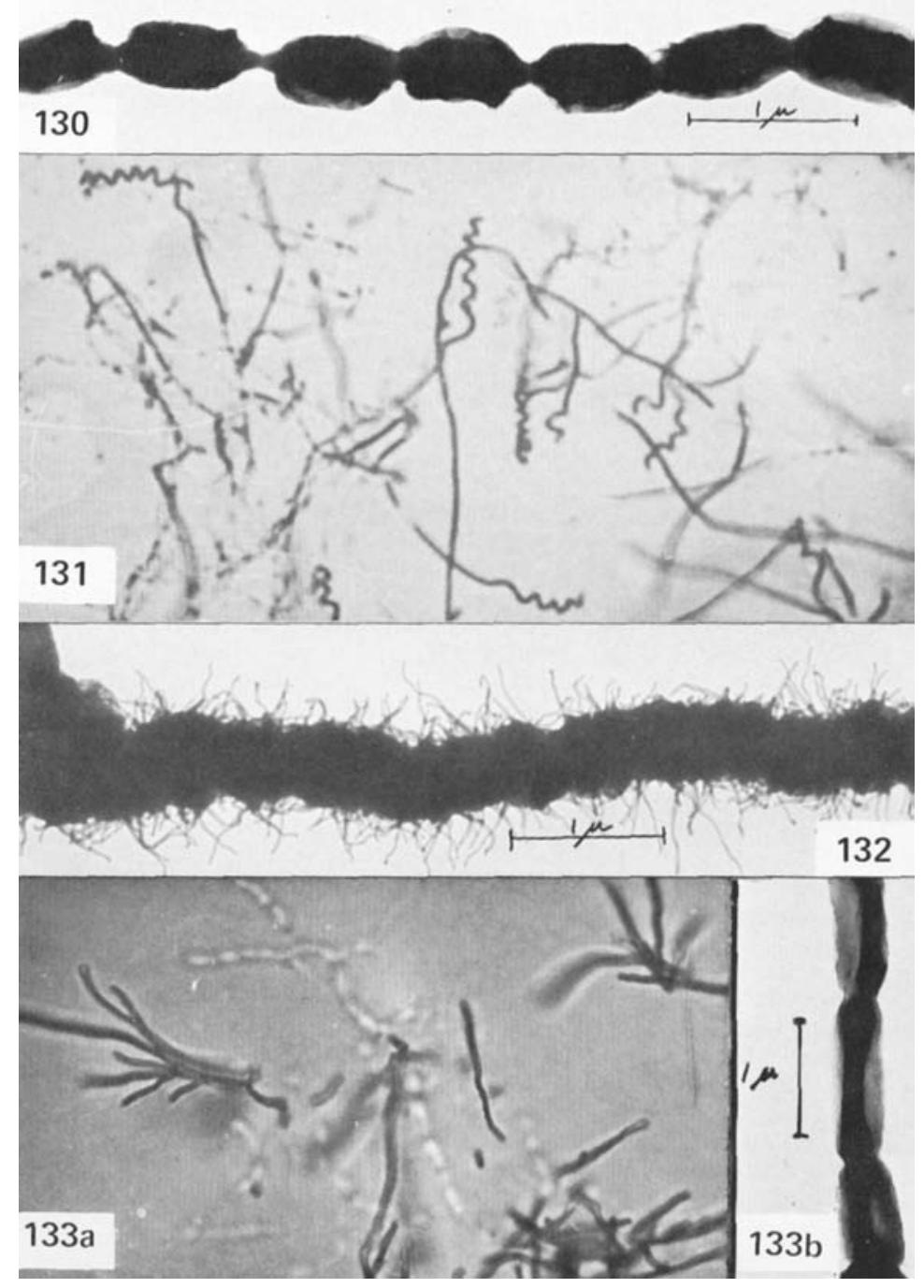

Figure 130. S. parvullus. Smooth spores; electron micrograph from 14 day culture on oatmeal agar. 1

Figure 131. S. parvullus. Spiral spore chains $(400 \mathrm{x})$ on yeast-malt agar, 14 days. 5

Figure 132. S. pilosus. Hairy to spiny spores; electron micrograph from 14 day culture on oatmeal agar.

Figure 133. S. pluricolorescens. (a) RF spore chains (500x) on glycerol-a sparagine agar, 7 days. 8 (b) Smooth spores; electron micrograph from 21 day culture on oatmeal agar. 11 
Streptomyces pluricolorescens Okami and Umezawa. Description: Okami and Umezawa in Waksman 1961, 259-260. See also: Maeda et al. 1956, 75-80. Type strain: 91-T1-1 (Y. Okami, personal communication). ISP 5019 from Y. Okami as 91-Tl-1 (NIHJ 238). ISP description by Group A-2.

Spore chain morphology: Section Rectiflexibiles. Mature spore chains moderately short with 3-10, or sometimes more than 10 spores per chain (Fig. 133). This morphology is observed on yeast-malt agar, oatmeal agar, salts-starch agar and glycerol-asparagine agar. Spore surface: Smooth (Fig. 133).

Color of colony: Aerial mass color in the Yellow or Red color-series on yeast-malt agar, oatmeal agar, salts-starch agar and glycerol-asparagine agar. (Usually pale yellow in 7 days becoming pale orange-yellow or grayish yellowish pink in 14 to 21 days.)

Reverse side of colony: Grayed yellow to yellow-brown (modified slightly by red in 14 to 21 days) on yeast-malt agar, oatmeal agar, saltsstarch agar and glycerol-asparagine agar; substrate pigment is not a $\mathrm{pH}$ indicator.

Color in medium: Melanoid pigments not formed in peptone-yeastiron agar and tyrosine agar. No pigment found in medium in yeast-malt agar, oatmeal agar, salts-starch agar or glycerol-asparagine agar.

Carbon utilization: D-Glucose, D-xylose, D-mannitol, D-fructose and rhamnose are utilized for growth. No growth or only trace of growth on sucrose, $\underline{I}$-inositol and raffinose. Utilization of $\underline{L}$-arabinose is doubtful.

Streptomyces prasinopilosus Ettlinger, Corbaz and Hutter. Description: Ettlinger et al. 1958, 345. (Designated as synonym for Streptomyces hirsutus by Hütter 1962a, 33.) Type strain: ETH 13765 (Ettlinger et al. , ibid.). ISP 5098 from R. Hutter as ETH 13765. ISP description by Group A-6.

Spore chain morphology: Section Retinaculiaperti. Mature spore chains generally 10 to 50 spores per chain (Fig. 135). This morphology is seen on yeast-malt agar, oatmeal agar, salts-starch agar and glycerol-asparagine agar. Spore surface: Hairy (Fig. 134).

Color of colony: Aerial mass color in the Green color-series on yeast-malt agar, oatmeal agar, salts-starch agar and glycerol-asparagine agar.

Reverse side of colony: Grayed yellow or grayed greenish yellow on oatmeal agar, salts - starch agar and glycerol-asparagine agar, and grayed yellow modified by orange on yeast-malt agar. Substrate pigment is not a pH indicator. (One observer reports slight change from orange to brown with $\mathrm{NaOH}_{\text {.) }}$

Color in medium: Melanoid pigments not formed in peptone-yeastiron agar and tyrosine agar. No pigment found in medium in yeast-malt agar, oatmeal agar, salts-starch agar or glycerol-asparagine agar.

Carbon utilization: D-Glucose, L-arabinose, I-inositol, D-fructose and rhamnose are utilized for growth. No growth or only trace of growth on sucrose and raffinose. Variable reports on growth with D-xylose and D-mannitol.

Streptomyces prasinus Ettlinger, Corbaz and Hütter. Description: 

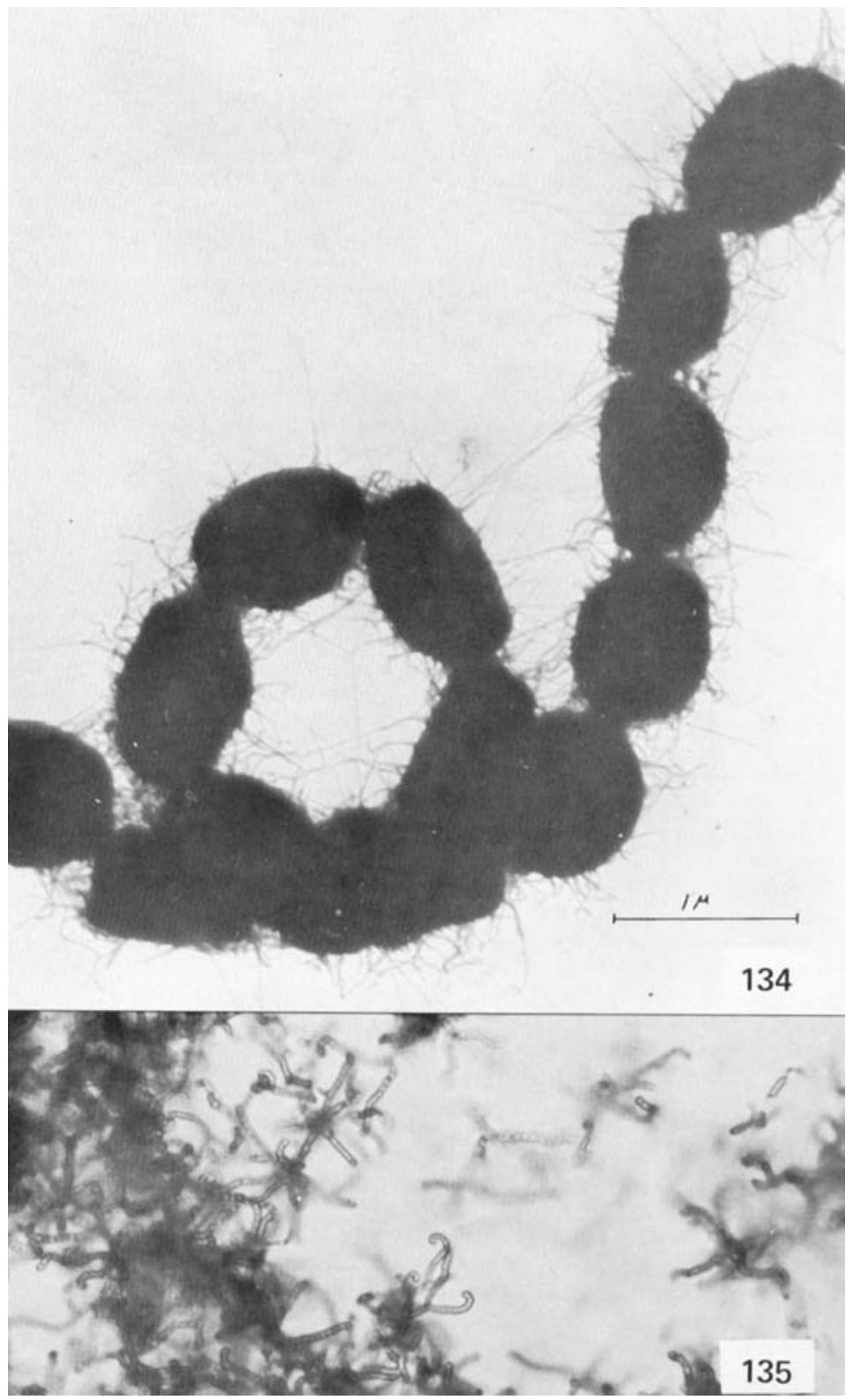

Figure 134. S. prasinopilosus. Hairy spores; electron micrograph from 14 day culture on oatmeal agar. 1

Figure 135. . prasinopilosus. RA spore chains $(1200 \mathrm{x})$ on yeast malt agar, 14 days. 21 
Ettlinger et al. 1958, 343. Type strain: ETH 13815 (ibid.). ISP 5099 from R. Hütter as ETH 13815. ISP description by Group A-8.

Spore chain morphology: Section Retinaculiaperti or Spirales. Spirals are poorly developed and show only one to three turns; loops and hooks are of small diameter on short spore chains and therefore are not typical of well-developed RA spore chains. Mature spore chains moderately short with 3 to 10 , or sometimes more than 10 spores per chain (Fig. 137). This morphology is seen on yeast-malt agar, oatmeal agar, salts-starch agar and glycerol-asparagine agar. Spore surface: Spiny (Fig. 136).

Color of colony: Aerial mass color in the Green color-series on yeast-malt agar, oatmeal agar, salts-starch agar and glycerol-asparagine agar.

Reverse side of colony: No distinctive pigment (grayed yellow to yellow-brown on yeast-malt agar and oatmeal agar, and grayed yellowbrown modified slightly by green on salts-starch agar and glycerolasparagine agar). Substrate pigment is not a $\mathrm{pH}$ indicator.

Color in medium: Melanoid pigments not formed in peptone-yeastiron agar and tyrosine agar. No pigment found in medium in yeastmalt agar, oatmeal agar, salts-starch agar and glycerol-asparagine agar.

Carbon utilization: D-Glucose, sucrose, D-xylose, I-inositol, Dmannitol, D-fructose and rhamnose are utilized for growth. Variable reports on growth with $\underline{L}$-arabinose and raffinose.

Streptomyces puniceus Finlay and Sobin. Description: Finlay and Sobin, German patent application PA352176-27.5.50, 1951; Finlay and Sobin, German Patent 834582 Klasse 30h, Gruppe 6, P $1727 \mathrm{IVa} / 30 \mathrm{~h}$, March 1952. (Name without description: Streptomyces puniceus in Patelski 1950, 186-188 and in Finlay et al. 1951, 1-3.) Type strain: Pfizer 1314-5 (German patent application and patent, ibid.). ISP 5083 from J. Routien for Chas. Pfizer and Co., Inc. as Pf 1314-5. ISP description by Group A-11.

Spore chain morphology: Section Rectiflexibiles. Mature spore chains generally long, often with more than 50 spores per chain ( $F$ ig. 138). This morphology is seen on yeast-malt agar, oatmeal agar, saltsstarch agar and glycerol-asparagine agar. Spore surface: Smooth (Fig. 138).

Color of colony: Aerial mass color in the Yellow color-series on yeast-malt agar, oatmeal agar, salts-starch agar and glycerol-asparagine agar. One observer places this culture in the Gray series (tabs $2 \mathrm{dc}$, yellowish gray and $3 \mathrm{fe}$, light grayish brown) on the se media .

Reverse side of colony: Violet on yeast-malt agar, oatmeal agar, salts-starch agar, glycerol-as paragine agar. Reverse color is changed from violet to blue-violet or blue by addition of $0.05 \mathrm{~N} \mathrm{NaOH}$ and from violet to pink or red with $0.05 \mathrm{~N} \mathrm{HCl}$.

Color in medium: Melanoid pigments not formed in peptone-yeast-iron agar and tryosine agar. Traces of blue or violet pigment found in medium in yeast-malt agar and glycerol-asparagine agar after 14-21 days. Pigment, when present, is changed from blue or violet to red-violet by $0.05 \mathrm{~N} \mathrm{HCl}$.

Carbon utilization: D-Glucose, D-xylose, D-mannitol and D-fructose are utilized for growth. No growth or only trace of growth on 


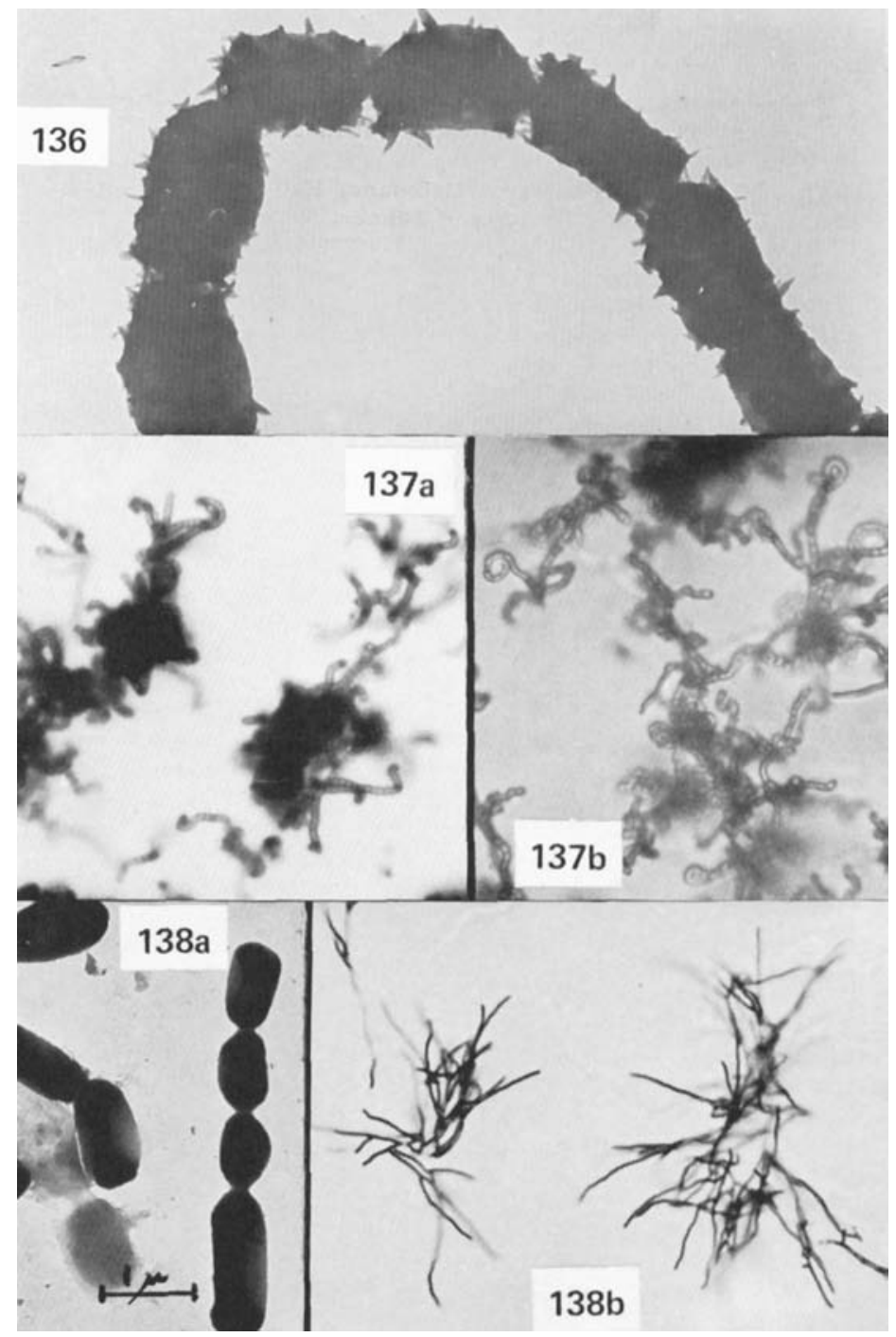

Figure 136. S. prasinus. Spiny spores; electron micrograph from 14 day culture on oatmeal agar. 1

Figure 137. S. prasinus. Spiral or RA spore chains. (a) Short chains with hooks and incomplete spirals, salts-starch agar, 14 days $(800 x){ }^{22}$ (b) Imperfect spirals, salts - starch agar, 21 days $(1200 x) .^{24}$

Figure 138. S. puniceus. (a) Smooth spores; electron micrograph from 28 day culture on salts - starch agar. ${ }^{4}$ (b) $\underline{R}$ F spore chains $(300 \mathrm{x}$ ) on glycerol-a sparagine aga $r, 14$ days. 4 
L-arabinose, I-inositol and rhamnose. Utilization of sucrose is doubtful and reports are variable for growth with raffinose.

Streptomyces ramulosus Ettlinger, Gaümann, Hüter, KellerSchierlein, Kradolfer, Neipp, Prelog and Zähner. Description: Ettlinger et al. 1958, 216-219. Type strain: ETH 17653 (ibid.). ISP 5100 from $R$. Hütter as ETH 17653. ISP description by Group A-9.

Spore chain morphology: Section Retiflexibiles. Short dichotomous spore chains often occur in dense clumps or clusters. Short spore chains of 3 to 10 spores per chain. This morphology is seen on yeastmalt agar, salts-starch agar and glycerol-asparagine agar. Spore surface: Smooth (Fig. 139).

Color of colony: Aerial mass color in the Gray color-series on yeastmalt agar, salts-starch agar and glycerol-asparagine agar; poor sporulation on oatmeal agar.

Reverse side of colony: Substrate is colorless on oatmeal agar and grayed reddish brown to dark brown on yeast-malt agar, salts-starch aga $r$ and glycerol-asparagine agar. (One observer, only, reports reverse color as changed from grayed red to grayed yellow by 0.05 $\mathrm{N} \mathrm{NaOH}$ and from grayed red to grayed purplish color by $0.05 \mathrm{~N} \mathrm{HCl}$.)

Color in medium: Melanoid pigments probably not formed in peptoneyeast-iron agar and tyrosine agar (a light orange pigment is formed in peptone-yeast-iron agar). Red pigment found in medium in yeast-malt agar and glycerol-asparagine agar; red to violet pigment found in oat- meal agar and salts-starch agar. One observer, only, reports pigment changed to yellow by $0.05 \mathrm{~N} \mathrm{NaOH}$ and to violet by $0.05 \mathrm{~N} \mathrm{HCl}$ (2 observers reported no change).

Carbon utilization: D-Glucose, D-mannitol and raffinose are utilized for growth. Doubtful growth on D-fructose. No growth or only trace of growth on L-arabinose, sucrose, D-xylose, $\underline{I}$-inositol and rhamnose.

Streptomyces recifensis de Morais, de Lima and Maia. Description: Falcao de Morais et al. 1957, 239-253. Type strain: AX-18 (ibid.).

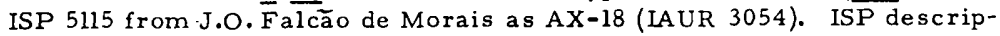
tion by Group A-7.

Spore chain morphology: Section Retinaculiaperti; spore chains representative of Section RF are also present. Mature spore chains generally 10 to 50 spores per chain (Fig. 141). This morphology is found on yeast-malt agar, oatmeal agar, salts-starch agar and glycerol-asparagine agar. Spore surface: Smooth (Fig. 140).

Color of colony: Aerial mass color in the Gray color-series on yeast-malt agar, oatmeal agar, salts-starch agar and glycerol-asparagine agar.

Reverse side of colony: No distinctive pigment on oatmeal a'gar, salts-starch agar and glycerol-asparagine agar; grayed yellow modified by dark grayish green on yeast-malt agar. Substrate pigment is not a $\mathrm{pH}$ indicator.

Color in medium: Melanoid pigments not formed in peptone-yeastiron agar and tyrosine agar. No pigment found in medium in yeast-malt agar, oatmeal agar, salts-starch agar or glycerol-asparagine agar.

Carbon utilization: D-Glucose, L-arabinose, sucrose, D-xylose, $\underline{D}$-mannitol, $\underline{D}$-fructose and raffinose are utilized for growth. No growth or only trace of growth on I-inositol and rhamnose. 

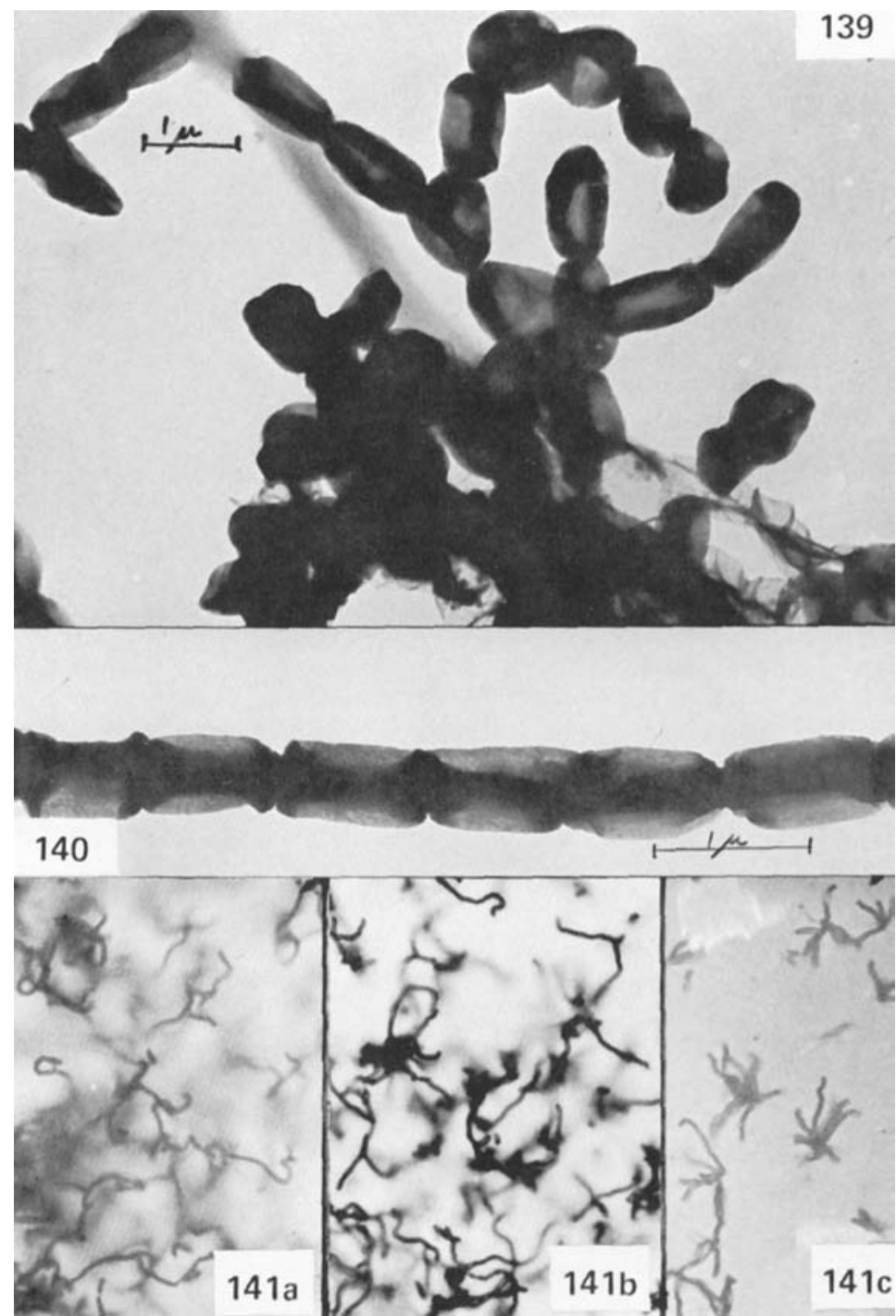

Figure 139. S. ramulosus. Smooth spores; electron micrograph from 21 day culture on salts-starch agar. 1

Figure 140. S. recifensis. Smooth spores; electron micrograph from 14 day cutture on oatmeal agar. ${ }^{1}$

Figure 141. S. recifensis. (a) RA spore chains (360x) on glycerol a sparagine agar. (b) $\underline{R A}$ to $\underline{R F}$ spore chains $(360 \mathrm{x})$ on glycerol asparagine agar. (c) $\underline{R}$ spore chains on oatmeal agar. 27 
Streptomyces resistomycificus Lindenbein. Description: Lindenbein 1952, 376-378; see also Lindenbein and Olfermann in Brockmann and Schmidt-Kastner 1951, 479-480. Type strain: Pürk 262 (ibid.). ISP 5133 from P. Wilde as Pürk 262 (ETH 23893). ISP description by Group A-6.

Spore chain morphology: Section Spirales, but with many spore chains representative of Section_RA (especially when sporophores are immature). Mature spore chains gene rally 10 to 50 spores per chain (Fig. 143). This morphology is seen on yeast-malt agar, oatmeal agar, salts-starch agar and glycerol-asparagine agar. Spore surface: Smooth (Fig. 142).

Color of colony: Aerial mass color in the Gray color-series on yeastmalt agar, oatmeal agar, salts-starch agar and glycerol-asparagine agar.

Reverse side of colony: Dark reddish brown on yeast-malt agar; grayed brown to reddish brown on oatmeal agar and glycerol-asparagine agar; and grayed yellow to faint pinkish yellow on salts-starch agar. Substrate pigment is not a $\mathrm{pH}$ indicator.

Color in medium: Melanoid pigments formed in peptone-yeast-iron agar, tyrosine agar and tryptone-yeast extract broth. Pigments other than melanoids not formed in yeast-malt agar, oatmeal agar, saltsstarch agar or glycerol-asparagine agar.

Carbon utilization: D-Glucose, L-arabinose, sucrose, D-xylose, I-inositol, D-mannitol, D-fructose, rhamnose and raffinose are utilized for growth.

Actinomyces roseofulvus Preobrazhenskaya. Description: Preobrazhenskaya in Gauze et al. 1957, 53 and 55. Type strain: 14535 (Preobrazhenskaya, personal communication). Streptomyces roseofulvus (Preobrazhenskaya) Pridham et al. 1958, 61. ISP 5172 from T.P. Preobrazhenskaya as 14535 . ISP description by Group A-10.

Spore chain morphology: Section Rectiflexibiles. Mature spore chains generally long and straight, often with more than 50 spores per chain. This morphology is seen on yeast-malt agar, oatmeal agar and salts-starch agar; poor sporulation on glycerol-asparagine agar. Spore surface: Smooth (Fig. 144).

Color of colony: Aerial mass color in the Red color-series on yeastmalt agar, oatmeal agar and salts-starch agar in 21 days. Younger cultures or cultures on media giving poor sporulation may show white aerial mycelium.

Reverse side of colony: Colorless or pale grayed yellow to pale pinkish yellow on yeast-malt agar, oatmeal agar, salts-starch agar and glycerol-asparagine agar. Reverse color is changed from colorless or pale yellow to pale pink by addition of $0.05 \mathrm{~N} \mathrm{NaOH}$, or from pinkish yellow to pale yellow with $0.05 \mathrm{~N} \mathrm{HCl}$.

Color in medium: Melanoid pigments not formed in peptone-yeastiron agar, tyrosine agar or tryptone-yeast extract broth. Traces of pale grayish yellow or pale brownish gray pigment may be found in yeast-malt agar, oatmeal agar and salts-starch agar. These faint pigments may be pH sensitive (one observer, only); the change is from pale yellow to pale pink by $0.05 \mathrm{~N} \mathrm{NaOH}$.

Carbon utilization: D-Glucose, L-arabinose, sucrose, D-xylose, Dfructrose, rhamnose and raffinose are utilized for growth. No growth or only trace of growth on $\underline{I}$-inositol and $\underline{D}$-mannitol. 


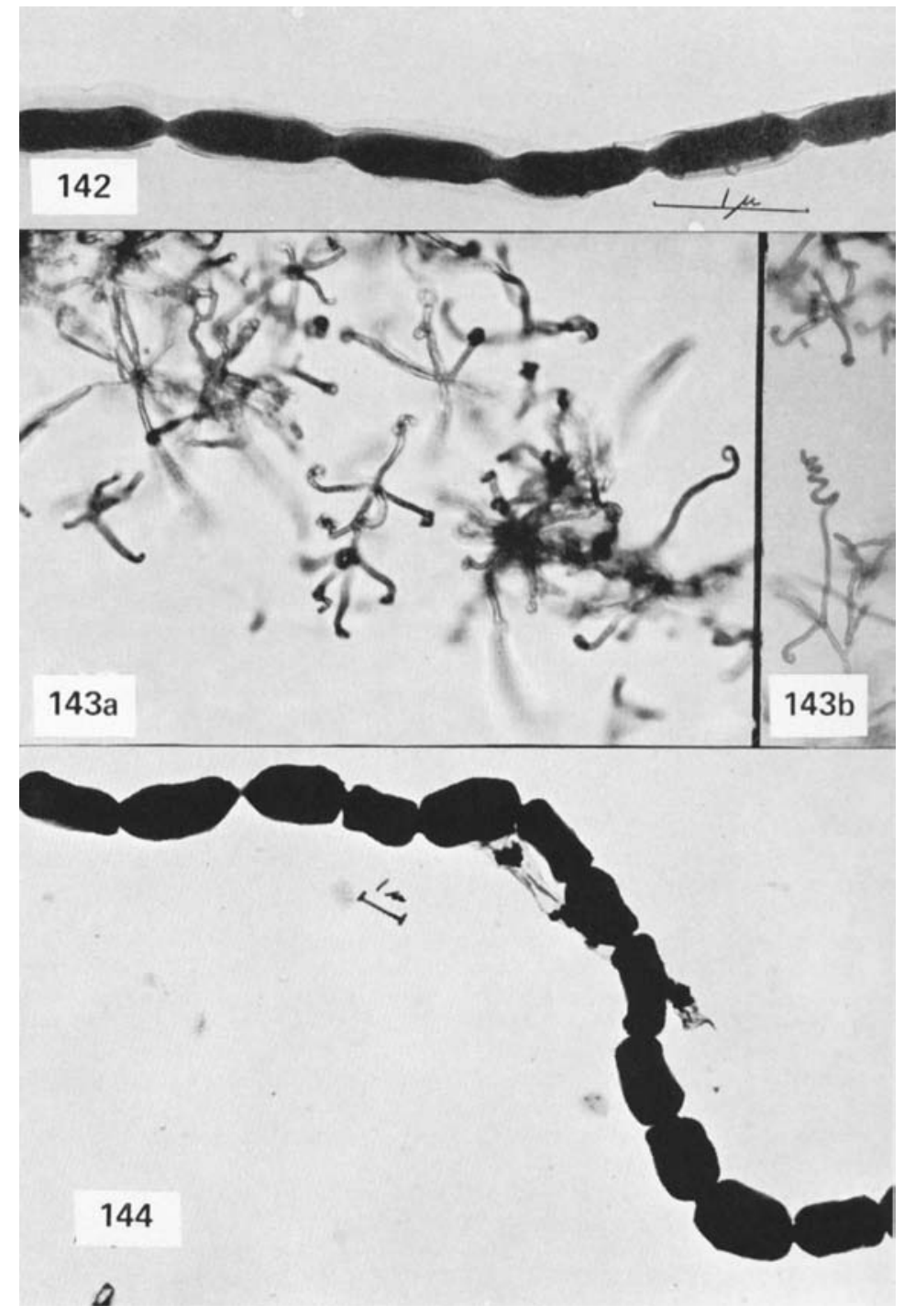

Figure 142. S. resistomycificus. Smooth spores; electron micrograph from 14 day culture on oatmeal agar. 1

Figure 143. S. resistomycificus. Spiral spore chains (1200x) on (a) oatmeal agar, 14 days, (b) salts-starch agar, 14 days. Many spirals have only one or two turns at the tip of spore chain and resemble RAA chains. $2 \mathrm{l}$

Figure 144. A. roseofulvus. Smooth spores; electron micrograph from 10 day culture on yeast-malt agar. ${ }^{17}$ 
Actinomyces roseolilacinus Preobrazhenskaya and Sveshnikova. Description: Preobrazhenskaya and Sveshnikova in Gauze et al. 1957, 32 and 35 . Type strain: 14250 (ibid. ; type strain selected by T.P. Preobrazhenskaya, personal communication). Streptomyces roseolilacinus (Preobrazhenskaya and Sveshnikova) Pridham et al. 1958, 68. ISP 5173 from T.P. Preobrazhenskaya as 14250. ISP description by group A-10.

Spore chain morphology: Section Retinaculiaperti to Spirales Spirals are prominent on salts-starch agar, but spore chains representative of Section RA are more common on yeast-malt agar and oatmeal agar; poor sporulation on glycerol-asparagine agar. Mature spore chains generally 10 to 50 spores per chain. Spore surface: Smooth.

Color of colony: Aerial mass color in the Red color-series on yeastmalt agar, oatmeal agar and salts-starch agar.

Reverse side of colony: No distinctive pigment on yeast-malt agar, oatmeal agar, salts-starch agar or glycerol-asparagine agar; substrate pigment is not a $\mathrm{pH}$ indicator (or shows only slight change with 0.05 $\mathrm{N} \mathrm{HCl}$ or $\mathrm{NaOH}$ on salts-starch agar and glycerol-asparagine agar).

Color in medium: Melanoid pigments not formed in peptone-yeastiron agar and tyrosine agar. Pigments not formed in medium or found only as traces of pale yellowish or brownish gray, in yeast-malt agar, oatmeal agar, salts-starch agar and glycerol-asparagine agar.

Carbon utilization: $\underline{D}$-Glucose and $\underline{L}$-arabinose are utilized for growth. No growth or only trace of growth on sucrose, D-xylose, Iinositol, D-mannitol, rhamnose and raffinose. Doubtful growth with D-fructosé.

Actinomyces roseolus Preobrazhenskaya and Sveshnikova. Description: Preobrazhenskaya and Sveshnikova in Gauze et al. 1957, 32-37. Type strain: 5449/54 (Preobrazhenskaya, personal communication). Streptomyces roseolus (Preobrazhenskaya and Sveshnikova) Pridham et al. 1958, 61. ISP 5174 from T.P. Preobrazhenskaya as 5449/54. ISP description by Group A-12.

Spore chain morphology: Section Rectiflexibiles (Fig. 145). Mature spore chains generally long with 10 to 50 or more spores per chain on yeast-malt agar, oatmeal agar, salts-starch agar and glyce rol-asparagine agar. Spore surface: Smooth (Fig. 145).

Color of colony: Aerial mass color in the Red color-series on yeastmalt agar and salts-starch agar, and in the Red or Yellow series on oatmeal agar. Sporulation may be poor on glycerol-asparagine agar.

Reverse side of colony: No distinctive pigments on yeast-malt agar, oatmeal agar, salts-starch agar or glycerol-asparagine agar; substrate pigment is not a $\mathrm{pH}$ indicator.

Color in medium: Melanoid pigments not formed in peptone-yeastiron agar and tyrosine agar. No pigment found in medium in yeastmalt agar, oatmeal agar, salts-starch agar or glycerol-asparagine agar.

Carbon utilization: $\underline{D}$-Glucose, L-arabinose, D-xylose and rhamnose are utilized for growth. No growth or only trace of growth on sucrose, I-inositol, D-mannitol and raffinose. Variable reports of slight growth with D-fructose. 
Streptoverticillium roseoverticillatum (Shinobu) Farina and Locci. Descriptions: Shinobu 1956,84-93; Farina and Locci 1966, 39, 49; Baldacci, Farina and Locci 1966, 163-164. Type strain: 462 (Shinobu, 1956). Streptomyces roseoverticillatus Shinobu 1956, 84. ISP 5039 from R.

Shinobu as 462 . ISP description by Group A-9.

Spore chain morphology: Umbellate monoverticillate (= Streptomyces Section Verticillati, biverticillate). Mature spore chains short, generally 3 to 10 spores per chain (Fig. 146). This morphology is seen on yeast-malt agar, oatmeal agar, salts-starch agar and glycerol-asparagine agar. Spore surface: Smooth (Fig. 146).

Color of colony: Aerial mass color in the Red color-scries on yeastmalt agar, oatmeal agar, salts-starch agar and glycerol-asparagine agar.

Reverse side of colony: Grayed yellow is modified by red on yeastmalt agar, oatmeal agar, salts-starch agar and glycerol-asparagine agar. Only slight changes, if any, occur when $\mathrm{pH}$ is changed by addition of $0.05 \mathrm{~N} \mathrm{NaOH}$ or $\mathrm{HCl}$.

Color in medium: Melanoid pigments formed in peptone-yeast-iron aga $r$ and tryptone-yeast extract broth. Traces of yellow, orange or red pigment may be found in yeast-malt agar and oatmeal agar. This pigment, when present, is not affected by $\mathrm{pH}$ or is changed slightly from orange in presence of $0.05 \mathrm{~N} \mathrm{NaOH}$ to pink in presence of $0.05 \mathrm{~N} \mathrm{HCl}$.

Carbon utilization: D-Glucose is utilized for growth. No growth or only trace of growth on L-arabinose, D-xylose, D-mannitol, rhamnose and raffinose. Variable reports of doubtful growth to no growth with sucrose, I-inositol and D-fructose.

Streptomyces roseus (Krainsky) Pridham, Hesseltine and Benedict. Description: Actinomyces roseus Krainsky 1914, 680-683; A. roseus (Krainsky) Waksman and Curtis 1916, 125 and 128; Waksman 1919, 148149. Streptomyces roseochromogenes (Jensen) Waksman and Henrici 1948, 937; Streptomyces roseus (Krainsky) Pridham et al. 1958, 75. (The name A. roseus was probably first validly published by B. Namyslowski 1912, 567. This culture is unavailable. Nocardia rosea Chalmers and Christopherson 1916, 270 (Val. Publ., Leg.) is probably unrelated, in a different genus, and in no way associated with eit her Namyslowski's or Krainsky's organism.) Type strain: IMRU 3772 (IMRU 3772 is identified as the "type" culture in Waksman 1961, 270-271. It is treated here as a suggested neotype for A. roseus Krainsky). ISP 5076 from S.A. Waksman as IMRU 3772. ISP description by Group A-8.

Spore chain morphology: Section Rectiflexibiles; flexible spore chains predominate. Mature spore chains moderately short with 3 to 10 , or sometimes more than 10 spores per chain. Representative morphology may be found on yeast-malt agar, oatmeal agar, salts-starch agar, and glycerol-asparagine agar, but sporulating surface is slow to develop or may be poorly developed on these media. Spore surface: Smooth (Fig. 147).

Color of colony: Aerial mass color in the Red color-series on oatmeal agar, salts-starch agar and glycerol-asparagine agar after 14-21 days; Yellow color-series on yeast-malt agar.

Reverse side of colony: No distinctive pigment (grayed yellow to yellow-brown) on yeast-malt agar, oatmeal agar, salts-starch agar or glycerol-asparagine agar; substrate pigment is not a $\mathrm{pH}$ indicator. 


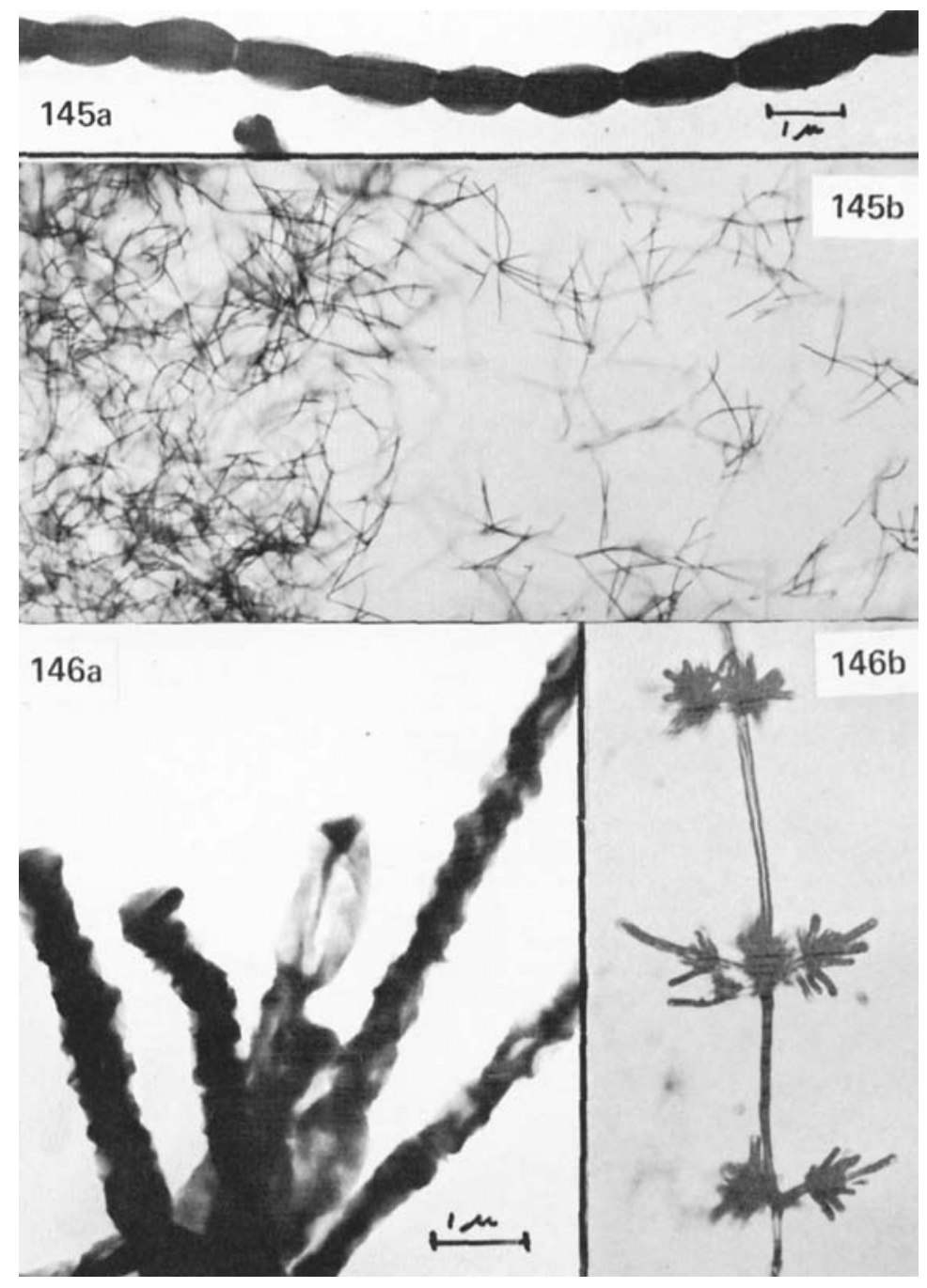

Figure 145. A. roseolus. (a) Smooth spores; electron micrograph from 14 day culture on oatmeal agar. 31 (b) RF spore chains $(150 \mathrm{x})$ on oatmeal agar, 14 days. 31

Figure 146. Streptoverticillium roseoverticillatum. (a) Smooth spores; electron micrograph from $2 \mathrm{l}$ day culture on salts - starch agar.9 (b) BIV (monoverticillate umbellate) morphology $(400 \mathrm{x})$ on oatmeal agar, 14 days. 10 
Color in medium: Melanoid pigments not formed in peptone-yeasti ron agar and tyrosine agar. No pigment found in medium in yeast-malt agar, oatmeal agar, salts-starch agar or glycerol-asparagine agar.

Carbon utilization: D-Glucose and D-xylose are utilized for growth. No growth, or only trace of growth on L-arabinose, sucrose, I-inositol, D-mannitol, rhamnose and raffinose. Utilization of D-fructose is doubtful.

Streptomyces rutgersensis (Waksman and Curtis) Waksman and Henrici. Descriptions: Actinomyces rutgersensis Waksman and Curtis 1916, 128; Waksman 1919, 152-153. Streptomyces rutgersensis (Waksman and Curtis) Waksman and Henrici 1948, 952. Type strain: IMRU 3350 (Waksman 1961, 272-273). ISP 5077 from S. A. Waksman as IMRU 3350. ISP description by Group A-9.

Spore chain morphology: Section Rectiflexibiles to Retinaculiaperti. Short spore chains on this strain are irregularly bent or turned and are not typical of either RF or RA cultures (Fig. 148). (The characterization by Waksman and Curtis 1916, describes spiral spore chains. Atypical spirals are now very rare: reported by only one observer.) Usually only 3 to 10 spores per chain on yeast-malt agar, oatmeal agar, salts-starch agar and glycerol-asparagine agar. Spore surface: Smooth (Fig. 148).

Color of colony: Aerial mass color in the Yellow color-series on yeast-malt agar, oatmeal agar, salts-starch agar and glycerol-asparagine agar.

Reverse side of colony: Grayed yellow modified by green on yeastmalt agar, oatmeal agar, salts-starch agar and glycerol-asparagine agar; substrate color is not a $\mathrm{pH}$ indicator.

Color in medium: Melanoid pigments not formed in peptone-yeastiron agar, tyrosine agar and tryptone-yeast extract broth. Pigments not formed in significant amounts in yeast-malt agar, oatmeal agar, salts-starch agar or glycerol-asparagine agar.

Carbon utilization: D-Glucose, L-arabinose, D-xylose, D-mannitol and $\underline{D}$-fructose are utilized for growth. No growth or only trace of growth on sucrose, I-inositol, rhamnose and raffinose.

Streptomyces sioyaensis Nishimura, Okamoto, Mayama, Ohtsuka, Nakajima, Tawara, Shimohira and Shimaoka. Description: Nishimura et al. 1961, 255-263. Type strain: H-690 (ibid.). ISP 5032 from $\mathrm{H}$. Nishimura as $\mathrm{H}-690$. ISP description by Group A-3.

Spore chain morphology: Section Spirales. Mature spore chains generally 10 to 50 spores per chain; longer chains are sometimes observed (Fig. 149). Morphology can be observed on oatmeal agar and glycerol-asparagine agar in 14 to 21 days. Typical aerial mycelium may develop slowly or fail to develop on yeast-malt agar and salts-starch agar. Spore surface: Smooth (Fig. 149).

Special morphological characteristics: One observer reports disintegration of spiral spore chains in dark liquid droplets.

Color of colony: Aerial mass color in the Gray color-series on yeastmalt agar, oatmeal agar, salts-starch agar and glycerol-asparagine agar.

Reverse side of colony: No distinctive pigments (grayed yellow or grayed yellow modified by green) on yeast-malt agar, oatmeal agar, salts- 


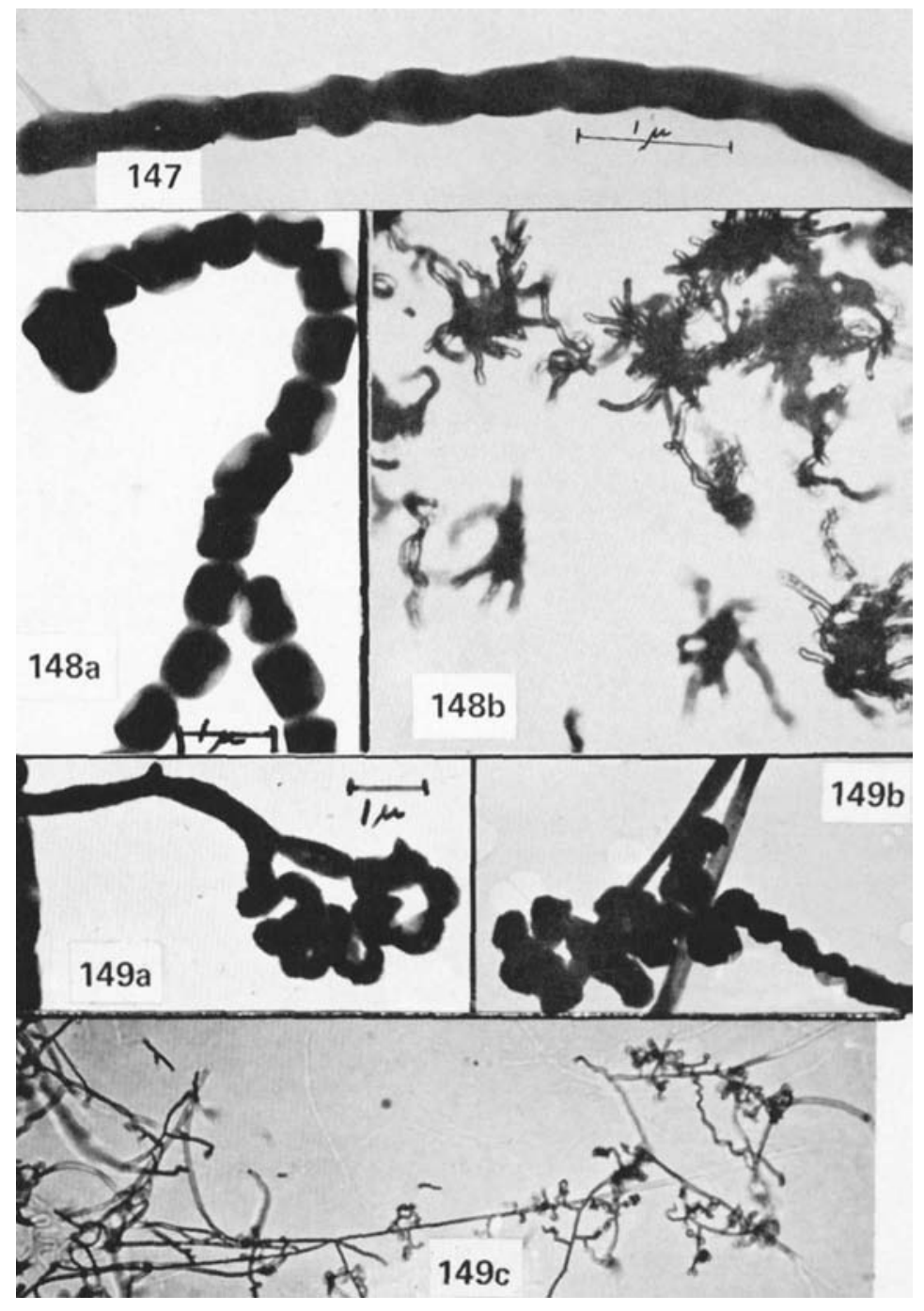

Figure 147. S. roseus, Smooth spores; electron micrograph from 14 day culture on yeast-malt agar.l

Figure 148. S. rutgersensis. (a) Smooth spores; electron micrograph from 21 day culture on yeast-malt agar. 9 (b) Short flexuous or crooked spore chains $(400 x)$ on salts-starch agar. 10

Figure 149. S. sioyaensis. (a,b) Smooth spores in spirals; electron micrograph from 14 day culture on oatmeal agar and yeast-malt

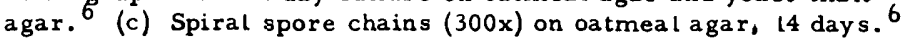


starch agar and glycerol-asparagine agar; substrate pigment is not a $\mathrm{pH}$ indicator.

Color in medium: Melanoid pigments not formed in peptone-yeasti ron agar and tyrosine agar. Trace of yellow pigment found in medium in yeast-malt agar, oatmeal agar, salts-starch agar and glycerol-asparagine agar; this pigment is not $\mathrm{pH}$ sensitive.

Carbon utilization: D-Glucose, sucrose, D-xylose, I-inositol, Dmannitol, D-fructose and raffinose are utilized for growth. No growth or only trace of growth on L-arabinose and rhamnose.

Streptomyces spiroverticillatus Shinobu. Description: Shinobu 1958,87-93. Type strain: 508 (ibid.). ISP 5036 from R. Shinobu as 508. ISP description by Group $\overline{A-5}$.

Spore chain morphology: Section Retinaculiaperti. Shinobu's original description makes note of verticils or whorls "near the base of the aerial mycelium". Although this culture is not verticillate in the sense of the present study (Shirling and Gottlieb 1966, 326-328), one observer confirms the occasional whorl-like arrangement of spore chains. Mature spore chains generally long, often with more than 50 spores per chain (Fig. 151). This morphology is seen on yeast-malt agar, oatmeal agar, salts-starch agar and glycerol-asparagine agar. Spore surface: Smooth (Fig. 150).

Special morphological characteristics: Conidia-like fragments in substrate mycelium (one observer); sclerotia ( 2 observers).

Color of colony: Aerial mass color in the White color-series on yeast-malt agar and glycerol-asparagine agar; White or Red series on oatmeal agar and salts-starch agar.

Reverse side of colony: Grayed yellow to yellow-brown is modified by red or orange on yeast-malt agar, oatmeal agar, salts-starch agar and glycerol-asparagine agar. Reverse color is changed slightly from yellow-brown to reddish brown by addition of $0.05 \mathrm{~N} \mathrm{NaOH}$ and from reddish-brown to yellow-brown with $0.05 \mathrm{~N} \mathrm{HCl}$.

Color in medium: Melanoid pigments not formed in peptone-yeastiron agar and tyrosine agar. Pigments other than traces of yellow not formed in yeast-malt agar, oatmeal agar, salts-starch agar or glycerolasparagine agar. One observer reports a trace of yellow pigment that may change to pink with addition of $0.05 \mathrm{~N} \mathrm{NaOH}$.

Carbon utilization: D-Glucose, L-arabinose, D-xylose and D-fructose are utilized for growth. No growth or only trace of growth on I-inositol, D-mannitol, rhamnose and raffinose. Variable reports on growth with sucrose.

Streptomyces tendae Ettlinger, Corbaz, Hütter. Description: Ettlinger et al. 1958, 351-352. Type strain: ETH 11313 (ibid.). ISP 5101 from $\bar{R}$. Hütter as ETH 11313 . ISP description by Group A-10.

Spore chain morphology: Section Retinaculiaperti or Spirales. Straight to flexuous spore chains are most common on yeast-malt agar and epirals a re best developed on salts-starch agar. Straight, flexuous, RA, and spiral spore chains are recorded for oatmeal agar and glycerolasparagine agar (Fig. 152). Mature spore chains generally 10 to 50 spores per chain, longer chains are sometimes observed. Spore surface: Smooth (Fig. 152).

Color of colony: Aerial mass color in the Gray color-series on yeast- 


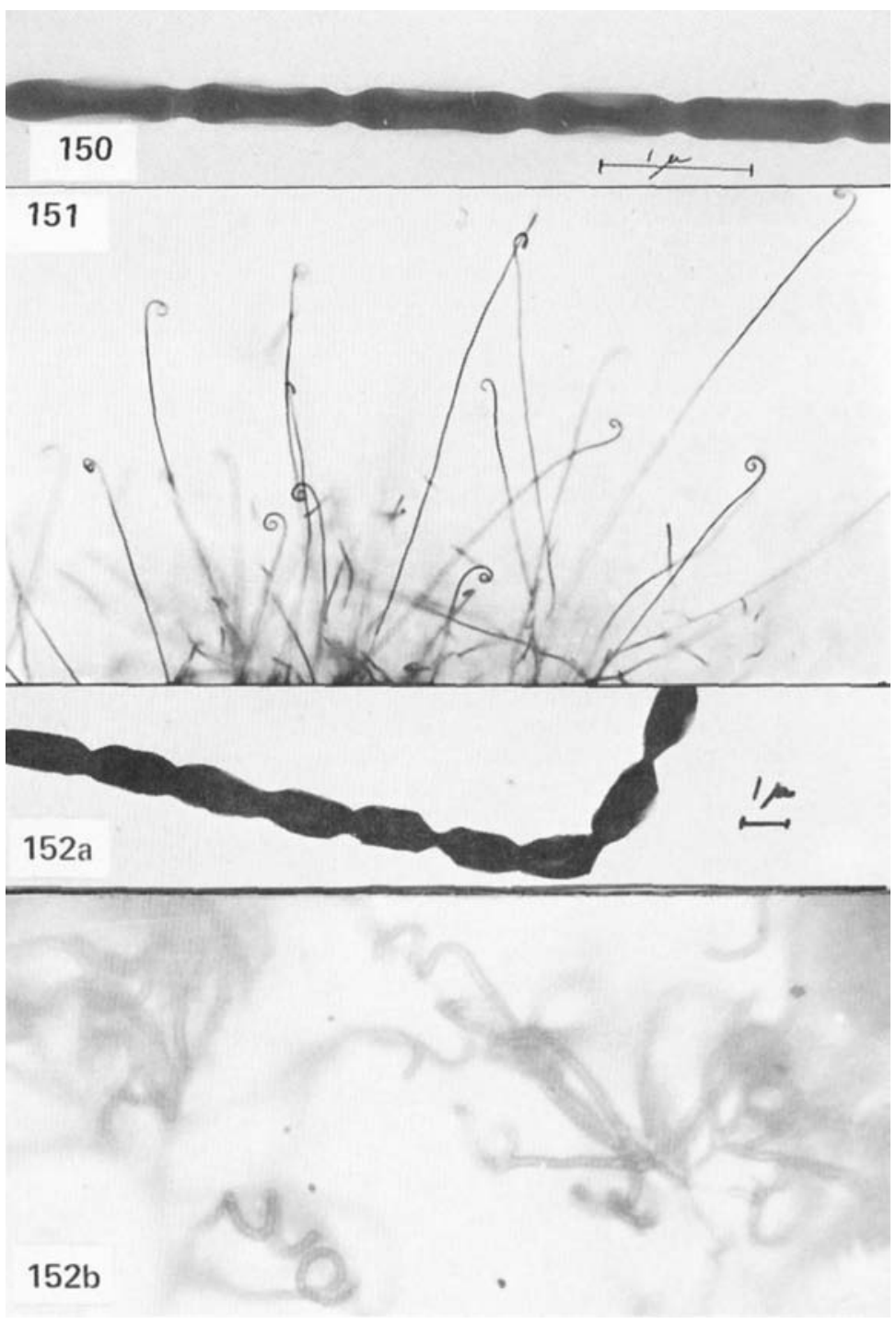

Figure 150. S. spiroverticillatus. Smooth spores; electron micrograph from 14 day culture on oatmeal agar. 1

Figure 151. S. spiroverticillatus. RA spore chains on oatmeal agar, 9 days. 19

Figure 152. S. tendae. (a) Smooth spores; electron micrograph from 10 day culture on yeast-malt agar ${ }^{17}$ (b) Spiral spore chains $(1000 \mathrm{x})$ on oatmeal agar, 14 days. ${ }^{18}$ 
malt agar, oatmeal agar and salts-starch agar.

Reverse side of colony: Yellow or greenish yellow on yeast-malt agar, oatmeal agar, salts-starch agar and glycerol-asparagine agar. Reverse color is changed from yellow to orange by addition of $0.05 \mathrm{~N} \mathrm{HCl}$.

Color in medium: Melanoid pigments not formed in peptone-yeastiron agar, tyrosine agar or tryptone-yeast extract broth. Yellow pigment found in medium in glycerol-asparagine agar; traces of yellow pigment may also diffuse into yeast-malt agar, oatmeal agar or salts-starch agar. The yellow pigment is changed to yellowish orange or orange by $0.05 \mathrm{~N} \mathrm{HCl}$.

Carbon utilization: D-Glucose, L-arabinose, sucrose, D-xylose, I-inositol, D-mannitol, D-fructose and rhamnose are utilized for growth. No growth or only trace of growth on raffinose.

Actinomyces toxytricini Preobrazhenskaya and Sveshnikova. Description: Preobrazhenskaya and Sveshnikova in Gauze et al. 1957, 44 and 47. Type strain: 13887/54 (Preobrazhenskaya, personal communication). Streptomyces toxytricini (Preobrazhenskaya and Sveshnikova) Pridham et al. 1958, 68. ISP 5178 from T. P. Preobrazhenskaya as $13887 / 54$. ISP description by Group A-6.

Spore chain morphology: Section Retinaculiaperti or Spirales. Long spore chains of the RA type as well as straight to flexuous sporophores a re common on salts-starch agar, glycerol-asparagine agar, yeastmalt agar and oatmeal agar. Spirals are most numerous as long chains of more than 50 spores on yeast-malt agar and oatmeal agar. Chains of 10 to 50 or more spores per chain are also found on salts-starch agar and glycerol-asparagine agar (Fig. 153). Spore surface: Smooth (Fig. 153).

Color of colony: Aerial mass color in the Red color-series on yeastmalt agar, oatmeal agar and salts-starch agar.

Reverse side of colony: No distinctive pigment (grayed yellow to yellow-brown) on yeast-malt agar, oatmeal agar, salts-starch agar or glycerol-asparagine agar. Substrate pigment is not a $\mathrm{pH}$ indicator.

Color in medium: Melanoid pigments formed in peptone-yeast-iron agar and tryptone-yeast extract broth. Pigments other than melanoids not formed in yeast-malt agar, oatmeal agar, salts-starch agar or glycerol-asparagine agar.

Carbon utilization: D-Glucose is utilized for growth. Doubtful traces of growth or no growth on L-arabinose, sucrose, D-xylose, $\underline{I}$-inositol, rhamnose and raffinose. Utilization of $\underline{D}$-mannitol and $\underline{D}-$ fructose is also doubtful.

Streptomyces toyocaensis Nishimura, Katagiri, Sato, Mayama and Shimaoka. Description: Nishimura et al. Japanese Patent 236280 , 1954. See also Nishimura et al. 1956, 60-62; Jap. Pat. SHO 32-3049, 1957. Type strain: 278 (Nishimura et al. Jap. Pat. 236280). ISP 5030 from $H$. Nishimura as 278 . ISP description by Group A-2.

Spore chain morphology: Section Spirales. Mature spore chains generally 10 to 50 spores per chain (Fig. 155). This morphology is seen on yeast-malt agar, oatmeal agar, salts-starch agar and glycerolasparagine agar. Spore surface: Spiny (Fig. 154).

Color of colony: Aerial mass color in the Gray color-series on yeastmalt agar, oatmeal agar, salts-starch agar and glycerol-asparagine agar. 

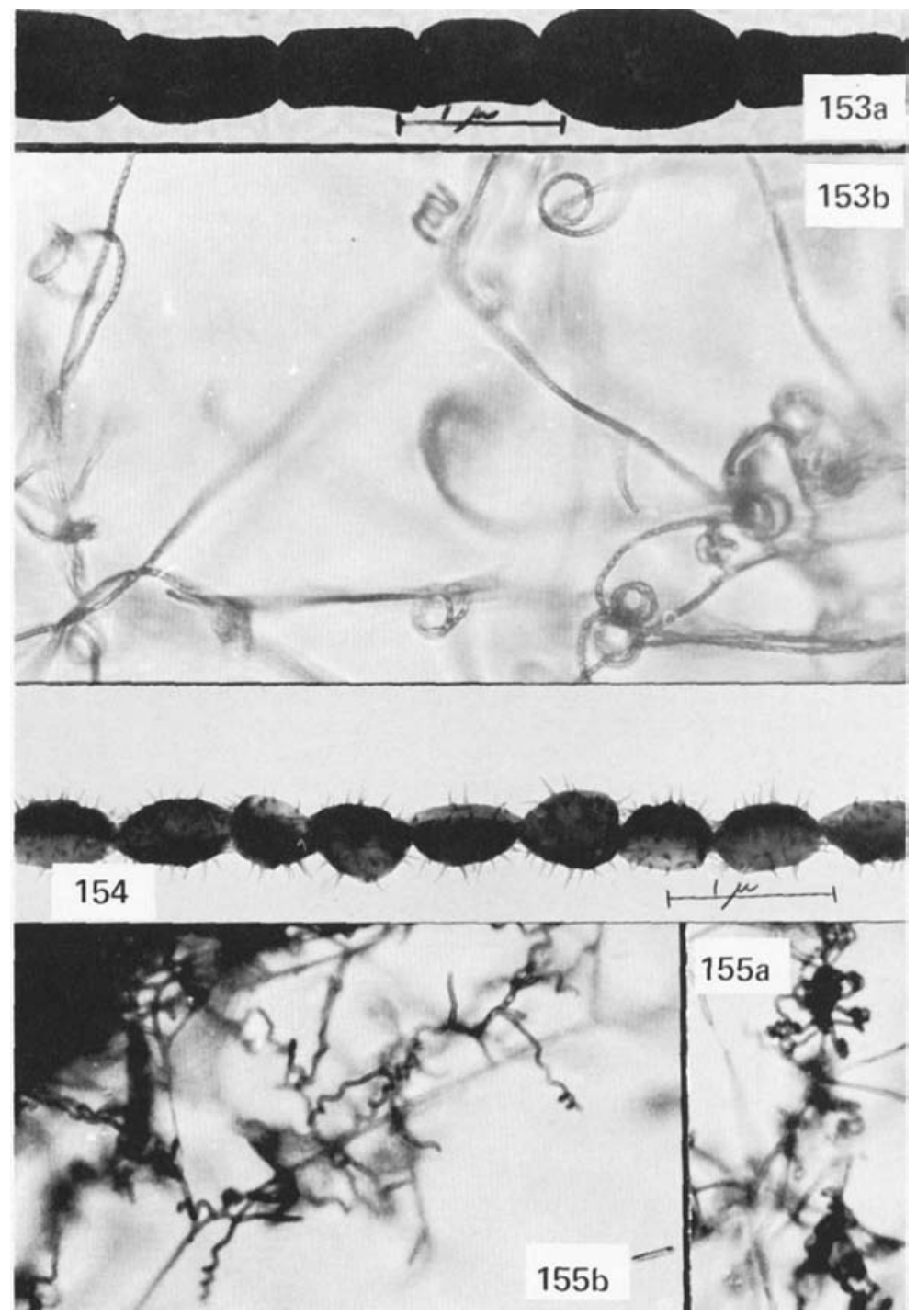

Figure 153. S. toxytricini. (a) Smooth spores; electron micrograph from $2 L$ day culture on yeast-malt agar. ${ }^{32}$ (b) RA to Spiral spore chains $(1200 \mathrm{x})$ on oatmeal agar, 14 days. 24 Straight to flexuous spore chains are also observed.

Figure 154. S. toyocaensis. Spiny spores; electron micrograph from 14 day culture on oatmeal agar.

Figure 155. S. toyocaensis. Spiral spore chains (500x) on oatmeal agar, 7 days. (a) Tight spirals. (b) Open spirals. 8 
Reverse side of colony: No distinctive pigment on yeast-malt agar, oatmeal agar, saits-starch agar or glycerol-asparagine agar; substrate pigment is not a $\mathrm{pH}$ indicator.

Color in medium: Melanoid pigments not formed in peptone-yeastiron agar and tyrosine agar. No pigment found in medium in yeastmalt agar, oatmeal agar, salts-starch agar or glycerol-asparagine agar.

Carbon utilization: D-Glucose, L-arabinose, I-inositol, D-mannitol and D-fructose are utilized for growth. No growth or only trace of growth on rhamnose and raffinose. Utilization of sucrose and D-xylose is doubtful.

Actinomyces variabilis Preobrazhenskaya, Ryabova and Blinov. Description: Preobrazhenskaya et al. in Gauze et al. 1957, 170-171. Type strain: $5557 / 54$ (Preobrazhenskaya, personal communication). Streptomyces variabilis (Preobrazhenskaya, Ryabova and Blinov) Pridham et al. 1958, 70. ISP 5179 from T.P. Preobrazhenskaya as $5557 / 54$. ISP description by Group A - 5 .

Spore chain morphology: Section Spirales. Open spirals are conspicuous on salts-starch agar, rare on yeast-malt agar. Flexuous spore chains, loops, hooks and spirals suggestive of Scction RA are found on oatmeal agar, salts-starch agar and glycerol-asparagine agar (Fig. 157). Spore surface: Spiny. Spines are short; one observer reports warty to smooth spores (Fig. 156).

Color of colony: Aerial mass color in the Gray color-series on oatmeal agar and salts-starch agar; Gray or Red series on yeast-malt agar. Aerial spore mass is not well-developed on glycerol-asparagine agar.

Reverse side of colony: No distinct pigment on oatmeal agar, saltsstarch agar or glycerol-as paragine agar; reddish brown on yeast-malt agar.

Color in medium: Melanoid pigments not formed in peptone-yeastiron agar and tyrosine agar. No pigment found in medium in yeast-malt agar, oatmeal agar, salts-starch agar or glycerol-asparagine agar.

Carbon utilization: D-Glucose, L-arabinose, D-xylose, I-inositol, D-mannitol, D-fructose and rhamnose are utilized for growth. No growth or only trace of growth on sucrose and raffinose.

Streptomyces violaceoruber (Waksman and Curtis) Kutzner and Waksman. Descriptions: Actinomyces violaceus or A. violaceus-ruber Waksman and Curtis 1916, 110-111 and 127; Waksman 1919, 160-163; Streptomyces violaceoruber Kutzner and Waksman 1959, 528-536. Type strain: IMRU 3030 (Waksman 1961, 282-284; Kutzner and Waksman 1959, 528-536). ISP 5049 from R. Gordon as IMRU 3030. ISP description by Group A-11.

Spore chain morphology: Section Spirales, but spore chains representative of Sections $\underline{R F}$ and $\underline{R A}$ are also reported. Mature spore chains generally 10 to 50 or more spores per chain (Fig. 159). Typical morphology on yeast-malt agar, oatmeal agar, salts-starch agar and glycerolasparagine agar. Spore surface: Smooth (Fig. 158).

Color of colony: Aerial mass color in the Gray color-series on yeastmalt agar, oatmeal agar, salts-starch agar and glycerol-asparagine agar.

Reverse side of colony: Blue or violet, depending on $\mathrm{pH}$ (see below), on yeast-malt agar, oatmeal agar, salts-starch agar and glycerol- 


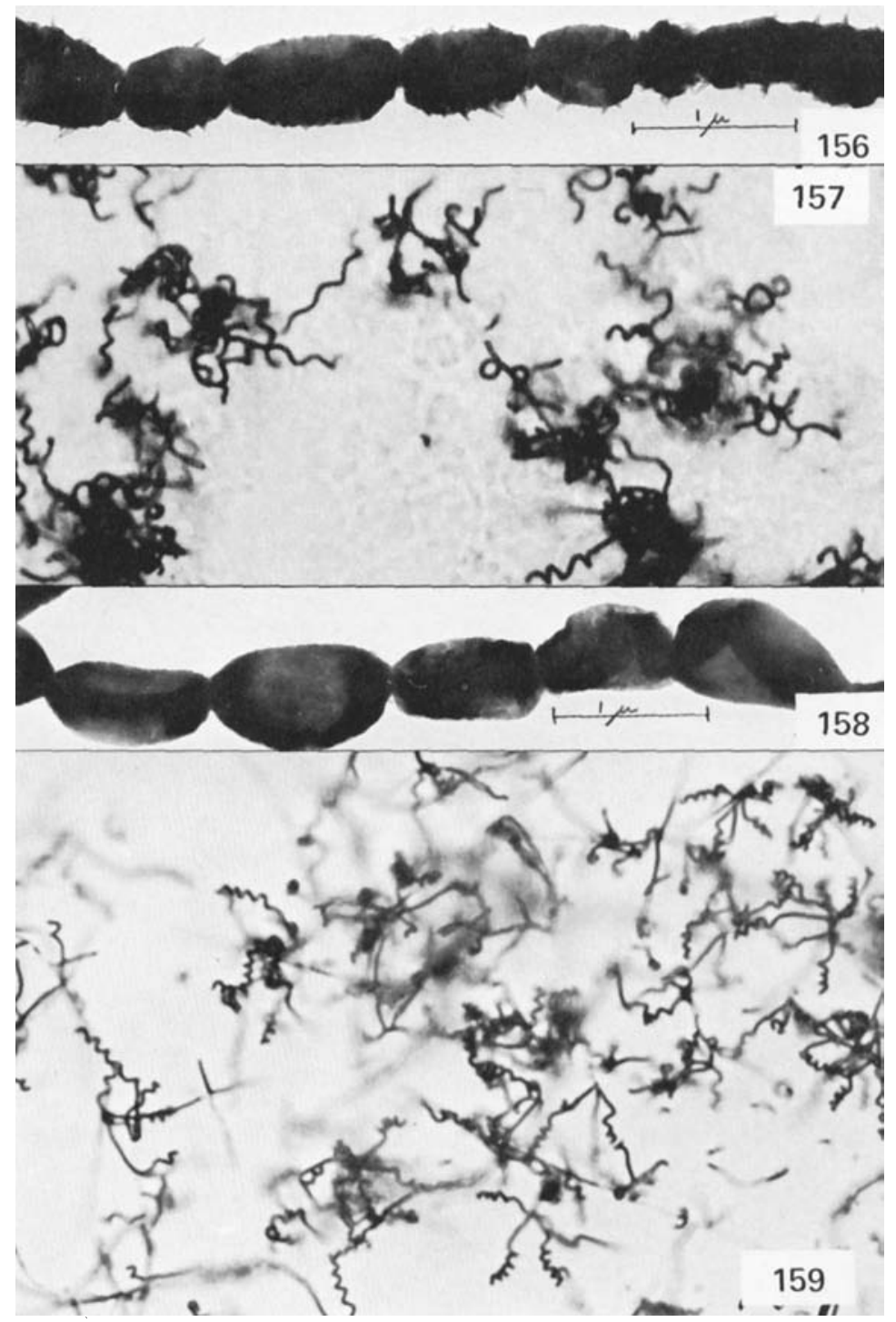

Figure 156. A. variabilis. Spiny spores; electron micrograph from 14 day culture on oatmeal agar. 1

Figure 157. A. variabilis. Spiral spore chains (open spirals, 400x) on oatmeal agar, 14 days. 19

Figure 158. S. violaceoruber. Smooth spores; electron micrograph from 14 day culture on oatmeal agar. 1

Figure 159. S. violaceoruber. Spiral spore chains $(300 x)$ on salts starch agar, 14 days. 4 
asparagine agar. Reverse pigment is a $\mathrm{pH}$ indicator changing from violet or blue-violet to blue by addition of $0.05 \mathrm{~N} \mathrm{NaOH}$ and from violet to redviolet or red with $0.05 \mathrm{~N} \mathrm{HCl}$.

Color in medium: Melanoid pigments not formed in peptone-yeast-iron agar, tyrosine agar or tryptone-yeast extract broth. Blue or violet pigment found in medium in yeast-malt agar, oatmeal agar, saltsstarch agar and glycerol-asparagine agar. This pigment is $\mathrm{pH}$ sensitive; color changes a re identical to changes noted for reverse color.

Carbon utilization: D-Glucose, L-arabinose, D-xylose, I-inositol, D-mannitol, D-fructose and rhamnose are utilized for growth. No growth or only trace of growth on sucrose. Variable reports on growth with raffinose.

Streptomyces virginiae Grundy, Whitman, Rdzok, Rdzok, Hanes, Sylvester. Description: Grundy et al. 1952, 399-408. Type strain: NA255-B8 (ibid.). ISP 5094 from $T$. Oliver for Abbott Labs. as NA255-B8 (M808). ISP description by Group A-7.

Spore chain morphology: Section Retinaculiaperti, including flexuous, looped and spiral forms characteristic of this section. (Terminal spirals on long spore chains may be common in some areas on mass cultures.) Mature spore chains moderately long with 10 to 50 , or sometimes more than 50, spores per chain (Fig. 161). This morphology is seen on yeast-malt agar, oatmeal agar, salts-starch aga $r$ and glycerolasparagine agar. Spore surface: Smooth (Fig. 160).

Color of colony: Aerial mass color in the Red or Gray color-series on yeast-malt agar, oatmeal agar, salts-starch agar and glycerol-asparagine agar. Color tabs selected by observers: Grayish yellowish pink ( $5 \mathrm{dc}$, 6ec, Red series); pale purple ( $7 \mathrm{fe}$, Gray series).

Reverse side of colony: No distinctive pigment (grayed yellow to yellow-brown) on yeast-malt agar, oatmeal agar or glycerol-asparagine agar; dark grayed yellow may be modified by traces of red or violet on salts-starch agar. Substrate pigment is not a $\mathrm{pH}$ indicator.

Color in medium: Melanoid pigments formed in peptone-yeast-iron agar and tryptone-yeast extract broth. Pigments other than melanoids not formed in yeast-malt agar, oatmeal agar, salts-starch agar or glyercol-asparagine agar.

Carbon utilization: D-Glucose and D-fructose are utilized for growth. Trace of growth on L-arabinose, sucrose, D-xylose, I-inositol, Dmannitol, rhamnose and raffinose is similar to, or only slightly better than growth on basal medium without carbon.

Streptomyces xanthochromogenus A rishima, Sakamoto and Sato. Description: A rishima et al . 1956, 469-471. Type strain: 689 (ibid.). ISP 5111 from T. Niida, for Meiji Seika Kaisha, Ltd. as 689. ISP description by Group A-7.

Spore chain morphology: Section Rectiflexibiles. Mature spore chains generally 10 to 50 or more spores per chain. This morphology is seen on yeast-malt agar, oatmeal agar, salts-starch agar and glycerolasparagine agar. Spore surface: Smooth (Fig. 162).

Color of colony: Aerial mass color in the Yellow color-series on yeast-malt agar, oatmeal agar, salts-starch agar and glycerol-asparagine agar.

Reverse side of colony: No distinct pigment (yellow, grayed yellow 


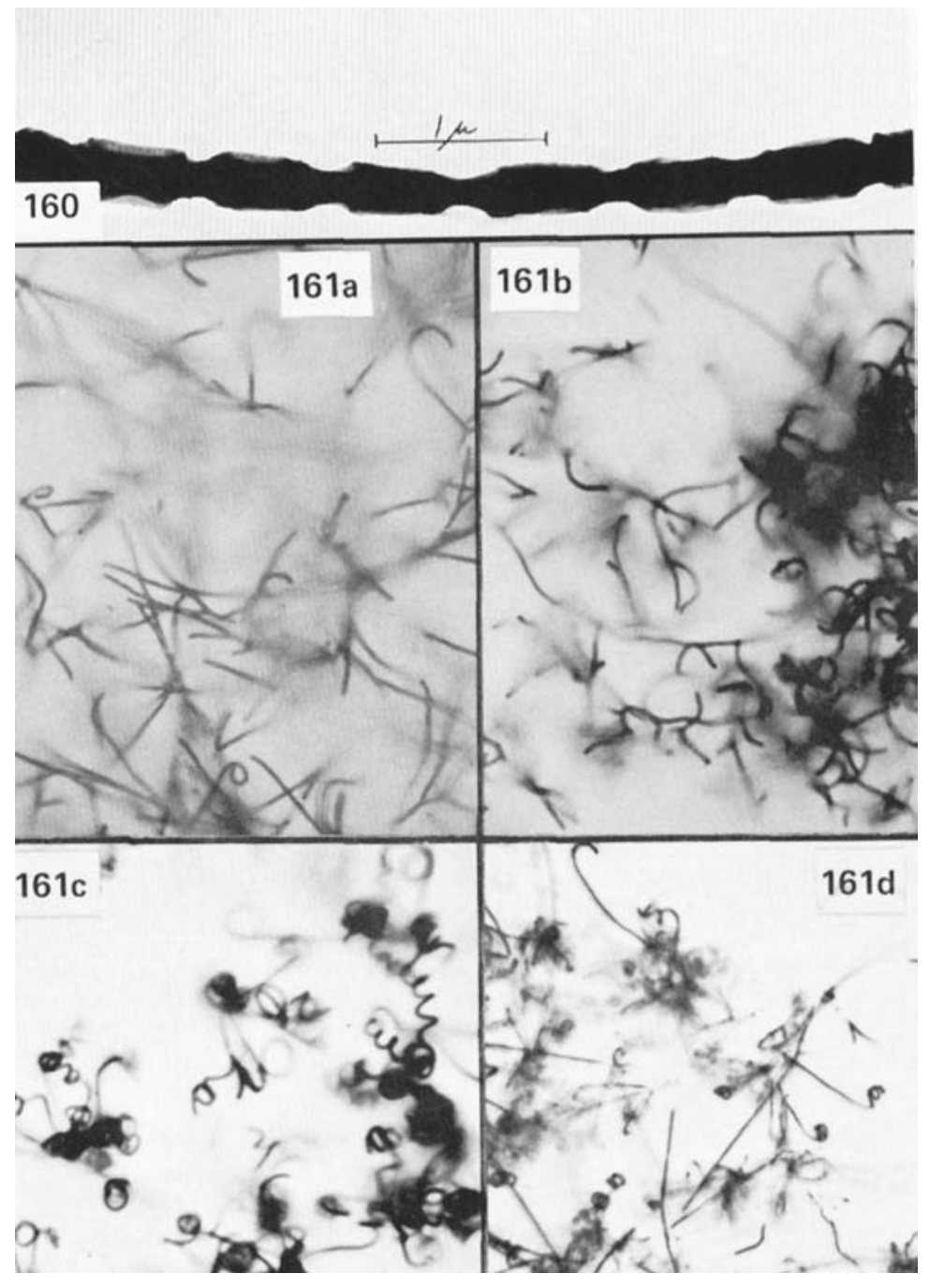

Figure 160. S. virginiae. Smooth spores; electron micrograph from 14 day culture on yeast-malt agar. ${ }^{1}$

Figure 161. S. virginiae. Full range of RA morphology on 14 day

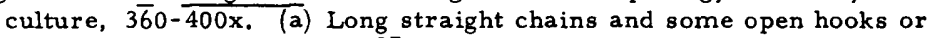
loops on salts-starch agar. 27 (b) Flexuous chains and some primitive spirals on yeast-malt agar. 27 (c) Spirals on oatmeal agar. ${ }^{12}$ (d) Hooks and spirals (300x) on glycerol-asparagine agar. ${ }^{12}$ 
or yellow-brown) on yeast-malt agar, oatmeal agar, salts-starch agar or glycerol-asparagine agar; substrate pigment is not a $\mathrm{pH}$ indicator.

Color in medium: Melanoid pigments formed in peptone-yeast-iron agar, tyrosine aga $r$ and tryptone-yeast extract broth. Yellow pigment may be found in oatmeal agar and salts-starch agar or may be absent. Yellow pigment is not $\mathrm{pH}$ sensitive.

Carbon utilization: D-Glucose, D-xylose, D-mannitol and D-fructose are utilized for growth. Only trace of growth indicating doubtful utilization of I-inositol, rhamnose and raffinose. Variable reports on growth with $\underline{L}-a$ rabinose and sucrose.

St reptomyces xanthophaeus Lindenbein. Description: Lindenbein 1952, 378-379. Type strain: Wüst 70 (ibid.). ISP 5134 from P. Wilde as Wüst 70. ISP description by Group A-8.

Spore chain morphology: Section Rectiflexibiles. Mature spore chains very long, usually more than 50 spores per chain (Fig. 163). This morphology is found on oatmeal agar, salts-starch agar and glyce rol-asparagine agar; poor sporulation on yeast-malt agar. Spore surface: Smooth (Fig. 163).

Color of colony: Aerial mass color in the Red or Gray color-series on oatmeal agar, salts-starch agar and glycerol-asparagine agar. Nearest matching color tabs: Grayish yellowish pink ( $5 \mathrm{dc}$, Red series) to light grayish reddish brown ( 5 fe to 4 li, Gray color-series).

Reverse side of colony: Colorless or characteristic grayed yellow to yellow-brown on yeast-malt agar, oatmeal agar and glycerol-asparagine agar, but very dark reddish gray to near black on salts-starch agar. Reverse color is not a pH indicator.

Color in medium: Melanoid pigments formed in peptone-yeast-iron agar and tryptone-yeast extract broth. Pigments other than traces of yellow not formed in yeast-malt agar, oatmeal agar, salts-starch agar or glycerol-as paragine agar.

Carbon utilization: D-Glucose is utilized for growth. No growth or only trace of growth on L-arabinose, sucrose, D-xylose, I-inositol, D-mannitol, D-fructose, rhamnose and raffinose.

\section{ACKNOWLEDGMENTS}

The Subcommittee on Actinomycetes of the Committee on Taxonomy, ASM, perticipated in the planning of the project, preparation of descriptions and editing of the manuscript. Members of the Subcommittee (other than the a thors) during the period covered by this report were: T. G. Pridham, E.J. Backus and W. Grundy.

We a re grateful to A. A Ichida, Jann M. Ichida, J anet Stevens, Margaret Speer and Louise Hoffhines of the Ohio Wesleyan ISP statf for technical services, for assistance in locating authentic type cultures and descriptive literature, and for help in collating data from cooperating laboratories.

C. W. Christensen of Difco Laboratories rendered valuable as sistance in directing the formulation of dehydrated culture media according to ISP specifications. The technical and financial assistance of Difco Laboratories, Detroit, Michigan, in supplying these standardized media 

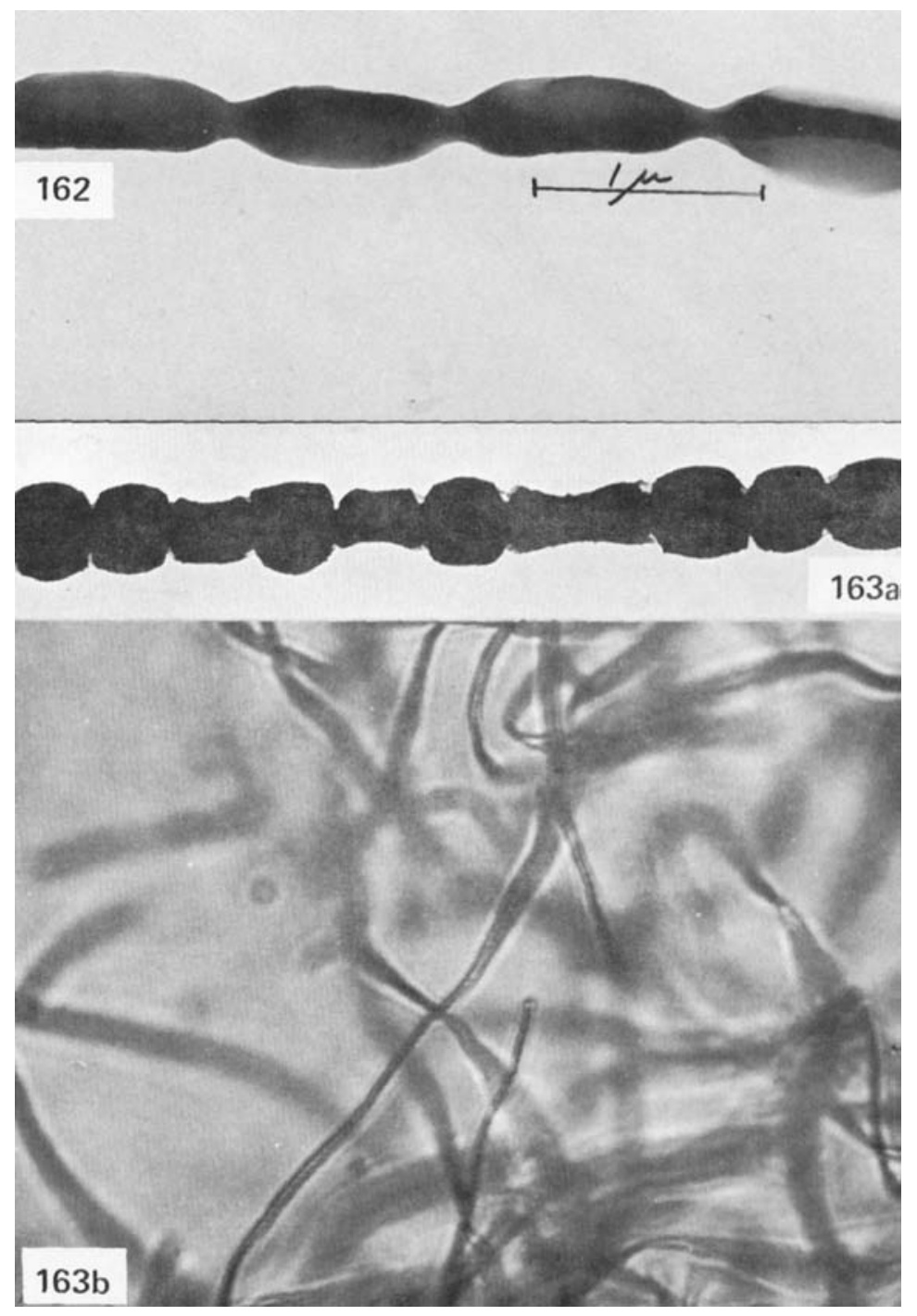

Figure 162. S. xanthochromogenus. Smooth spores; electron micrograph from 14 day culture on oatmeal agar. 1

Figure 163. S. xanthophaeus . (a) Smooth spores; electron micrograph from $2 \mathrm{~L}$ day culture on glycerol-asparagine agar. 23 (b) $\mathrm{RF}_{\text {, very }}$ long chains of spores on glycerol-asparagine agar, 21 days. 23 
to collaborators throughout the world is gratefully acknowledged.

This research was supported by National Science Foundation Grant GB 509 and GB 4365. The Subcommittee on Actinomycetes of the Committee on Taxonomy, ASM, and the Subcommittee on Taxonomy of Actinomycetes of the International Committee on Bacteriological Nomenclature are co-sponsoring advisors.

\section{BIBLIOGRA PHY}

Arishima, M., J. Sakamoto and T. Sato. 1956. Studies on an antibiotic Streptomyces No. 689 strain. Part I. Taxonomic studies. J. Agric. Chem. Soc., Japan 30: 469-471.

Backus, E. J., H. D. Tresner and T. H. Campbell. 1957. The nucleocidin and alzopeptin producing organisms: Two new species of Streptomyces. Antibiotics and Chemotherapy $7: 532-541$.

Baldacci, E. 1958. Development in the classification of antinomycetes. Giorn. Microbiol. 6: 10-27.

G. Farina and R. Locci. 1966. Emendation of the genus Streptoverticillium Baldacci (1958) and revision of some species. Gicrn. Microbiol. 14: 153-171.

Benedict, R. G., L. A. Lindenfelser, F. H. Stodola and D. H. Traufler, 1951. Studies on Streptomyces griseocarneus and the production of hydroxystreptomycin. J. Bact. 62: 487-497. . F. H. Stodola, O. L. Shotwell, Anne Marie Borud and L. A. Lindenfelser. 1950. A new streptomycin. Science 112: 77-78.

Bergey, D. H. , F. C. Harrison, R. S. Breed, B. W. Hammer and F. M. Huntoon. 1923. Bergey's Manual of Determinative Bacteriology. 1st. ed. The Williams and Wilkins Co. 1-442.

Brockmann, H. and A. Bohne. 1954. Picromycin, its salts and the process of producing same. U.S. Pat. 2,693,433 Nov. 2, U.S. Patent Office.

- and G. Schmidt-Kastner. 1951. Resistomycin, ein neues Antibioticum aus Actinomyceten. Naturwissenschaft n 38: 479-480.

Buchanan, R., J. Holt and E. Lessel. 1966. Index Bergeyana. The Williams and Wilkins Co., Baltimore.

Burns, J. and D. F. Holtman, 1959. Tennecetin: A new antifungal antibiotic. Antibiotics and Chemothe rapy 9: 398 -405 .

Calhoun, K. M. and L. E. Johnson. 1956. Taxonomic and microbiologic studies of Streptomyces chartreusis, n. sp. Antibiotics and Chemothe rapy 6: 294-298.

Cataldi, M. 1963. In Trejo, W. and R. E. Bennett. Streptomyces species comprising the blue-spore series. J. Bact. 85: 683-684. O. L. Galmarini and J. Pahn. 1962. Curamycin and its production. U.S. Patent 3,015,607 Jan. 2. U.S. Patent Office.

Chalmers, A. J. and J. B. Christopherson. 1916. A Sudanese actinomycosis. Ann. Trop. Med. Parasit. 10:223-282.

Corbaz, R., L. Ettlinger, E. Gaumann, W. Keller, F. Kradolfer, E. Kyburz, L. Neipp, V. Prelog, R. Reusser and H. Zähner. 1955. St offwechselprodukte von Actinomyceten. Narbomycin. Helv. Chim. Acta. 38: 935-942. L. Ettlinger, E. Gäumann W. Keller-Schierlein, F. Kradolfer, L. Neipp, V. Prelog, P. Reusser and H. Zähner. 1957. Stoffwechselprodukte von Actinomyceten. Echinomycin. Helv. Chim. Acta 40: $199-204$. 
L. Ettlinger, E. Gäumann, W. Keller-Schierlein, L. Neipp, V. Prelog, P. Reusser and H. Zähner.1955. Stoffwechselprodukte von Actinomyceten. Angolamycin. Helv. Chim. Acta 38:1202-1209.

, L. Ettlinger, W. Keller-Schierlein and H. Zähner. 1957a. Zur Systematik der Actinomyceten. 1. Über Streptomyceten mit rhodomycinartigen $P$ igmenten. Arch. Mikrobiol. 25: 325-332.

, L. Ettlinger, W. Keller-Schierlein and H. Zähner. 1957b. Zur Systematik der Actinomyceten. 2. Über Actinomycin bildende Streptomyceten. Arch. Mikrobiol. 26: 192-208.

Cron, M. J., D. F. Whitehead, I. R. Hcoper, B. Heinemann and J. Lein. 1956. Bryamycin, a new antibiotic. Antibiotics and Chemothe rapy 6: 63-67.

DeBoer, C., A. Dietz, J. R. Wilkins, C. N. Lewis and G. M. Savage. 1955. Celesticetin - a new crystalline antibiotic. I. Biologic studies of celesticetin, p. 831-836. In Antibiotics Annual 1954-1955. Medical Encyclopedia Inc., New York.

Donovick, R., J. F. Pagano and J. Vandeputte. 1961. Thiostrepton, its salts and production. U.S. Patent. 2,982,689 May 2. U.S. Patent Office.

Ettlinger, L., R. Corbaz and R. Hütter. 1958. Zur Systematik der Actinomyceten. 4. Eine Arteinteilung der Gattung Streptomyces Waksman et Henrici. Arch. Mikrobiol. 31: 326-358.

, E. Gäumann, R. Hütter, W. Keller-Schierlein, K. Kradolfer, L. Neipp, V. Prelog and H. Zähner. 1958. Über die Isolie rung und Charackterisierung von Acetomycin. Helv. Chim. Acta 4l; 216-219.

Falcão de Morais, J. O., O. Gonçalves de Lima and Maria Dália Maia. 1957. Novo estudo sôbre Nocardia recifei Lima et al. c sua designação como Streptomyces recifensis. Anais Soc. Biol. Pernambuco 15(1): 239-253.

Farina, G. and R. Locci. 1966. Contributo allo studio di Streptoverticillium: descrizione di una nuova specie (Streptoverticillum baldacci sp. nov.) ed esame di alcune specie precedentemente delineate. Giorn. Microbiol. 14: 33-52.

Finlay, A. C., G. L. Hobby, F. Hochstein, T. M. Lees, T. F. Lenert, J. A. Means, S. Y. P'An, P. P. Regna, J. B. Routien, B. A. Sobin, K. B. Tate and J. H. Kane. 1951. Viomycin, a new antibiotic active against Mycobacteria. Amer. Rev. Tuberc. 63: 1-3.

, and B. A. Sobin. 1950. Verfahren zur Herstellung eines Antibioticum. German Pat. Appl. P.A. 352176-27.5.50 May 26. München.

, and B. A. Sobin. 1952. Verfahren zur Herstellung eines Antibiotikums. German Patent 834582 Klasse 30h Gruppe 6, P1727 IVa/30h. March 20. Deutsches Patentamt, Bundesrepublik Deutschland.

Frommer, W. 1959. Zur Systematik der Actinomycin bildenden Streptomyceten. Arch. Mikrobiol. 32: 197-206.

Gauze, C. F., T. P. Preobrazhenskaya, E. S. Kudrina, N. O. Blinov, I. D. Ryabova and M. A. Sveshnikova. 1957. Problems of classification of actinomycetes-antagonists (in Russian). Government Publishing House of Medical Literature, Medgiz, Moscow. 1-398.

Gottlieb, D. 1963. Recommendations for descriptions of some Actinomycetales appearing in patent applications. Intern. Bull. Bact. Nomen. Taxon. 13: 169-170. 
, and E. Shirling. 1967. Cooperative description of type cultures of Streptomyces. 1. The International Streptomyces Project. Intern. J. Syst. Bacteriol. 17: 315-322.

Griffith, R. S. and F. B. Peck, J r. 1956. Vancomycin, a new antibiotic, p. 619-622. In Antibiotics Annual 1955-1956. Medical Encyclopedia Inc., New York.

Grundy, W. E. , Alma L. Whitman, E. G. Rdzok, E. J. Rdzok, Marjorie E. Hanes and J. C. Sylvester. 1952. Actithiazic acid. I. Microbiological studies. Antibiotics and Chemotherapy 2 : 399-408.

Heinemann, B., M. A. Kaplan, R. D. Muir and I. R. Hooper. 1953. Amphomycin, a new antibiotic. Antibiotics and Chemotherapy 3: $1239-1242$.

Hesseltine, C. W., J. N. Porter, N. Deduck, M. Hauck, N. Bohonos and J. H. Williams. 1954. A new species of Streptomyces. Mycologia 46: 16-22.

Hickey, R. J., C. J. Corum, P. H. Hidy, I. R. Cohen, U. F. B. Nager and Eleanore Kropp. 1952. Ascostin, an antifungal antibiotic produced by a Streptomycete. Antibiotics and Chemothe rapy $2: 472-483$.

Hirsch, P. 1960. Einige weitere, von Luftverunreinigungen lebende Actinomyceten und ihre Klassifizierung. Arch. Mikrobiol. 35: $391-414$.

Hosoya, S., N. Komatsu, M. Soeda and Y.Sonoda. 1952. Trichomycin, a new antibiotic produced by Streptomyces hachijoensis with trichomonadicidal and antifungal activity. Japan. J. Exp. Med. 22: 505-509.

- N. Komatsu, M. Soeda, T. Yuwaguchi and Y. Sonoda. 1952. Trichomycin, a new antibiotic with trichomonadicidal and antifungal activities. J. Antibiotics Tokyo 5: 564-566.

Hütter, R. 1962a. Zur Systematik der Actinomyceten. 7. Streptomyceten mit blauem, blaugrünem and grünem Luftmycel. Arch. Mikrobiol. 43: 23-49.

- 1962b. Zur Systematik der Actinomyceten. 8. Quirlbildende Streptamyceten. Arch. Mikrobiol. 43: 365-391.

, W. Keller-Schierlein and H. Zähner. 1961. Zur Systematik der Actinomyceten. 6. Die Produzenten von Makrolid-Antibiotica. Arch. Mikrobiol. 39: 158-194.

Krainsky, A. 1914. Die Aktinomyceten und ihren Bedeutung in der Natur. Zbl. Bakt. Abt. 2, 41: 649-688.

Krasil'nikov, N. A. 1941. Guide to the actinomycetes (in Russian). Akad. Nauk. S.S.S. R., Moscow. 1-158.

- 1949. Guide to the bacteria and actinomycetes (in Russian). Akad, Nauk. S. S.S. R., Moscow. 1-830.

, A. I. Koreniako, M. M. Meksina, L. K. Valedinskaia, and N. M. Vesselov. 1957. On the culture of the Actinomyces No. 111. Act. luridus nov. sp., producing an antiviral antibiotic, luridin. Mikrobiologiya 26: 558-564.

- and Yün Chi-Sheng. 1960. A new species of the Actinomyces aurantiacus group (in Russian). Mikrobiologiya 29: 482-489. 
Kudrina, E. S. 1957a. Characteristics of antagonistic actinomycetes of the Helvolus series (in Russian), p. 77-100. In Gauze, G. F. , T. P. Preobrazhenskaya, E. S. Kudrina, N. O. Blinov, E. D. Ryabova and M. A. Sveshnikova. Problems of classification of actinomycetes-antigonists. Government Publishing House of Medical Lite rature, Medgiz, Moscow.

McCormick, M. H. and M. M. Hoehn. 1953. Isolation of a new antibiotic from Streptomyces fasiculatus nov. sp. Antibiotics and Chemothe rapy $3: 718-720$.

, W. M. Stark, G. E. Pittenger, R. C. Pittenger and J. M. MCGuire. 1956. Vancomycin, a new antibiotic, p. 606-61l. In Antibiotics Ann. 1955-1956. Medical Encyclopedia Inc., New York.

Maeda, K., T. Takeuchi, K. Nitta, K. Yagishita, R. Utahara, T. Osato, M. Ueda, S. Kondo, Y. Okami and H. Umezawa. 1956. A new antitumor substance pluramycin. J. Antibiotics, Tokyo Ser. A, 9: $75-81$.

Nakazawa, K. 1955. Streptomyces albireticuli nov. sp. J. Agric. Chem. Soc. of Japan, 29: 647-649.

Namyslowski, B. 1912. Beitrag zur Kenntnis der menschlichen Hornhautbakteriosen. Zbl. Bakt. Abt. 1, Orig. 62: 564-568.

Nishimura, H. 1954. Toyocamycin, a new antibiotic and process for producing the same. Japan Patent 236-280 Oct. 21. Japan Patent Office Official Gazette.

- 1957. Japan Patent SHO 32-3049 May 21. Japan Patent Publ. - 1961. Japan Patent 19, 750 October 19. Japan Patent Office. - K. Katagiri, K. Sato, M. Mayama and H. Shimaoka. 1956. Toyocamycin, a new anti-candida antibiotic. J. Antibiotics, Tokyo Ser. A, 9: 60-62.

S. Okamoto, M. Mayama, H. Ohtsuka, K. Nakajima, K. Tawara, M. Shimohira and N. Shimaoka. 1961. Siomycin, a new Thiostrepton-like antibiotic. J. Antibiotics, Tokyo Ser. A, 14: 255-263.

K. Sasaki, M. Mayama, N. Shimaoka, K. Tawara, S. Okamoto and K. Nakajima. 1960. Minomycin, a new antibiotic pigment from a Streptomyces sp. J. Antibiotics, Tokyo Ser. A, 13:327-330.

Okami, Y. 1952. On the new Streptomyces isolated from soil. J. Antibiotics, Tokyo Ser. A, 5: 477-480.

, and H. Umezawa. 1953a. In Okami, Okuda, Takeuchi, Nitta and Umezawa. Studies on anti-tumor substances produced by microorganisms, IV. Sarkomycin-producing streptomyces and two other streptomyces producing the anti-tumor substance No. 289 and caryomycin. J. Antibiotics, Tokyo Ser. A, 6: 153-157.

, and H. Umezawa. 1953b. In Umezawa, Takeuchi, Okami and Tazaki. On screening of antiviral substances produced by streptomyces and on an antiviral substance achromovi romycin. Jap. J. Med. Sci. Biol. 6: 261-268.

, and H. Umezawa. 1961. Streptomyces pluricolorscens Okami, Y. and Umezawa, H. n. sp., p. 259-260. In S. A. Waksman, The actinomycetes. Vol. 2. Classification, identification and description of genera and species. The Williams and Wilkins Company, Baltimore. 
Oliver, T. J., A. Goldstein, R. R. Bower, J. C. Holper and R. H. Otto. 1962. M-141, a new antibiotic. I. Antimicrobial properties, identity with Actinospectacin, and production by Streptomyces flavopersicus sp. n. Antimicrobial Agents and Chemotherapy 1961: 495-501.

Pagano, J. R., M. J. Weinstein, H. A. Stout and R. Donovick, 1956. Thiostrepton, a new antibiotic. I. In vitro studies, p. 554-559. In Antibiotics Annual 1955-56. Medical Encyclopedia, Inc., New York.

Patelski, R. A. 1950. Terramycin and viomycin. Introductory remarks on their chemical, physical and antimicrobial properties. Veterans Administration, Central Office, Wash. 25, D. C. ㅁ: 186-188.

Pittenger, R. C. and R. B. Brigham. 1956. Streptomyces orientalis, n. sp. , the source of vancomycin. Antibiotics and Chemotherapy b: $642-647$.

, and Phoebe Nelms. 1953. In McCormick, Mack H. and Marvin M. Hoehn. Isolation of a new antibiotic from Streptomyces fasiculatus nov. sp. Antibiotics and Chemotherapy 3: 718-720.

Porter, J. N., R. I. Hewitt, C. W. Hesseltine, G. Krupka, J. A. Lowery, W. S. Wallace, N. Bohonos and J. H. Williams. 1952. Achromycin: a new antibiotic having trypanocidal properties. Antibiotics and Chemotherapy 2: 409-410.

Preobrazhenskaya, T. P. 1957a. Characteristics of antagonistic actimycetes of the Fradiae series (in Russian), p. 51-57. In Gauze, G. F., T. P. Preobrazhenskaya, E. S. Kudrina, N. O. Blinov, I. D. Ryabova and M. A. Sveshnikova. Problems of classification of actinomycetes-antagonists. Government Publishing House of Medical Literature, Medgiz, Moscow.

- 1957b. Characteristics of antagonistic actinomycetes of the Coerulescens series (in Russian), p. 119-130. In Gauze, G. F., T. P. Preobrazhenskaya, E. S. Kudrina, N. O. Blinov, I. D. Ryabova and M. A. Sveshnikova. Problems of classification of actinomycetes-antagonists. Government Publishing House of Medical Literature, Medgiz, Moscow.

, N. O. Blinov and I. D. Ryabova. 1957. Characteristics of antagonistic actinomycetes of the Griseus series (in Russian), p. 131-145. In Gauze, G. F., T. P. Preobrazhenskaya, E. S. Kudrina, N. O. Blinov, I. D. Ryabova and M. A. Sveshnikova. Problems of classification of actinomycetes-antagonists. Government Publishing House of Medical Literature, Medgiz, Moscow. , E. S. Kudrina, I. D. Ryabova and N. O. Blinov. 1957.

Characteristics of antagonistic actinomycetes of the Aureus series (in Russian), p. 149-161. In Gauze, G. F., T. P. Preobrazhenskaya, E. S. Kudrina, N. O. Blinov, I. D. Ryabova and M. A. Sveshnikova. Problems of classification of actinomycetes-antagonists. Government Publishing House of Medical Literature, Medgiz, Moscow. , and I. D. Ryabova. 1957. Characteristics of antagonistic actinomycetes of the Chrysomallus series (in Russian), p. 162-168. In Gauze, G. F., T. P. Preobrazhenskaya, E. S. Kudrina, N. O. Blinov, I. D. Ryabova and M. A. Sveshnikova. Problems of classification of actinomycetes-antagonists. Government Publishing House of Medical Literature, Medgiz, Moscow. 
I. D. Ryabova and N. O. Blinov. 1957. Characteristics of antagonistic actinomycetes of the Chromogenes series (in Russian) p. 169-177. In Gauze, G. F., T. P. Preobrazhenskaya, E. S. Kudrina, N. O. Blinov, I. D. Ryabova and M. A. Sveshnikova. Problems of classification of actinomycetes-antagonists. Government Publishing House of Medical Literature, Medgiz, Moscow.

, and M. A. Sveshnikova. 1957. Characteristics of antagonistic actinomycetes of the Lavendulae-Roseus series (in Russian), p. 31-50. In Gauze, G. F., T. P. Preobrazhenskaya, E. S. Kudrina, N. O. Blinov, I. D. Ryabova and M. A. Sveshnikova. Problems of classification of actinomycetes-antagonists. Government Publishing House of Medical Literature, Medgiz, Moscow.

Pridham, T. G., C. W. Hesseltine and R. G. Benedict. 1958. A guide for the classification of streptomycetes according to selected groups: placement of strains in morphological sections. Appl. Microbiol. 6: 52-79.

A. J. Lyons, Jr., and H. L. Seckinger. 1965. Comparison of some dried holotype and neotype specimens of streptomycetes with their living counterparts. Internat. Bull. Bact. Nomen. Tax. 15: 191-237.

Ryabova, I. D. and T. P. Preobrazhenskaya. 1957. Characteristics of antagonistic antinomycetes of the Violaceus series (in Russian), p. 178-197. In Gauze, G. F., T. P. Preobrazhenskaya, E. S. Kudrina, N. O. Blinov, I. D. Ryabova and M. A. Sveshnikova. Problems of classification of actinomycetes-antagonists. Government Publishing House of Medical Literature, Medgiz, Moscow.

Shinobu, R. 1955. On Streptomyces hiroshimensis nov. sp. Seibutsugakkaishi, Hiroshima Univ. 6: 43-46.

, 1956. Three new species of Streptomyces forming whirls. Mem. Osaka Univ. Lib. Arts and Ed., B. Nat. Sci., No. 5: 84-93.

, 1958. On Streptomyces spiroverticillatus nov. sp. Botan. Mag. Tokyo 71: 87-93.

, and M. Kawato. 1959. On Streptomyces massasporeus nov. sp. Botan. Mag., Tokyo 72: 283-288.

Shirling, E. B. and D. Gottlieb. 1966. Methods for characterization of Streptomyces species. Intern. J. of Systemat. Bacteriol. 16: $313-340$.

Smith, C. G., A. Dietz, W. T. Sokolski and G. M. Savage. 1956. Streptonivicin, a new antibiotic. Antibiotics and Chemotherapy 6: $135-142$.

Sveshnikova, M. A. 1957a. Characteristics of antagonistic actinomycetes of the Fuscus series (in Russian), p. 58-66. In Gauze, G. F. , T. P. Preobrazhenskaya, E. S. Kudrina, N. O. Blinov, I. D. Ryabova and M. A. Sveshnikova. Problems of classification of actomycetesantagonists. Government Publishing House of Medical Literature, Medgiz, Moscow.

- M. A. $1957 \mathrm{~b}$. Characteristics of antagonistic actinomycetes of the Roseoviolaceus series (in Russian), p. 67-71. In Gauze, G. F., T. P. Preobrazhenskaya, E. S. Kudrina, N. O. Blinov, I. D. Ryabova and M. A. Sveshnikova. Problems of classification of actinomycetesantagonists. Government Publishing House of Medical Literature, Medgiz, Moscow. 
Szabó I. and M. Marton. 1964. Comments on the first results of the international cooperative work on criteria used in characteriaztion of streptomycetes. Int. Bull. Bacteriol. Nomencl. Taxonom. 14: $17-38$.

Takamiya, A. and K. Tubaki. 1956. A new form of Streptomyces capable of growing autotrophically. Arch. Microbiol. 25:58-64.

Trejo, W. and R. E. Bennett. 1963. Streptomyces species comprising the blue-spore series. J. Bact. 85:676-690.

Tresner, H. D. and E. J. Backus. 1963. System of color wheels for streptomycete taxonomy. Appl. Microbiol. 11:335-338.

Waksman, S. A. 1919. Cultural studies of species of Actinomyces. Soil Sci. 8: 71-215.

, 1923. In Bergey, Harrison, Breed, Hammer and Huntoon, Bergey's Manual of Determinative Bacteriology, lst ed. 1-442. 1932. In Bunting, R. H., . Actinomyces in cacao-beans. Ann. Appl. Biol. 19 : 515-517.

- 1953. In Waksman and Lechevalier. Guide to the classification and identification of the actinomycetes and their antibiotics. The Williams and Wilkins Co., Baltimore. 1-162.

- 1961. The actinomycetes. Vol. 2. Classification, identification and descriptions of genera and species. The Williams and Wilkins Company, Baltimore. 1-363. and R.E. Curtis, 1916. The actinomyces of the soil. Soil Sci. $1: 99-134$. and F.J. Gregory. 1954. Actinomycin II. Classification of organisms producing different forms of actinomycin. Antibiotics and Chemotherapy 4:1050-1056.

, and A. T. Henrici. 1948. Family Actinomycetaceae Buchanan and Family Streptomycetaceae Waksman and Henrici p. 892-980. In Brecd, Murray and Hitchens, Bergey's Manual of Determinative Bacteriology, 6th ed., The Williams and Wilkins Co., Baltimore.

Watanabe, K., T. Tanaka, K. Fukuhara, N. Miyairi, H. Yonehara and H. Umezawa. 1957. Blastmycin, a new antibiotic from Streptomyces sp. J. Antibiotics, Tokyo Ser. A, 10: 38-45.

Yamaguchi, H., Y. Nakayama, K. Takeda, K. Tawara, K. Maeda, T. Takeuchi and H. Umezawa. 1957. A new antibiotic, althiomycin. J. Antibiotics, Tokyo Ser. A, 10: 195-200.

Yamaguchi, T. 1954. Studies on the antibiotic substance-producing strains H-2075, H-2609 (S. hachijoensis nov. sp.) and H-3030. J. Antibiotics, Tokyo Ser. A, 7:10-14.

Ziegler, D. W., R. N. Wolfe and̄ J. M. McGuire. 1956. Vancomycin, a new antibiotic, p. 612-618. In Antibiotics Annual 1955-1956. Medical Encyclopedia Inc., New York.

\section{SOURCES OF ILLUSTRATIONS}

1. H. D. Tresner and M. C. Davies, Lederle Labs., Div. American Cyanamid Co., Pearl River, New York 10965, U.S. A.

2. Sara Wold and Lucia Anderson, Parke, Davis and Co., Detroit, Mich., 48232, U.S. A.

3. Elio Baldacci, G. Farina and R. Locci. Instituto Di Patologie, Vegetale dell' Universita', Via Celoria N. 2, Milano, Italia. 
4. Ralf Hütter, Mikrobiol. Institut, Eidg. Tech. Hochschule, 8006 Zürich, Switzerland.

5. J. O. Falcão de Morais, Inst. de Química da Univ. Fed. de Pernambuco, Recife, Pernambuco, Brazil.

6. N. A. Krasil'nikov, Inst. Microbiol., Acad, Sciences, Moscow B-133, U.S.S.R.

7. Carol S. Cassidy and K. E. Crook, Jr., Bristol Labs, , Inc. Syracuse, New York, U.S.A.

8. T. Cross and Miss A. Maciver, Bradford Institute of Technology, Bradford 7, Yorkshire, England.

9. M. Mayama and Terada, Div. of Bacteriol., Shionogi Research Lab., Shionogi and Co., Ltd., Fukushima-ku, Osaka, Japan.

10. M. Mayama and K. Tawara, Shionogi Res. Lab., Shionogi and Co., Ltd. Fukushima-ku, Osaka, Japan.

11. Miss Ballin, Dept. Textile Industries, Bradford Inst. of Technology, Bradford 7, Yorkshire, England.

12. N. McClung and G. Michaels, Dept. Microbiol., Univ. Georgia, Athens, Ga., U.S.A.

13. W. Trejo, E. R. Squibb and Sons, New Brunswick, New Jersey, U.S.A.

14. F. Mach, Inst. für Mikrobiologie, Griefswald, Ludwig-Jahn-Str. 15, German Democratic Republic.

15. V. D. Kuznetsov, USSR Res. Inst. for Antibiotics, Moscow, U.S.S.R.

16. G. v. Mierlo, Lab. f. Microbiol., Delft, Netherlands.

17. J. Mathews, The Upjohn Co., Kalamazoo, Mich. 49001, U.S.A.

18. Y. Ohara and H. Nonomura, Faculty of Engineering, Yamanashi Univ., Kofu, Japan.

19. H. Prauser, Inst. Mikrobiol. Exptl. Therapie, Beuthenbergstr. 11, Jena, German Democratic Republic.

20. C. E. Higgens, Eli Lilly and Co., Indianapolis, Indiana, U.S.A.

21. P. Hirsch, Dept. Microbiology and Public Health, Michigan State Univ., East Lansing, Michigan, U.S.A.

22. J. Rosillo and J. Spyvee, Boots Pure Drug Co., Ltd., Antibiot. and Ferm. Div., Nottingham, England.

23. T. J. Oliver, Abbott Laboratories, N. Chicago, Illinois, U.S.A.

24. K. Nakazawa, Takeda Chem. Ind., Ltd., Juso-Higashiyodogawaku, Osaka, Japan.

25. V. A. Tsyganov, Res. Inst. of Antibiotics, Leningrad, L-20, U.S.S.R.

26. Y. Okami, Nat'l Inst. of Health of Japan, Shinagawa, Tokyo, Japan.

27. Karl H. Wallhausser, Farbwerke Hoechst Ag., Chemische Verfahren stednik, Elektronenmikroskopiche Augnahme Photograph, Frankfurt a/M - Höchst Germany.

28. G. A. deVries, Centraalbureau voor Schimmelcultures, Baarn, Netherlands.

29. T. G. Pridham and A. J. Lyons, Northern Utilization Res, and Dev. Div. Peoria, Illinois, 61604, U.S. A.

30. Wanda Woznicka, Panstwowy Zaklad Higieny, Ul Chocimska 24, Warszawa 12 Poland.

31. T. R. Vernon, Dept. Scientific and Ind. Res., Private Bag, Auckland $\mathrm{Cl}$, New Zealand.

32. W. Hodgkiss and J. M. Shewan, Torry Res. Sta. Aberdeen, Scotland. 